\title{
The Excavations
}

\author{
Mahmoud El-Tayeb with contributions by Ewa Czyżewska-Zalewska and Ewa Skowrońska
}

As mentioned in the introduction, the first season of the Early Makuria Research Project was launched in 20042005 with a preliminary reconnaissance survey followed by a test excavation at the cemetery field in El-Zuma. The survey revealed that the cemetery contains 29 burial mounds which are still visible on the ground surface (Obłuski 2005). The tumuli are situated in groups on a plateau, and are separated from one another by some minor watercourses running downwards from the west due east towards the river floodplain. The burials are characterized by superstructures of various sizes and in various states of preservation. Classified as large (type I), medium (type II), and small (type III), it was expected that each type of mound would conceal a different form of substructure. In order to verify this assumption, three different tumuli of types I, II, and III were chosen for excavation during the 2004-2005 season: T.2, representing type I; T.23, representing type II; and T.22, representing type III. Since then 28 tumuli have been successively excavated and investigated in different ways over a period of 12 years (20052017).

\section{Methods of Excavation}

In some cases, the methods of excavation used were not strictly textbook. Various unexpected factors and the specific conditions encountered on the ground dictated more suitable and practical approaches. It must be noted that the archaeological site at El-Zuma has been inscribed on the UNESCO World Heritage List since 2003. Accordingly, the excavation licence issued by the Sudanese Antiquities Service, which granted the project team permission to excavate the cemetery, was based on two clear conditions. Firstly, the panorama and the site landscape should be carefully preserved. Secondly, the site should be well protected, especially given that it is located in the middle of a modern-day village. Moreover, the large conical tumuli classified as type I should not be excavated so as not to remove or damage their superstructures. Other factors that prompted certain changes in the excavation methods stemmed from a modest budget and lack of sufficient time to conduct and complete the planned work.
In order to meet the conditions set out by the Antiquities Service, the mission's preparations for its first season started with a site inspection to examine and evaluate the state of preservation of all of the tumuli at the cemetery. This revealed that the summits of T.2 and T.5, two of the largest mounds, classified as type I, were severely damaged. This was a great pity, but at the same time it offered a unique opportunity for the mission to excavate these two disturbed mounds. T.2 was the first to be investigated. The extant superstructure stands to a height of only about $3 \mathrm{~m}$ above the present-day ground level, whereas its original height was estimated at $5-6 \mathrm{~m}$. A square trench measuring $6 \times 6 \mathrm{~m}$ was opened at the top centre of the mound, revealing a U-shaped shaft. Its excavation led to the discovery of a 9-m-long underground tunnel, starting from the rear of the main burial chamber, which had been cut into the southern wall of the shaft. At the opposite, southern, end of the tunnel there was an external shaft that exited at the edge of the mound's foot. T.5 was excavated in the same manner, and here again another tunnel in a similar location and also aligned north-south was encountered. The discovery of these two tunnels was significant because it gave rise to an idea about how to examine the other six large type I tumuli without disturbing their superstructures. Thereafter, searches on the southern side of these mounds in each case resulted in successful pinpointing of the external shaft of a tunnel that led directly to the main burial chamber [Fig. 3.1].

Tumuli types II and III are generally characterized by a visible depression at the top centre [Fig. 3.2]. They were usually excavated from the top of the mound, although the method used was not identical for each tumulus. In the case of the medium-size, type II burials, the choice of method mainly depended on the size and height of the mound. Nine tumuli out of eleven were excavated from the top to the bottom of the shaft [Fig. 3.3]. Meanwhile, the other two mounds were investigated by excavating a rectangular rather than square trench, which was cut into the top centre of the mound and extended southwards.

The smallest mounds in the field are nine in number. Only three of them were explored through a square trench cut into the top centre of the tumulus. The remaining six mounds were dissected by clearing the southern half to examine the grave shaft and look for any evidence of 


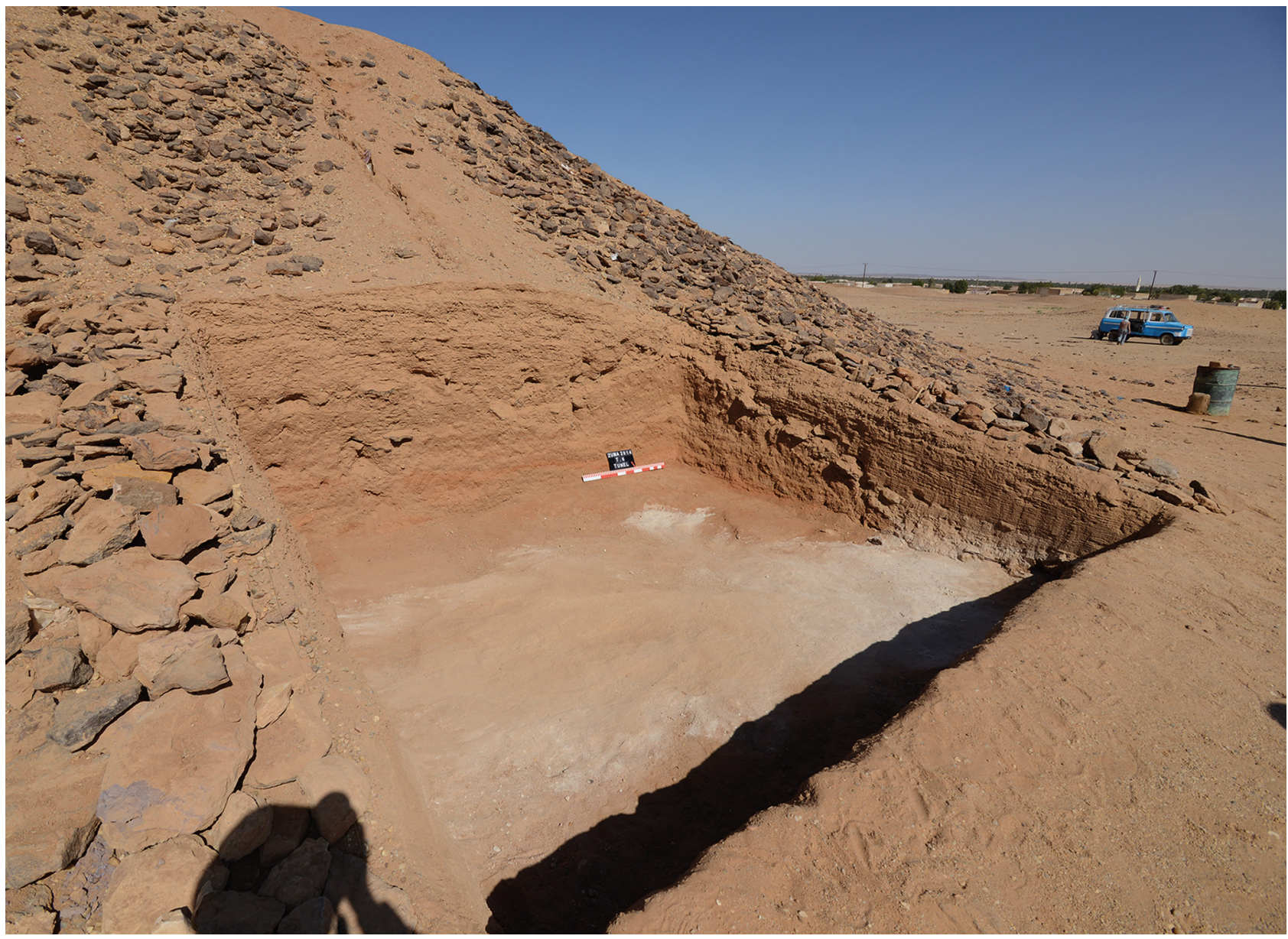

FIGURE 3.1 Tumulus 6, excavation of the external shaft РНОTO BY A. KAMROWSKI

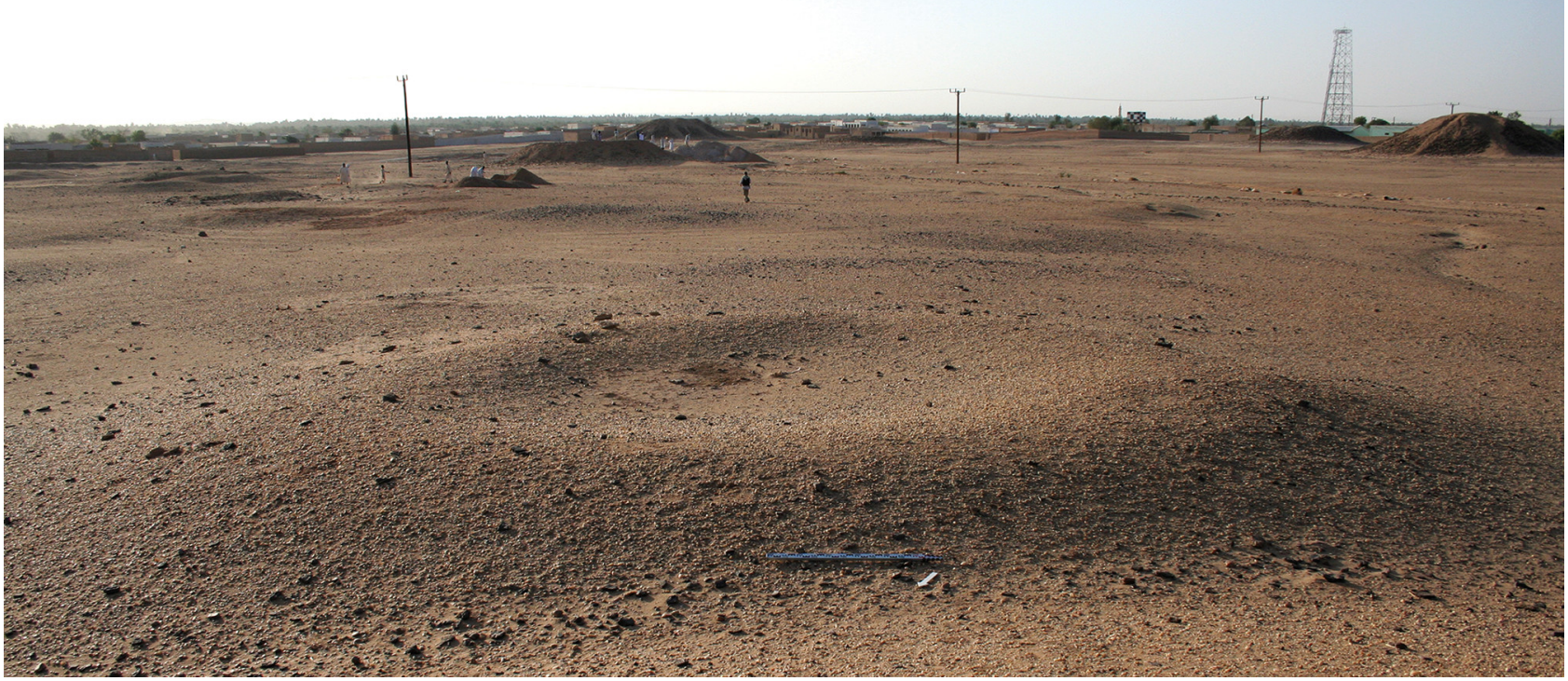

FIGURE 3.2 Tumulus 10, depression at the top of the mound РнОTO ВY К. КОTLEWSKI 


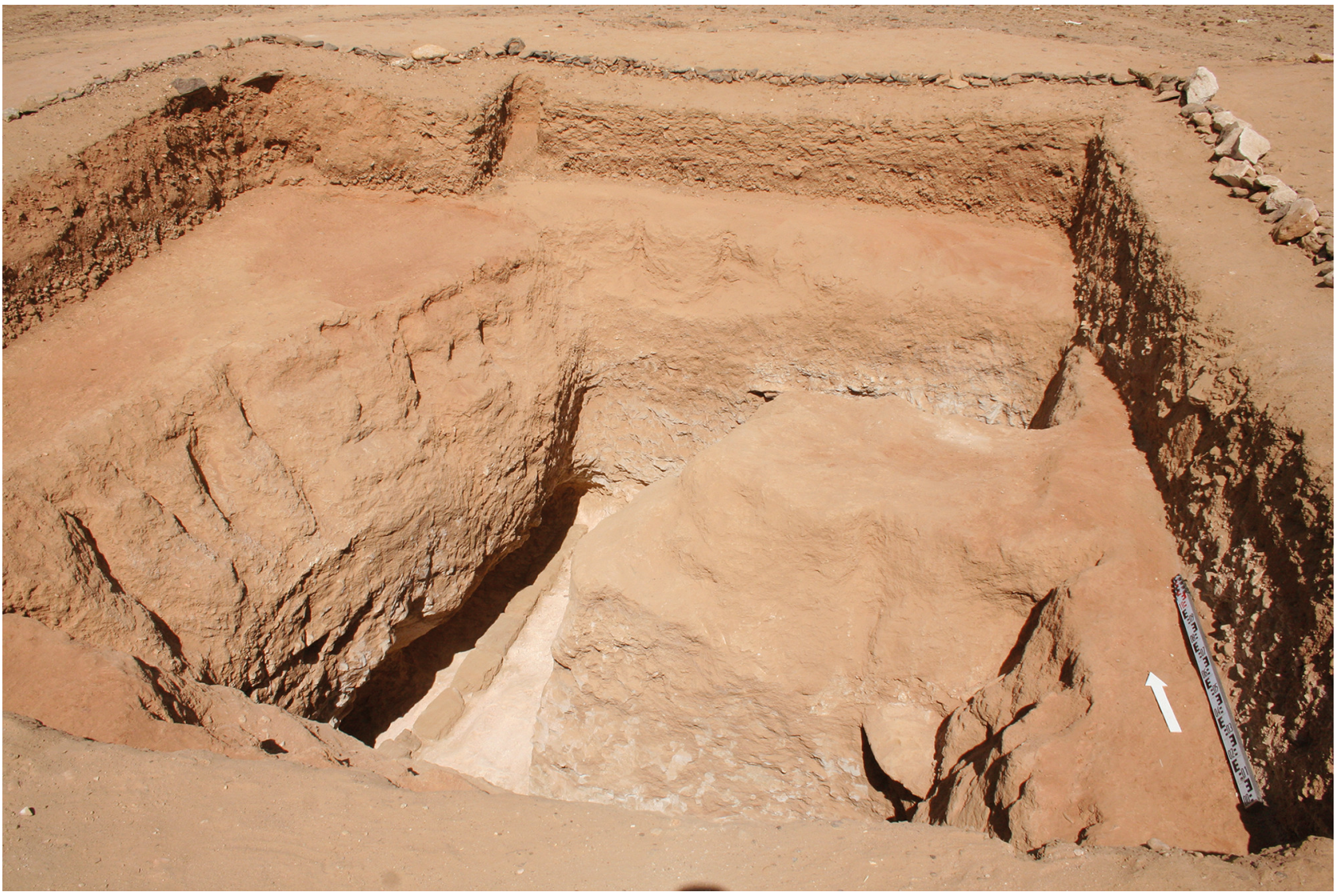

FIGURE 3.3 Tumulus 25, excavated from the top of the superstructure РНОTO ВY К. KOTLEWSKI

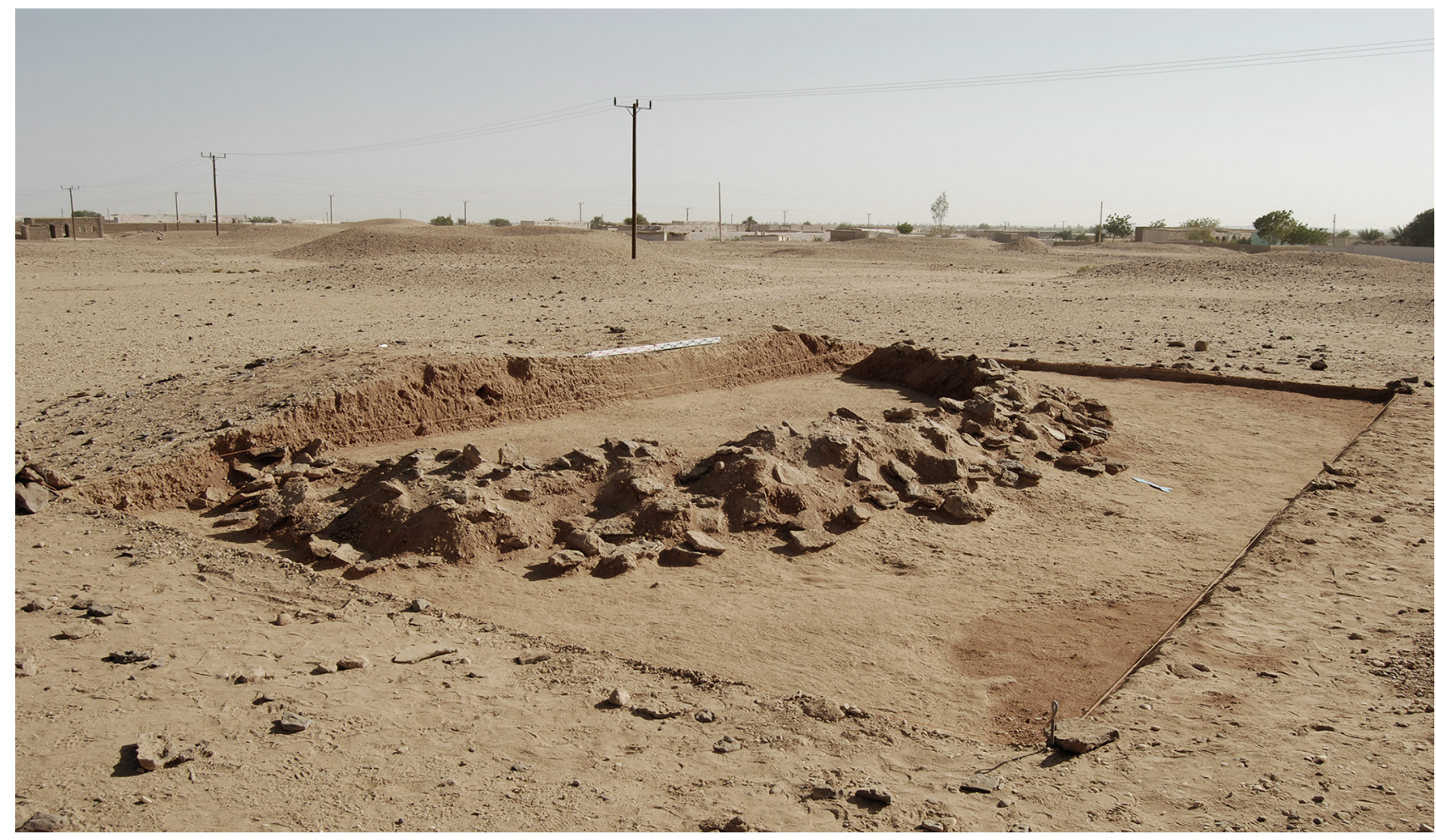

FIGURE 3.4 Tumulus 17, excavation of type III tumuli РНОТО вY О. ВIAŁOSTOCKA 
funerary rites which might have been performed on the ground surface near the shaft before it was finally filled in [Fig. 3.4].

The protection plan for the cemetery was accomplished by erecting about 1,200 concrete posts around the $2 \mathrm{~km}$ perimeter of the site and its buffer zone [see Fig. 1.2]. As a result, no more buses, trucks, or cars will be able to drive across the site, as long as these posts remain in place.

\section{2}

\section{Type I Tumuli}

\subsection{Tumulus 2}

Tumulus 2 lies in the south-eastern part of the cemetery surrounded by another four of the large tumuli (T.1, T.3, T.4 and T.5) constituting our first type. Together, they appear to form a separate group in the cemetery [see Fig. 1.2]. T.2 measures about $24 \mathrm{~m}$ in diameter with an estimated original height of at least $6 \mathrm{~m}$; however, the preserved height does not exceed $2 \mathrm{~m}$ at the highest point above the surrounding ground level. The superstructure is heavily disturbed, with most of the top having disappeared because it provided a source of readily available building material rather than as a result of grave plundering. This kind of destruction is fairly common today and does not necessarily mean that the substructure was penetrated. A test pit of $6 \times 6 \mathrm{~m}$ was dug into the top centre of the superstructure, reaching the original fill of the burial shaft at a depth of $0.70-1 \mathrm{~m}$ below the ground surface. The shaft presents a roughly rectangular outline (its sides measuring $4.50 \mathrm{~m}, 4.40 \mathrm{~m}, 3.50 \mathrm{~m}$, and $2.40 \mathrm{~m}$ respectively, and narrowing towards the bottom), and it is aligned north-south, with a substantial, buttress-like 'pier' projecting from the east wall, dividing the shaft into two halves and affording it a U-shaped plan [Fig. 3.5].

The real function of this pier-for it is certainly not a buttress-remains obscure. The fill, which consisted of whitish sand, appeared to be undisturbed except for a pit not exceeding $1 \mathrm{~m}$ in diameter, located in the south-west corner of the shaft, which possibly attests to an aborted robbery attempt. The shaft proved to be about $2.5 \mathrm{om}$ deep. A step had been carved in the north-east corner of the shaft, about $1.30 \mathrm{~m}$ below ground level, allowing easy descent to the bottom. Another small step, about $0.30 \mathrm{~m}$ high, was at the foot of the pier, on its south-west corner. Opening off this shaft were three chambers. The southern chamber was sealed with a solid wall of unbonded mud bricks [Fig. 3.6], about $3.03 \mathrm{~m}$ long and o.5o $\mathrm{m}$ wide, built to a height of about $0.75 \mathrm{~m}$. The size of the bricks ranges between: $37-50 \mathrm{~cm} \times 22-25 \mathrm{~cm} \times 9^{-12} \mathrm{~cm}$. Evidence of attempted looting was noted in the form of the previ- ously mentioned pit observed in the shaft fill. The second chamber, on the west side of the shaft, had an intact blocking wall which was $2.00 \mathrm{~m}$ long, with a height ranging from $0.55 \mathrm{~m}$ to $0.65 \mathrm{~m}$. The third blocking wall, in the north-west corner of the shaft, was built of six courses of bricks and was also found untouched. Further mud bricks covered the entire floor of the shaft (up to a height of about $0.30 \mathrm{~m}$ ). Two of the three chambers appeared to be designated for grave goods. Both were found intact. The northwestern chamber (Ch. 3 ), which is the smallest of all, is of a rare type of construction [Fig. 3.7]. It is hewn into the north-west corner of the shaft and accessed through an entrance about 1.10-1.50 $\mathrm{m}$ wide and about $0.70 \mathrm{~m}$ high. The grave offerings appeared to be arranged in a specific order, presumably reflecting a local rite so far unknown in the region. Two large cattle bones were found at the far eastern side of the chamber, followed by three beer jars (two of which were large, with cups covering their mouths). Seven small red bowls and fragments of small and large animal bones had been placed together next to the beer jars. The last group comprised one small red bowl and fragments of large animal bones. This specific arrangement has never been observed in graves of the period elsewhere in Nubia. The other chamber containing grave goods, chamber 2, was hewn into the longest, west side of the shaft. Its maximum length is about $2.6 \mathrm{om}$ and it is $1.20 \mathrm{~m}$ wide and up to $0.70 \mathrm{~m}$ high. The entrance measures $2.17 \mathrm{~m}$ in length, with a height of $0.55^{-0.65} \mathrm{~m}$. A certain order in the deposition of the grave goods appears to have been followed here. Two large beer jars had been placed as one group in the northern part of the chamber. Then came nine small red bowls, another two beer jars next to them, a medium-sized table amphora, and a group of 13 small red bowls, which were deposited in an area at the southern end of the chamber. Animal bones from both large and small animals (identified as cattle and sheep/goat) were found near the first group of bowls in the middle of the chamber, and they were also associated with the second group of bowls at its southern end [Fig. 3.7 bottom].

Interestingly, chambers 2 and 3 were connected through a hole $\left(c .0 .15^{-0.20} \mathrm{~m}\right)$ made in the wall between them. These passages could have been of symbolic significance, allowing the soul of the grave occupant to move freely between the chambers. The nearest analogy for these holes could be from the burials at Ballana and Qustul, which have multiple chambers interconnected by doorways rather than holes, also to provide the soul of the deceased easy access to the grave goods. Chamber 2 was also indirectly connected via an external niche with chamber 1 , which was the main burial. This chamber is cut into the southern wall of the shaft. It is about the same 

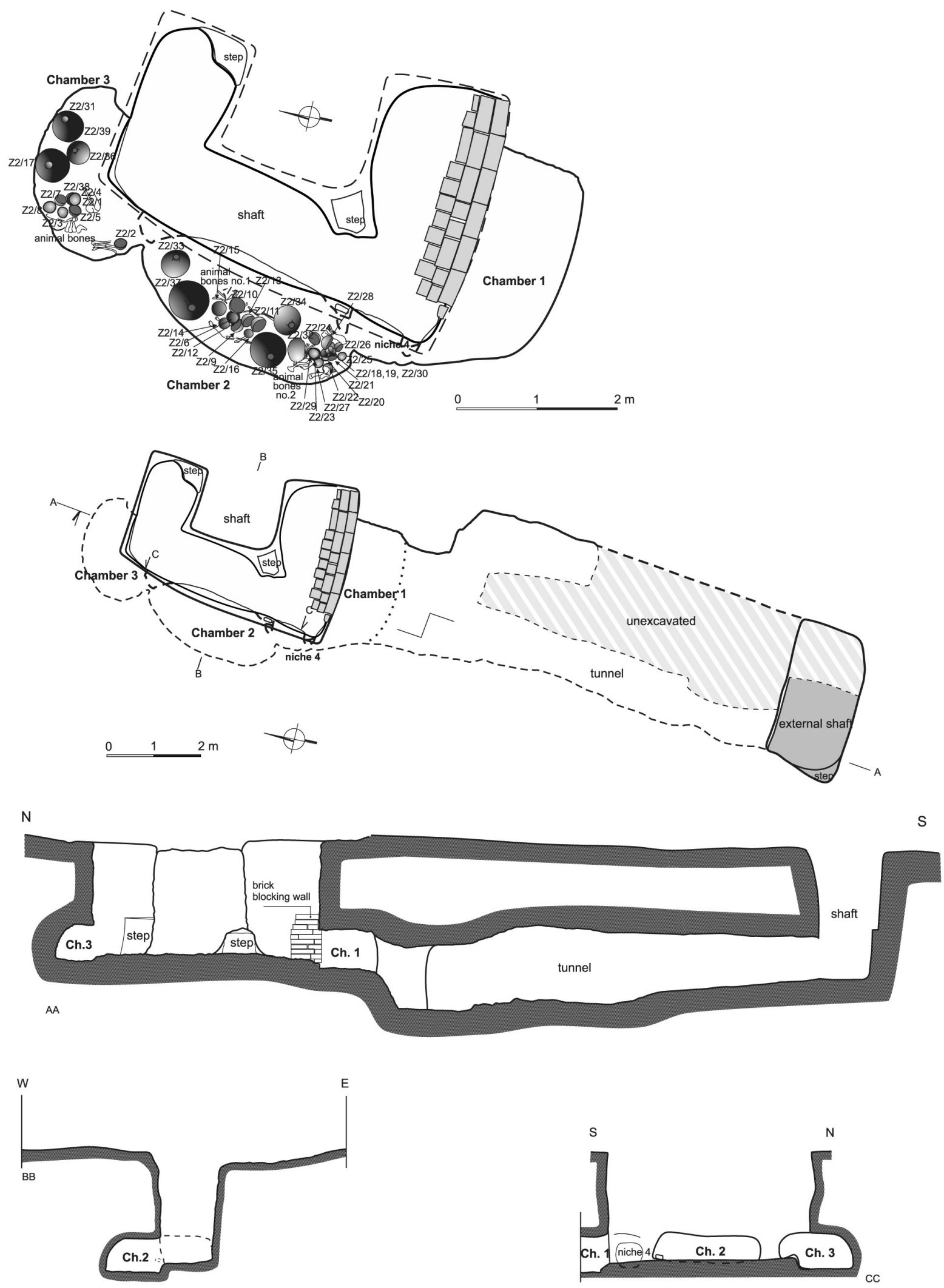

0

FIGURE 3.5 Tumulus 2, general plan and cross-sections

DRAWN BY U. WICENCIAK, A. OBŁUSKI, DIGITISED BY M. PUSZKARSKI 

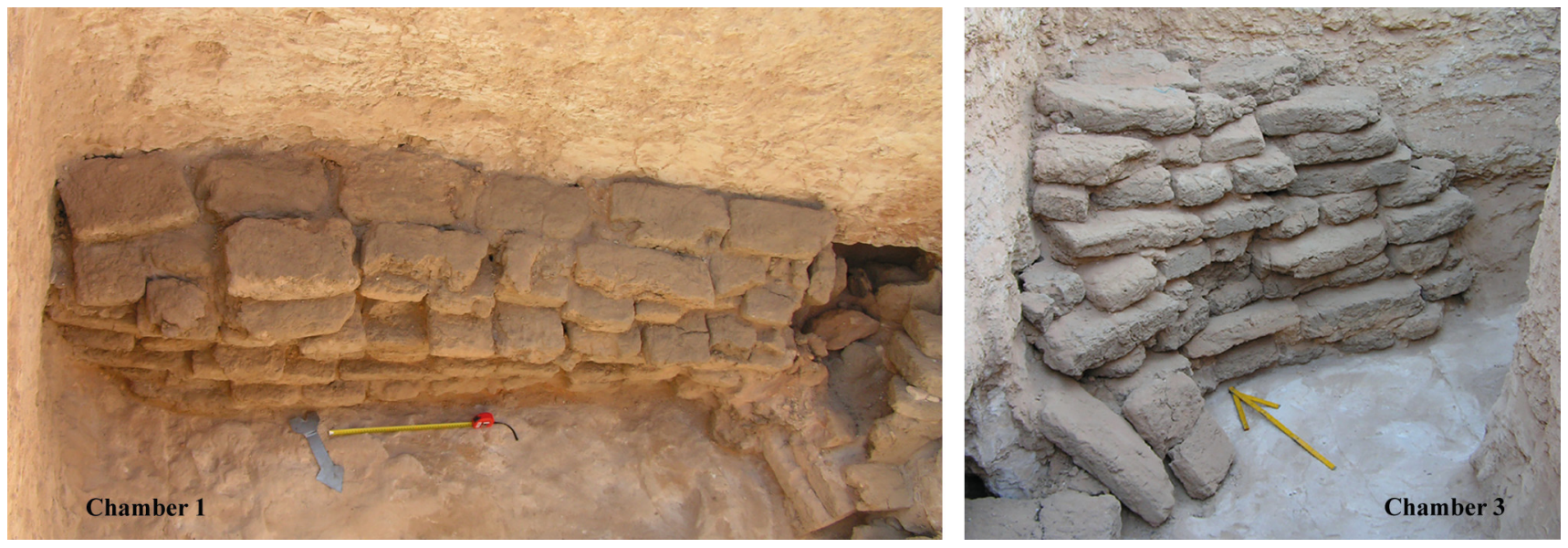

FIGURE 3.6 Tumulus 2, mud-brick blocking wall of chambers 1 and 3 PHOTOS BY A. OBєUSKI

size as chamber 2 (maximum length $2.30 \mathrm{~m}$; width $1.20 \mathrm{~m}$; height $c .0 .78 \mathrm{~m}$ ). Unfortunately, it was found totally rifled. A dark brown/black residue of what might have been the leather straps of a bier was the sole evidence still visible on the eastern side of the burial chamber. Many white and blue tubular faience beads were found in the same area around the black residue. The rear of the chamber opens onto a wide $\mathrm{N}-\mathrm{S}$ tunnel, its floor located about $0.70 \mathrm{~m}$ below the floor level of the chamber. Thorough exploration of the tunnel was not an easy task due to the soft, fragile sandstone of the roof, which threatened to collapse because of the humidity and changes in interior environment [Fig. 3.8]. However, nothing of note was found in the section that was cleared of the sediments filling it, only a fragment of human skull, a cattle bone, some pottery sherds, and several small, rusted iron fragments-a nail and probably some arrowheads. The tunnel was about 9.0o $\mathrm{m}$ long, 2.00-3.20 $\mathrm{m}$ wide and about $0.70-1.30 \mathrm{~m}$ high. It terminated in an external shaft $(3.00 \mathrm{~m} \times 1.20 \mathrm{~m} \times 2.00 \mathrm{~m})$ at the southern edge of the tumulus. The devastation of the burial and the tunnel, not to mention the huge quantities of sediment inside them, suggested that this tomb had been repeatedly plundered and left open for long periods. The chamber could have been broken into from above through the robber pit as well as through the underground tunnel. For more detailed information see Mahmoud ElTayeb 2005, 390-394.

\section{$2.2 \quad$ Tumulus 3}

Tumulus 3 is located at the southern end of the cemetery, just a few metres from the northern wall of El-Zuma Hospital. As already mentioned, this tumulus is attributed to type I, as are those adjacent to it, namely T.4, located a short distance roughly north, and T.1, which lies a short distance north-east of T.3 [see Fig. 1.2]. These three mounds are identified as a group representing the smallest of the type I tumuli. Their diameters at the time of excavation ranged between $30 \mathrm{~m}$ and $35 \mathrm{~m}$, with a maximum preserved height of about 3.50 $\mathrm{m}$ [Fig. 3.9]. The conical mound (although its top is disturbed) is built from a mixture of earth and gravel, covered from top to bottom by densely packed pieces of black ferruginous sandstone. Most probably, the original height of the mound was not less than $6 \mathrm{~m}$. Over time it has been exposed to different forms of destruction caused by natural factors, such as wind and rainwater erosion, and human factors, such as grave robbing and scavenging for building materials, resulting in severe damage to the tumulus (the same thing can be said about the other tumuli at the cemetery).

As already mentioned above, the site is inscribed on the UNESCO World Heritage List. Therefore, the NCAM approved the mission's work there on condition that the eight large tumuli should only be investigated in a manner that would not cause any kind of destruction. Therefore, only limited trial trenching could be conducted to gain some data which could help in understanding the nature, function, and date of these enigmatic monuments. In accordance with these constraints, investigations were directed to the southern side of $\mathrm{T}_{3}$, where some traces of whitish sandstone had been noted. Based on previous experience, whitish sandstone remains at the southern foot of a mound usually denote the exact location of the external shaft of a tunnel of the type described above. Consequently, a large rectangular trench of about $8 \mathrm{~m} \times 4 \mathrm{~m}$ was set out on this spot. After removal of accumulated sediment to a depth of about $0.50 \mathrm{~m}$, the examined area was reduced to form a square of about $5 \mathrm{~m} \times 5 \mathrm{~m}$ when the outline of the external shaft became visible. The shaft had a rectangular ground plan measuring $2.72 \mathrm{~m} \times 1.6 \mathrm{om}$ with a depth of $1.40 \mathrm{~m}$. Access to the bottom of the shaft 

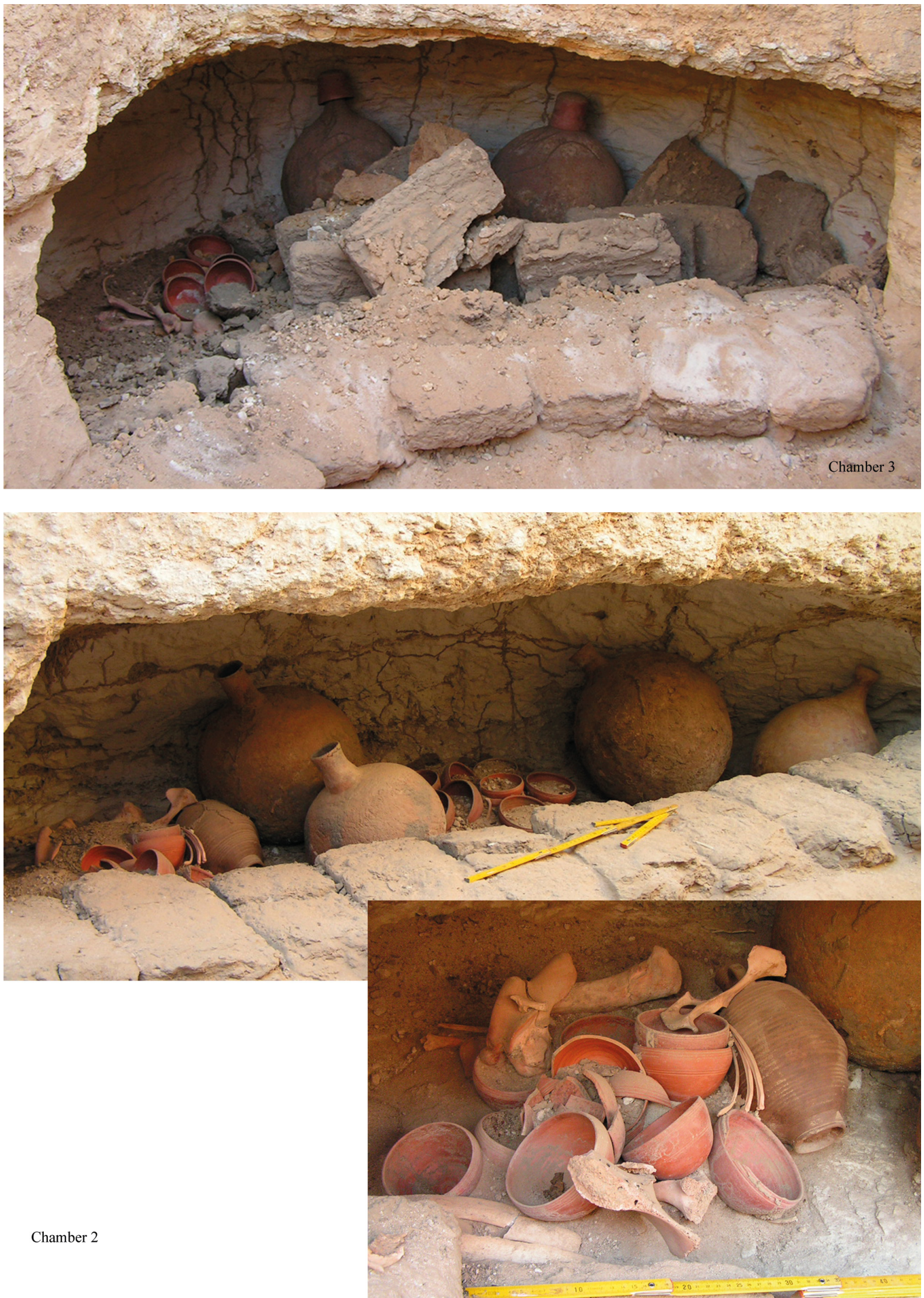

FIGURE 3.7 Tumulus 2, view of chamber 3 before excavation (top) and view of chamber 2 (bottom), with details of grave offerings (inset) PHOTOS BY U. WICENCIAK 

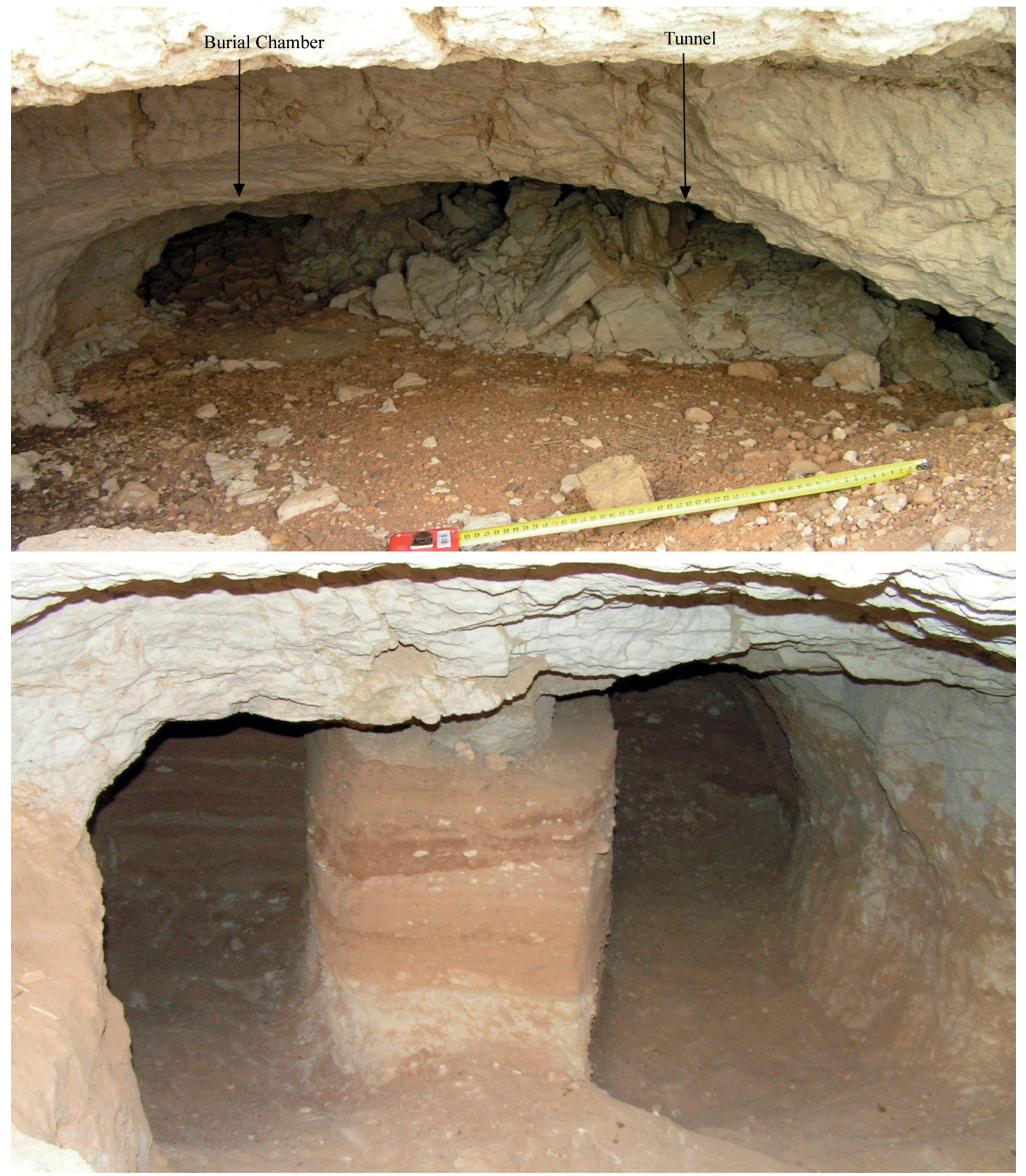

FIGURE 3.8 Tumulus 2, view of the burial chamber and the tunnel fill (top); view of the partly excavated tunnel, facing south PнотOS вY А. OвŁUSKI 


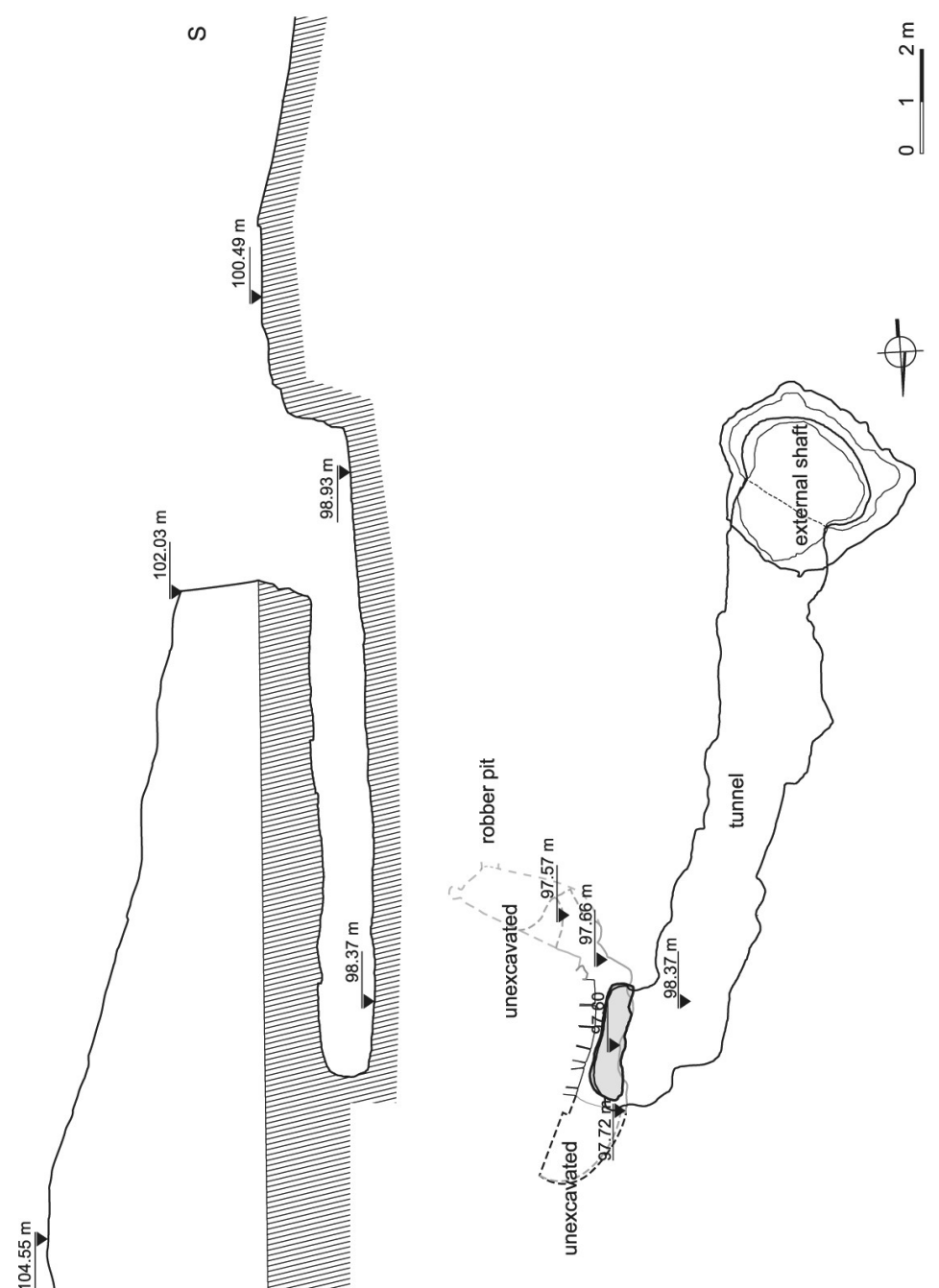

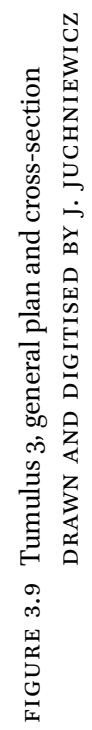



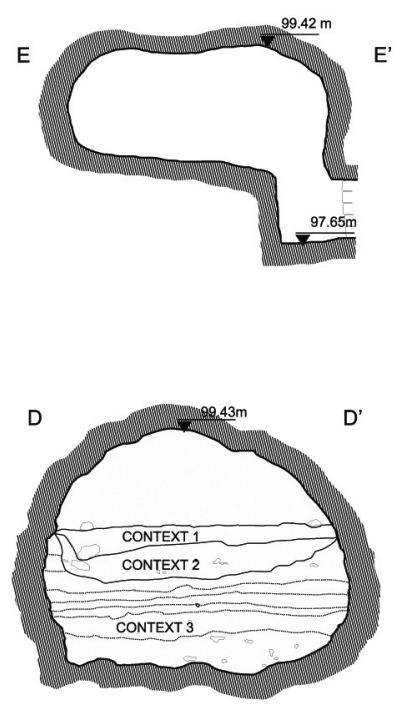

$D^{\prime}$
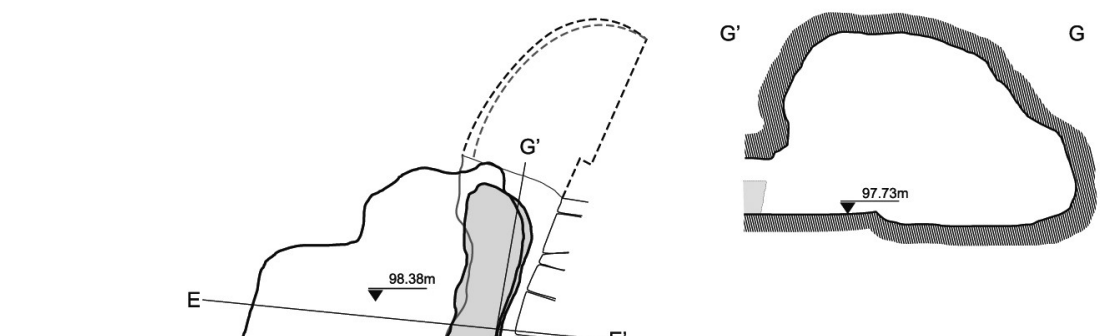

0 $1 \mathrm{~m}$

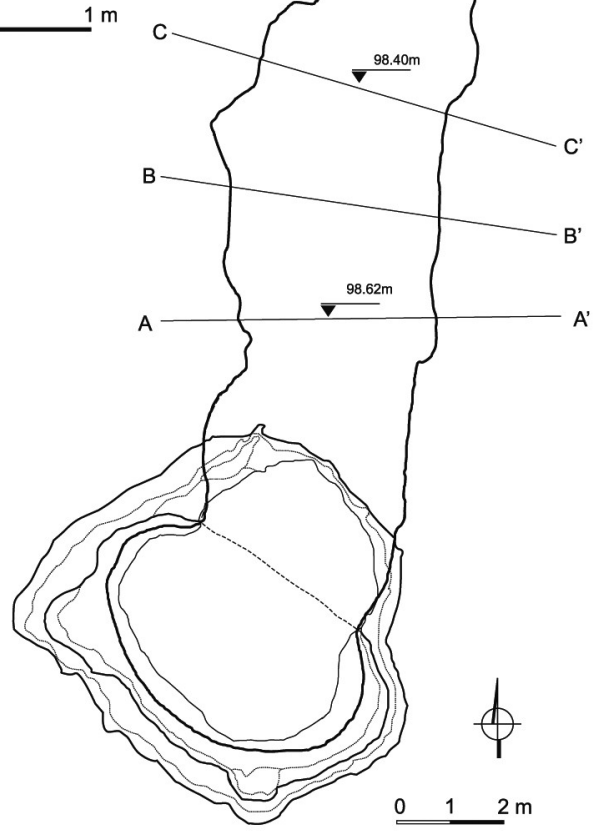

Context 1 - upper layer of the tunnel fill, th. approx. $10-20 \mathrm{~cm}$, sand, dust and dry mud; colour dark grey beige probably deposited by rainwater:

Context 2 - robber activity, thin layers of brown sand, faintly visible;

Context 3 - context consisting of several thin layers of waterborne deposits that poured in through the tunnel

FIGURE 3.10 Tumulus 3, sediment layers inside the tunnels DRAWN AND DIGITISED BY J. JUCHNIEWICZ

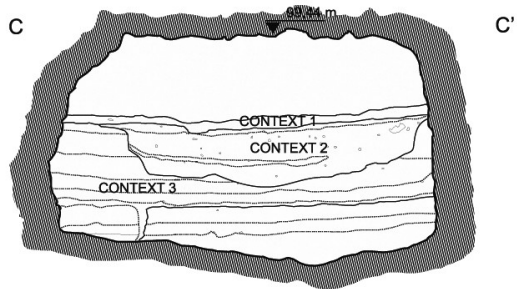

$C^{\prime}$
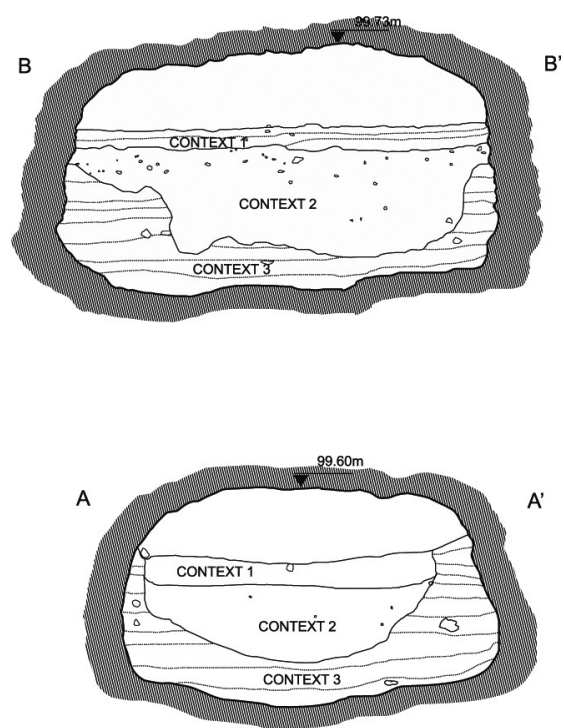

0 $1 \mathrm{~m}$ 


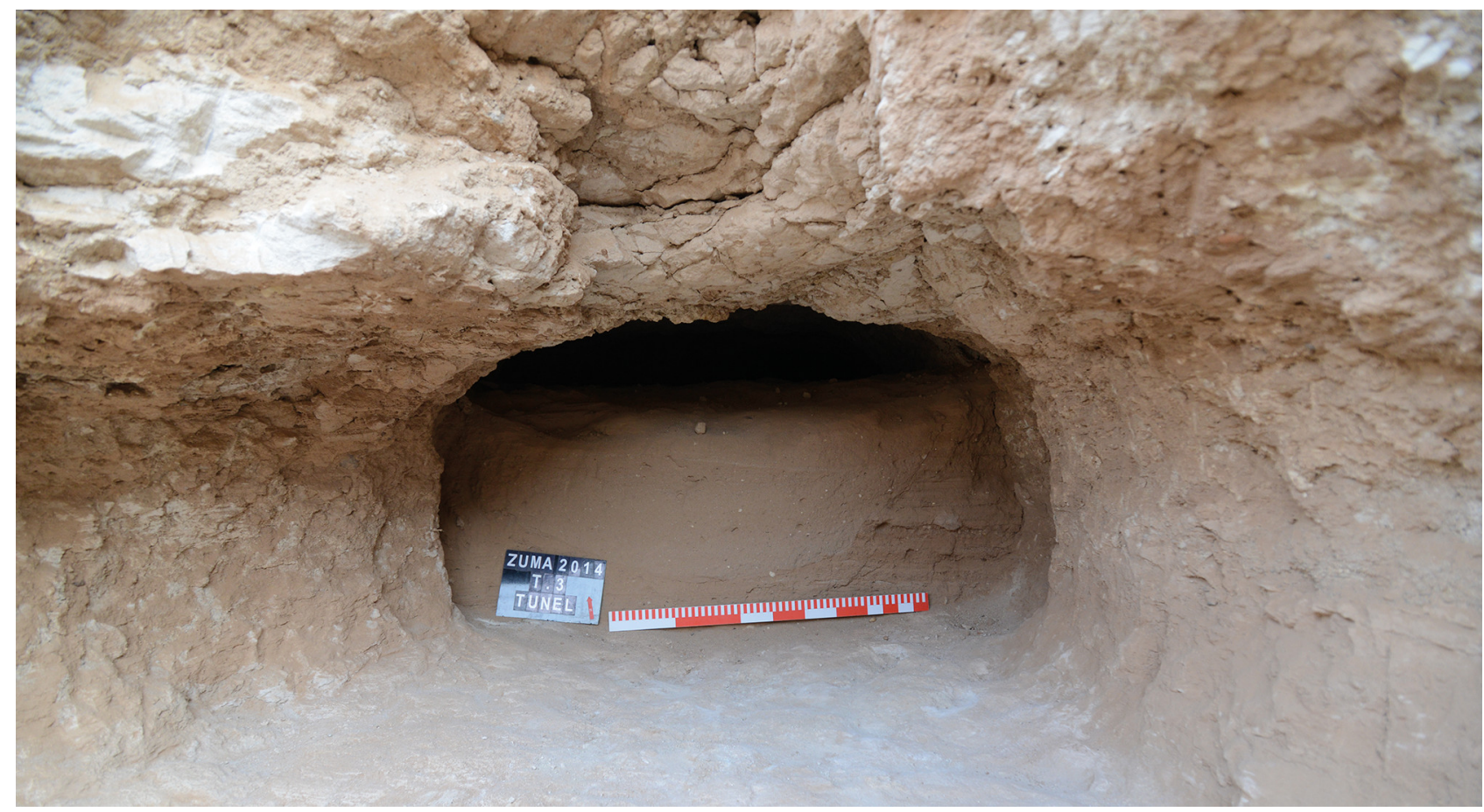

FIGURE 3.11 Tumulus 3, view of the tunnel beneath the tumulus PHOTO BY A. KAMROWSKI

was facilitated by two steps cut into two opposite corners (south-east and south-west), at a depth of about $0.65 \mathrm{~m}$. In their search for the tunnel, the robbers appear to have missed the right place, as they broke through the top of the tunnel entrance causing some damage to its roof. The external shaft and the tunnel were both found filled with earth and sand, indicating that the passage to the burial chambers had been left open for a long period. The tunnel was $11.81 \mathrm{~m}$ long and $1.88 \mathrm{~m}$ wide with a height ranging from $0.93 \mathrm{~m}$ at the entrance to $1.06 \mathrm{~m}$ further in. Leading northwest and terminating above the west chamber, the tunnel appears to have been dug in the wrong direction. In both T.2 and T.5 the tunnel had been dug from south to north to reach the main chamber, hewn into the southern side of the principal grave shaft (Mahmoud El-Tayeb 2007, 73-80, Figs. 3b, 5; 2010b, Fig. 6).

However, detailed examination of the fill in the tunnel of T.3 led to a significant discovery. Near the hole leading down to chamber 2, some broken mud bricks were noted. Undoubtedly, these fragments in this specific location attest to the existence of a wall that blocked the way down to the burial chambers. Repeated plundering of the grave had a severe impact, not only on the mud-brick blocking wall, which was completely destroyed, but also on all of the burial chambers. The fill stratigraphy shows at least three phases of plundering activity [Fig. 3.10]. The importance of this stems from the fact that it is the first noted instance of such a situation in El-Zuma burials of type I.
Although the evidence is incomplete due to the large scale of destruction, this discovery again raises the question of what purpose the tunnel served. As previously mentioned, the tunnel opens directly into the underlying west chamber (Ch. 2) [Fig. 3.11], which measures about $4.50 \mathrm{~m}$ in length, $1.20 \mathrm{~m}$ in width, and about $0.67 \mathrm{~m}$ in height.

Most probably, this grave was of similar construction to others of the same type, consisting of a U-shaped vertical shaft and a number of lateral niches hewn into its side walls. This is attested by two holes of about $0.60 \mathrm{~m} \times$ $0.40 \mathrm{~m}$ that connected chamber 2 with the chambers on its southern and northern sides [Fig. 3.12 top]. The southern chamber (Ch. 1) measured $3 \mathrm{~m} \times 1 \mathrm{~m}$ and was $0.60 \mathrm{~m}$ high [Fig. 3.12 bottom]. All three chambers were found completely filled with sediment that had poured in through the tunnel. Due to the poor condition of the ceiling in the northern chamber (Ch.3), no attempt was made to explore it. However, clearing the two other chambers (western and northern) of sand and debris revealed that both of them had been thoroughly plundered and badly damaged. Only some fragments of human and animal bones were found scattered in the tunnel and chamber 1 (for more about the animal bone remains see Chapter 8 in this volume; on the human remains see Chapter 6 in this volume). There are two small, unexplained niches in chamber 1. One is cut into the south wall and the other, reminiscent of a shelf, is cut into the east side of the chamber and appeared to contain some long fragments of bone (prob- 

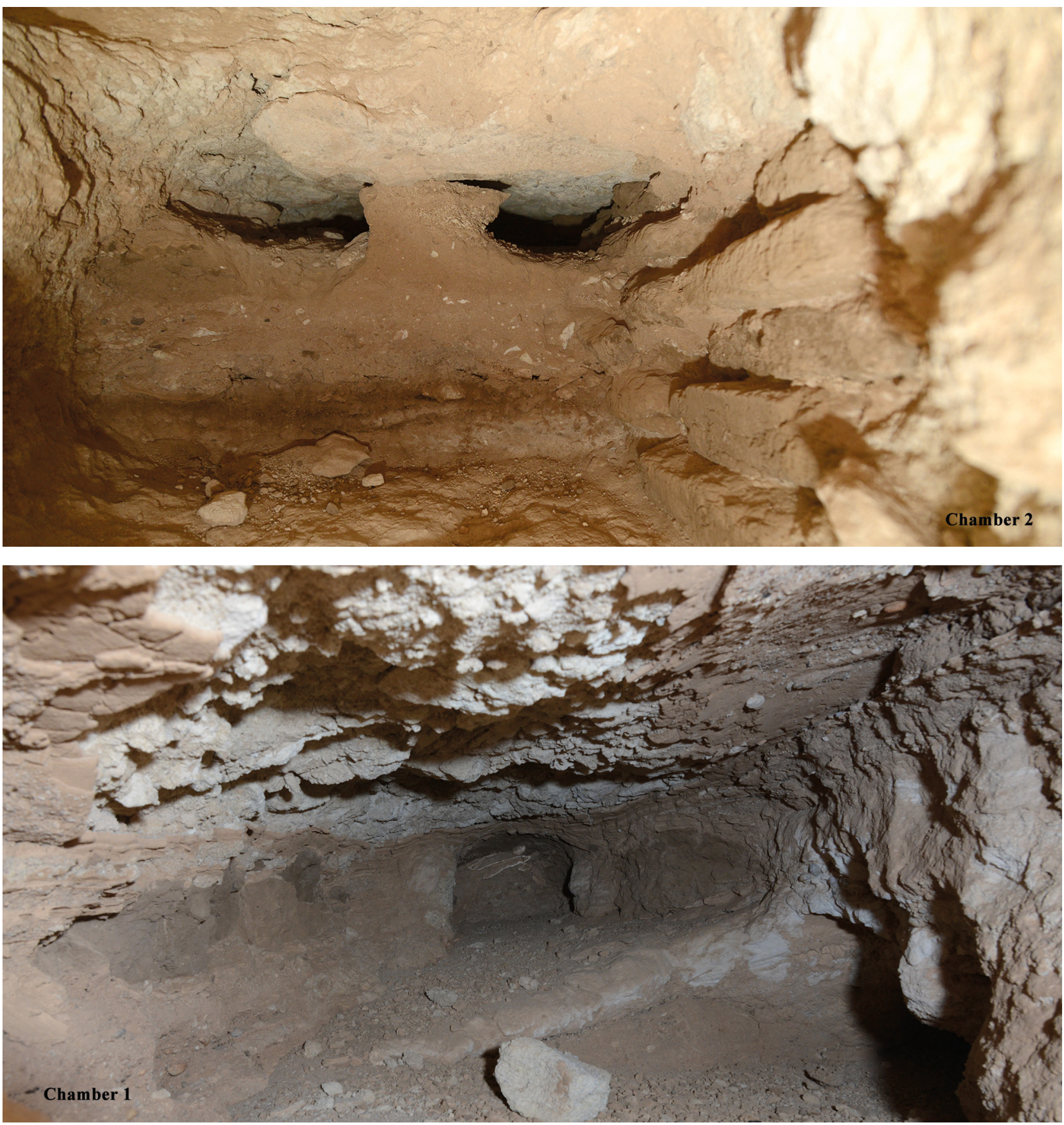

FIGURE 3.12 Tumulus 3, view of the unexcavated western chamber 2, facing north (top); view of the southern chamber 1 (bottom)

PHOTOS BY A. KAMROWSKI

ably a cattle scapula). Further excavation to determine the form of these two small niches was difficult due to the threat of ceiling collapse and the uncomfortable conditions inside the chamber, where there was very little space and fresh air. Comparing the uncovered part of the burial substructure with the ones beneath tumuli 2,5 , and 6 , there is clearly a great difference in size and the quality of workmanship. No explanation for these observations can be offered without full excavation of the burials. For more detailed information see Mahmoud El-Tayeb, Skowrońska, and Czyżewska 2016, 119-120.

\subsection{Tumulus 5}

Tumulus 5 lies slightly east of the central part of the cemetery and is one of the eight largest mounds at this site. Its maximum diameter is about $26 \mathrm{~m}$, with a preserved height of about $3.20 \mathrm{~m}$, though it may originally have measured as much as $6 \mathrm{~m}$ in height [Fig. 3.13]. 


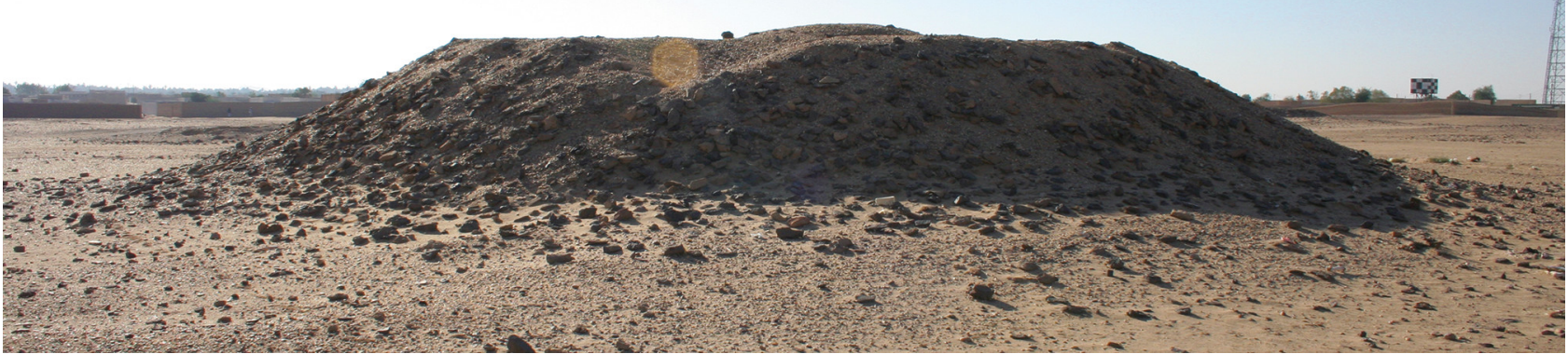

FIGURE 3.13 Tumulus 5 , view of the mound, looking west PHOTO BY K. KOTLEWSKI
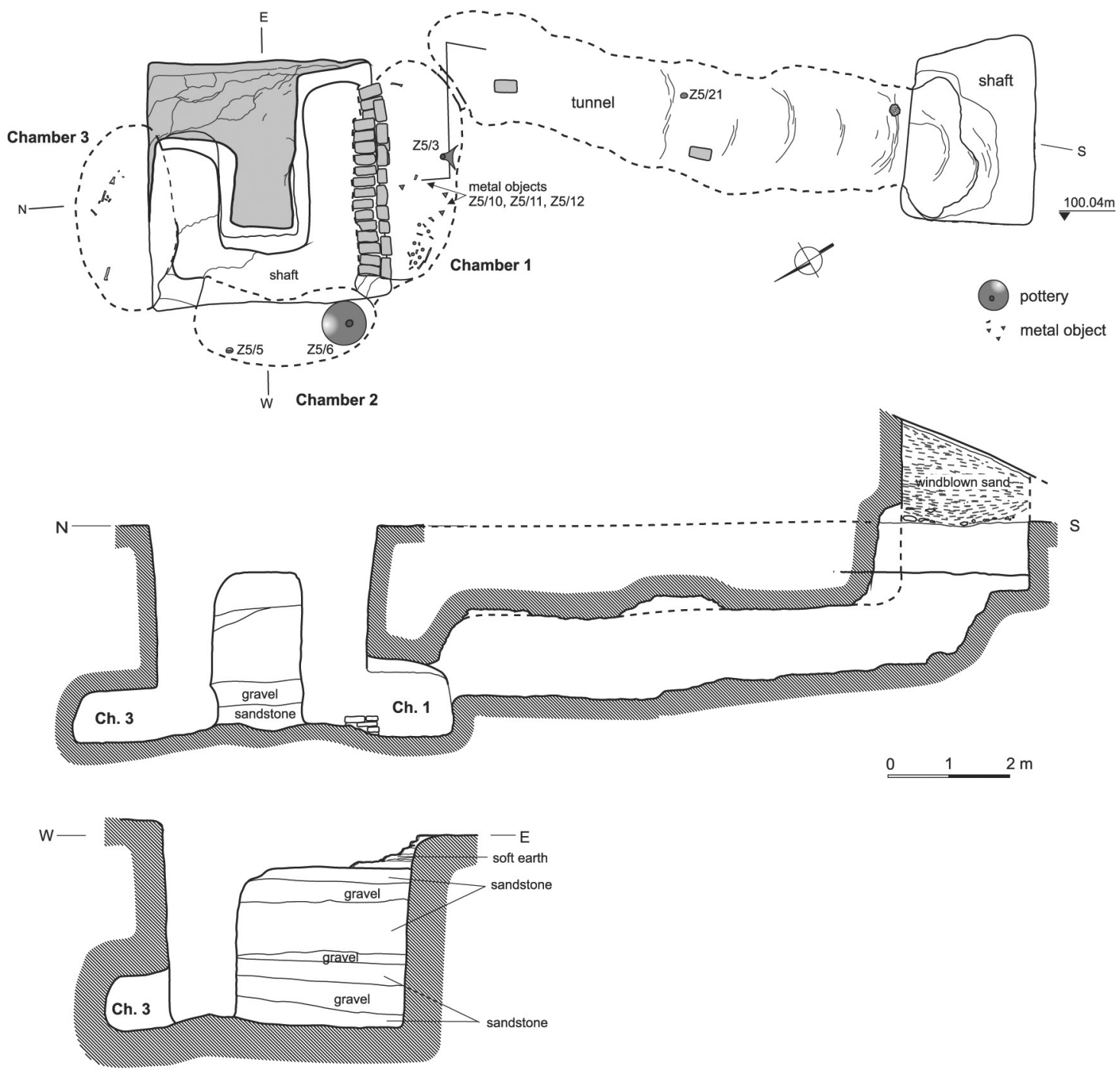

FIGURE 3.14 Tumulus 5, general plan and cross-sections DRAWN BY A. BŁASZCZYK, K. OCHNIO, E. KLIMASZEWSKA-DRABOT, K. KOTLEWSKI, M. WYBIERALSKA, DIGITISED BY M. PUSZKARSKI 
At the time of excavation, most of the summit of the tumulus had already been removed, leaving an almost flat top disturbed by some irregular pits. The easiest and most effective way to explore a mound in this state is to set out a rectangular or square test pit centrally at the top of the mound, provided that the excavator is aware of the whereabouts of the main shaft of the burial [Fig. 3.14].

In this case, a pit measuring $10 \mathrm{~m} \times 10 \mathrm{~m}$ was dug to a depth of about $1 \mathrm{~m}$, thereafter reduced to $10 \mathrm{~m} \times 8 \mathrm{~m}$ and ultimately to $8 \mathrm{~m} \times 6 \mathrm{~m}$ (the longer sides oriented eastwest). The top of an almost square shaft appeared under a layer of crushed white sandstone that also comprised the upper part of the fill. The shaft measured $3.80-3.70 \mathrm{~m}$ $\times 3.65 \mathrm{~m}$. Unlike other burials in the region, it was filled completely with rough stones of different size. Some $40 \mathrm{~cm}$ below the soft surface deposit, a sandstone layer representing the second geological stratum in this part of the site was worked into a kind of pier projecting from the east wall, a feature that turned the ground plan of the shaft into a U-shape with unequal sides measuring $2.14 \mathrm{~m}$ long on the north and 3.30 $\mathrm{m}$ on the south [Fig. 3.15]. The burial contained three lateral niches hewn into the south, west, and north walls of the shaft. All three chambers were blocked with the same kind of stones and stone slabs that filled the shaft. All of the sealing structures were found intact, promising undisturbed burials unless the chambers had been broken into from elsewhere. Unfortunately, the burial had indeed been plundered from the outside, through a tunnel penetrating the southern chamber from the south.

In keeping with the regional burial tradition, the southern chamber (Ch. 1) contained the body, while the other two chambers (Ch. 2 and Ch. 3) were set aside for grave offerings. Chamber 1 was entered by the robbers through a hole about $1 \mathrm{~m}$ in diameter, dug into the rear of the chamber on its east side [Fig. 3.16]. This chamber had been thoroughly ransacked, leaving only some disarticulated long bones of a human skeleton, a few potsherds, and some wooden remains suggestive of a bier used in the inhumation process. Chamber 2, which opens off the west side of the shaft, is separated from chamber 1 by a low partition wall hewn from the same sandstone as the whole tomb.

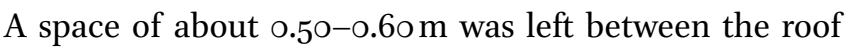
and the top of this wall, which appears to be an innovation replacing the hole made in the partition walls of some of the burial chambers at this cemetery. Only one very large beer jar ( $75 \mathrm{~cm}$ high, $60 \mathrm{~cm}$ in diameter) and a small broken cup were left behind by the grave robbers. Chamber 3 , the northern one, is separated from chamber 2 by another low partition wall that leaves a gap to the roof. Chamber 3 appeared undisturbed but proved to be completely devoid of grave goods apart from some remains of oxid- ised organic material, probably an item of basketry which left a distinct brown residue on the floor of the chamber. It is assumed that this chamber, which indeed had not been penetrated, held grave offerings, mainly food, set out in traditional baskets and on plates woven from plant fibres (Sudanese Arabic: sabat/guffa and tabaq). The food must have attracted white ants and rats (one naturally mummified rat was found among the stones in the shaft fill). Nothing but faint traces of these woven vessels could be discerned on the chamber floor. The tunnel in T.5 measured $7.30 \mathrm{~m}$ in length, $1.28 \mathrm{~m}$ in width, and $1.50 \mathrm{~m}$ in height. An external shaft of rectangular section had been cut at the south edge of the burial mound and sealed, originally with stones similar to those in the main shaft. The stones were, however, found in great disorder, indicating secondary penetration. It seems that the entrance had been left open to be filled with sand and earth from the top of the mound. Careful examination of this tunnel structure leaves little doubt that it was part of the original tomb layout. The robbers took advantage of it, but its original purpose remains obscure. For more detailed information see Mahmoud El-Tayeb 2010a, 205-209; 2010b, 468-471.

\subsection{Tumulus 8}

Tumulus 8 is located in the northern part of the cemetery. The mound was built from a mixture of earth, sand, and gravel, covered by small pieces of black ferruginous sandstone. It has a diameter of about $28.60 \mathrm{~m}$ and a maximum height of $4.91 \mathrm{~m}$. Although no indications of earlier activity were observed on the surface around the lower part of the tumulus, a rectangular pit of about $8 \mathrm{~m} \times 4 \mathrm{~m}$ was discovered on the southern side of the mound. The outline of a large robber pit measuring $5 \mathrm{~m} \times 3.60 \mathrm{~m}$ appeared at a depth of $0.10-0.40 \mathrm{~m}$. The uncovered external shaft is roughly rectangular in plan and aligned east-west, the north side measuring $2 \mathrm{~m}$, the south $2.05 \mathrm{~m}$, the east $1.25 \mathrm{~m}$, and the west $1 \mathrm{~m}$, reaching a depth of $1.95 \mathrm{~m}$ on the south side and $2.30 \mathrm{~m}$ on the north [Fig. 3.17].

Access to the bottom of the shaft was facilitated by a single step hewn out in its south-east corner at a depth of about $0.90 \mathrm{~m}$ from the ground surface, while there was another step rising about $0.40 \mathrm{~m}$ from the bottom of the shaft to the entrance of the tunnel [Fig. 3.18]. Here again, on their way down the robbers missed the centre of the external shaft, and as a result they partially destroyed the ceiling of the tunnel at its entrance. The relatively narrow entrance to the tunnel is sub-rectangular, measuring $1.26 \mathrm{~m}$ wide and $1.36 \mathrm{~m}$ high. So far the tunnel of T.8 is the narrowest and the most irregular in shape, as well as being the most poorly constructed of all eight tunnels excavated at the cemetery. Its maximum length reaches $6.40 \mathrm{~m}$, while 


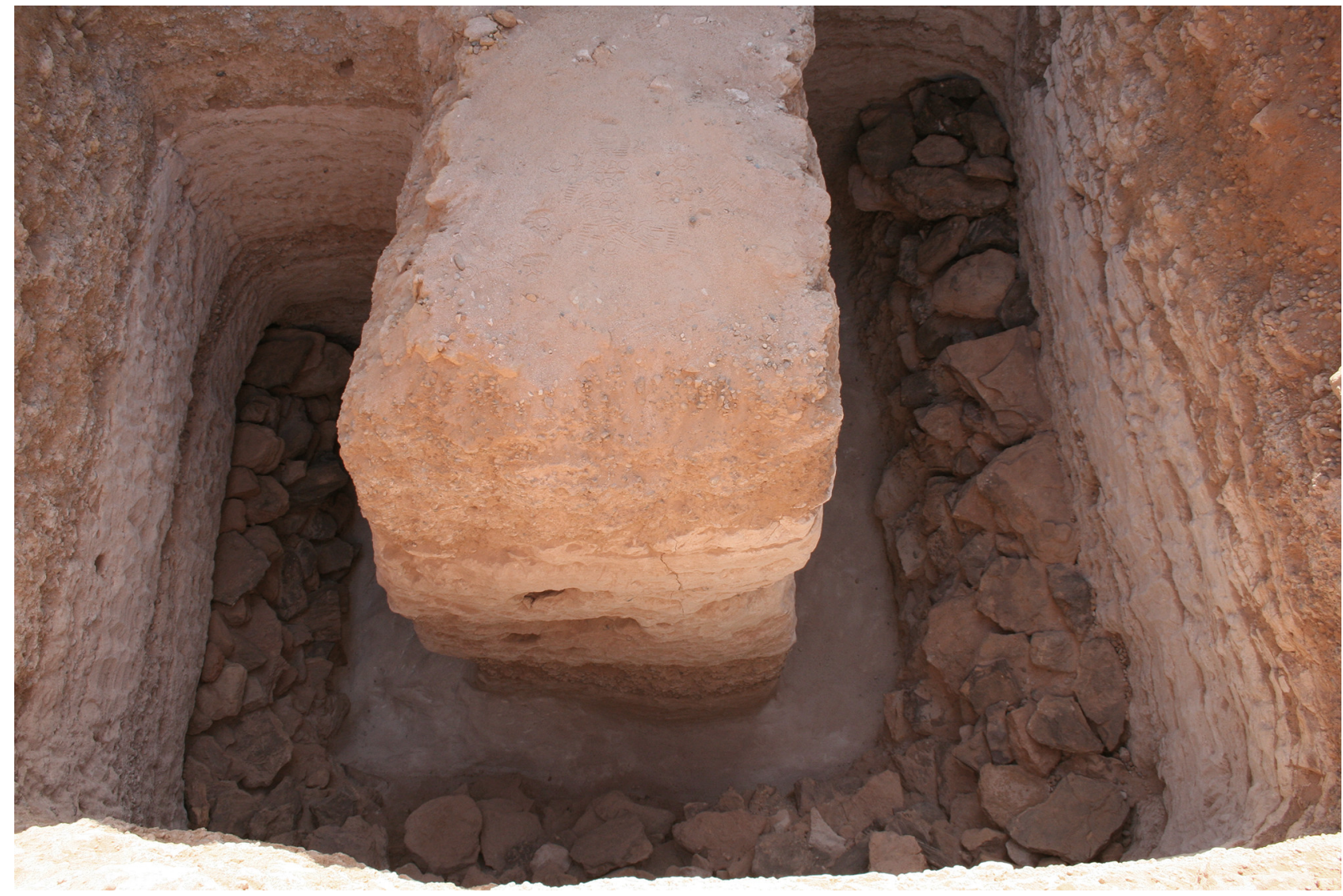

FIGURE 3.15 Tumulus 5 , view of the excavated shaft with stone blocking walls PHOTO BY K. KOTLEWSKI

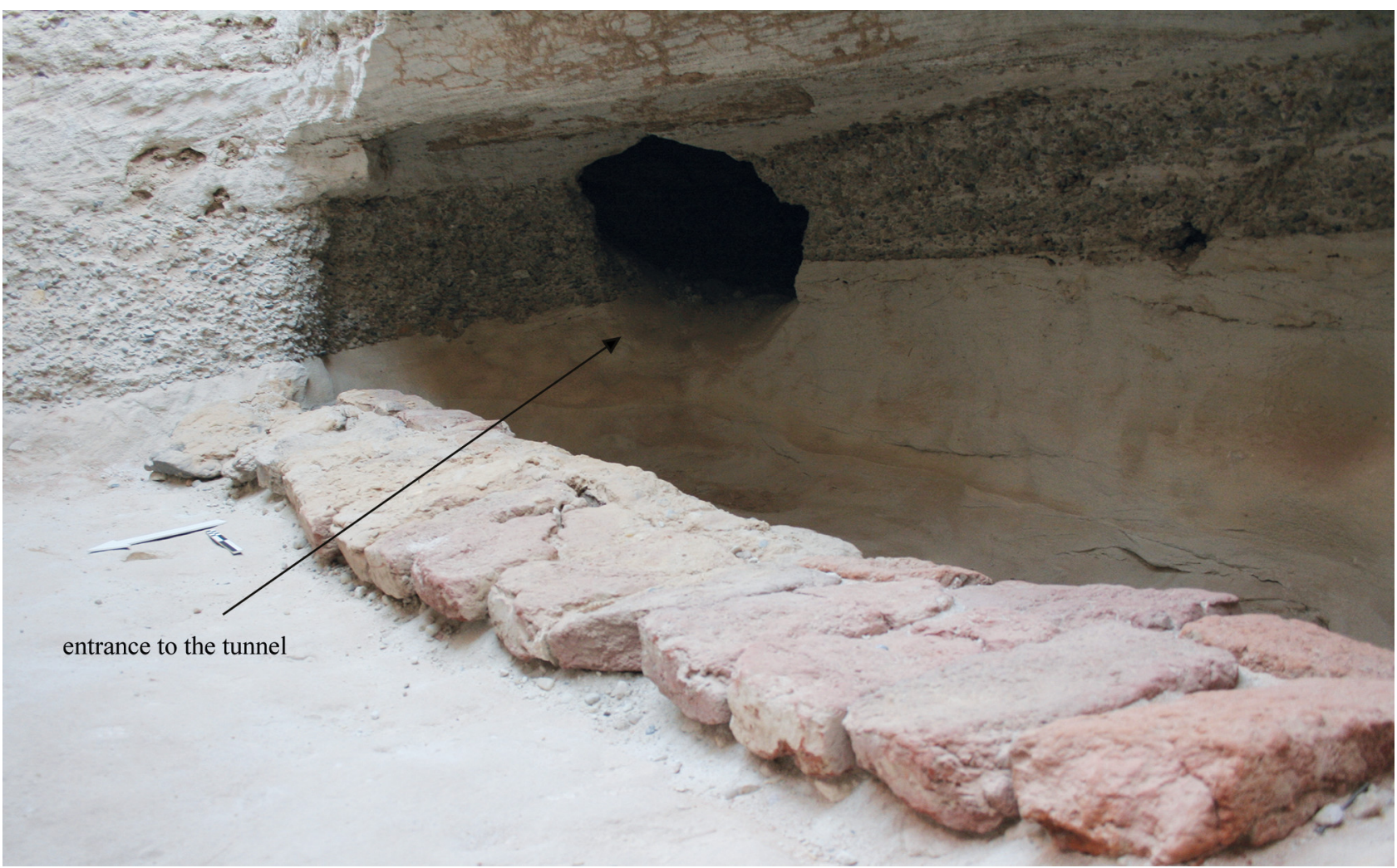

FIGURE 3.16 Tumulus 5, view of chamber 1. Note the entrance to the tunnel from the east side of the chamber

PHOTO BY K. KOTLEWSKI 


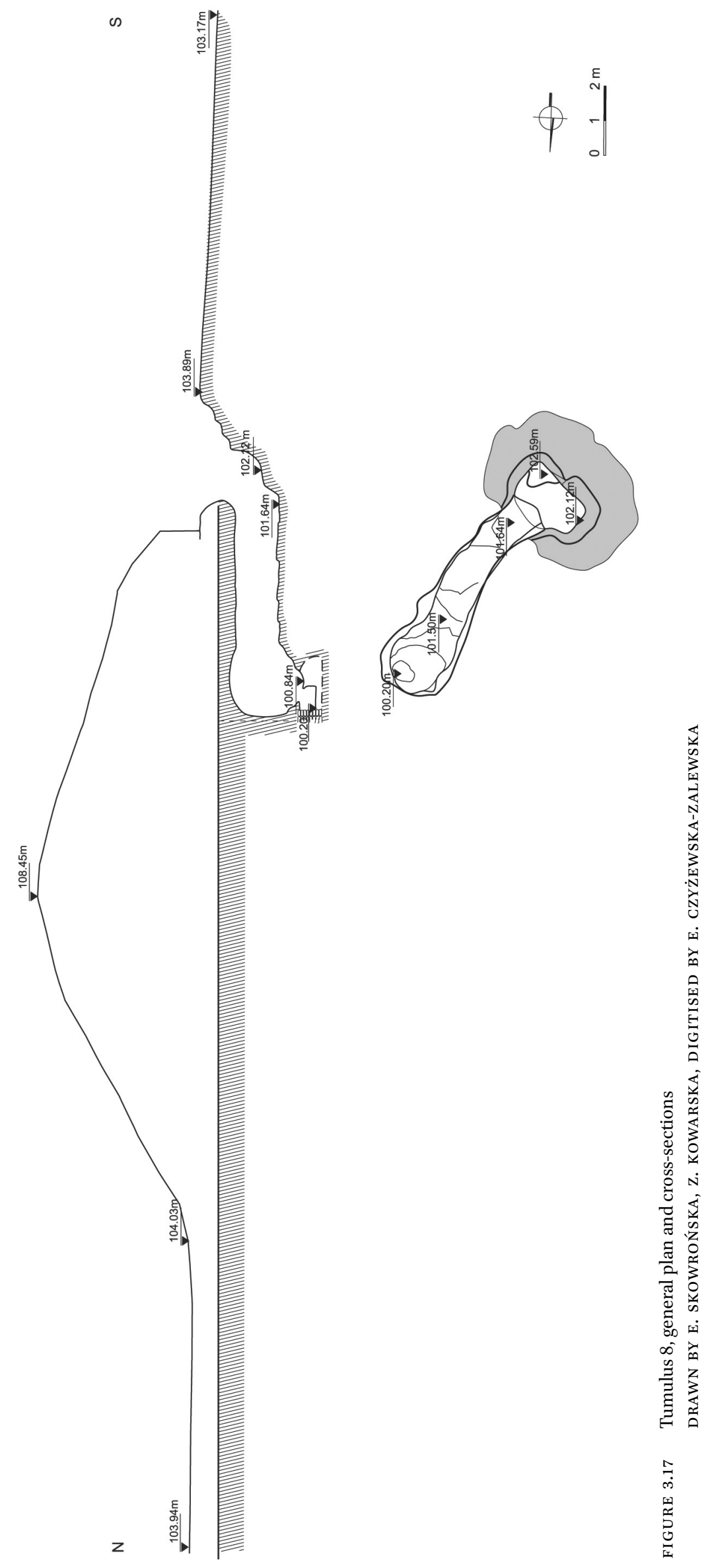




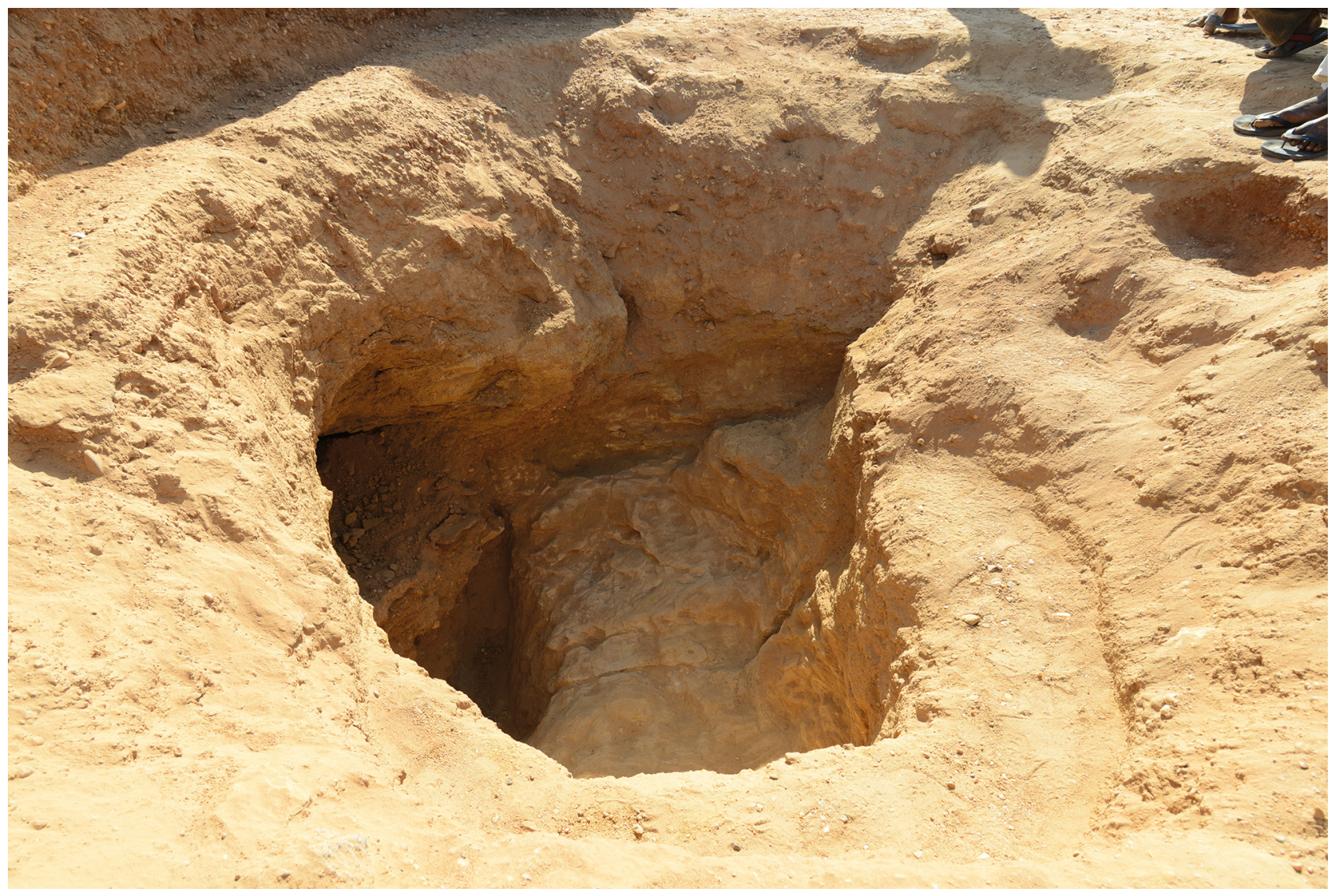

FIGURE 3.18 Tumulus 8, view of the external shaft and the entrance to the tunnel, facing north PHOTO BY A. KAMROWSKI

its width ranges from $1.26 \mathrm{~m}$ at the entrance to $2.05 \mathrm{~m}$ at the end. The last $2 \mathrm{~m}$ of the tunnel has a gradual downward incline of about $0.50 \mathrm{~m}$ towards a hole leading into the west side of the main burial chamber (Ch. 1, on the south side). The hole, which perforated the ceiling of chamber 1 , is of elongated, irregular shape, measuring $0.63 \mathrm{~m} \times$ $0.46 \mathrm{~m}$ [Fig. 3.19 top]. The southern chamber (Ch. 1) measures $2.00 \mathrm{~m} \times 1.20 \mathrm{~m}$ and is $0.65 \mathrm{~m}$ high, while chamber 2 is $3.40 \mathrm{~m}$ long but only $0.65 \mathrm{~m}$ wide, and measures about $0.65 \mathrm{~m}$ at its highest point [Fig. 3.19 bottom]. The ceilings of both chambers slope markedly towards the rear of the chamber, a construction practice which has so far been noted only in this burial and in T.3. Red bricks bearing traces of white plaster were reused in the seven courses making up the blocking walls of these burial chambers. As mentioned elsewhere, these bricks were most probably brought from the nearby ruins of an old Meroitic official building, the location of which remains unknown. The substructure of the tomb appears to have been penetrated and looted on multiple occasions. As a result, the two chambers, the tunnel, and the external shaft were all found filled with compact, brownish earth. The excavation of chamber 1 brought to light a pile of broken human and animal bones mixed together in the centre of the chamber, while only one small light brown bowl was noted near the red-brick blocking wall. Fragments of cattle bones were also found in the fill of the tunnel and the external shaft. For the same reasons as noted in T.3, no further work was conducted. Nonetheless, the results of this quite limited investigation have added further evidence relating to the origin and function of the tunnels beneath the El-Zuma tumuli. For more detailed information see Mahmoud ElTayeb, Skowrońska, and Czyżewska 2016, 120-121.

\subsection{Tumulus 1}

Tumulus 1 is located on the far south-eastern fringes of the cemetery [see Fig. 1.2]. It measures about $34 \mathrm{~m}$ in diameter, with a preserved height of about $5.37 \mathrm{~m}$. The search for the external shaft of this tumulus started on its southern side, where some remnants of whitish crushed sandstone were recorded at the foot of the mound. Grave robbers had earlier made at least three failed attempts to find this shaft. They partly succeeded on their fourth attempt, although they missed the centre of the external shaft, thus badly damaging the ceiling of the tunnel entrance. The external shaft is rectangular in plan and aligned east-west. It meas- 

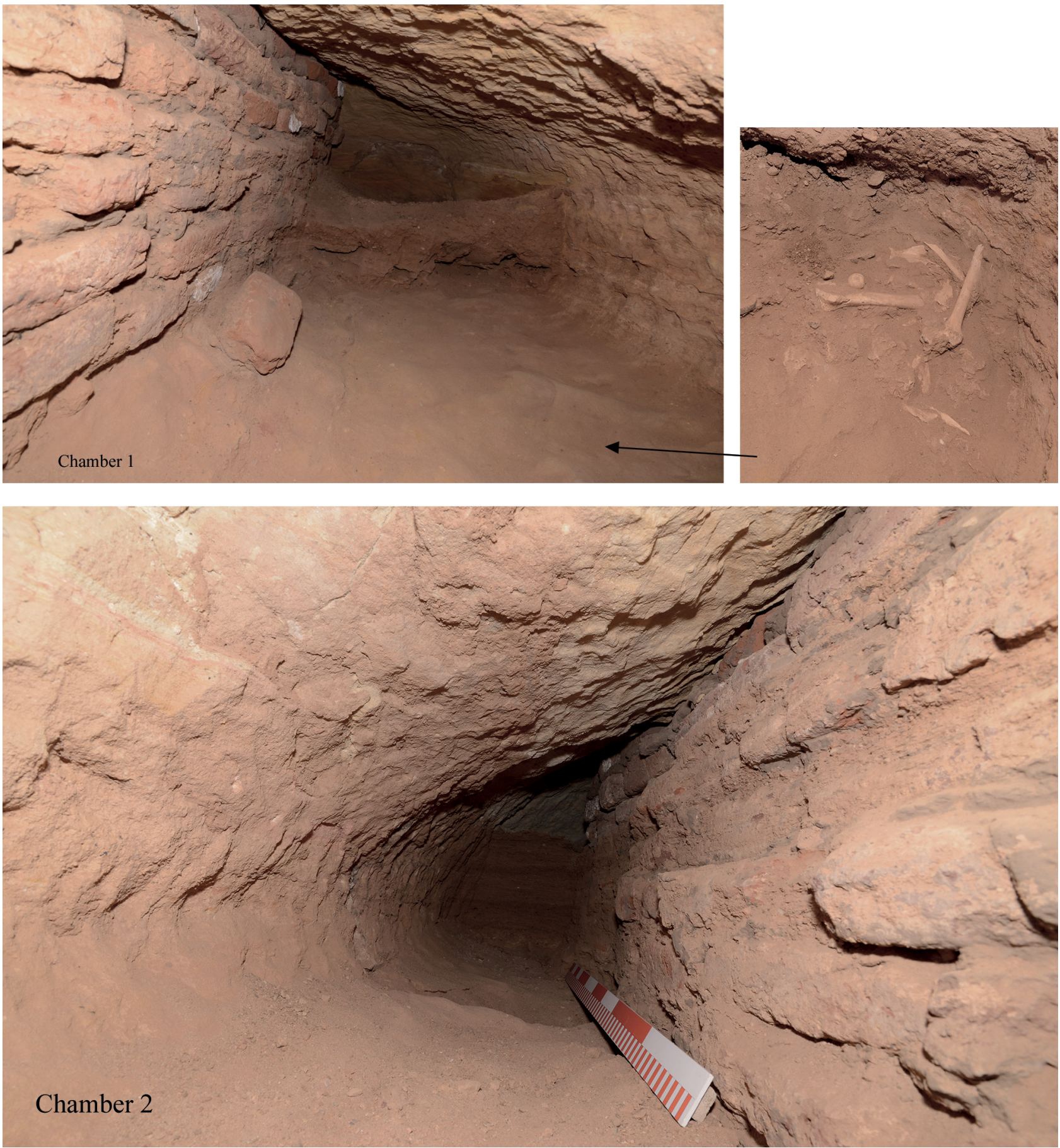

FIGURE 3.19 Tumulus 8 , view of the southern chamber 1, facing east (top), view of the human bones excavated in the southern part of the chamber (top right); view of chamber 2 (bottom) PHOTOS BY A. KAMROWSKI

ures $3.70 \mathrm{~m}$ in length and $1.70 \mathrm{~m}$ in width with a maximum depth of about $2.60 \mathrm{~m}$. The shaft is provided with two steps cut into its south-east and south-west corners at respective depths of about $1.13 \mathrm{~m}$ and $1.33 \mathrm{~m}$ below ground level [Fig. 3.20].

Cleaning of the external shaft revealed the existence of a wide tunnel aligned north-south. The entrance to the tunnel is about $3.00 \mathrm{~m}$ wide and about $1.6 \mathrm{om}$ high The tunnel is supported by four pillars that divide it into two wings: east and west [Fig. 3.21]. The first pillar is located at a distance of $5.45 \mathrm{~m}$ from the south wall of the external shaft. Like the tunnel in T.4, the east wing of this tunnel, which measures $13.30 \mathrm{~m}$ in length, extends northwards, terminating in a rounded dead-end. The west wing 


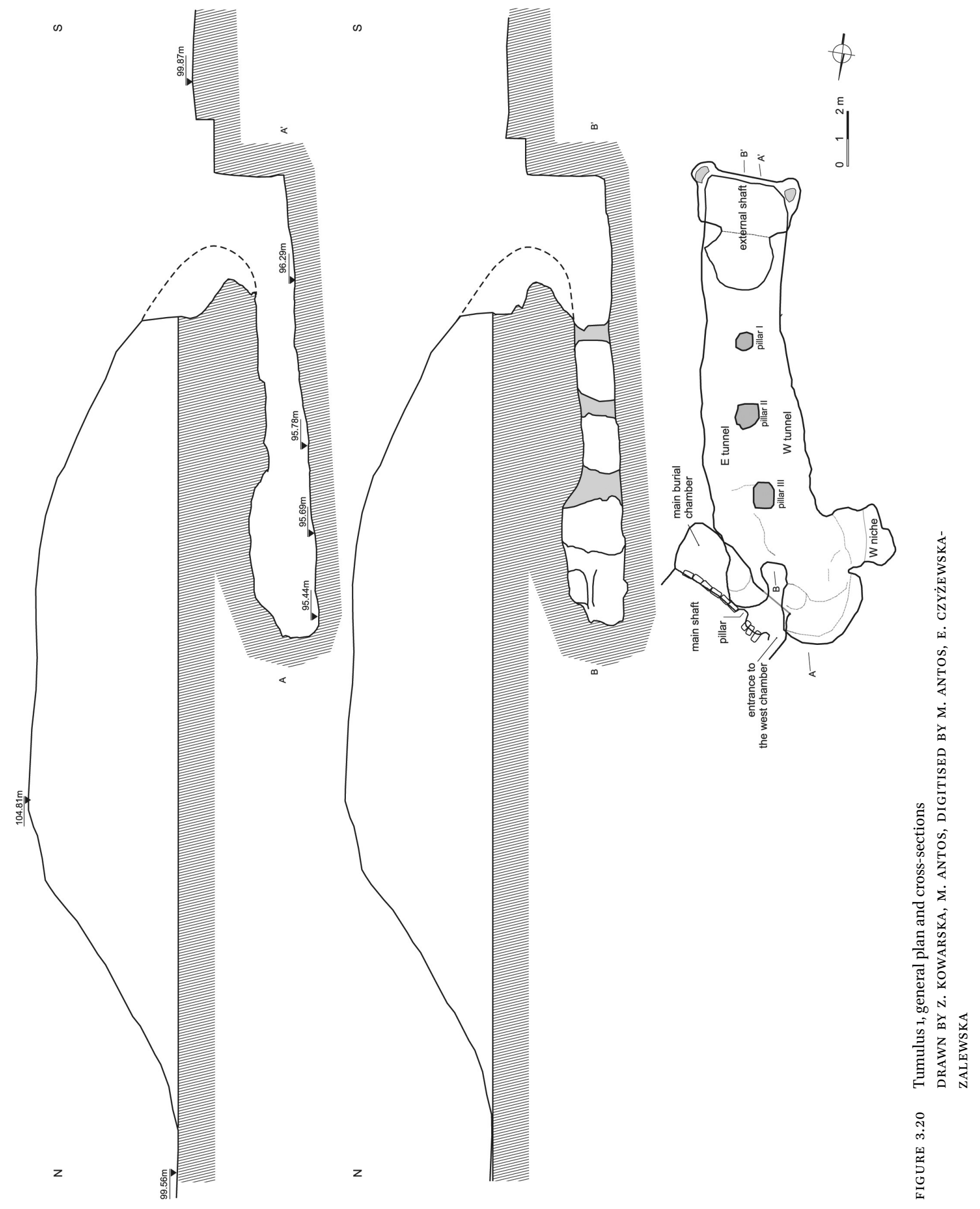




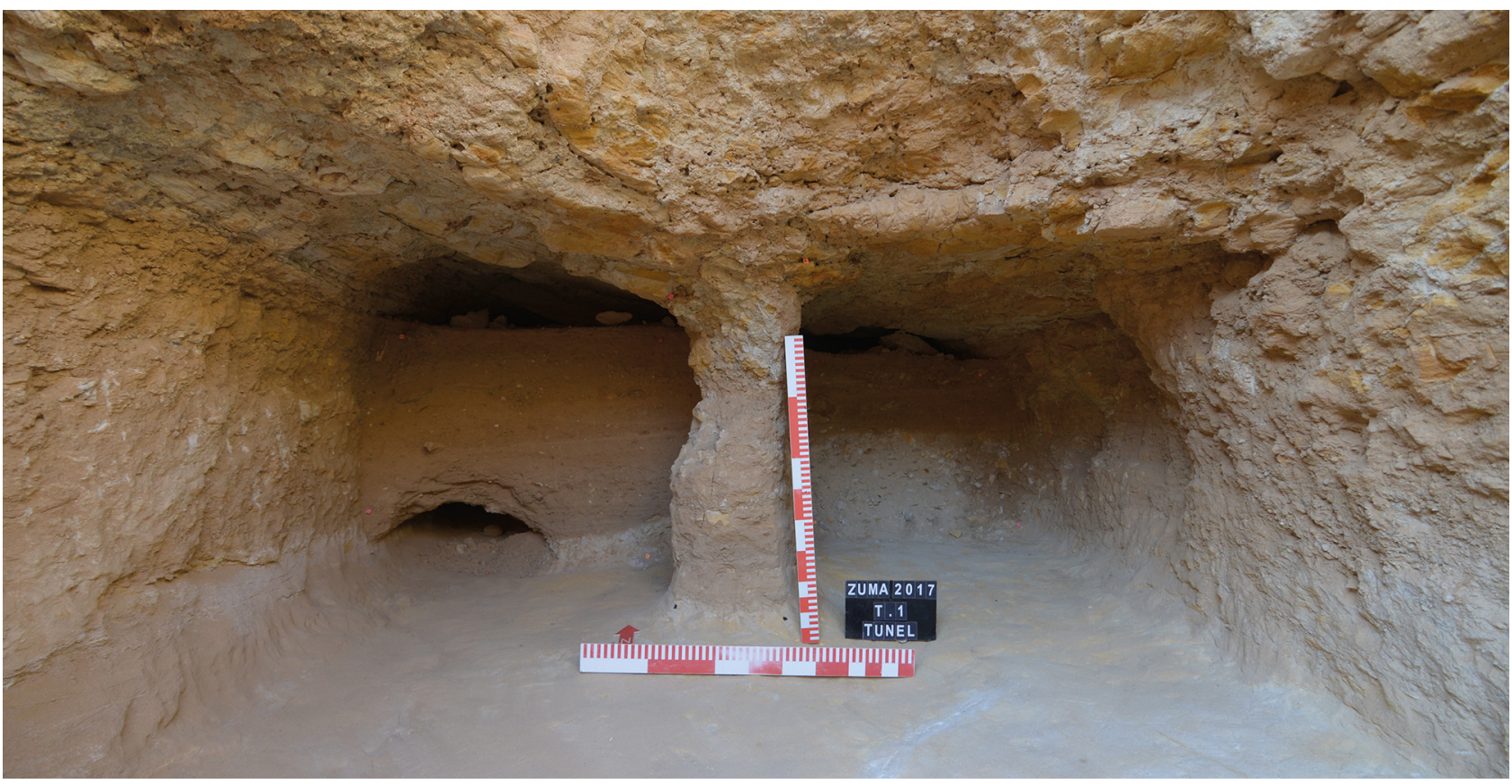

FIGURE 3.21 Tumulus 1, view of the tunnel, looking north Pното BY A. KAMROWSKI

is slightly longer, measuring $14.20 \mathrm{~m}$, with a wider, rounded dead-end. At a distance of about $9 \mathrm{~m}$ into the west wing of the tunnel, there was an extremely unusual construction, unlike any ever noted in this type of burial at El-Zuma. It was discovered hewn into the west wall of the west wing and took the form of an open niche measuring about $2.00 \mathrm{~m} \times 1.20 \mathrm{~m}$. It is not clear, however, if the original plan had been to construct a side chamber here, which was never completed, or if this western lateral niche, provided with a bench-like feature, represented a new element in the burial tradition of the period. One large cattle bone (a scapula) was the only item found on top of the bench [Fig. 3.22 top].

Another modification in burial practice is the location and construction of the main burial chamber, which was found cut into the east wall of the west wing of the tunnel. The burial chamber was cut into the sandstone bedrock at about $1.50 \mathrm{~m}$ above the tunnel floor. It was covered by a mixture of sand, earth, and partly collapsed roof. Excavation revealed that the burial had been badly rifled in the past [Fig. 3.22 bottom]. Fragments of a disarticulated human skeleton, one medium-sized beer jar, pottery sherds, and broken pieces of various ornaments, as well as metal fragments, including a gold earring, were noted; they were scattered in the burial chamber and all along the tunnel (see Volume III, Chapter 5). The results of preliminary bone analysis conducted in the field were of great interest, for they pointed to the discovery of fragments from at least seven human skulls, in addition to
11 fragments of human right femurs (see Chapter 6, this volume). The burial chamber is approximately rectangular [see Fig. 3.23 bottom] and oriented north-west-southeast. It measures $4.56 \mathrm{~m} \times 1.30 \mathrm{~m}$ on the north-western side and $1.86 \mathrm{~m} \times 0.85 \mathrm{~m}$ on the south-eastern side, with a height of $0.95 \mathrm{~m}$. Its entrance, from the side of the main burial shaft, is about $1.30 \mathrm{~m}$ wide, and it is divided by a small, fragile pillar, far smaller in size than the one discovered in the burial chamber of T.6 (Mahmoud El-Tayeb, Skowrońska, and Czyżewska 2016, 122-123). The blocking wall (about $0.85 \mathrm{~m}$ high), separating the main shaft and the burial chamber, consists of nine courses of mud bricks lightly bonded with a thin layer of mud mortar [Fig. 3.23] .

Two weeks after the mission left El-Zuma, the author heard from the foreman of the site workers that a large hole had appeared in the summit of the tumulus, similar to the one recorded in T.4 [see Fig. 3.29]. On site, it appeared that the situation was even worse and more frightening than that of T.4. In contrast to T.4, the pit at the top of T.1 reached the bottom of the main burial shaft directly in front of the burial blocking wall. The pressure of the sand falling in through the shaft had been great enough to destroy some of the mud-brick courses of the blocking wall. In consequence, sand had filled half of the burial chamber and poured down on to the tunnel floor. The only effective way to secure the pit from the top of the tumulus was to seal it with heavy concrete slabs since these mounds are a favourite playground of local children. The external shaft of the tumulus has been protected by building the same 

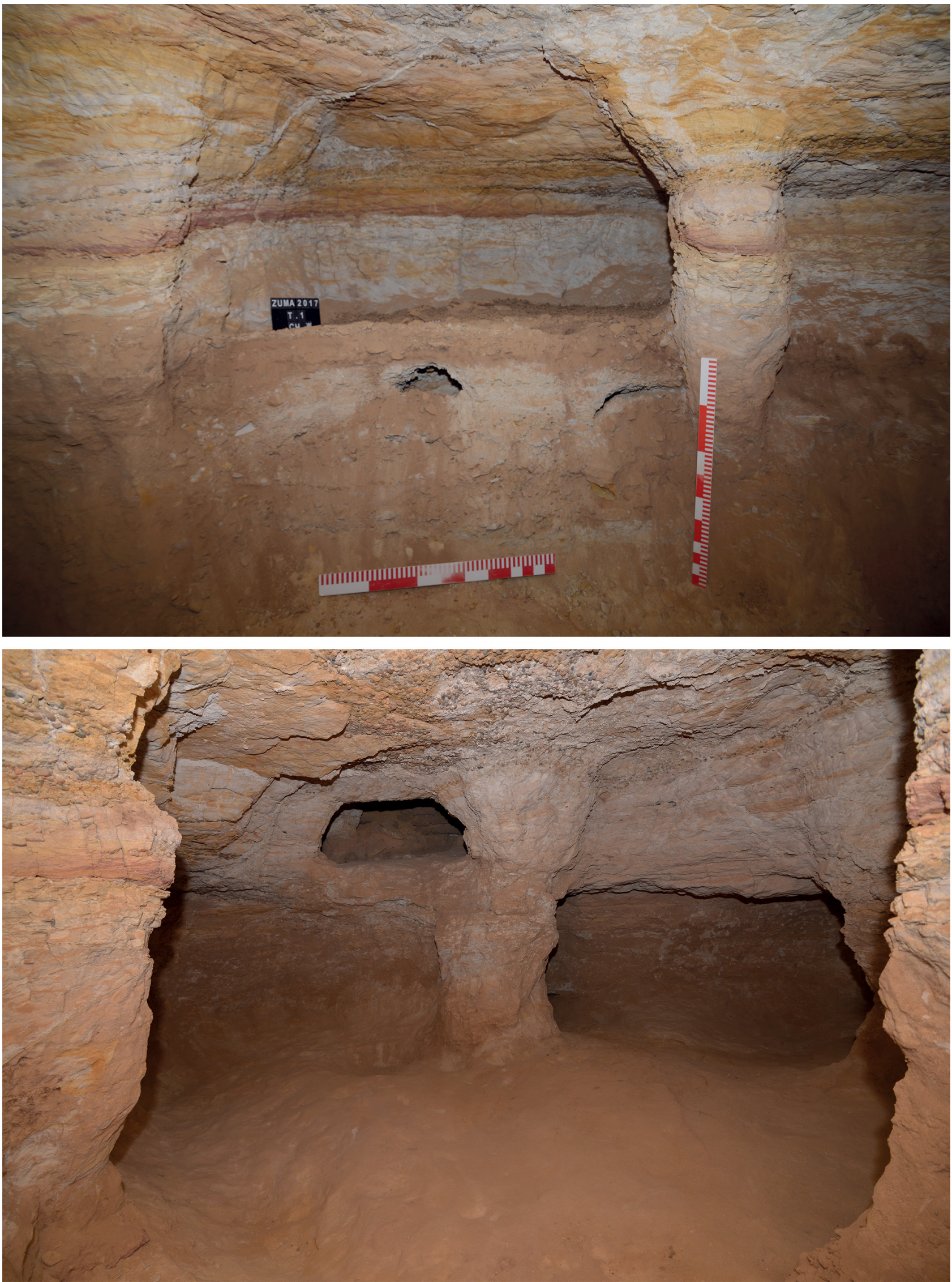

FIGURE 3.22 Tumulus 1, view of the side niche, facing west (top); rear entrance of chamber 1 (bottom) PHOTOS BY A. KAMROWSKI 

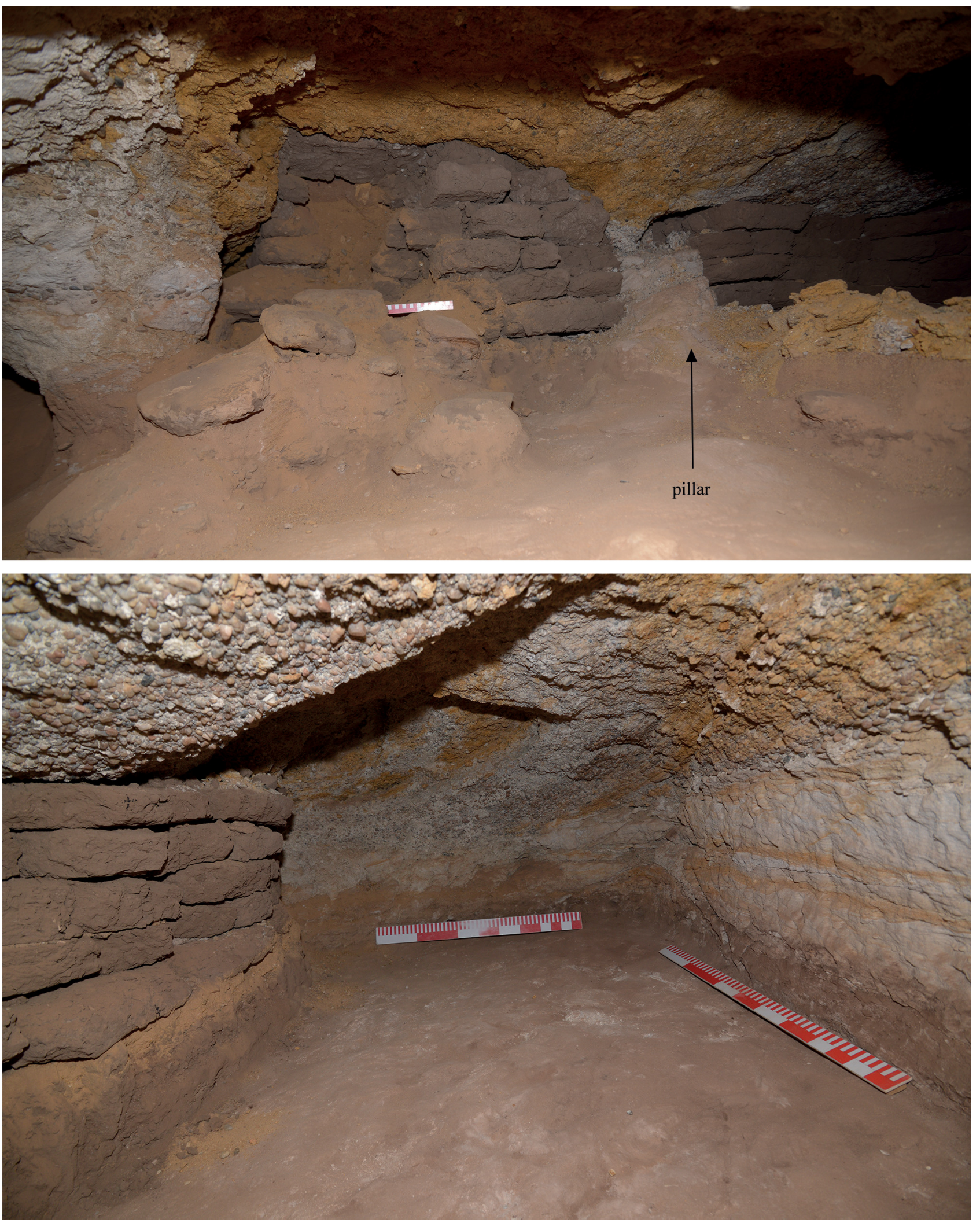

FIGURE 3.23 Tumulus 1, view of the fragile pillar in chamber 1 (top); chamber 1 after excavation (bottom)

PHOTOS BY A. KAMROWSKI 

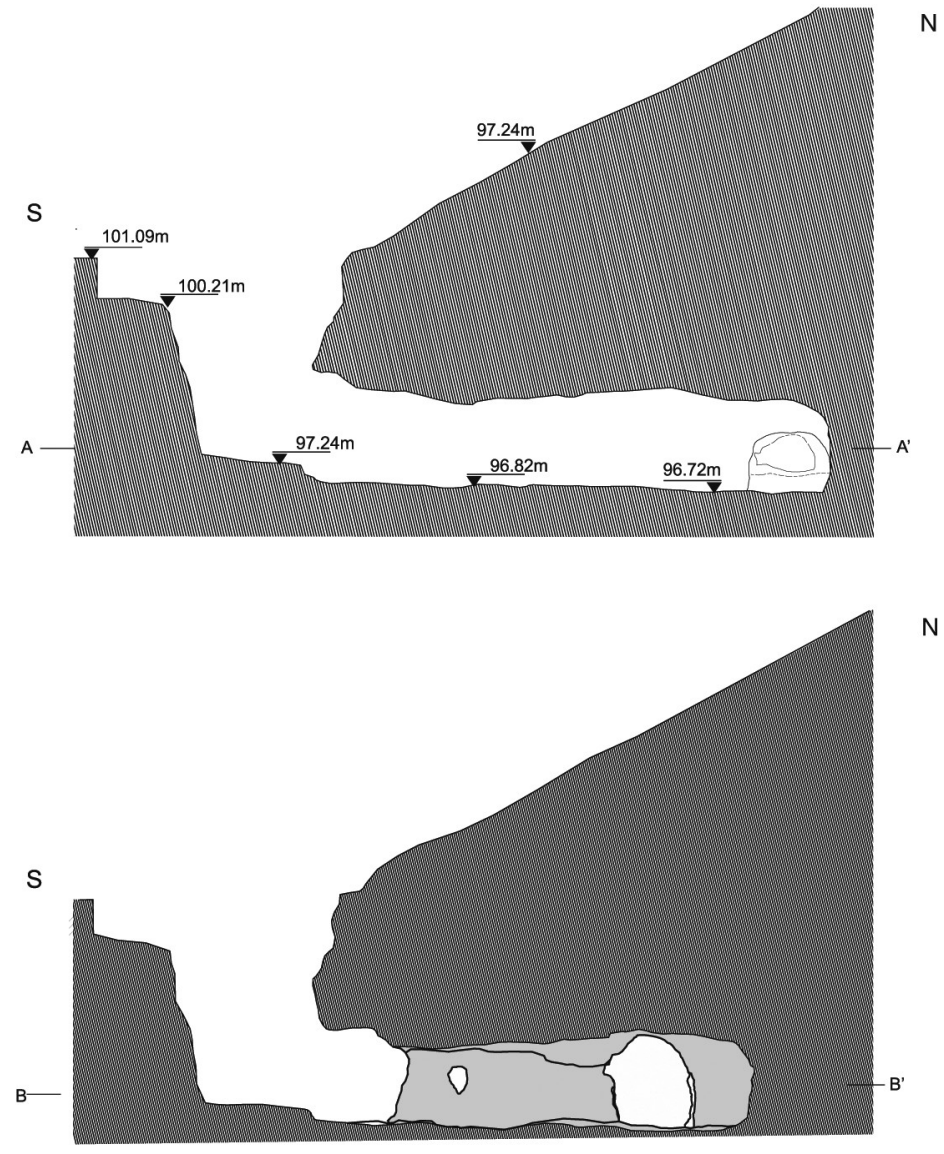

$\mathrm{N}$
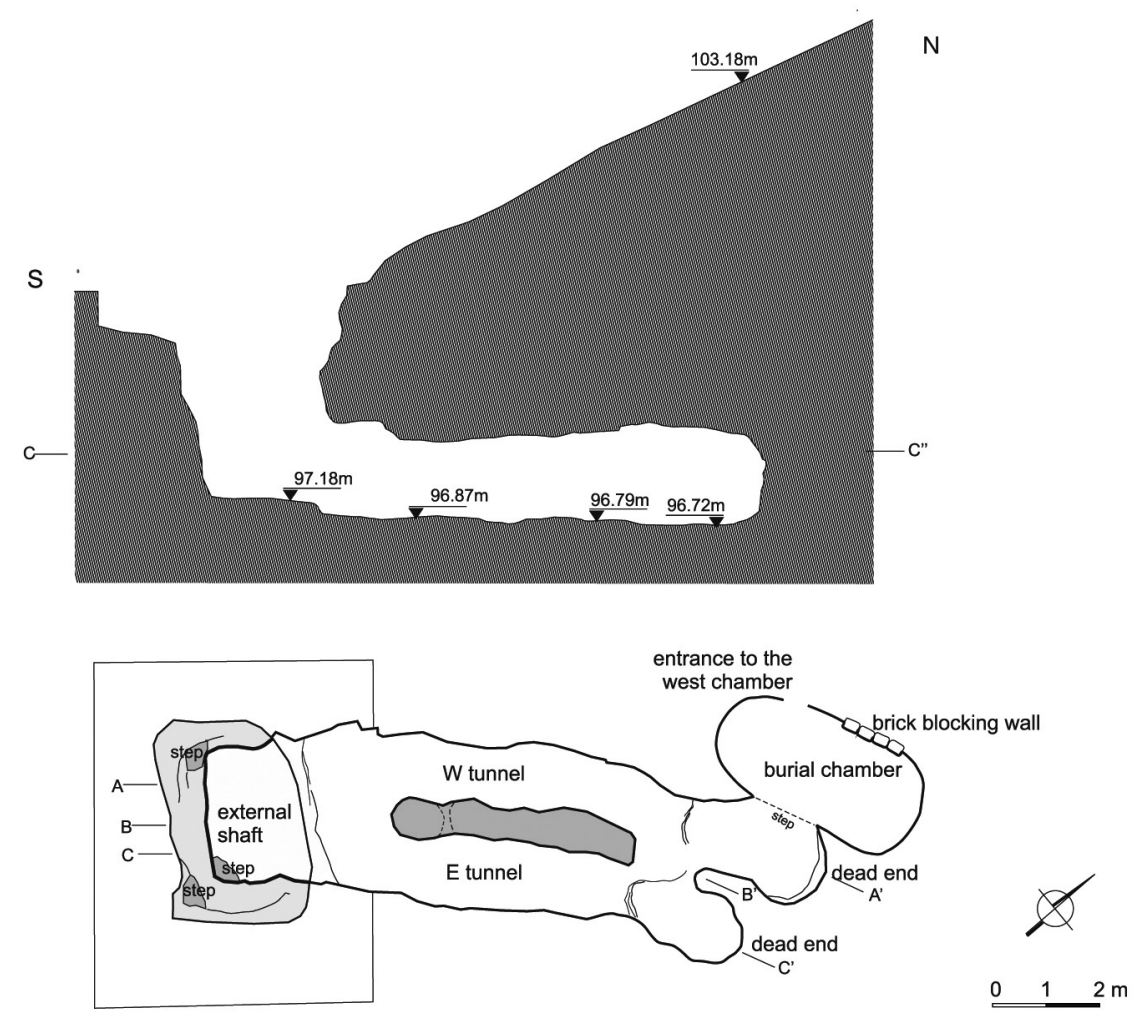

FIGURE 3.24 Tumulus 4, general plan and cross-sections

DRAWN BY M. ANTOS, DIGITISED BY M. ANTOS, E. CZYŻEWSKA-ZALEWSKA 


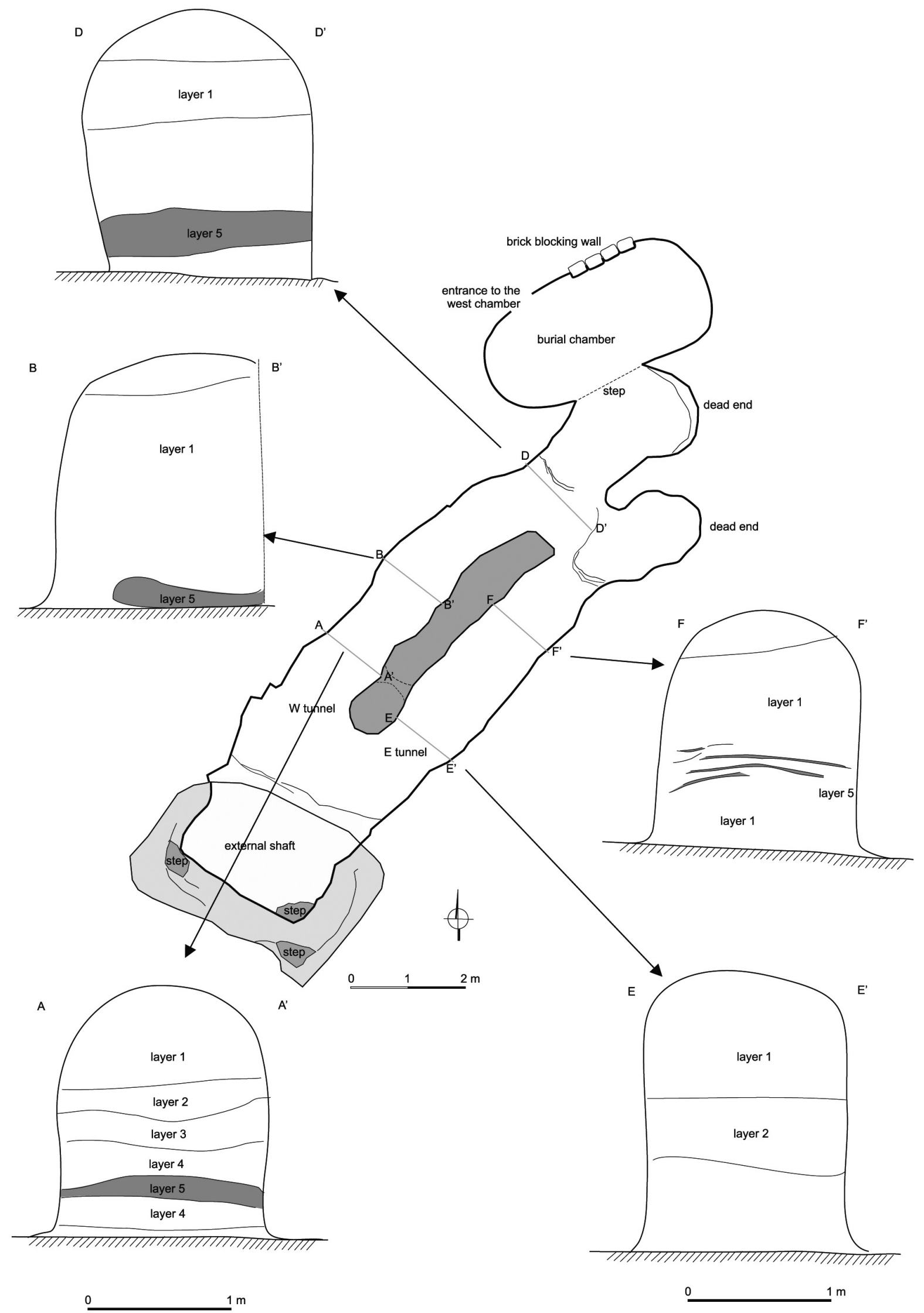

FIGURE 3.25 Tumulus 4, sediment layers inside the tunnels DRAWN BY M. ANTOS, DIGITISED BY M. ANTOS, E. CZYŻEWSKA-ZALEWSKA 


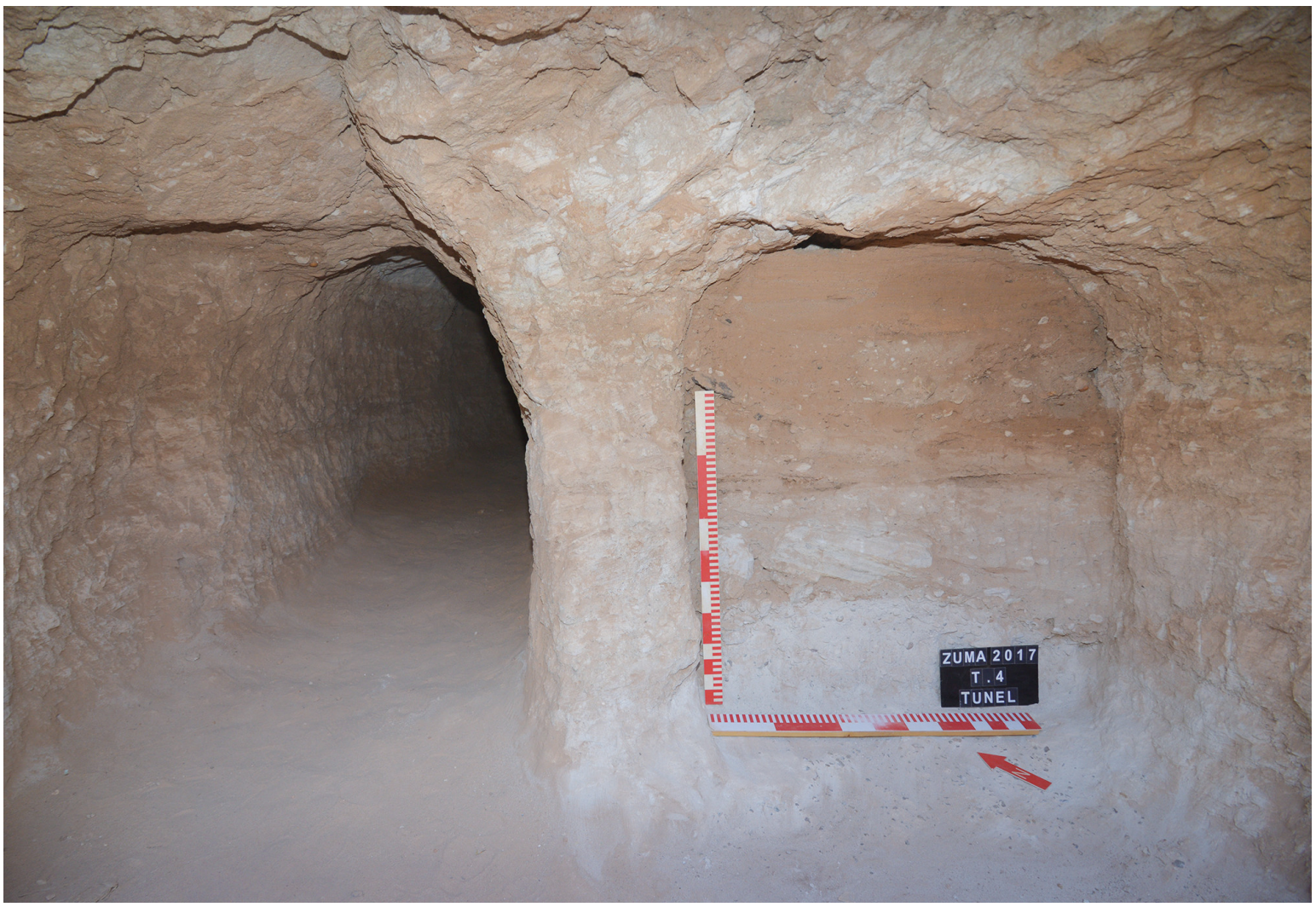

FIGURE 3.26 Tumulus 4, underground tunnel divided by pillars into two wings (east wing filled with sediments)

PHOTO BY A. KAMROWSKI

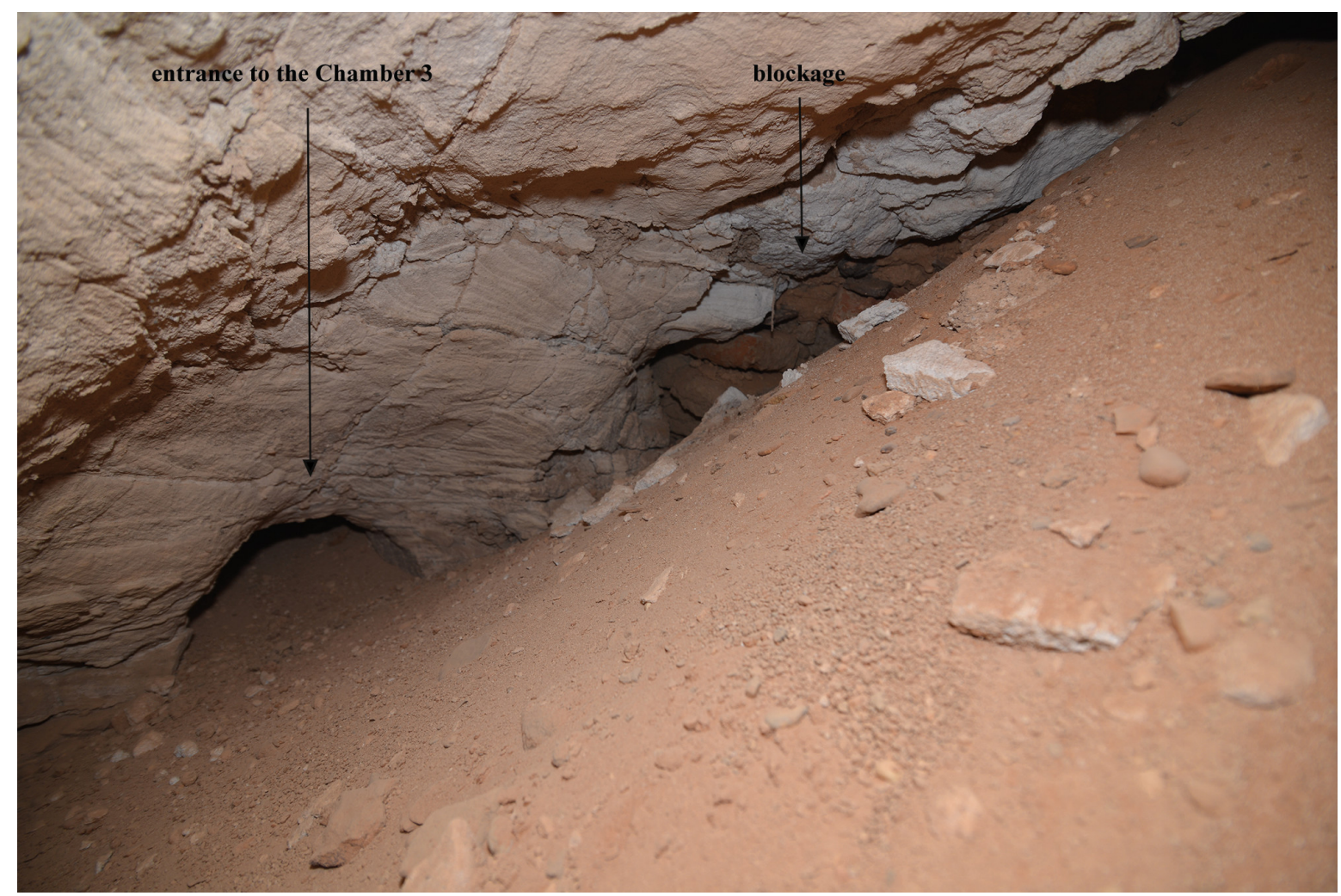

FIGURE 3.27 Tumulus 4, view of burial chamber 2. Note the red-brick blocking wall and the entrance to a secondary chamber (Ch. 3)

PHOTO BY A. KAMROWSKI 

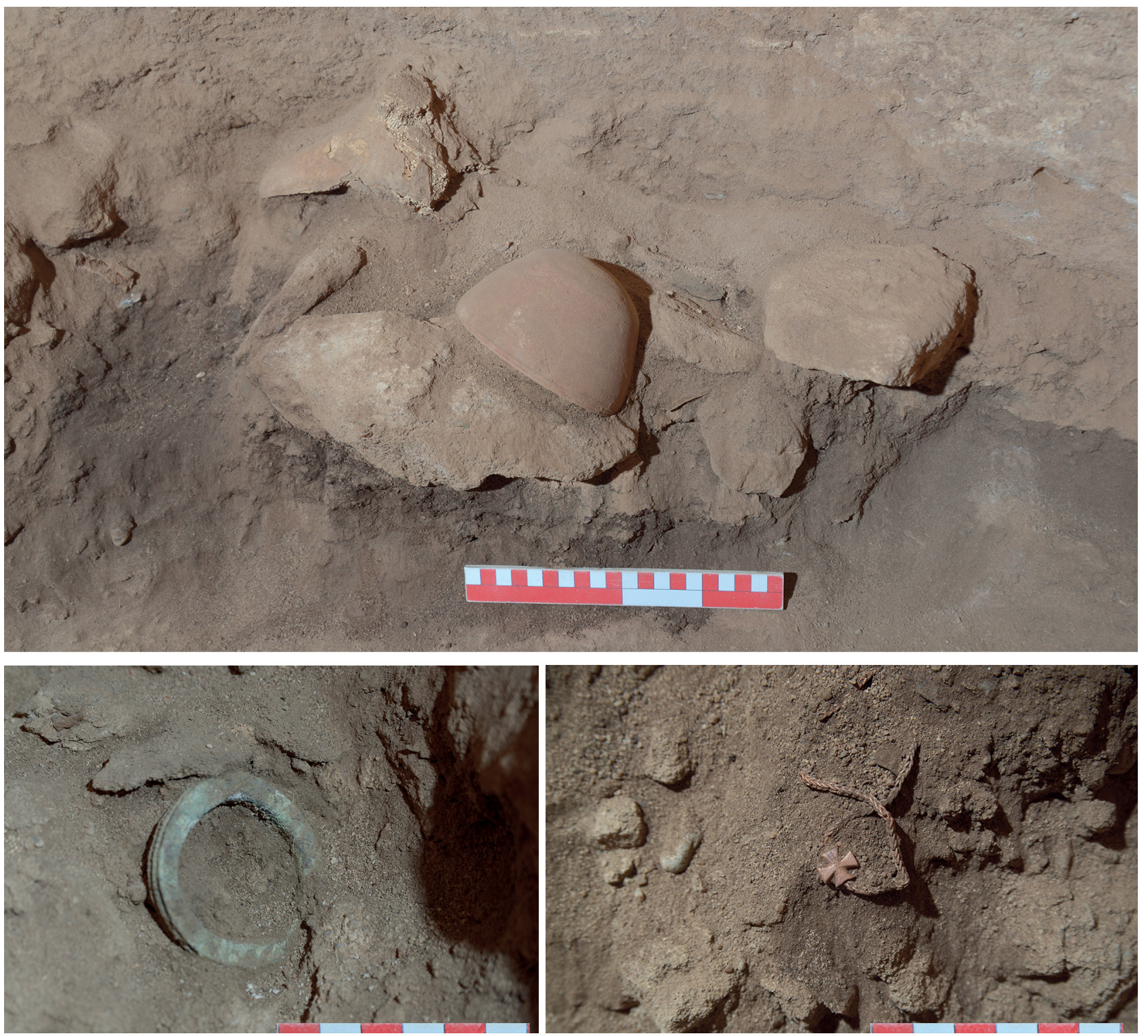

FIGURE 3.28 Tumulus 4, close-up, objects visible in the sand layers in front of the burial chamber (top); bronze ring (bottom left) and chain with crosses (bottom right) in situ PHOTOS BY A. KAMROWSKI

type of construction as in T.4 (a vaulted roof), using metal beams and red bricks. A metal grid was also installed for safety purposes and to provide an easy means of descending to the bottom of the shaft. For more detailed information see Mahmoud El-Tayeb 2017, 346-35o.

\subsection{Tumulus 4}

Tumulus 4 is located at the south-west side of the cemetery site [see Fig. 1.2]. Like the abovementioned tumuli, it has a conical shape and was built of earth and gravel, covered with small rough black stones. Its maximum diameter is about $34 \mathrm{~m}$ with a height of up to $6.20 \mathrm{~m}$, making it one of the largest type I tumuli. A successful attempt to find the external shaft and the tunnel entrance was made at the end of the sixth excavation season, in 2013. Thereafter, during the cleaning of the entrance to the tunnel, the ceiling, which was very fragile, started to collapse. For lack of time and for safety reasons, the excavation of this feature was suspended until 2017. During the 2017 season, work was resumed with the aim of excavating the tunnel in order to reach the burial chamber and thus gain a better understanding of the burial practice and determine its date. To this end, the external shaft was fully unearthed, revealing some damage done by robbers to the top of the tunnel's entrance [Fig. 3.24]. The external shaft is rectangular in shape, oriented east-west, and measures $3.80 \mathrm{~m}(\mathrm{E}-\mathrm{W})$ by $2.45 \mathrm{~m}(\mathrm{~N}-\mathrm{S})$ on the ground surface, narrowing towards the bottom, where it measures only $2.00 \mathrm{~m} \times 2.60 \mathrm{~m}$, with 


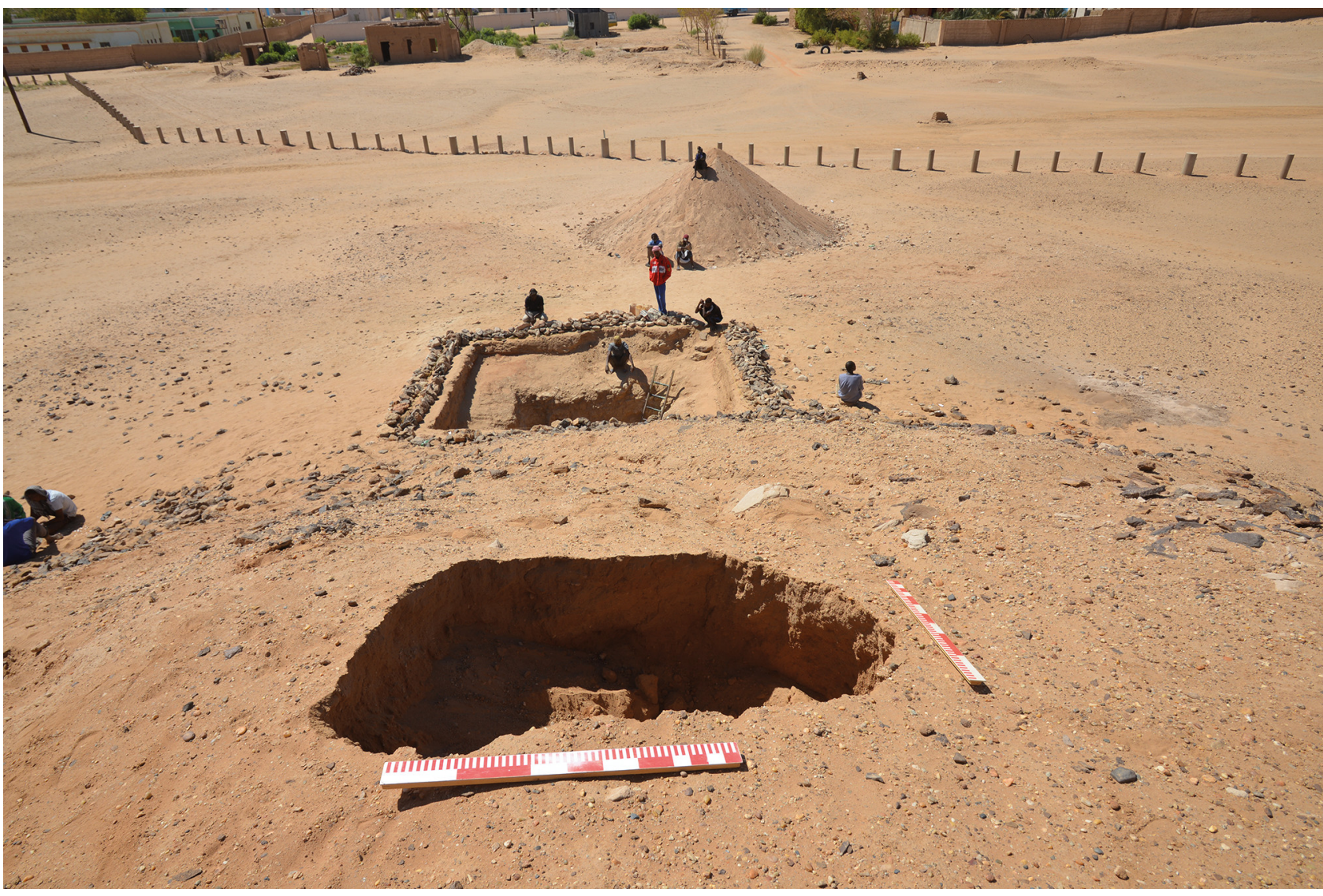

FIGURE 3.29 Tumulus 4, view of the hole on top of the mound. Excavation of the tunnel in the background PHOTO BY A. KAMROWSKI

a maximum depth of about $3 \cdot 30 \mathrm{~m}$. Access to the bottom of the shaft was made easier by two steps cut into the south-east and south-west corners of the shaft at a depth of about $1.50 \mathrm{~m}$ below ground level. The entrance to the tunnel is about $2.70 \mathrm{~m}$ wide. During the 2013 season only a stretch of $1.50 \mathrm{~m}$ from the edge of the shaft was cleared of fill [Fig. 3.25].

At a distance of about $2 \mathrm{~m}$, it appeared that the tunnel was divided into east and west wings by a partition wall hewn from the sandstone bedrock [Fig. 3.26], rather than by pillars such as those in T.1, T.6, and T.7 (Mahmoud El-Tayeb, Skowrońska, and Czyżewska 2016). The wall itself is about $5.50 \mathrm{~m}$ long and is provided with one small hole made at a distance of $1.50 \mathrm{~m}$ from its southern end. The tunnel height at the entrance point is about $1.62 \mathrm{~m}$, becoming lower towards the central section, and measuring about $1.59 \mathrm{~m}$ at its northern end. The eastern wing of the tunnel is only about $8.25 \mathrm{~m}$ long, while the western wing is $9.90 \mathrm{~m}$ long. Although both wings terminate in a dead-end at their northern extremity, a small chamber is cut into the west wall of the western wing. A rear chamber entrance is cut about $0.60 \mathrm{~m}$ above the floor level of the tunnel. The chamber itself measures approximately $2.70 \mathrm{~m}$ in length from north to south and $1.20 \mathrm{~m}$ east to west, with a $1.5 \mathrm{O}-\mathrm{m}$-wide entrance. It was found full of earth from the side of the tunnel, as well as loose sand that had poured into it through a hole in its roof, which was later discovered to be dug into the summit of the tumulus. Part of a wall built of reused red bricks was noted on the far north side of the chamber, almost entirely covered by the sand that had poured into it [Fig. 3.27].

The location of this relatively small chamber is quite unusual, and it was found to contain the remains of offerings that had escaped the robbers' attention and lay mixed with the sand in front of the chamber's rear entrance. These discoveries leave no room for doubt that this was the main burial chamber [Fig. 3.28].

Evidently, the grave robbers had forced their way into this chamber through the west wing of the tunnel. This is attested by several small finds, pottery vessels and broken human bones that were found scattered across the floor of the tunnel during excavation. However, the issue of the hole at the top of the mound remains unresolved. This hole measures about $0.65 \mathrm{~m}$ in width and is of irregular 
shape. It reached down roughly to the north-eastern side of the burial chamber directly from the top. The question is whether this hole is evidence of a second attempt to rob the burial, or whether it resulted from structural movement of the sandstone bedrock that caused some damage, including the partial splitting of the chamber's ceiling. Unfortunately, in view of this situation and the serious risk of collapse, the burial chamber was not fully excavated. The chamber and the northern end of the tunnel's west wing were tightly sealed with sacks full of sand. Thereafter, the hole at the top of the tumulus was also filled with sand to avoid any further destruction, and above all as a safety precaution [Fig. 3.29].

At the end, further safety measures were taken by constructing a solid cover over the external shaft. Twothirds of the shaft were covered using iron beams (Arabic: kamar) and red bricks, creating a type of vault known in Arabic as aged. The last portion was covered with a metal grid provided with a door that offers easy access to the tunnel whenever needed [Fig. 3·3o]. For more detailed information see Mahmoud El-Tayeb 2017, 340-346.

\subsection{Tumulus 6}

Tumulus 6 lies on the west side of the cemetery [see Fig. 1.2]. The mound is built of materials similar to those used for other type I tumuli. It has a diameter of about $5^{2} \mathrm{~m}$ and a height of up to $8.50 \mathrm{~m}$, making it the largest and tallest of the tumuli at El-Zuma. Efforts to detect the existence of a subterranean tunnel were focused on the southern side of the tumulus. A narrow rectangular vertical shaft was uncovered, measuring $4 \mathrm{~m}$ long by $1.75 \mathrm{~m}$ wide and $4 \mathrm{~m}$ deep. At a depth of between $1.82 \mathrm{~m}$ and $1.90 \mathrm{~m}$ from the ground surface, the shaft is provided with two steps cut into its south-east and south-west corners [Fig. 3·31].

The tunnel has an entrance of a type unique in late antique Nubia: it is rectangular, with a central pillar hewn from the bedrock. Its east side measures about $1.70 \mathrm{~m}$ in width and $1.76 \mathrm{~m}$ in height, while the west side is about $1.60 \mathrm{~m}$ wide and $1.96 \mathrm{~m}$ high. Both sides were found filled with compact sediment and stone slabs, the latter were especially abundant at the top of the east side entrance. These stone slabs appear to have been arranged to form an additional blocking wall after the partial removal of the fill in the east wing of the tunnel [Fig. 3.32]. The removal of the stone slabs and the earth fill from the east entrance revealed that the tunnel itself is divided from south to north by three pillars hewn from the same bedrock. Thus two passageways were created inside the tunnel [Fig. 3.33]. The west passage, which is about $9.70 \mathrm{~m}$ long and $1.60 \mathrm{~m}$ wide, appeared to terminate in a dead-end. The east wing is about $1.70 \mathrm{~m}$ wide and $19.30 \mathrm{~m}$ long. At its north end it is divided into two east and west niches interconnected by a small hole of unknown function. For the second time at this cemetery, there was evidence of the burial chamber having been penetrated through its roof by means of an irregular hole dug in the floor of the west niche, which made it possible to descend about $1.40 \mathrm{~m}$ to the underlying main burial chamber. However, for safety reasons no attempt was made to excavate the chamber, which appeared to have been disturbed and ransacked several times. The devastation of the burial is attested by several broken pottery vessels and fragments of animal bones, which were found within the fill of the tunnel and the external shaft. Strong evidence of tomb penetration is seen in the straight cut through the fill that covered the east wing of the tunnel and in the lining of the entrance with stone slabs. A small oil lamp, probably of Early Christian date, was found placed on top of the fill near the second pillar [Fig. 3.34]. The presence of this lamp and the removal of the fill from the east passage of the tunnel remain unexplained.

The southern, main, burial chamber is a large niche finely cut into the soft sandstone bedrock, with a roof that gently slopes from the entrance due south to the rear of the chamber. It measures about $5.00 \mathrm{~m} \times 1.20 \mathrm{~m}$ and $1.40 \mathrm{~m}$ in height. The chamber is blocked by a well-built wall consisting of 15 courses of reused red bricks bonded with lime mortar. On its west side this chamber is connected with the west chamber by a rectangular hole with rounded top, measuring $c$. o.6om long and $0.40 \mathrm{~m}$ wide [Fig. 3.35]. The plundered but archaeologically unexamined chamber (there was no way of securing the $16 \mathrm{~m}$ long tunnel, hence excavation was deemed unsafe) - as seen from above - still contained a number of pottery vessels, comprising cups, beer jars, one dish, and one unidentified ceramic object. More enigmatic is the presence of what appear to be two bodies laid on biers supported by stones at the corners. The bodies are wrapped in what may be now decayed linen [see Fig. 3.35]. To the east of these suspected bodies there is a human skull and what seems to be another body on a bier. The pair of suspected bodies appear to lie in extended position. Such an inhumation practice has never been recorded among the common burials of the period in question in the Dongola Reach. The nearest parallel can be found in the royal cemeteries of Ballana and Qustul. The existence of more than one inhumation in a single grave could suggest either multiple burials or human sacrifice; here again, for a parallel practice we can look to the royal cemeteries of Ballana and Qustul (see Emery and Kirwan 1938; Williams 1991). This speculation about the El-Zuma burial remains to be verified with further excavation. So far nothing more can be 

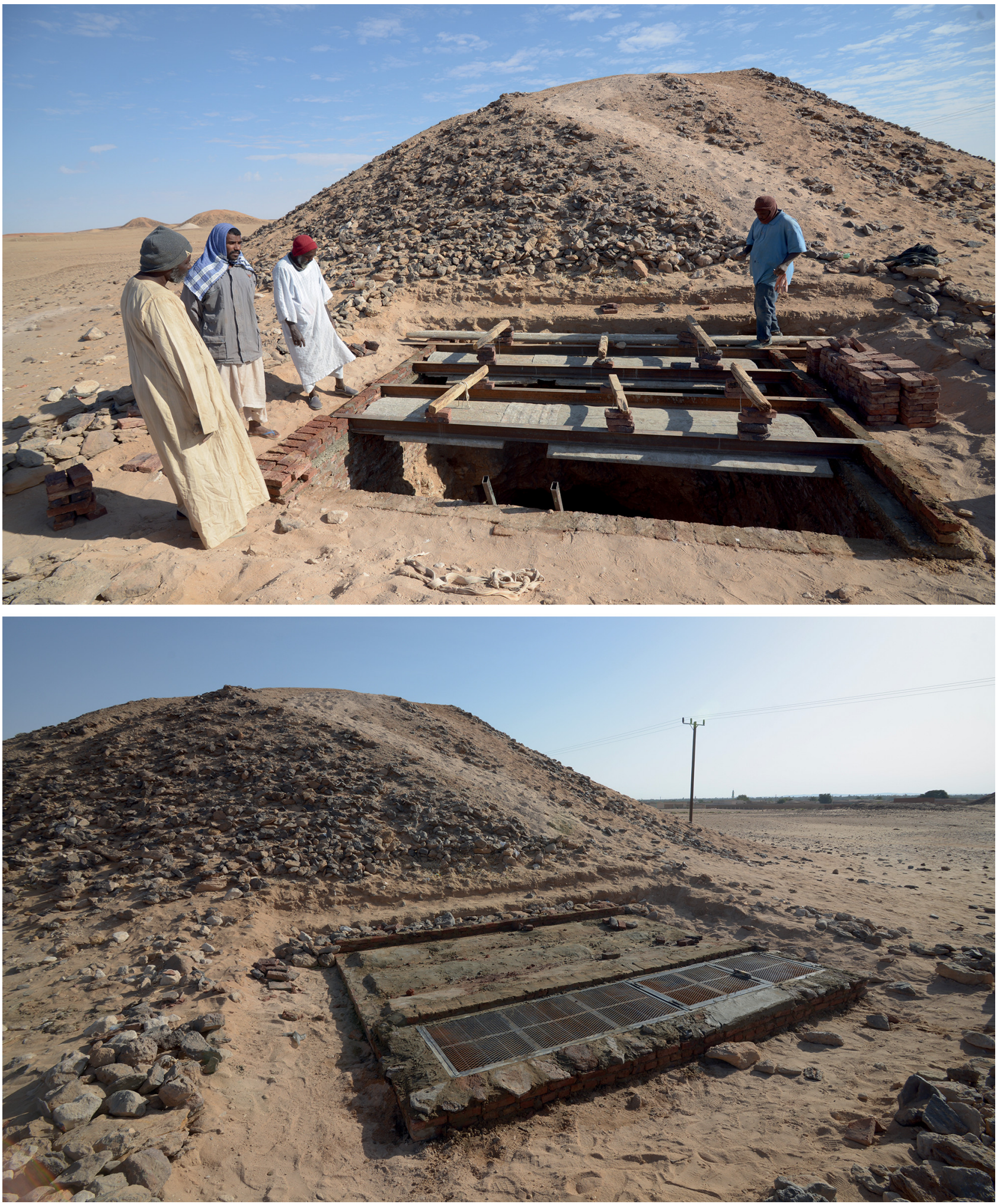

FIGURE 3.30 Tumulus 4, view of the mound from the south, work on construction of the roof shelter over the external shaft of the tumulus

PнотOS BY A. KAMROWSKI [TOP], z. KOWARSKA [вотTOM] 


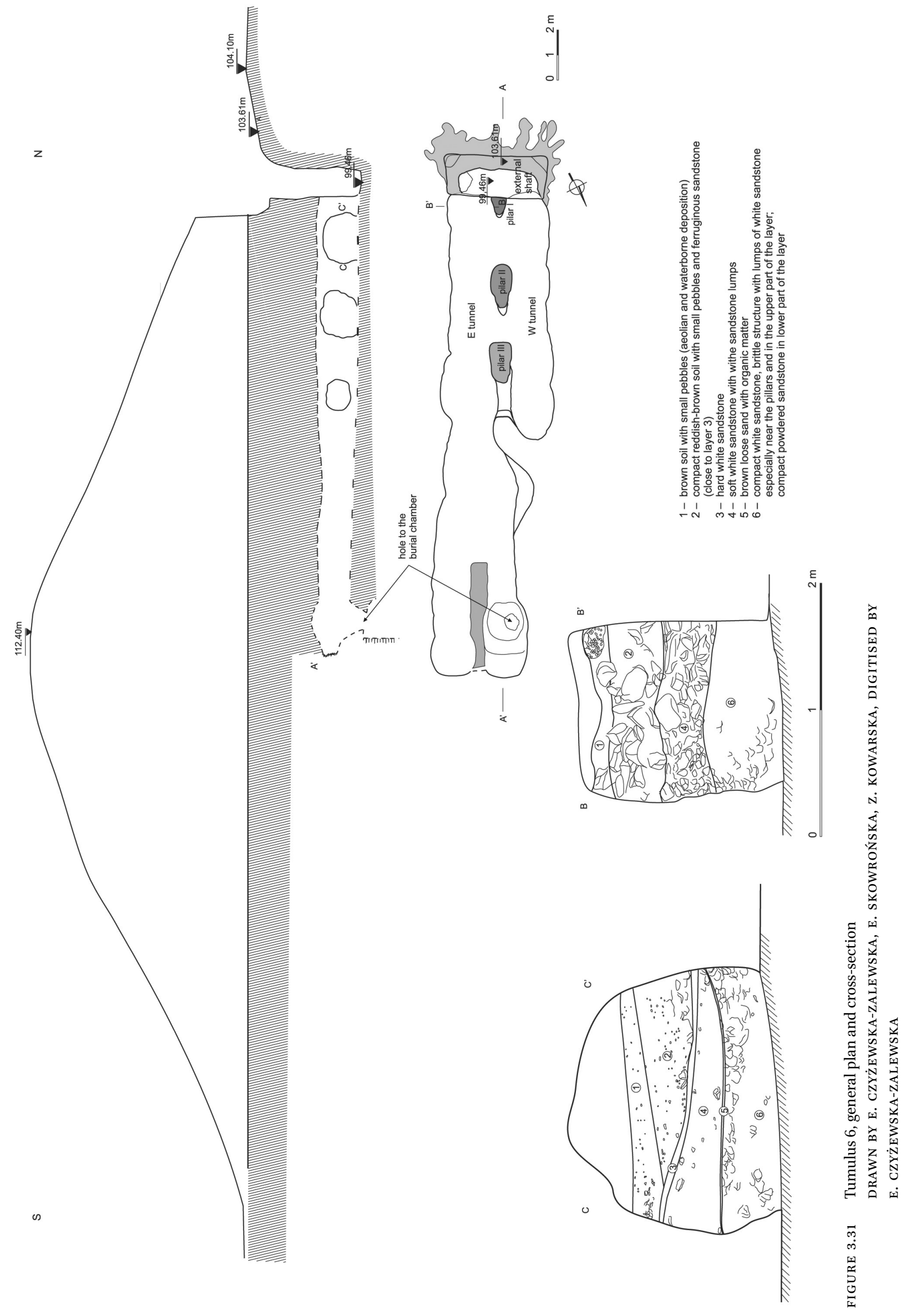




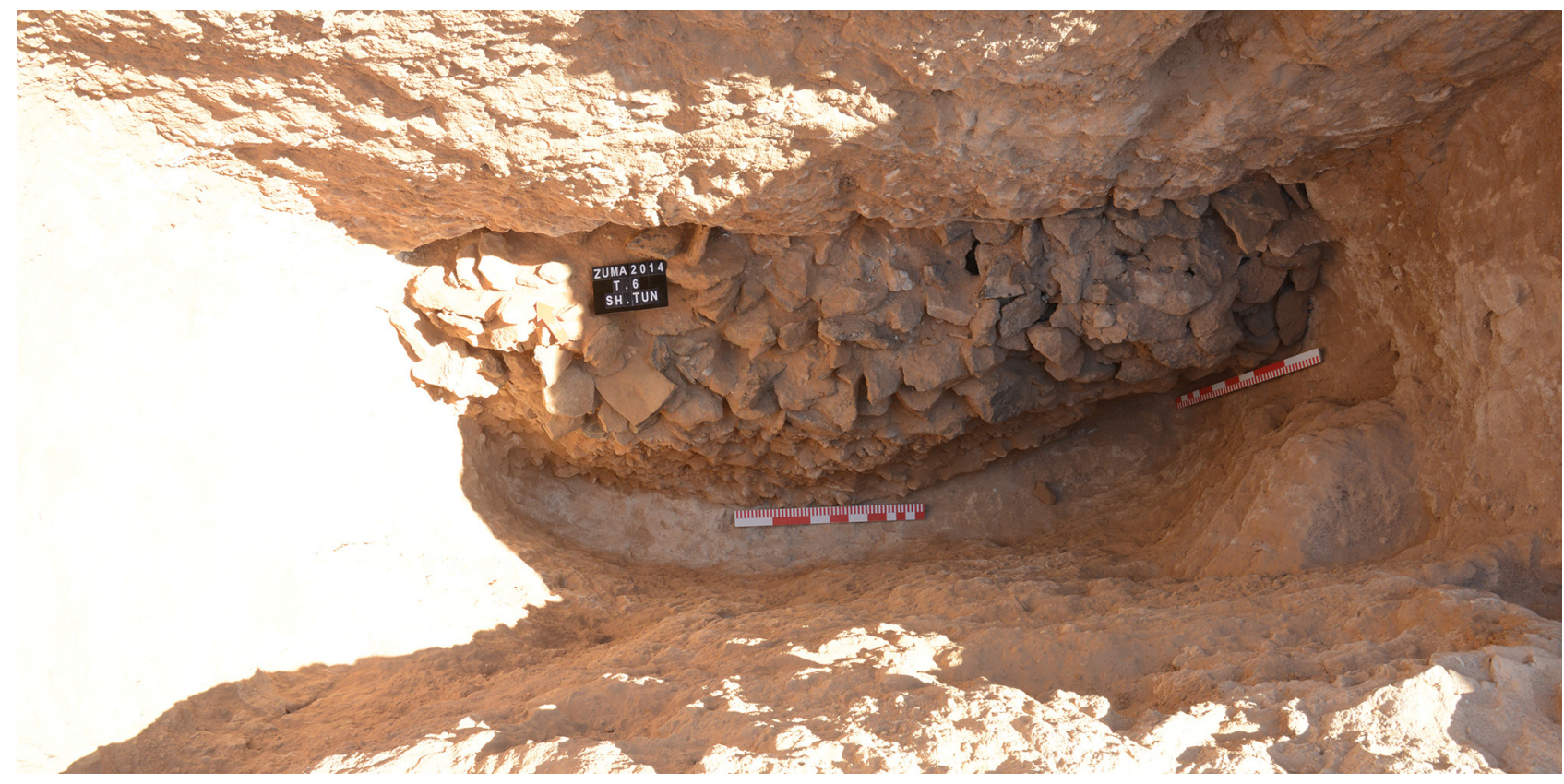

FIGURE 3.32 Tumulus 6, view of the external shaft and the stone blocking wall of the tunnel entrance, looking north

PHOTO BY A. KAMROWSKI

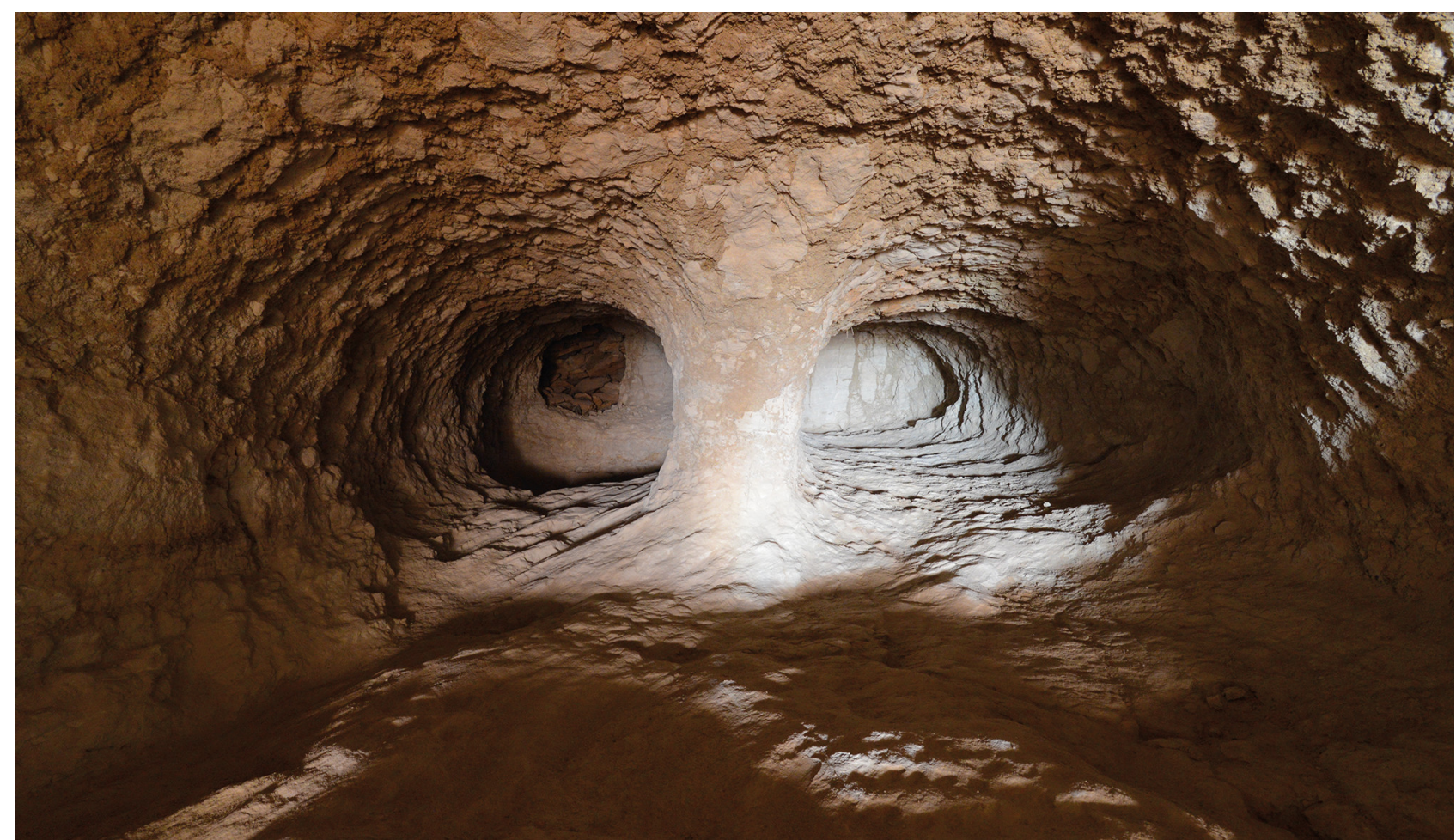

FIGURE 3.33 Tumulus 6, underground tunnel facing north PHOTO BY A. KAMROWSKI 


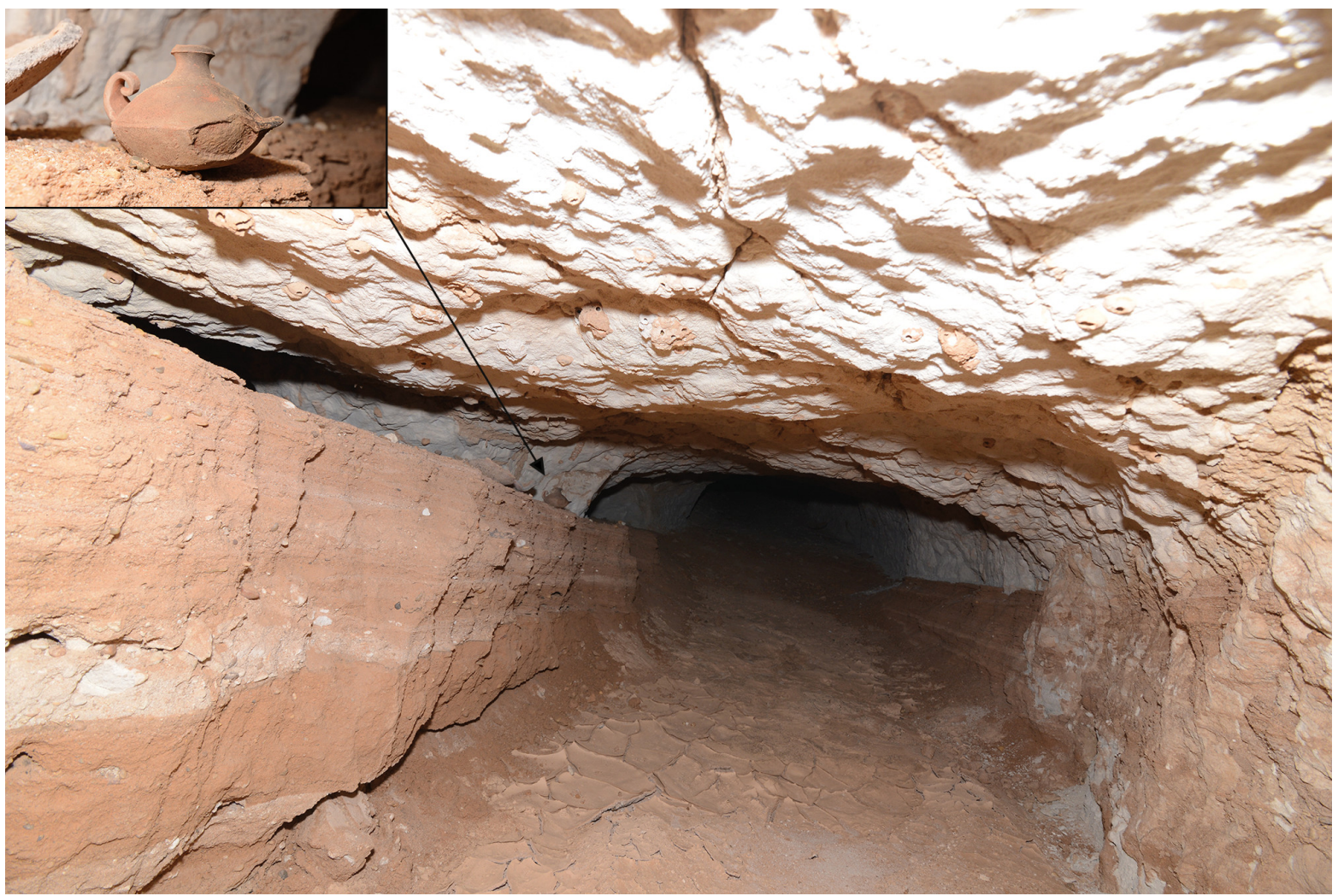

FIGURE 3.34 Tumulus 6, view of the oil lamp on top of the tunnel fill, facing north PHOTO BY A. KAMROWSKI

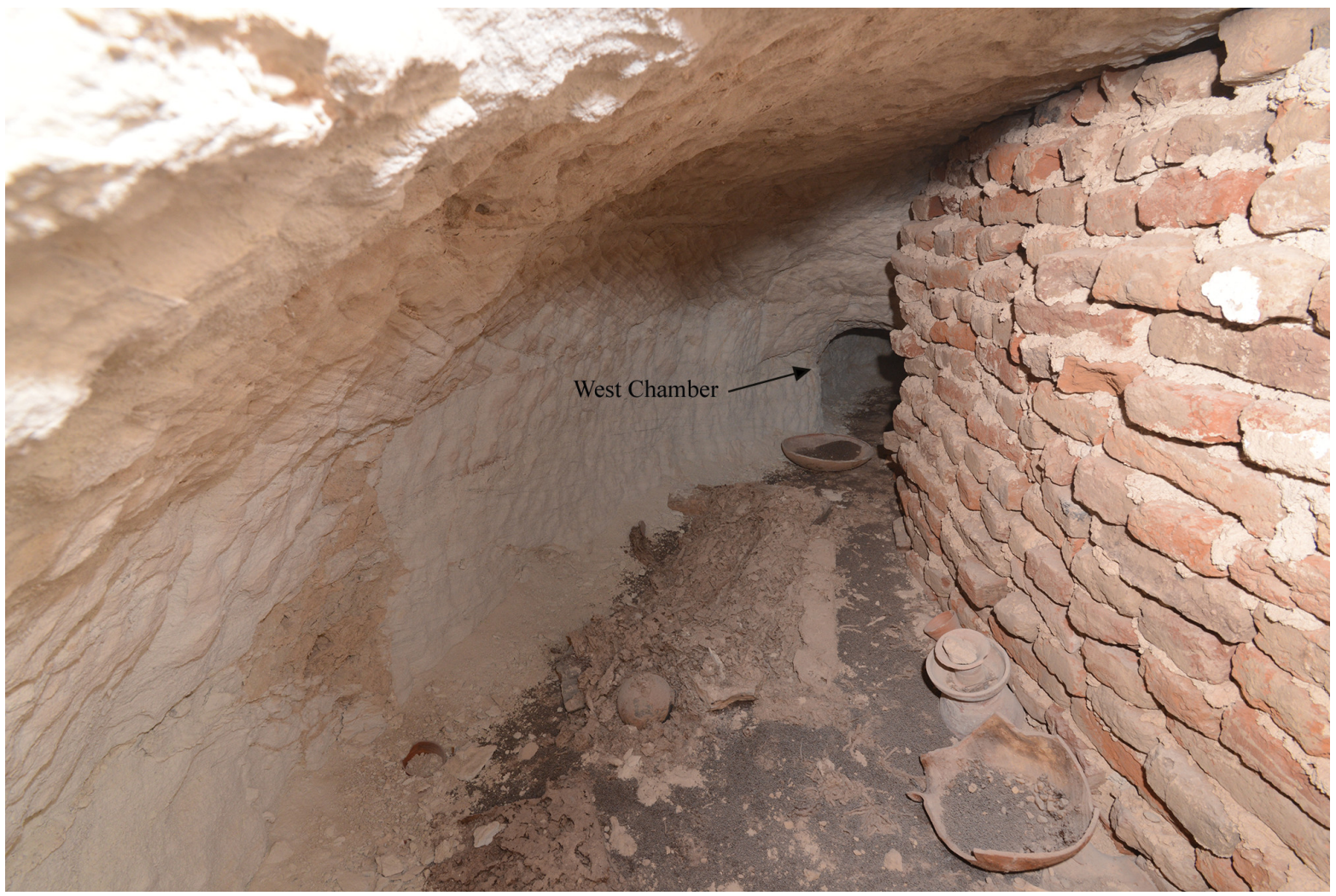

FIGURE 3.35 Tumulus 6, view of the main burial chamber. Note in the far west the open hole providing access to the west chamber, the scatter of objects in the middle and the vessel near the blocking wall

PHOTO BY A. KAMROWSKI 

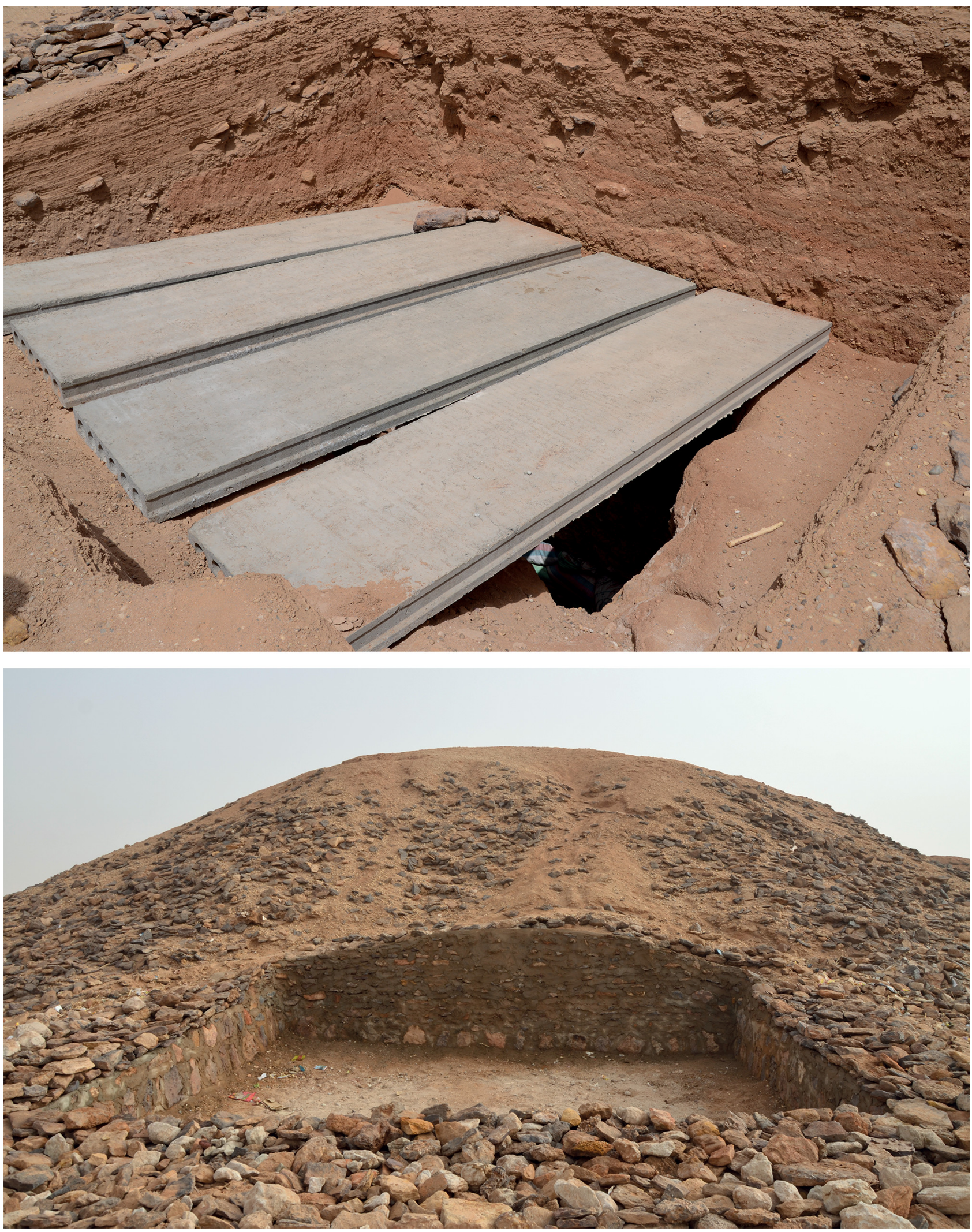

FIGURE 3.36 Tumulus 6, external shaft protected by concrete slabs

PHOTOS BY A. KAMROWSKI [TOP], z. KOWARSKA [воTTOM] 
said about this tomb, for much depends on the identification of the wrapped objects in particular, as well as the other contents of the chamber.

In order to protect the external shaft, the mission decided to construct a temporary roof, which can be removed when a more practical and durable solution is devised as part of the project to create an archaeological park at this site [Fig. 3·36]. For more detailed information see Mahmoud Mahmoud El-Tayeb, Skowrońska, and Czyżewska 2016, 122-123.

\subsection{Tumulus 7}

Tumulus 7 lies at the far north-west edge of the cemetery. It is the second largest of the type I tumuli [see Fig. 1.2], standing up to $7.87 \mathrm{~m}$ above ground level, with a diameter of about $50 \mathrm{~m}$. Like all type I tumuli, it is built from a mixture of earth, sand, and gravel, revetted with rough chunks of black ferruginous sandstone. As mentioned above, the external shaft had been partially examined in 2011. When work resumed, the whole shaft was excavated and proved to be about $3.60 \mathrm{~m}$ long by $1.30 \mathrm{~m}$ wide and $3.90 \mathrm{~m}$ deep, with one step cut into its south-west corner at a depth of $1.60 \mathrm{~m}$ [Fig. 3.37]. The destruction of the upper part of the tunnel entrance is an obvious indication of robber activity. The tunnel was found filled with compact sediment consisting of three different layers. At the very bottom was a layer of whitish-grey sandstone debris about $0.50 \mathrm{~m}$ thick, covered by another two layers of light brown sediment ( $0.50 \mathrm{~m}$ thick), and on top of that a $c$. o.6o-m-thick layer of dark brown sediment [Fig. 3.38]. There is no doubt that this fill accumulated as a result of the tunnel having been repeatedly broken into at different periods with long intervals between them [Fig. 3.39].

Clearing out the fill revealed that the tunnel, which is $17 \mathrm{~m}$ long, 3.6o $\mathrm{m}$ wide, and $1.75 \mathrm{~m}$ high, was divided into an east and a west passage by seven pillars cut in the sandstone bedrock, while the northern end was fashioned into two niches [see Fig. 3·37]. A hole in the east niche opens into the west side of the south chamber and connects the main burial chamber with the outside world through the tunnel [Fig. 3.40]. The main burial chamber, which is hewn into the south side of the main shaft, is a large lateral niche about $5 \mathrm{~m}$ long, $1.57 \mathrm{~m}$ wide, and $1.30 \mathrm{~m}$ high. The chamber has a unique, wide entrance divided in the middle by a pillar skilfully cut out of the sandstone bedrock, most probably to support the whole construction. On the west side another pillar separates the southern and western chambers. Generally, the east side of the south chamber is more finely hewn than the west side, with an almost flat roof and straight rear wall. The south chamber was found sealed by a wall of reused red bricks on both sides of the pillar. The blocking wall on the east side is well-built in regular courses, one header course laid as a foundation at the bottom, followed by 14 courses of stretchers bonded with lime mortar. The west wall is poorly constructed, as if it had been destroyed and then rebuilt in a hurry; however, the real reason behind its poor state of construction remains unknown [Fig. 3.41].

The main burial chamber had been severely ransacked. The remains of a broken bier and disarticulated human skeleton, scattered across the east side of the chamber, attest to an adherence to the well-established burial practice of the period: inhumation, usually in a contracted position, body laid on a bier at the east side of the chamber with head due east, facing north. The west side of the chamber contained some of the grave offerings that had been left behind by the robbers. These comprised complete and broken beer jars, small red bowls, and cups. Large fragments of animal bones, probably of cattle, were also amongst the offerings. The location of these offerings near the blocking wall of the entrance should not be taken as their original place of deposition due to the fact that the chamber had been visited by intruders. Using a camera attached to a long pole, it was possible to get an idea about the construction and contents of the western chamber. It appeared to be approximately of the same length as the southern chamber, but far narrower, with a sharply sloping roof. Its blocking wall was also roughly built of reused red bricks. The offerings, which consisted of about five large beer jars and several small vessels, mainly red bowls and cups, lined the rear wall and the blocking wall, indicating that the robbers totally ignored these types of grave goods, a phenomenon which has been repeatedly observed in burials of this period.

It is hoped that further excavation will provide more detailed information about these unexplored burials and help enrich our understanding of the origins of this culture. At this stage of research we can say that excavating the tunnels beneath T.3, T.6, T.7 and T.8 has shed much light on the origin and function of these enigmatic structures, though many issues remain unresolved.

As was the case with T.6, a temporary roof was installed above the external shaft in order to protect it [Fig. 3.42]. For more detailed information see Mahmoud El-Tayeb, Juszczyk-Futkowska, and Czyżewska 2014, 365-366; Mahmoud El-Tayeb, Skowrońska, and Czyżewska 2016, 123-125. 


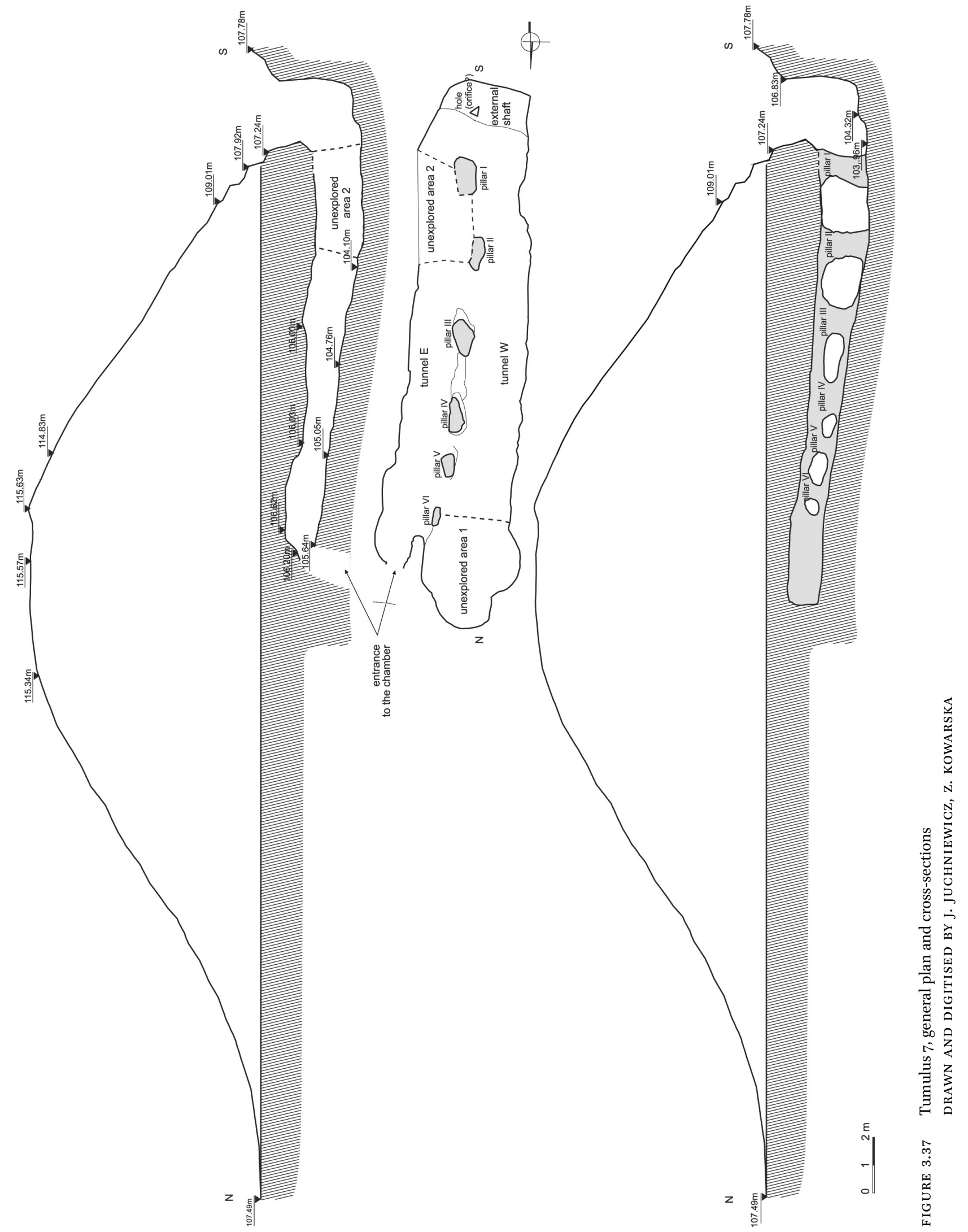




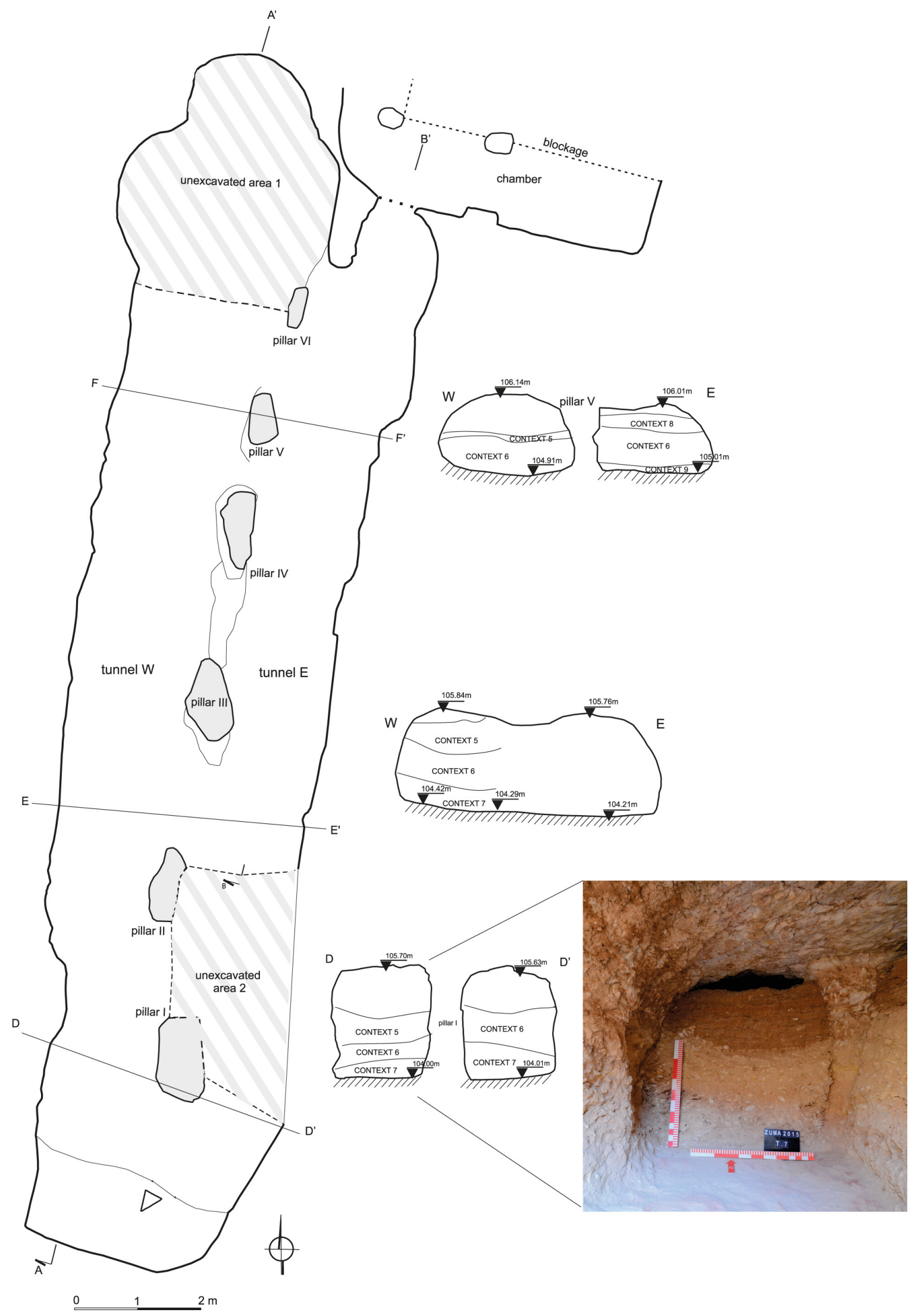

FIGURE 3.38 Tumulus 7, view of the sediment layers inside the tunnel DRAWN AND DIGITISED BY J. JUCHNIEWICZ, E. CZYŻEWSKA-ZALEWSKA, РHOTO BY A. KAMROWSKI 

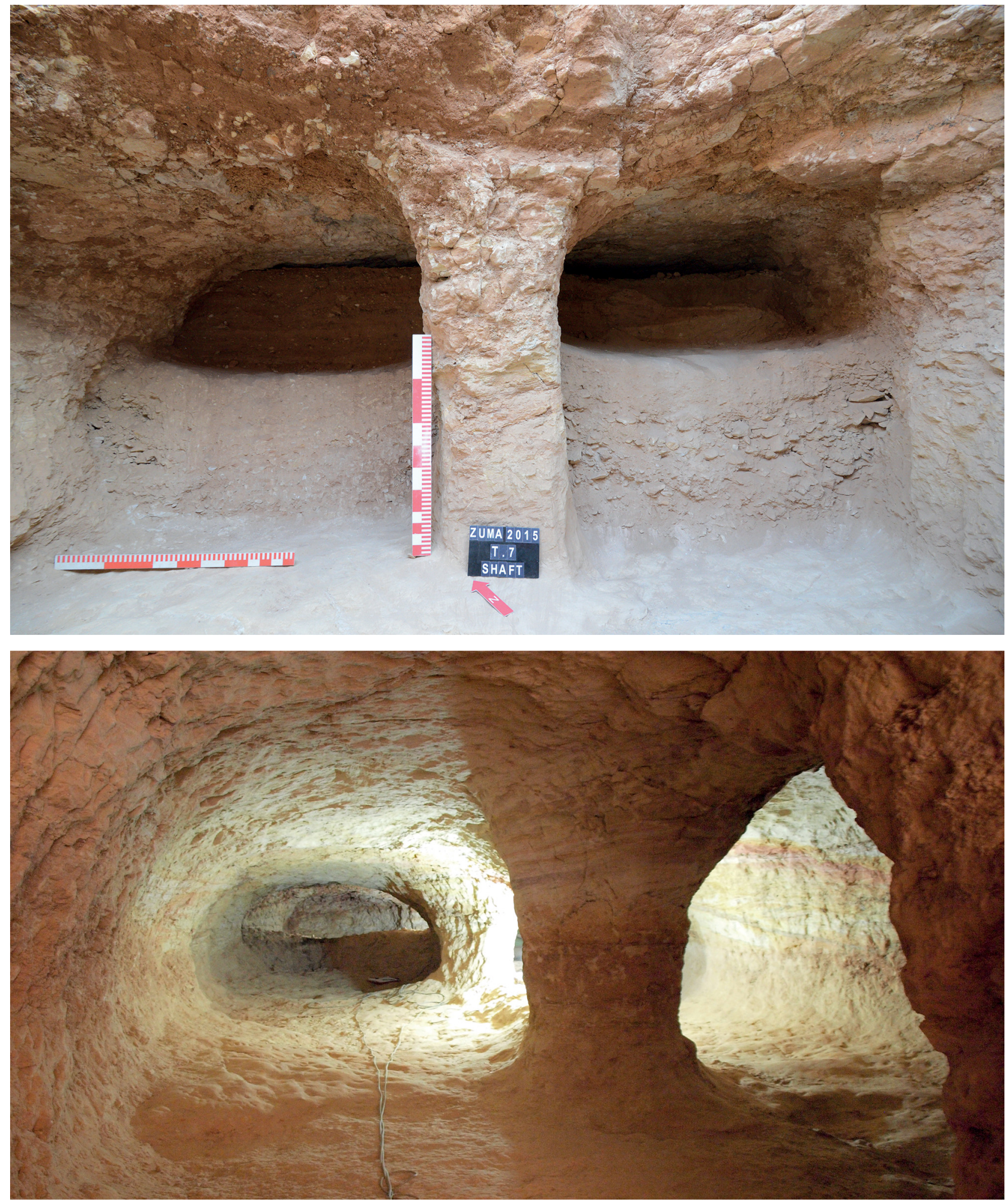

FIGURE 3.39 Tumulus 7, underground tunnel with part of the fill still in place (top) and completely removed (bottom)

PHOTOS BY A. KAMROWSKI [TOP], K. JUCHNIEWICZ [вотTOM] 


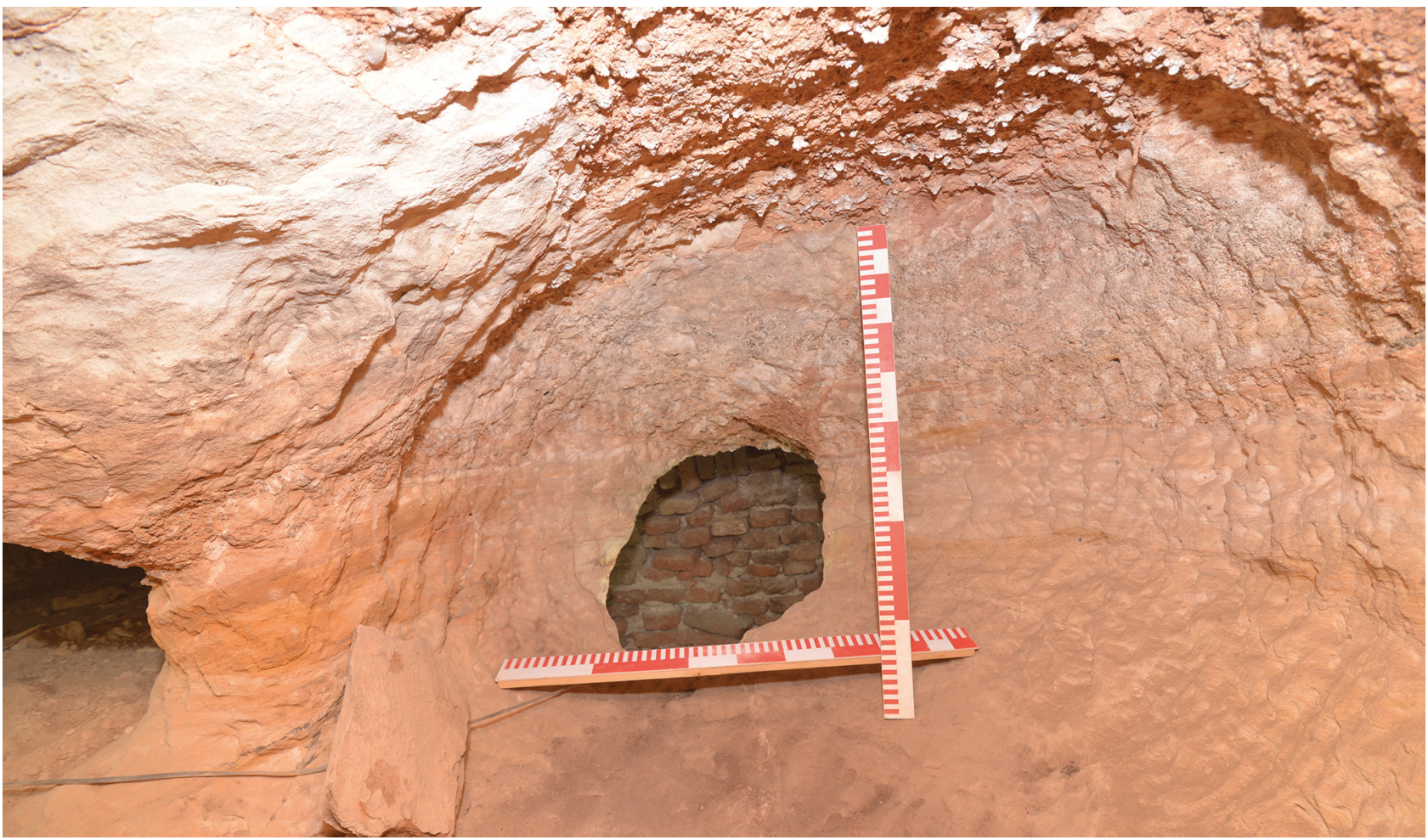

FIGURE 3.40 Tumulus 7, view of the northern end of the tunnel showing the hole opening on to the main burial chamber, facing north РНОTO BY A. KAMROWSKI

\subsection{Tumulus 12}

Tumulus 12 is located on the north-west side of the cemetery. In contrast to all of the other tumuli at this site, the remains of its superstructure appeared to have been heavily disturbed by robbers, or possibly it was never built to the standard height of other type II tumuli (the preserved height of type II tumuli is generally $2-3 \mathrm{~m}$ ) [Fig. 3.43].

The poorly discernible above-ground remains of T.12 consist of a very low earth ring with a slight depression in the centre, which is usually taken as an indication of burial plundering. The maximum diameter of the superstructure is about $21 \mathrm{~m}$ from north to south and $23 \mathrm{~m}$ east to west; the preserved height of the superstructure ranges from only $0.30 \mathrm{~m}$ to $0.60 \mathrm{~m}$. The generally poor appearance of what is left of the superstructure suggested that it most probably represented a type III tomb (typically superstructures of type III tombs are a very low mound not exceeding $0.70 \mathrm{~m}$ in height). In order to verify this assumption, a square trench measuring $6 \mathrm{~m} \times 6 \mathrm{~m}$ was excavated in the centre of the superstructure. Removing a layer of about $0.30 \mathrm{~m}$ of soil and aeolian sand revealed the outline of a large shaft measuring approximately $5.75 \mathrm{~m}$ on the north, $5.85 \mathrm{~m}$ on the east, $5.05 \mathrm{~m}$ on the south, and $5.75 \mathrm{~m}$ on the west side, with a maximum depth of $5.60 \mathrm{~m}$. The shaft tapered slightly towards the bottom. At floor level its dimensions were as follows: $5.69 \mathrm{~m}$ (west wall), $4.77 \mathrm{~m}$ (north wall), $4.8 \mathrm{om}$ (south wall), $1.60 \mathrm{~m}$ (east wall of the northern wing), and $1.84 \mathrm{~m}$ (east wall of the southern wing). The shaft had a very large pier projecting from the eastern wall, giving the shaft a U-shaped ground plan. This pier is so far the largest to have been discovered at ElZuma. The top of it measures $3 \mathrm{~m}$ on the north side, $3.6 \mathrm{om}$ on the south side and $2.40 \mathrm{~m}$ on the west side, while at the bottom it measures about $3.8 \mathrm{om}$ on the north, $3.92 \mathrm{~m}$ on the south and $2.69 \mathrm{~m}$ on the west side [Fig. 3.44].

The upper north and west sides of the shaft walls bear clear signs of destruction by grave robbers. On the southwest side of the shaft, at a depth of $3.20 \mathrm{~m}$ from the original ground surface, about 30 vessels of various types (large beer jars, bottles, bowls, and cups) as well as fragments of animal bones were unearthed in a layer about $1.20 \mathrm{~m}$ thick. The vessels were found in different states of preservation, from complete to fragmentary. They appear to have been deposited in great disorder; no intentional arrangement was observed [Fig. 3.45]. Most probably they had been taken out of the southern burial chamber (Ch. 1), which was found to be heavily looted. Nonetheless, in view 

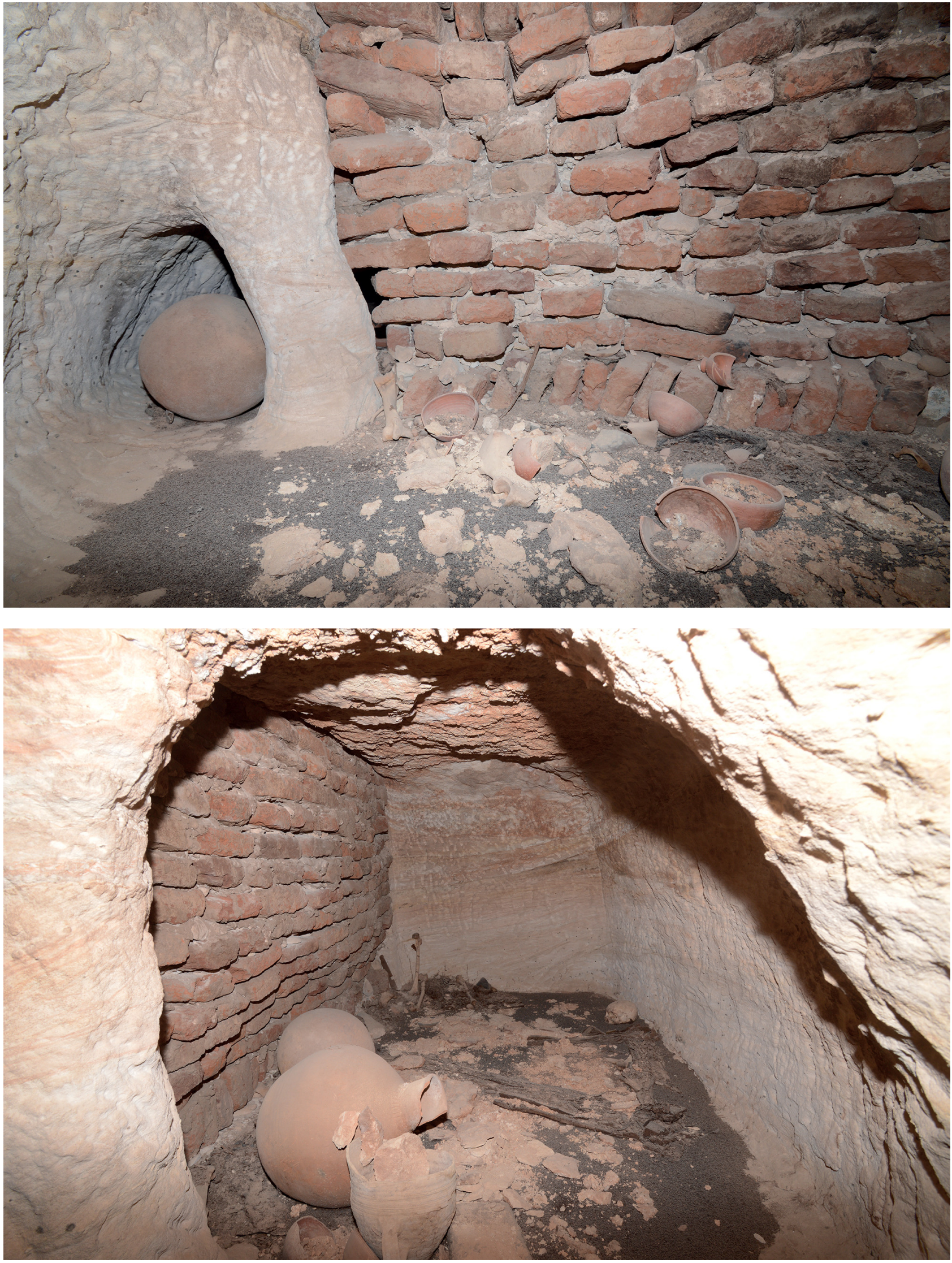

FIGURE 3.41 Tumulus 7, view of the red-brick wall on the west side of the main burial chamber-note the poor workmanship (top); east side of the burial chamber (bottom) PHOTOS BY A. KAMROWSKI 

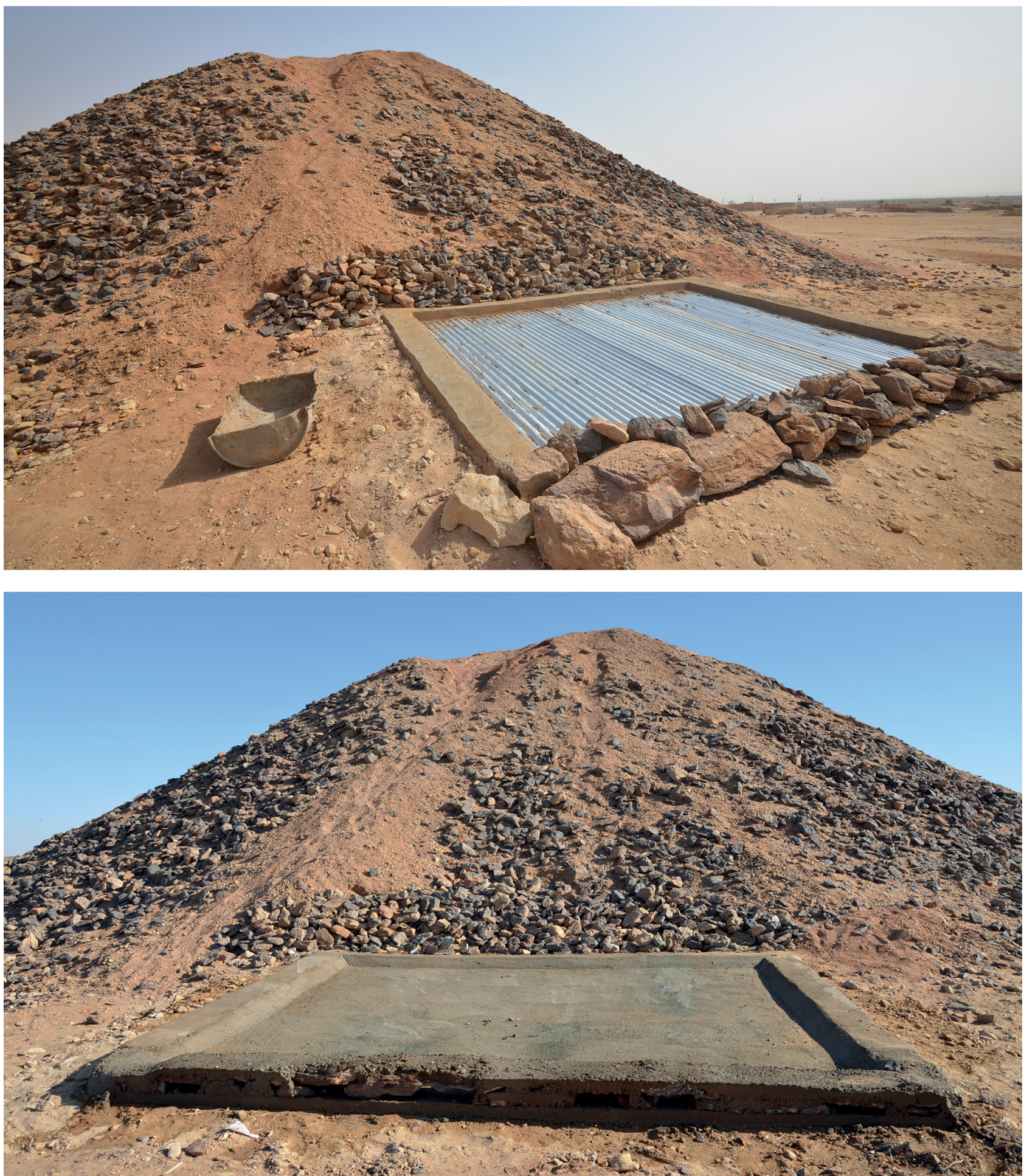

FIGURE 3.42 Tumulus 7, external shaft protected by a tin roof (top) reinforced with concrete mortar (bottom)

PHOTOS BY A. KAMROWSKI [TOP], z. KOWARSKA [вотTOM] 


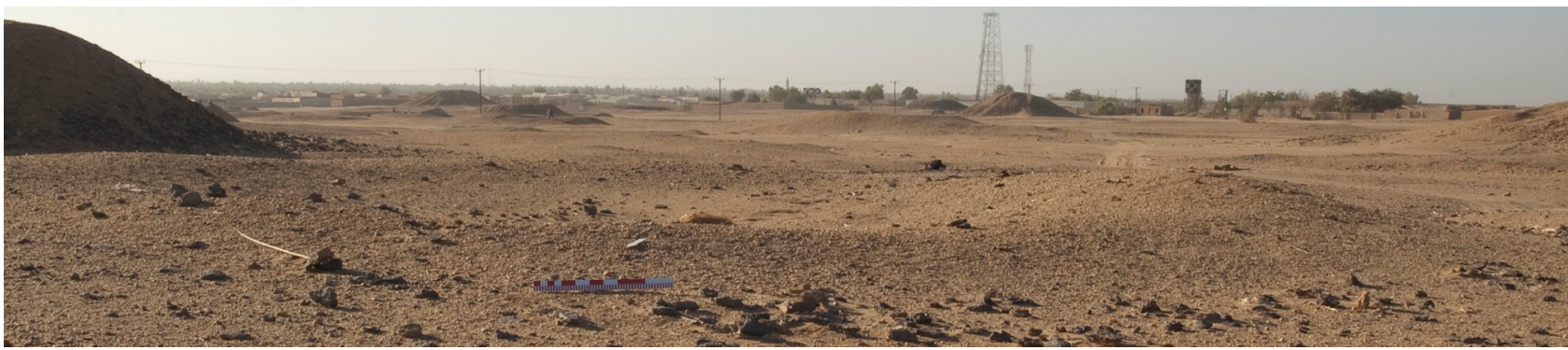

FIGURE 3.43 Tumulus 12, view of the tumulus superstructure, facing south PHOTO BY A. KAMROWSKI

of the fact that these objects were found $1.20 \mathrm{~m}$ above the entrance of the chamber, it is tempting to put forward the hypothesis that they may attest to a funerary banquet. Yet, we should bear in mind that funerary banquets, as noted by Patrice Lenoble, usually took place at the end of or during the inhumation process (for more on funerary banquets see Lenoble 1994). The shaft of T.12 is the deepest of all shafts beneath tumuli of types I and II known to date, reaching about $5.60 \mathrm{~m}$ below the present-day ground level. Despite this, no steps affording easier access to its bottom were noted. However, in both the north and south wings of the shaft a number of small holes were observed in its walls. Holes of about $0.15^{-0.25} \mathrm{~m}$ in diameter and o.10 $\mathrm{m}$ deep were recorded on the south side of the pier as well as in the south wall of the shaft. They were distributed in a zigzag pattern, and the distance between them ranged from $0.40 \mathrm{~m}$ to $1.00 \mathrm{~m}$. In the opposite (northern) wing small holes were noted in both the north wall of the shaft and the pier, but in no particular arrangement. The considerable depth of the shaft and the lack of steps suggest that these holes were most probably made to support a wooden framework (scaffold) that would have enabled the body and grave furnishings to be lowered into the burial chamber. At the bottom of the shaft were three side chambers. Chamber 1, cut into the southern side of the shaft, was aligned east-west; chamber 2, cut into the west wall, was aligned north-south, and chamber 3 was cut into the north wall, in an east-west alignment [see Fig. 3.44].

Initially, the three chambers had been sealed by walls built of re-used red bricks laid in alternate courses of rowlocks (in which each brick is laid on its long, narrow side with the end showing in the face of the wall) and stretchers, in a regular sequence, bonded with mud mortar. The red-brick walls were sealed on top by small, flat, rough stone slabs. To the best of our knowledge, this type of blocking has never before been recorded in Early Makurian burials [Fig. 3.46].

The three chambers (south, west, and north) were interconnected by slightly irregular rectangular holes, measuring between $0.30 \mathrm{~m}$ and $0.40 \mathrm{~m}$ long, and $0.20-0.25 \mathrm{~m}$ wide. Usually such interconnecting holes were found cut at the floor level of the chamber. However, this was the first noted instance of the holes being cut about $0.50 \mathrm{~m}$ above the floor level [Fig. 3.47]. Chamber 1 is a large niche measuring $5.30 \mathrm{~m} \times 2.36 \mathrm{~m}$ and $1.40 \mathrm{~m}$ high. Thorough excavation of the southern wing of the shaft revealed that chamber 1 had been penetrated by robbers from both the south-east and south-west. On the east side of the blocking wall the robbers dismantled the sealing slabs and destroyed six of the nine brick courses from top to bottom, creating a hole about $1.30 \mathrm{~m}$ wide and $1.40 \mathrm{~m}$ high. A similar situation, resulting in a hole of approximately the same dimensions, was recorded at the south-west end of the blocking wall. The destruction of this wall greatly weakened the soft sandstone into which the chamber is cut, leading to dangerous, deep cracks appearing in the south wall of the chamber, posing a real threat to the stability of the burial's structure.

Additionally, some parts of the west and central portions of the roof had partially delaminated and collapsed. Subsequently, loose earth and rough chunks of sandstone poured in through the dismantled south-west side of the blocking wall and filled half of the chamber [Fig. 3.48 top]. About 11 vessels were noted in the central section and east side of the chamber. The whole assemblage was aligned east-west along the rear wall of the burial chamber. It comprised eight beer jars, two storage jars, and one bowl, either complete or fragmentary [Fig. 3.48 bottom]. Moreover, about 22 small beads, one made of faience and 21 made of greenstone, were recovered from the east side of the burial chamber. Notably, not a single fragment of human bone was found either in or directly outside the southern chamber. Chamber 2 is hewn into the west wall of the shaft. It was similarly closed off by a red-brick wall measuring about $5 \mathrm{~m}$ long and $1 \mathrm{~m}$ high, sealed on top with stone slabs. Generally, the blocking wall was built using the same technique of rowlocks and stretchers, but laid in a different sequence. In this instance there were two courses of rowlocks at the very bottom, followed by one stretcher 


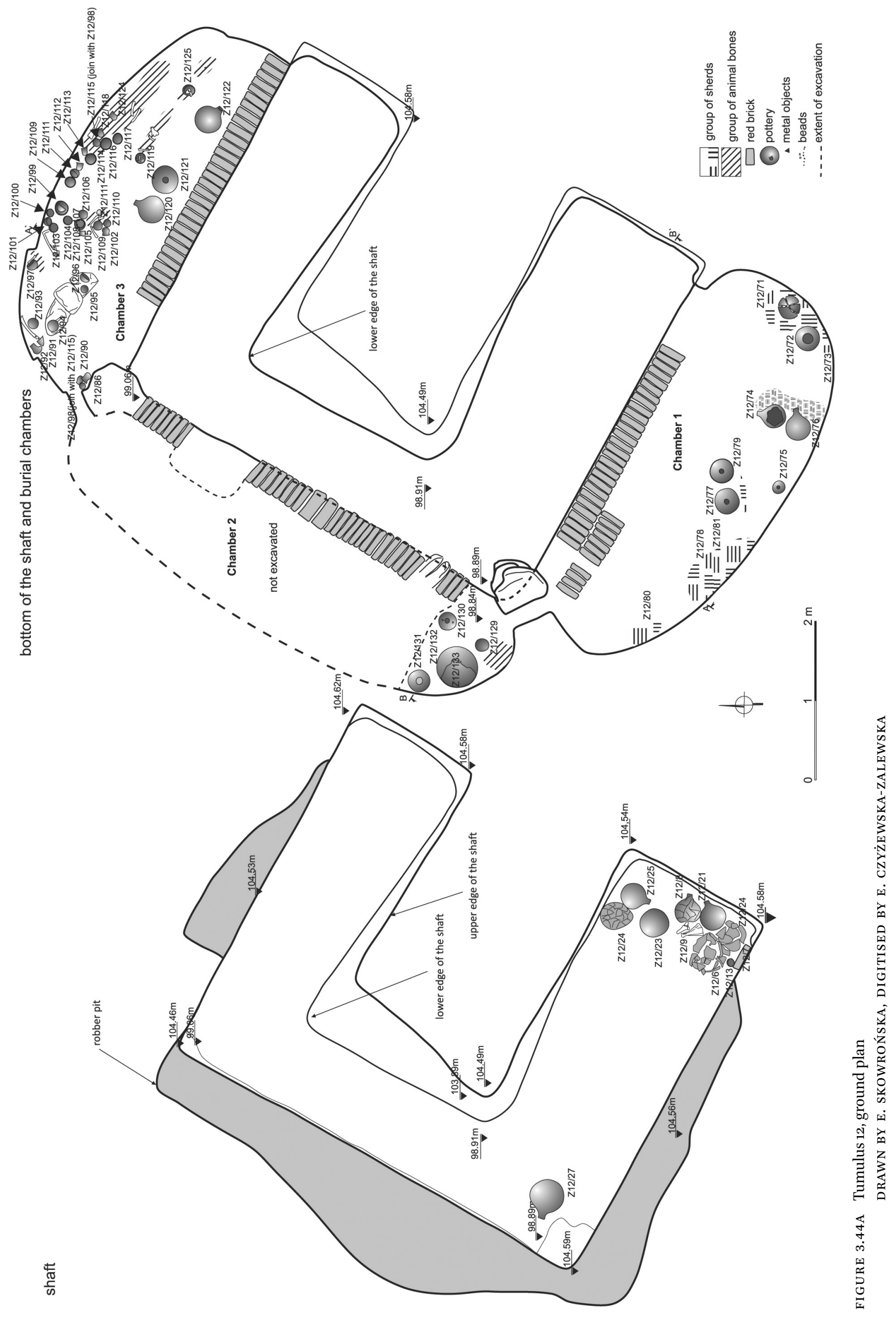



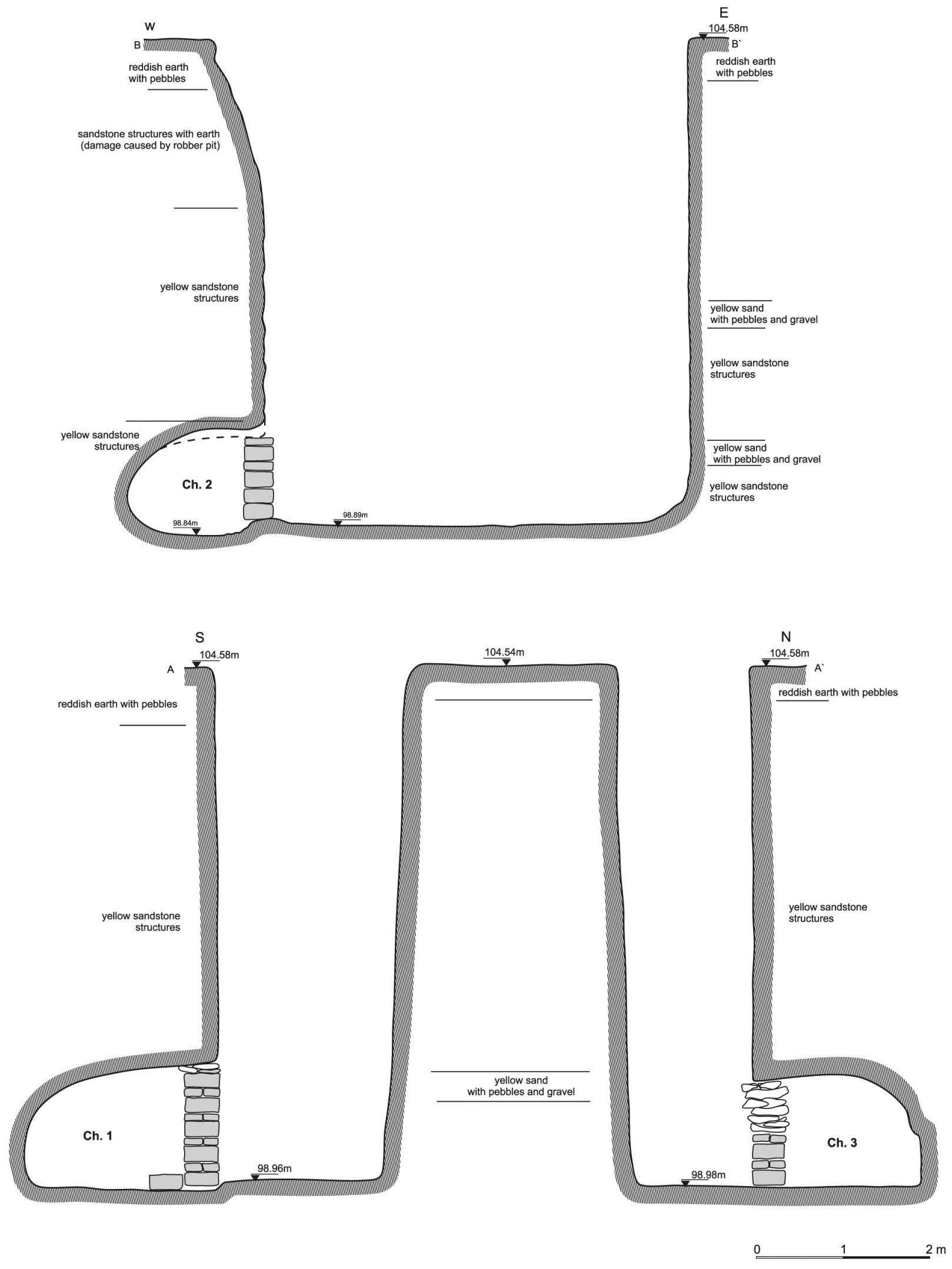

FIGURE 3.44B Tumulus 12, cross-sections of the tumulus

DRAWN BY E. SKOWROŃSKA, DIGITISED BY E. CZYŻEWSKA-ZALEWSKA 


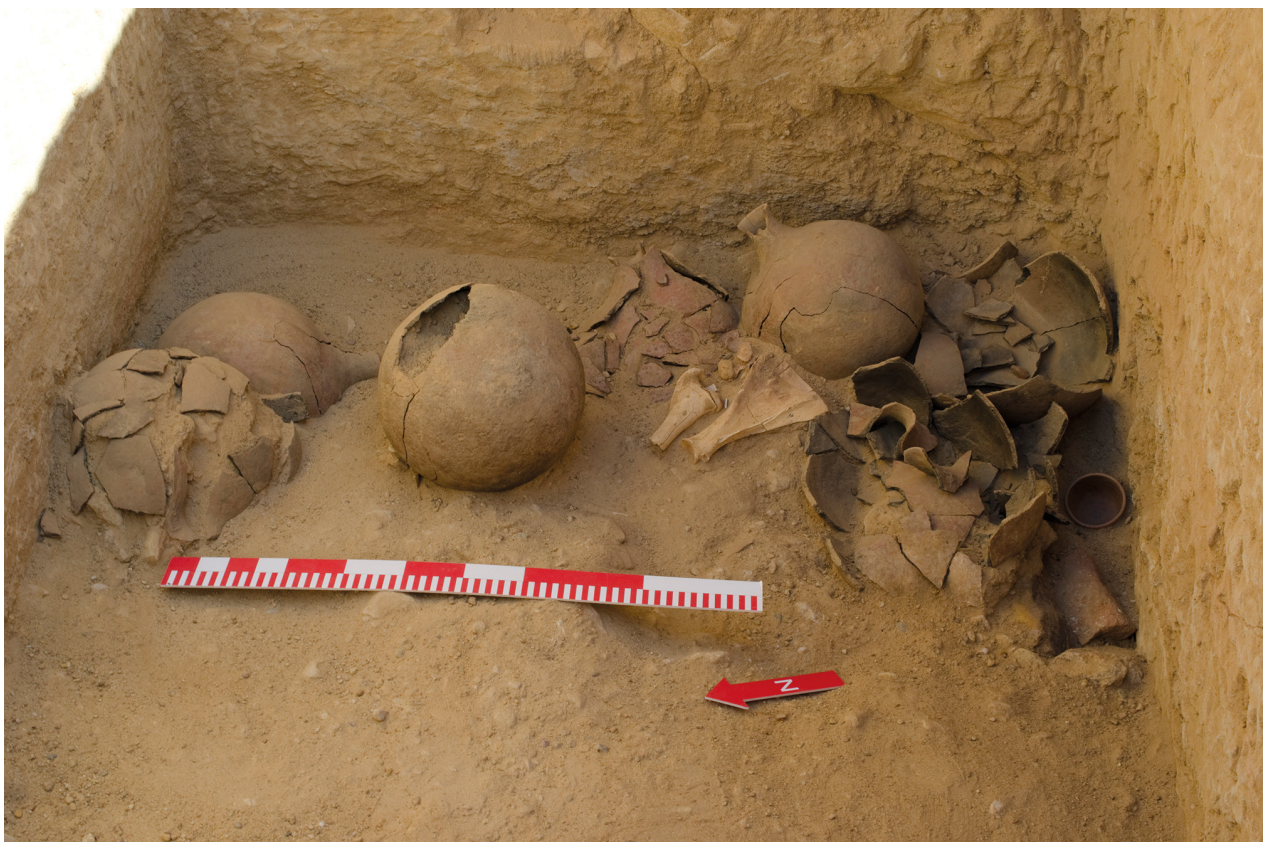

FIGURE 3.45 Tumulus 12, view of objects scattered on the south side of the shaft just in front of the main (southern) chamber 1 , facing east РНОTO BY E. SKOWROŃSKA
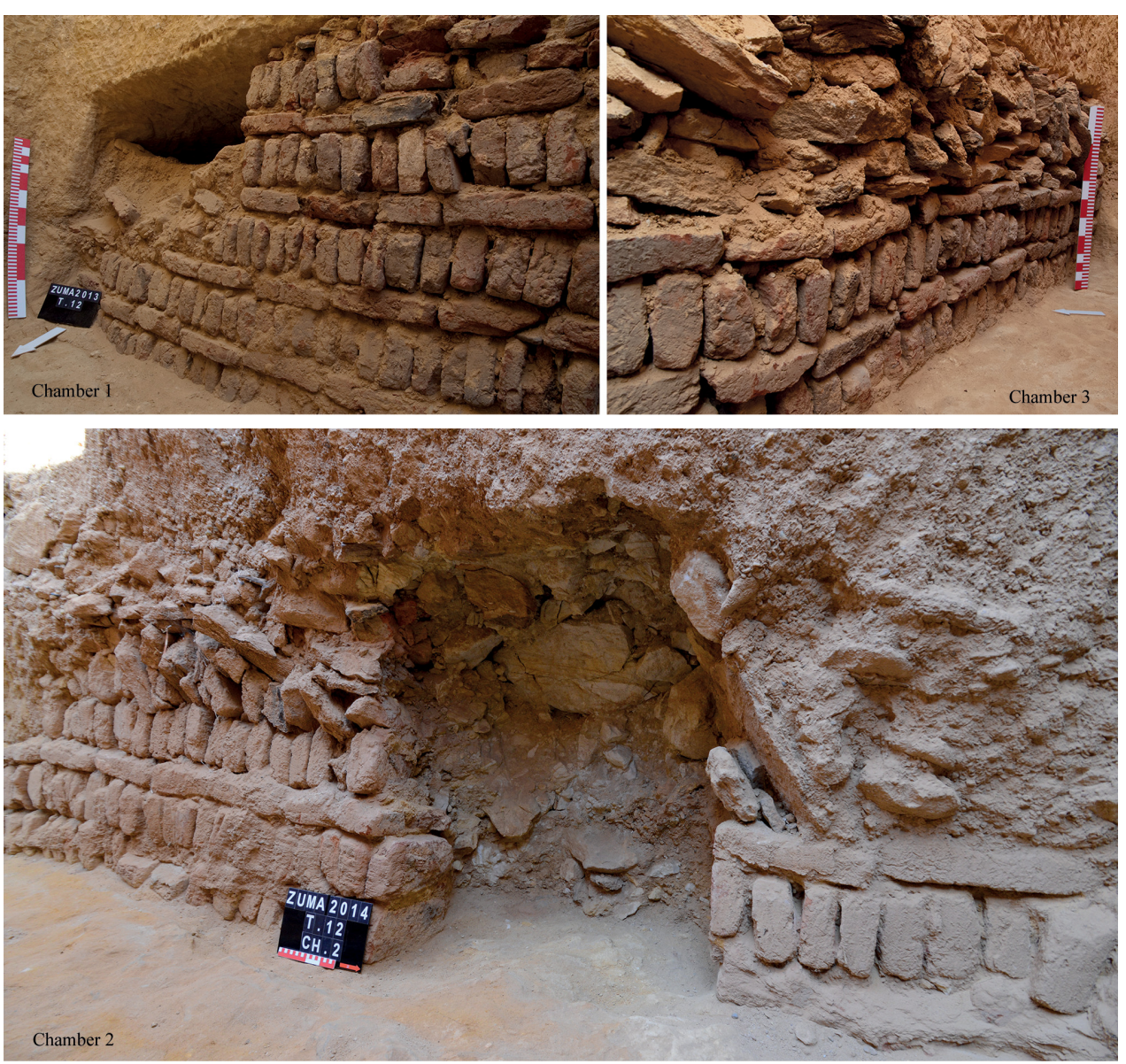

FIGURE 3.46 Tumulus 12, red-brick blocking wall in chamber 1 (top left); red-brick blocking wall in chamber 3 (top right); view of the collapsed ceiling on the north-west side of chamber 2 , facing west (bottom)

PHOTOS BY E. SKOWROŃSKA 


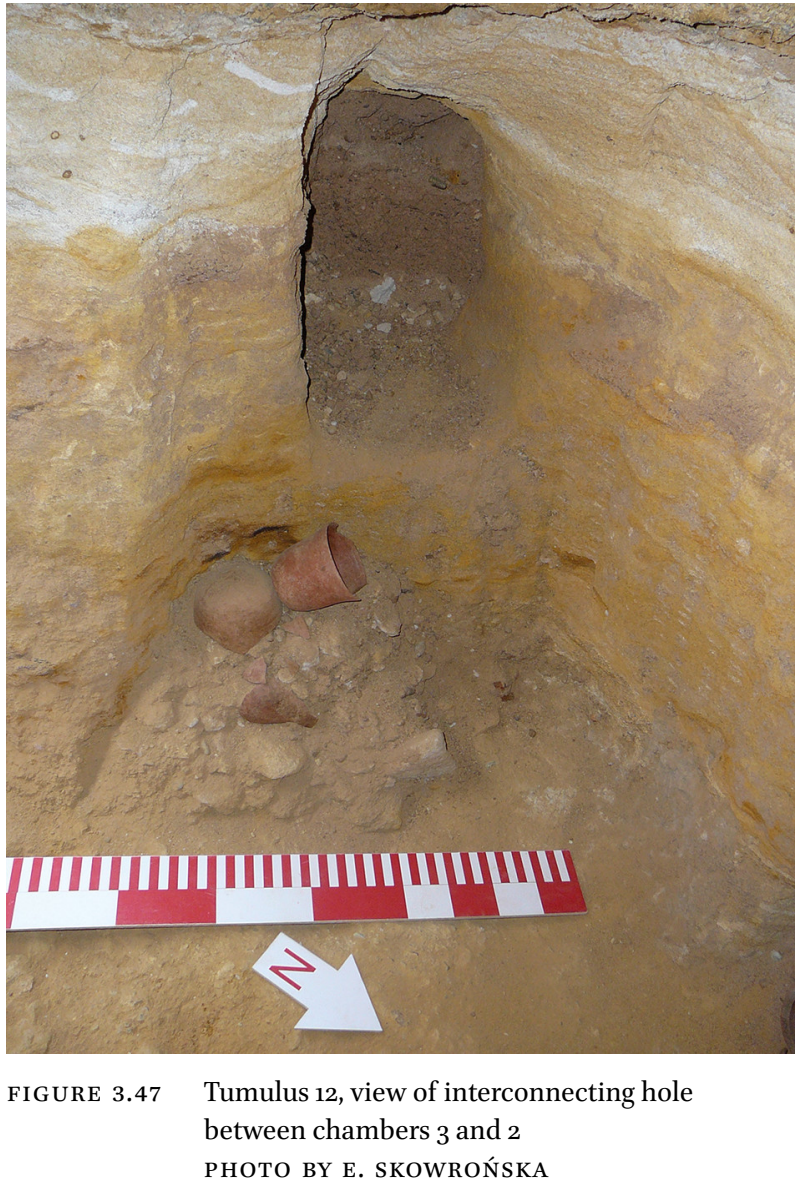

course, followed again by another two rowlock courses sealed by stone slabs. However, this wall was not as wellbuilt as the one in chamber 1 [Fig. 3.46 top right]. Here again it appears that the robbers had tried to break in from two ends of the burial (south and north). Unfortunately, due to this fact and the attempt to force their way from the top west side of the shaft, the robbers caused great damage to the west wall and the roof of the burial chamber. In view of this severe state of destruction, only a limited sondage was used to examine the disturbed sides. The southern side appeared to have been less affected by robber activity. The dense fill included some animal bones, a medium-size bowl, and one fragment of a large beer jar in addition to a complete small bottle. Under this fill two further medium-size complete beer jars were found deposited next to the entrance of the chamber. At the northern end of the chamber only one fragment of a large beer jar was found among the debris of the fallen roof [Fig. 3.49 top]. The devastation in this part made any further excavation impossible. Safety measures will be required before a thorough exploration of this chamber can be undertaken; therefore, work has been suspended until an adequate solution can be found which will enable the completion of this task [Fig. $\mathbf{3 . 4 6}$ bottom]. Chamber
3 is cut into the northern wall of the shaft. It is of similar dimensions to chamber 1 , measuring $5.08 \mathrm{~m} \times 1.85 \mathrm{~m}$ and $1.20 \mathrm{~m}$ high. The same construction technique was used for building the blocking wall, which consists of four alternate courses of red-brick rowlocks and stretchers, reaching $0.60 \mathrm{~m}$ high. Then a space of about $0.40 \mathrm{~m}$ is filled by a combination of large chunks of sandstone and black ferruginous stones, bonded with a mixture of mud and lime mortar [Fig. 3.49 bottom]. Tectonic movements appear to have affected the soft sandstone structure, as the northwest side of the chamber's roof had partially collapsed, destroying the stone seal and leaving a wide hole about $1 \mathrm{~m}$ high. Nonetheless, this chamber, which was intended exclusively for grave offerings, was certainly never penetrated or looted by robbers. Thirty-nine pottery vessels were found deposited all over the chamber. These comprise 24 bowls (only two of them broken) and 11 cups, of which five are complete, in addition to two beer jars, two storage jars, one piece of a ceramic scraper, and some large fragments of cattle bones. The majority of the small vessels and the animal bones were arranged along the rear wall of the chamber, while the storage and beer jars were located near the entrance, just behind the blocking wall. As noted above, chambers 3 and 2 are interconnected. For 

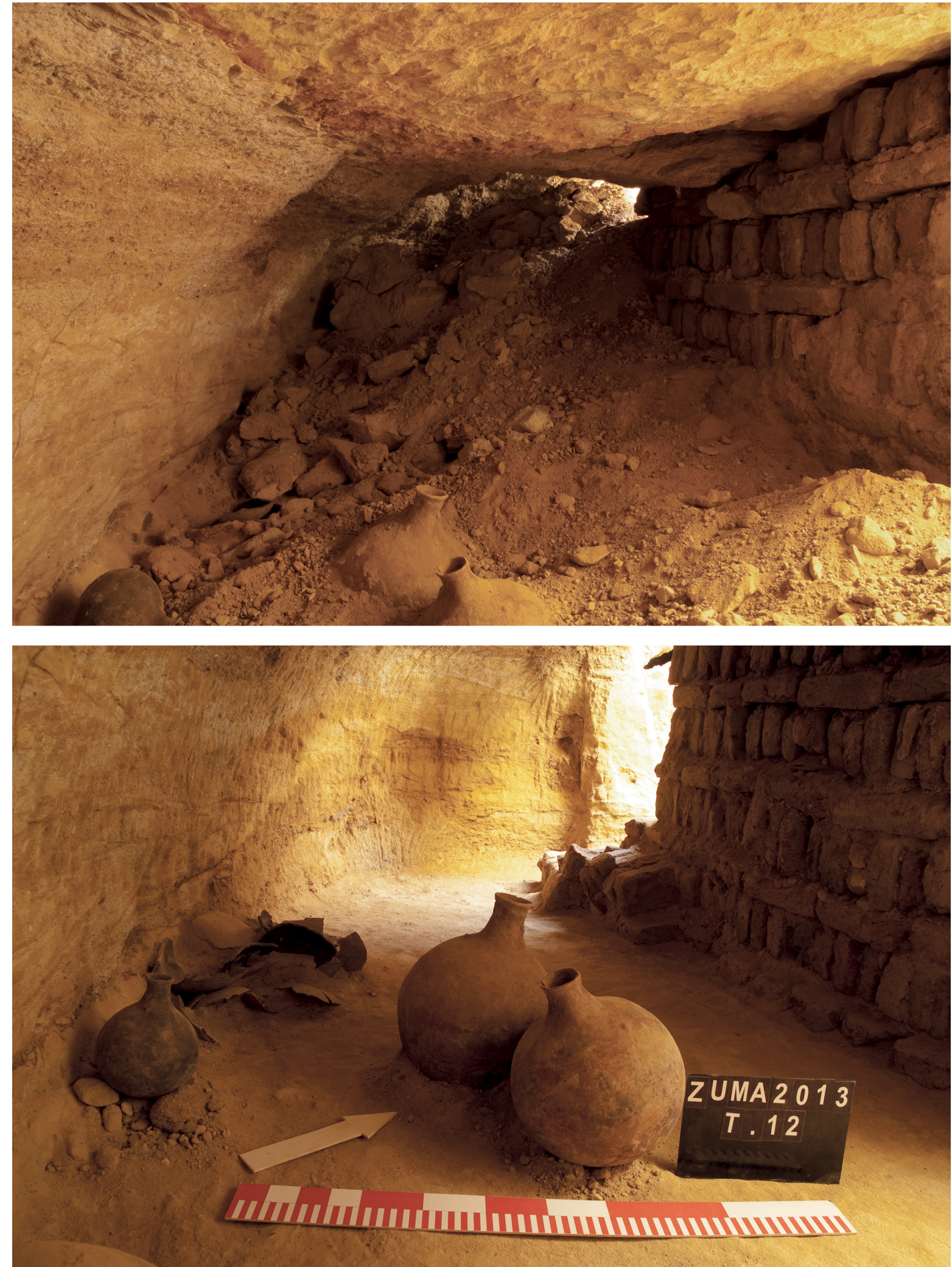

FIGURE 3.48 Tumulus 12, view of chamber 1 before excavation (note the earth fill flowing forth through a hole in the damaged blocking wall), looking west (top); the grave goods in chamber 1 (bottom)

PHOTOS BY E. SKOWROŃSKA 

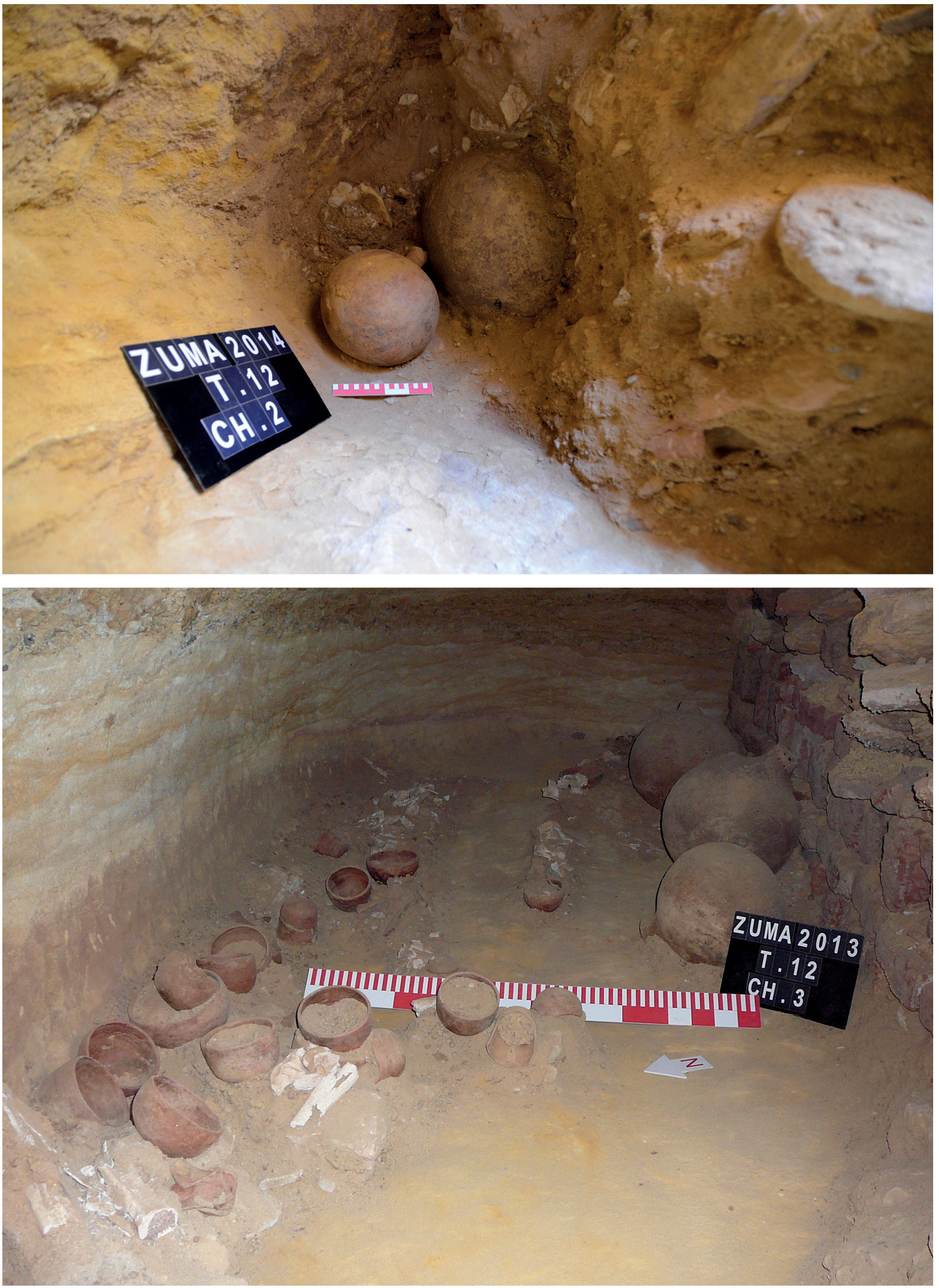

FIGURE 3.49 Tumulus 12, pottery in the collapsed chamber 2 (top); chamber 3, view of the grave goods (bottom)

PHOTOS BY A. KAMROWSKI [TOP], E. SKOWROŃSKA [воTTOM] 


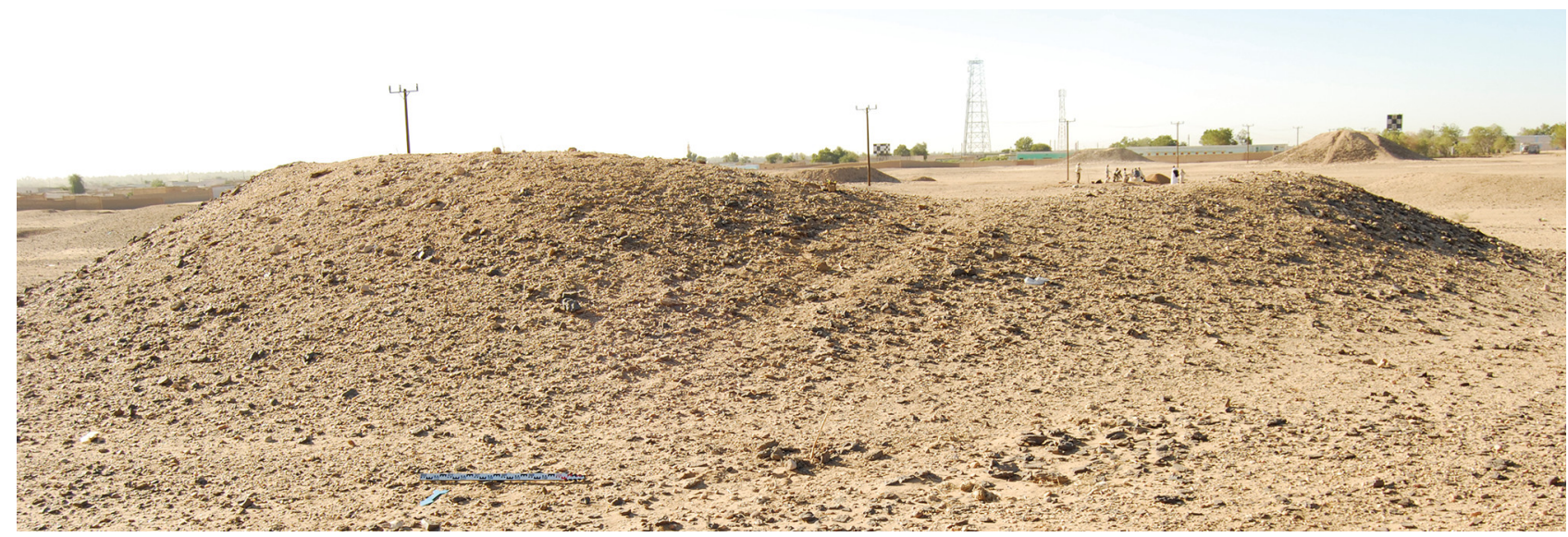

FIGURE 3.50 Tumulus 13, superstructure, facing south. Note the higher east side of the mound РНОТО BY О. ВIAŁOSTOCKA

more information see Mahmoud El-Tayeb, Skowrońska, and Czyżewska 2016, 110-114.

\subsection{Tumulus 13}

Tumulus 13 lies a short distance north-east of T.11. It consists of a circular mound with a diameter of about $27.70 \mathrm{~m}$ [Fig. 3.5o]. The mound is similar in shape to T.11; its preserved height ranges from $1.60 \mathrm{~m}$ on the southern side to $5 \mathrm{~m}$ on the north-east side. As with other tumuli at this cemetery, the same signs of robber activity were also clearly observed on the top central part of T.13. Unlike T.12, the shaft of T.13 was dug into a formation of hard white sandstone.

The removal of the upper layer of the fill made it possible to discern the top edge of a shaft which was U-shaped in plan. Further work revealed that only the southern, longer and larger side of the shaft had been disturbed, while the narrower and shorter northern side was found untouched. The general outline of the shaft represents a slightly deformed square, the sides of which measure $6 \mathrm{~m}(\mathrm{E}), 5.80 \mathrm{~m}(\mathrm{~W}), 4.50 \mathrm{~m}(\mathrm{~N})$ and $5.60 \mathrm{~m}(\mathrm{~S})$, with a maximum depth on the northern side of $4 \mathrm{~m}$, and $3.80 \mathrm{~m}$ on the southern side of the shaft [Fig. 3·51].

Access to the bottom was facilitated by four separate steps, cut in different parts of the shaft. Three of them are on the walls of the southern side; these are located in its north-east corner and south-west corner, with the third cut in the west wall. The fourth step is located in the north-east corner of the north side of the shaft. All of the steps were cut almost at the same level, about $1 \mathrm{~m}$ below the ground surface. For the first time at this cemetery five side chambers were discovered at the bottom of the grave. Chamber 1 is hewn into the south wall of the shaft's southern side. The robbers broke into it in the same manner as noted in chamber 1 of T.11, i.e. through a hole made in the east side of the blocking wall. The other four chambers were all found intact. Four of the five chambers, nos. 1, 3, 4, and 5, were sealed with red bricks in different arrangements. Only chamber 2, which is located in the south-west corner, was blocked using rough stone chunks [see Fig. 3.51]. Unfortunately, chamber 1, which is the main burial chamber, has not been excavated because of damage. As mentioned above, its solid red-brick wall had been destroyed on the east side leaving a hole about o.70 m wide. Apparently, during their search for valuable offerings, the robbers devastated the burial, damaging the skeleton and throwing out some of the pottery vessels. Two handmade beer jars, one red wheel-made bowl, and a human femur were found in the shaft in front of the robber pit [Fig. 3.52]. Work on the first chamber altered the burial environment causing a sudden collapse of the already cracked layers of the sandstone ceiling. Another attempt to investigate the west side of the chamber was ended by a further collapse of the roof. Therefore, for the safety of the team, the excavation of this chamber, regretfully, had to be abandoned [Fig. 3.53].

Chamber 2 is located in the south-west corner of the shaft between chambers 1 and 3. It is the only chamber to be sealed with rough sandstone on a red-brick foundation. The weak sandstone into which the chamber was hewn and environmental factors caused the partial collapse of the crumbling roof, but resulted in no serious damage. A group of seven pottery vessels was recorded in the centre and at the north-west side of the chamber. These were three handmade beer jars, two small wheelmade red ware bowls, and two small wheel-made red ware cups. Some fragments of animal bone were also found near these vessels [Fig. 3.54].

Chamber 3 was hewn into the west wall, and was completely sealed by large red bricks. Yet again, misfortune 
shaft

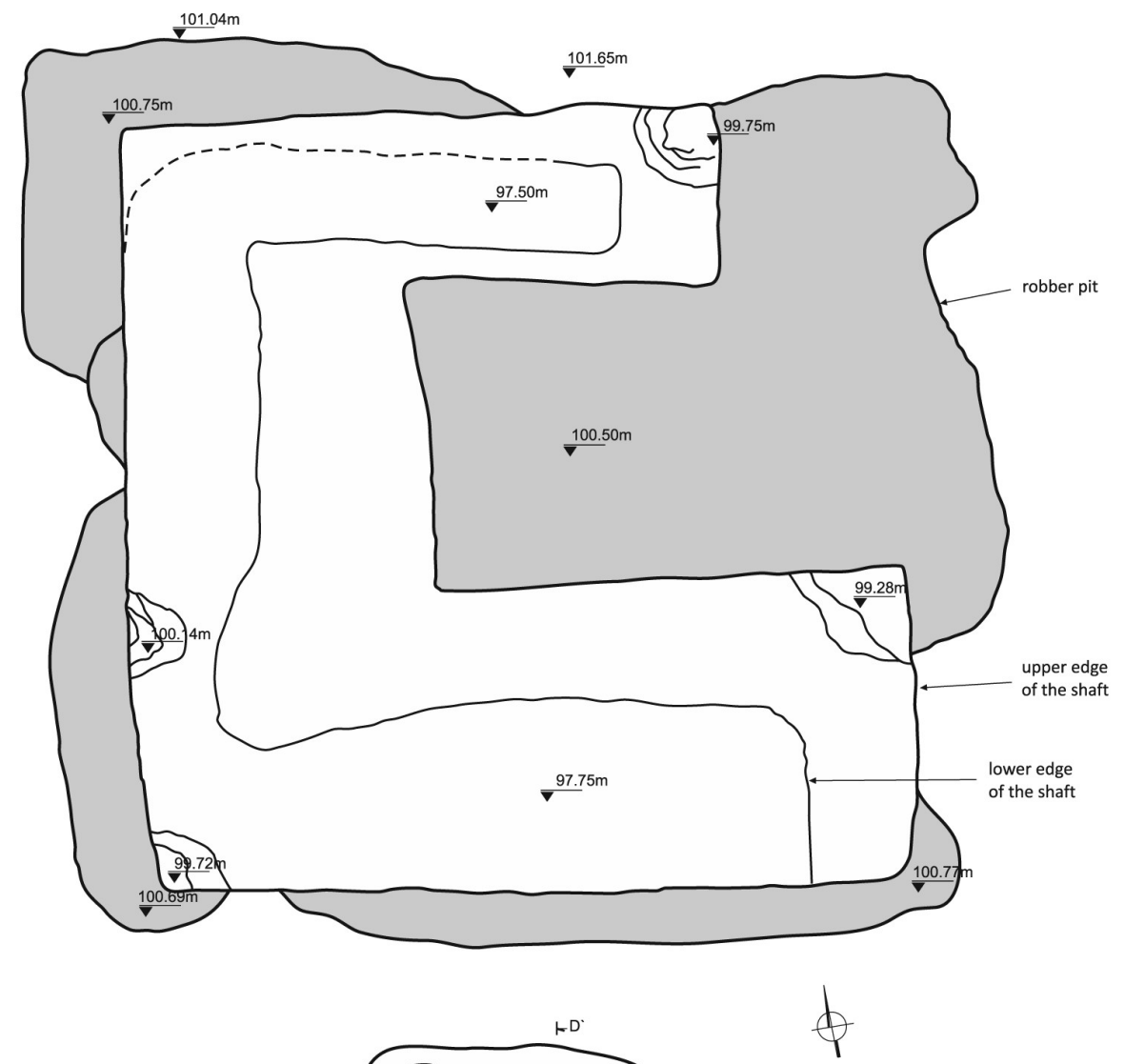

bottom of the shaft and burial chambers

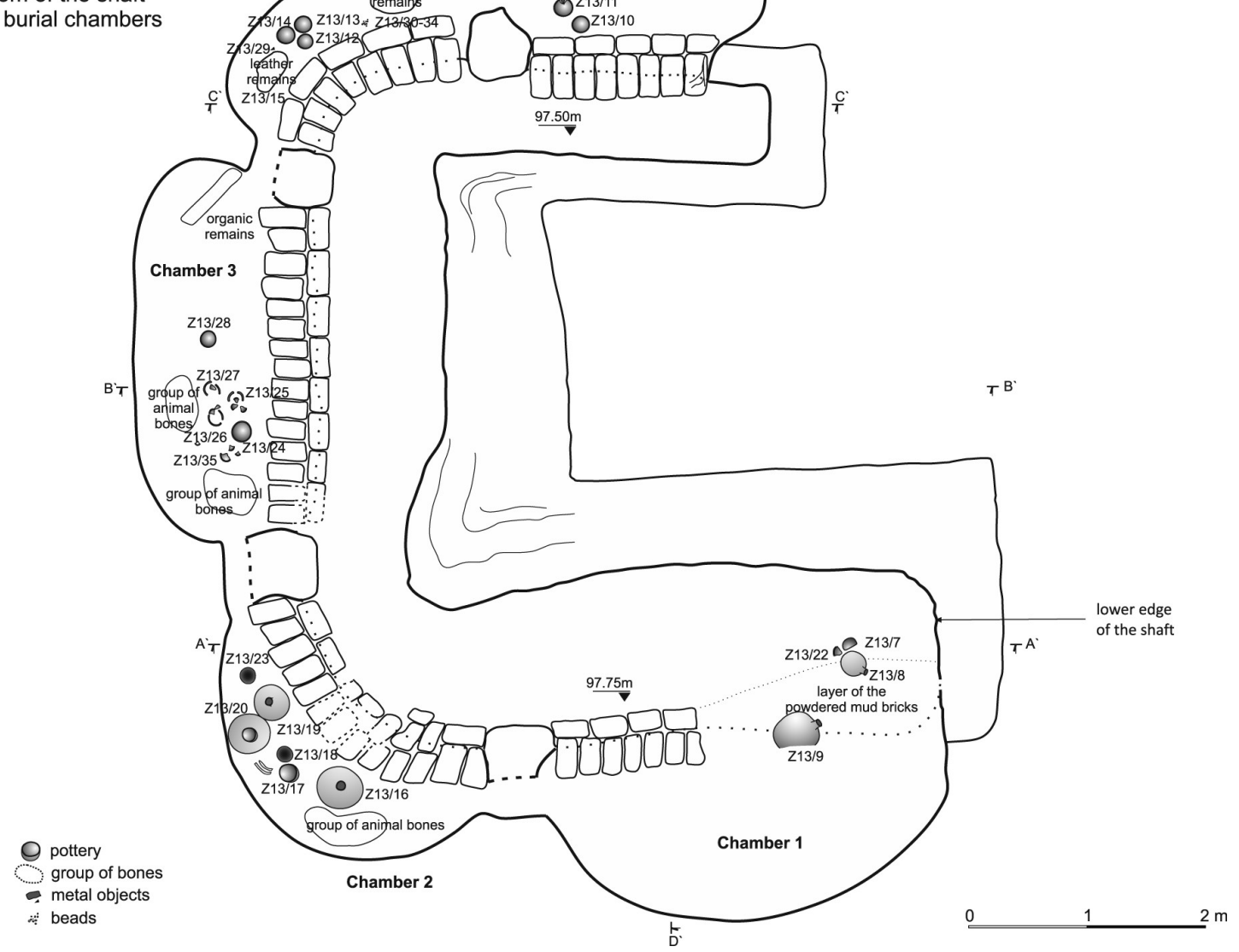

FIGURE 3.51A Tumulus 13, ground plan

DRAWN BY K. JUSZCZYK, O. BIAŁOSTOCKA, E. CZYŻEWSKA-ZALEWSKA,

E. KLIMASZEWSKA-DRABOT, DIGITISED BY E. CZYŻEWSKA-ZALEWSKA 

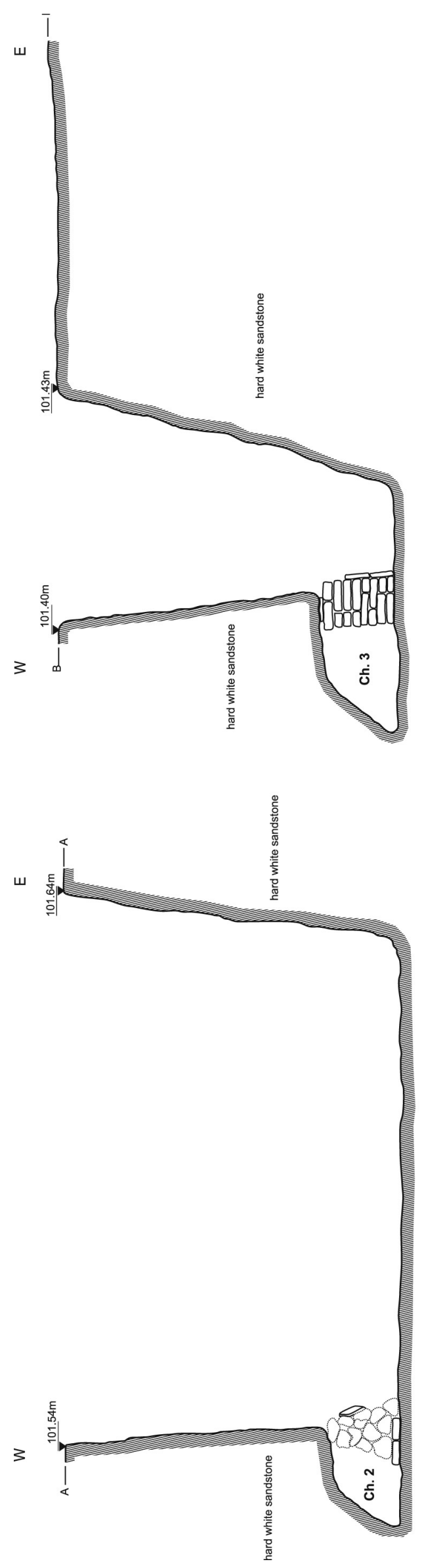
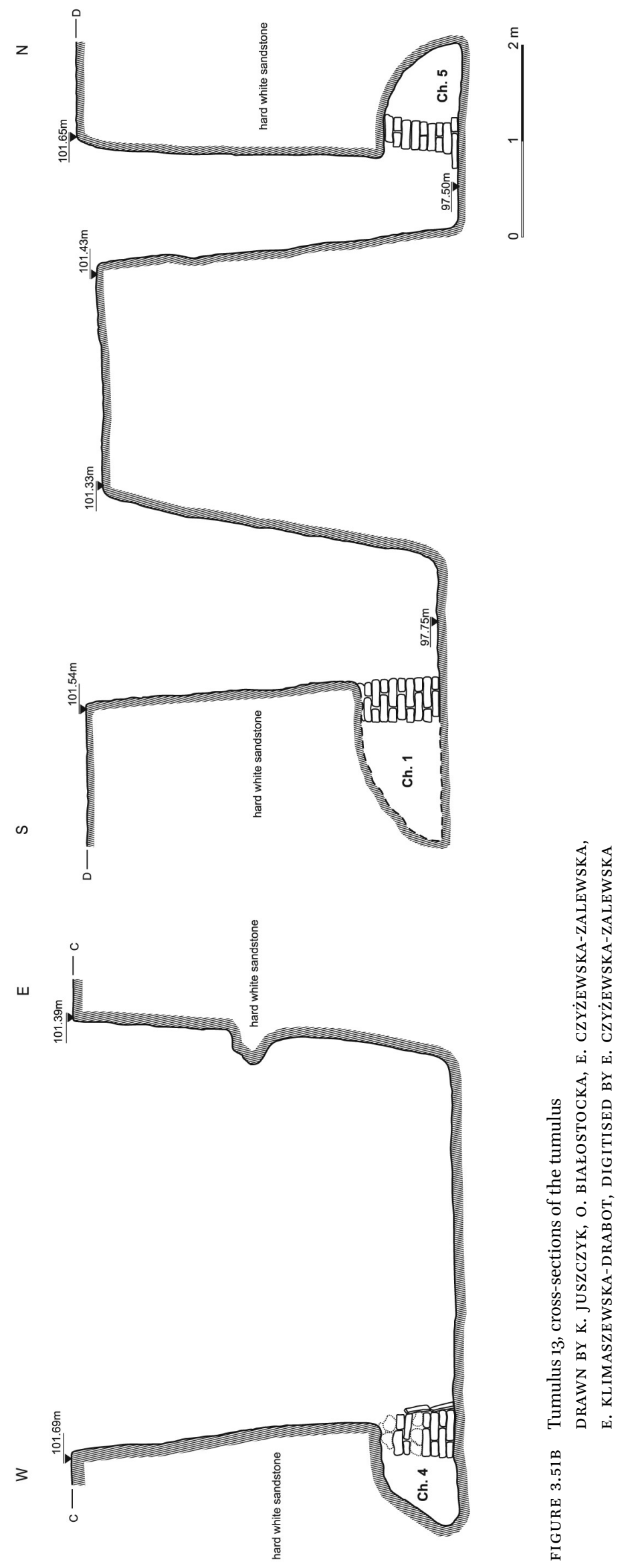


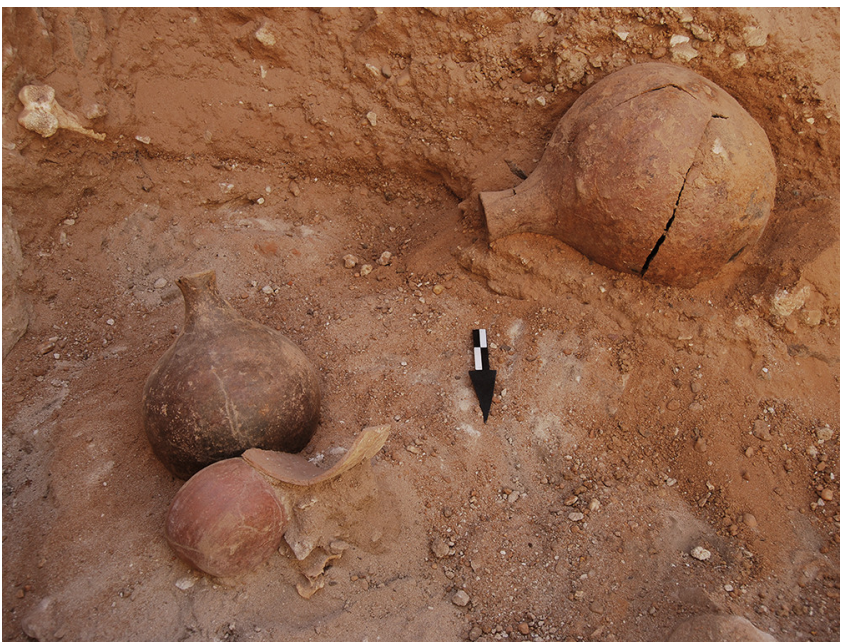

FIGURE 3.52

Tumulus 13, view of the funerary offerings in front of the robber pit, looking east

PHOTO BY O. BIAŁOSTOCKA

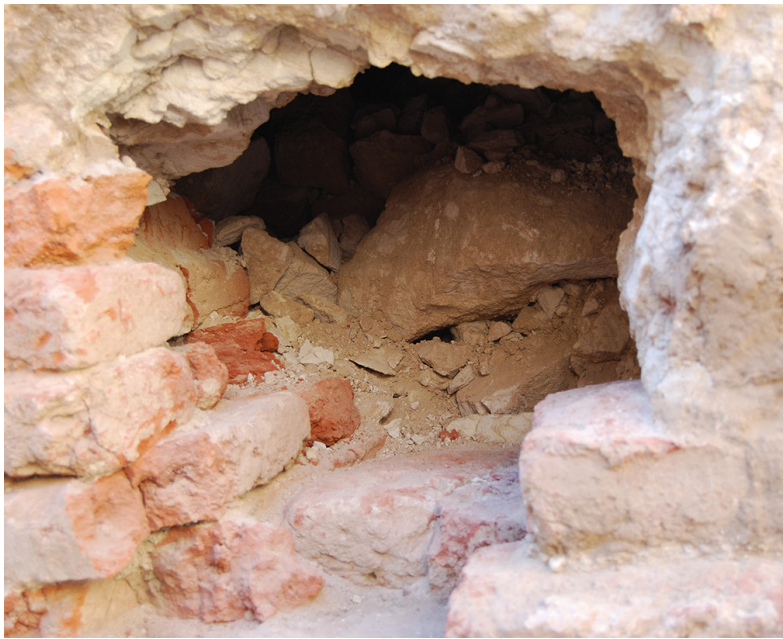

FIGURE 3.53

Tumulus 13, view of fallen stones from the ceiling of the southern burial chamber 1, looking south

РНОTO BY O. BIAŁOSTOCKA

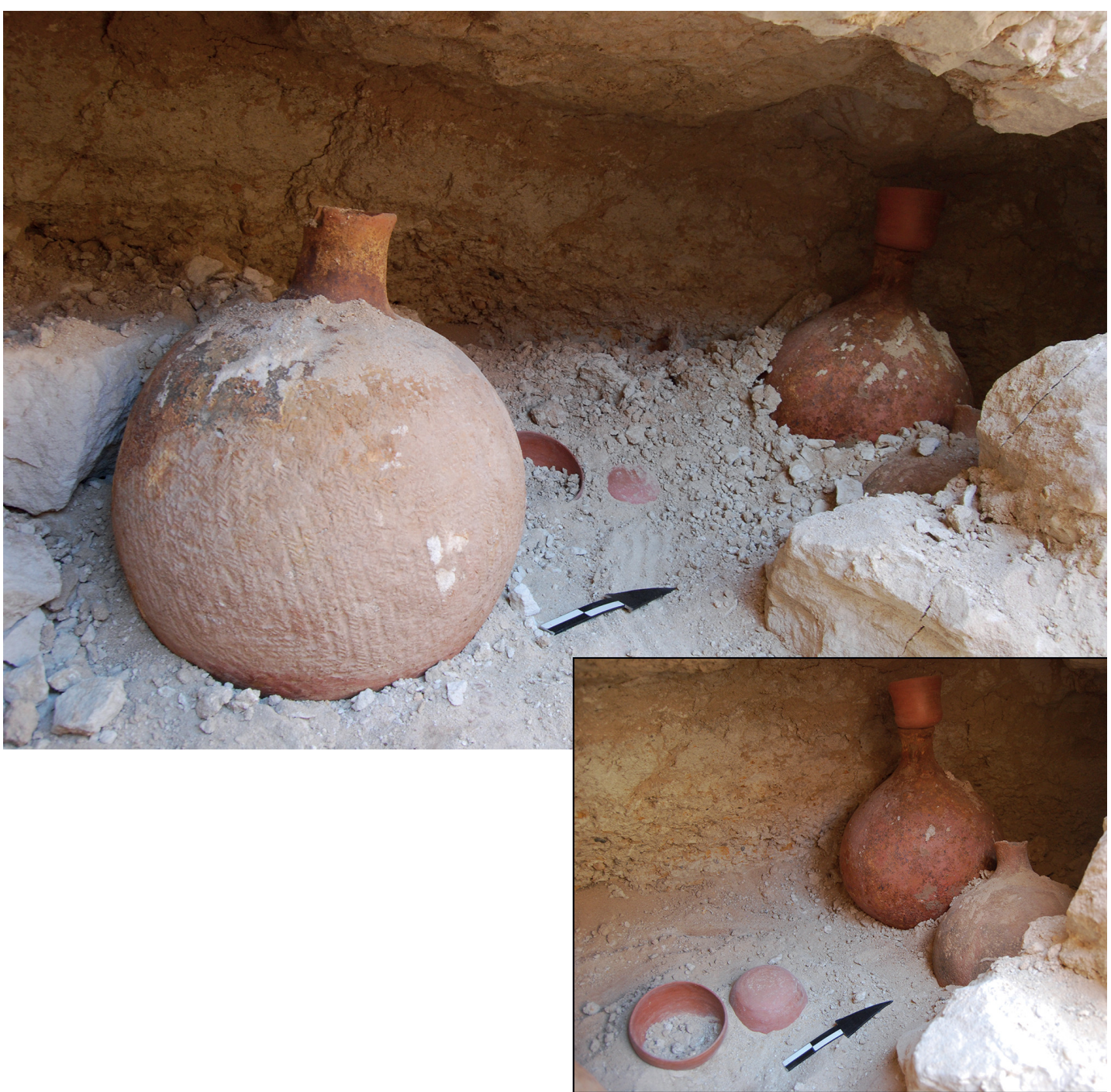

FIGURE 3.54 Tumulus 13, view of chamber 2 before and after excavation, facing west

PHOTO BY O. BIAŁOSTOCKA 


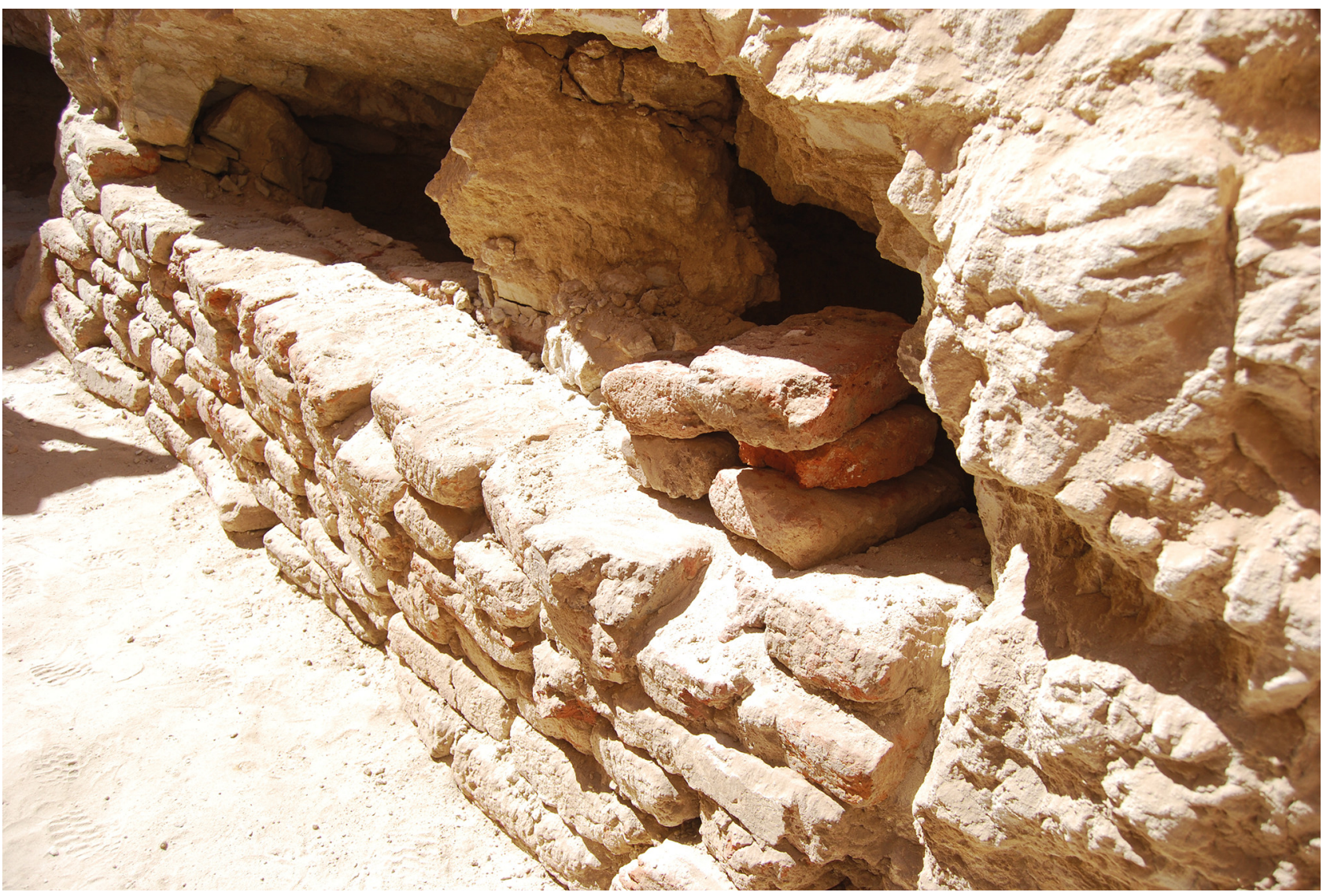

FIGURE 3.55 Tumulus 13, chamber 3, view of the fallen slabs from the ceiling, facing west Рното BY о. BIAŁOSTOCKA

beset the excavation of this chamber when a large portion of the ceiling collapsed after the partial dismantling of the blocking wall. After taking steps to secure the ceiling from further collapse and remove the fallen debris, the chamber was carefully examined. Fragments of six pottery vessels, which had been crushed by the fallen roof, were recovered from the central part of the chamber. On its northern side, faint traces of a brown organic material were noted. These might be the remains of a very decayed wooden beam; however, the nature of the original object was hard to identify [Fig. 3.55].

Two of the five chambers were cut into the northern side of the shaft. Chamber 4 was hewn into the northwest corner and chamber 5 occupied the narrow northern side. Chamber 4 was furnished with three wheel-made red bowls deposited in the centre. To the south-west of them was a leather case (bag) in a very bad state of preservation; however, it may have originally been decorated with beads, some of which were found scattered around it. Remains of an unidentified organic object, which seems to be a kind of vessel, were found east of the three bowls [Fig. 3.56 top]. The last chamber (Ch. 5) contained even fewer objects. Only two wheel-made red bowls and some animal bones had been deposited as grave goods [Fig. $3 \cdot 56$ bottom]. It is noteworthy that all five chambers in this burial are interconnected by holes made in the dividing walls. This practice was also noted in T.2, T.5, T.23, and T.25 at this cemetery, as well as having been recorded at other burial grounds: at Hammur-Abbassiya (tumuli 1 and 4) and Tanqasi (T.87) (Mahmoud El-Tayeb 2003, 130-134, Figs. 8, 13; Godlewski 2008, 469-476, Fig. 8). So far the function of these holes has not been determined. Another question that remains open to debate is why the north and west sides of the shaft were missed by the robbers. Was it because they already knew that digging there was not worth the effort, or did they not recognize the construction plan of the shaft?

Both tumuli 17 and 27 are attributed to the smallest group of burials designated type III. T.17 has a very low mound with a preserved height of about $0.45 \mathrm{~m}$ and a maximum diameter of $10 \mathrm{~m}$. It is located between T.18 and T.19, in the central part of the cemetery. In this area of the site, which in fact is not far from the above-described burials, the underlying geology is totally different. The surface is covered with aeolian sand beneath which there is a mixture of small stones, in addition to gravel and reddish soil 

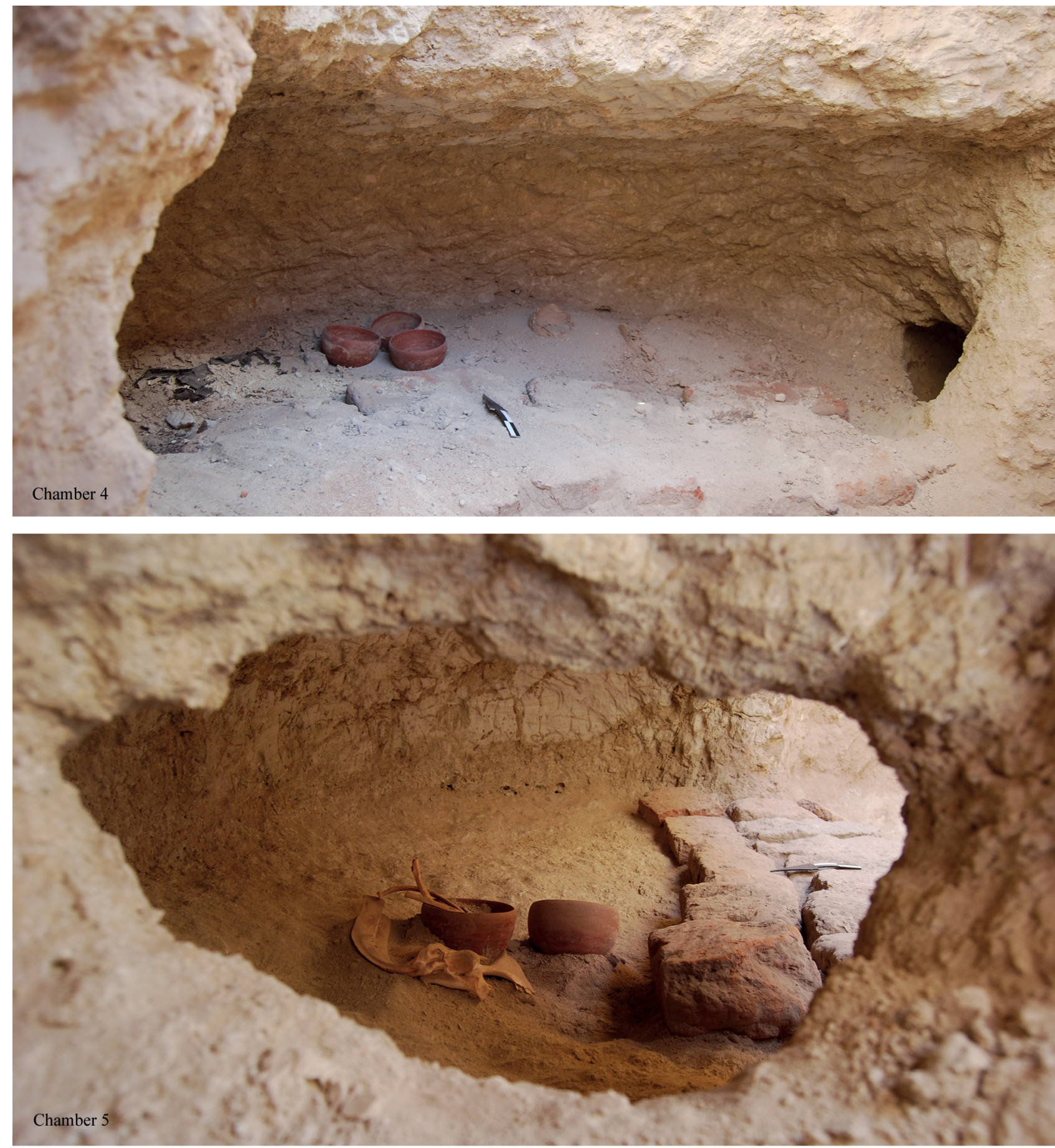

FIGURE 3.56 Tumulus 13, view of some offerings in chamber 4-note the hole interconnecting chambers 4 and 5 (top); view of the offerings in chamber 5 , looking east through the interconnecting hole between chambers 4 and 5 (bottom) PHOTOS BY O. BIAєOSTOCKA

forming a stratum $2.31 \mathrm{~m}$ thick, which extends to the bottom of the shaft. The floor at the bottom consists of a compact layer of black gravel and whitish-greyish sand. The body of the mound was built from a mixture of sand and gravel surrounded by a stone ring about $3.60 \mathrm{~m}$ in diameter, which originally demarcated the perimeter of the mound. The robbers had dug a large hole, about $2 \mathrm{~m}$ wide, at the top of the mound, but it seems that they missed the centre of the shaft and the blocking wall. However, by cutting part of the west wall of the shaft they were able to access the chamber directly. The shaft is aligned north-south and has a trapezoid plan, its sides 

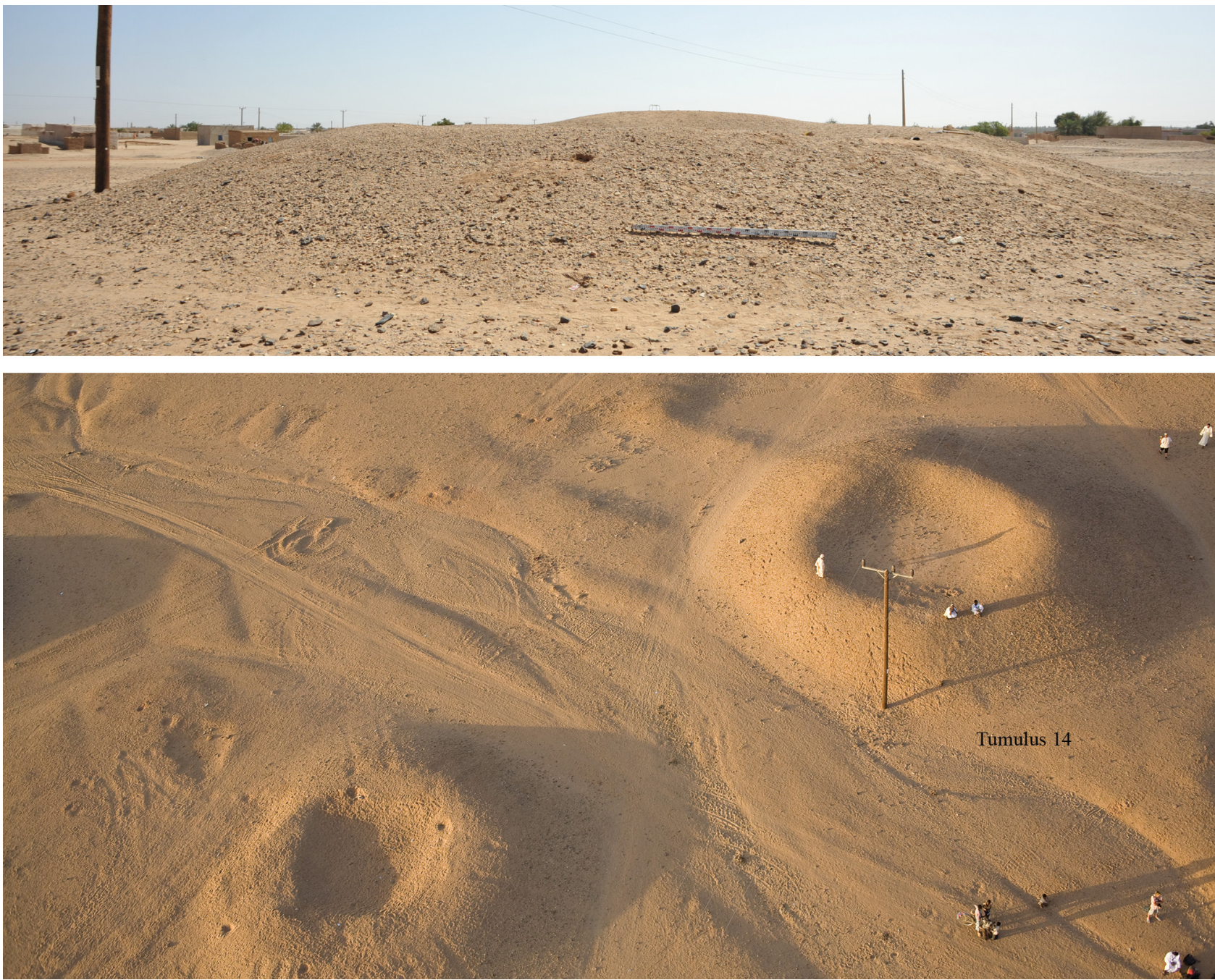

FIGURE 3.57 Tumulus 14, view of the superstructure, looking north-west (top); aerial view of the tumulus (bottom) PHOTOS вY т. WOJTCZAK [TOP], M. вOGACKI [вотTOM]

measuring $1.34 \mathrm{~m}(\mathrm{~W}), 1.80 \mathrm{~m}(\mathrm{E}), 0.98 \mathrm{~m}(\mathrm{~N})$, and $0.86 \mathrm{~m}(\mathrm{~S})$ on the ground surface, and $1.45 \mathrm{~m}(\mathrm{~W}), 1.24 \mathrm{~m}(\mathrm{E}), 0.70 \mathrm{~m}$ $(\mathrm{N})$, and $0.80 \mathrm{~m}(\mathrm{~S})$ at the bottom of the shaft. A single burial chamber, $2.40 \mathrm{~m}$ long, $0.80 \mathrm{~m}$ wide and $0.52 \mathrm{~m}$ high, was cut into the west wall. As noted above, the robbers cut through part of the west wall and removed some of the stones of the blocking wall from the south-west corner. In this way they managed to break into the burial chamber and severely damage the human skeleton. Although the skeleton was greatly disturbed, fragments of leg and foot bones suggest that it may have lain on its right side, in a contracted position, with head due north-west, facing south. The grave goods consisted of two complete handmade beer jars: a large brown one located on the northern side of the chamber, and a smaller one of black ware deposited on the opposite, southern, side. Moreover, one iron ring and a group of nine badly corroded iron arrowheads were also found. Other finds included 88 beads of different materials such as quartz, agate, faience, and probably ivory or bone. Fragments of beer jars used by the robbers as scrapers were found in the shaft fill as well as in the burial chamber itself. For more information see Mahmoud El-Tayeb and Czyżewska 2011.

\subsection{Tumulus 14}

This is a rounded mound located on the north-east side of the cemetery. Like the majority of the tumuli at this site, it was built from a mixture of sandy earth and gravel with some black ferricrete stones, and was characterized by a visible depression at the top centre. The mound has a maximum diameter of $32.10 \mathrm{~m}$ measured east to west, with a maximum height of $2.79 \mathrm{~m}$ on its higher east side [Fig. 3.57].

The U-shaped shaft [Fig. 3.58] has sides that measure $3.20 \mathrm{~m}(\mathrm{E}), 2.50 \mathrm{~m}(\mathrm{~W}), 5.6 \mathrm{om}(\mathrm{N})$, and $5.20 \mathrm{~m}(\mathrm{~S})$ on the original ground surface. The sides of the south pier 


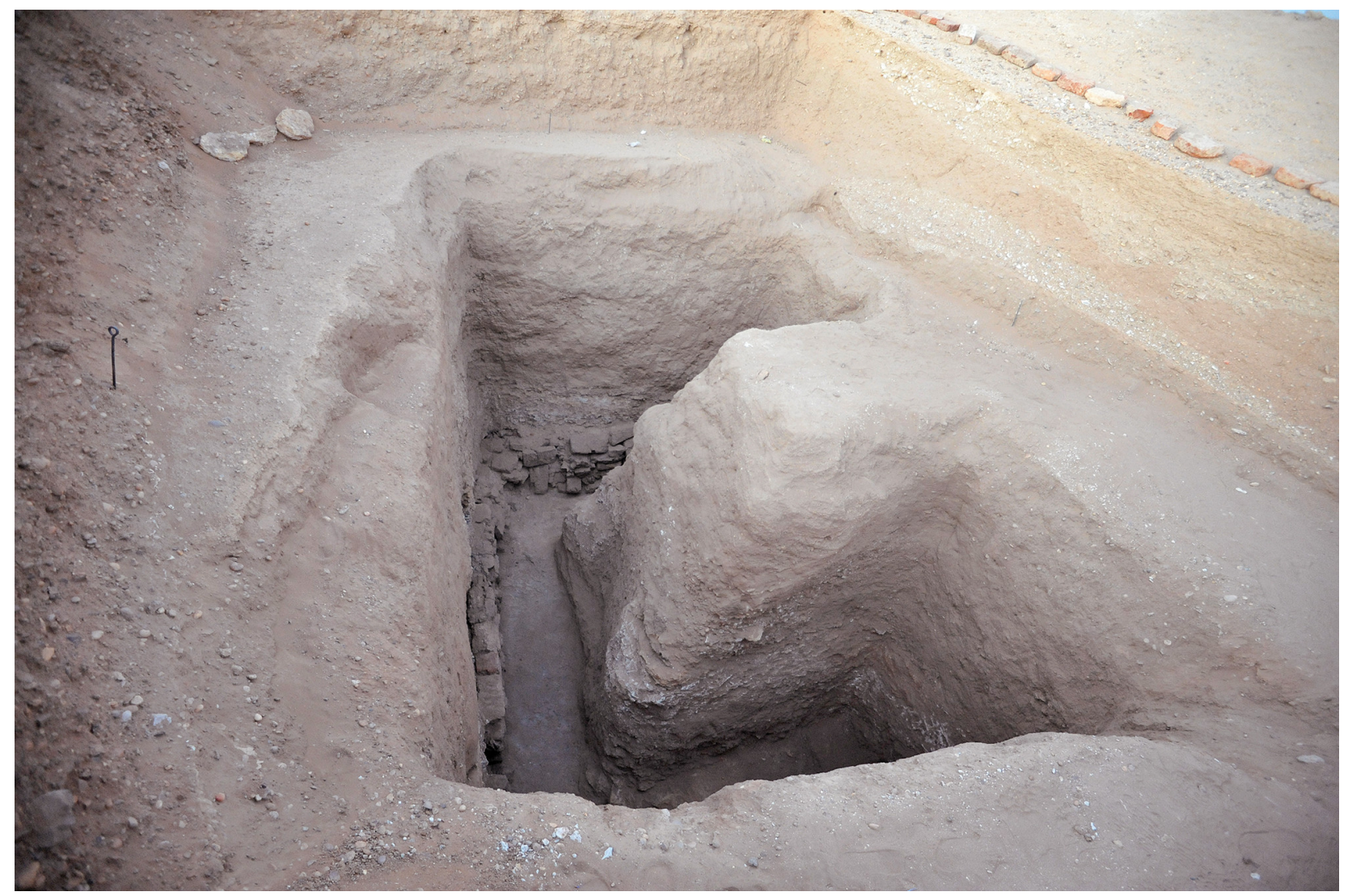

FIGURE 3.58 Tumulus 14, view of the U-shaped shaft, looking north Рното вY т. WOJTCZAK

measure $1.70 \mathrm{~m}(\mathrm{~W}), 1.60 \mathrm{~m}(\mathrm{~N})$, and $1.60 \mathrm{~m}(\mathrm{E})$, while the maximum depth of the shaft is $3.60 \mathrm{~m}$. Access to the bottom of the shaft was made easier by a single step created in the south-west corner of the pier's eastern side, at a height of $1.30 \mathrm{~m}$ from the bottom of the shaft. At the bottom of the shaft three side chambers were cut into its western, northern, and eastern walls [Fig. 3.59].

The main chamber (Ch. 1) occupies about two-thirds of the western side of the shaft, measuring $2.30 \mathrm{~m}$ long by $1.80 \mathrm{~m}$ wide and $0.80 \mathrm{~m}$ high at the entrance to the chamber. The other two chambers were approximately L-shaped in plan.

Chamber 2 extends from the end of the north part of chamber 1 up to the third quarter of the north wall and measures $1.20 \mathrm{~m}$ from north to south and $5.10 \mathrm{~m}$ from east to west, with an entrance height of $0.95 \mathrm{~m}$.

Chamber 3 is cut into the eastern wall of the shaft and extends into the north wall. The two parts of the chamber measure $4.90 \mathrm{~m}$ in length $(\mathrm{N}-\mathrm{S})$ by $1.20 \mathrm{~m}$ in width, and $1.60 \mathrm{~m}$ in length (E-W) by $1.30 \mathrm{~m}$ in width [see Fig. 3.59].

At the bottom of the shaft, both east and west wings were found covered by a quantity of broken mud- and fired bricks [Fig. 3.6o]. The latter were reused red bricks bearing traces of painted plaster. They were most probably brought from the same source as the reused red bricks which were discovered in other tumuli at this cemetery (e.g. in T.11 and T.13). Notably, some of these bricks were found cut or with rounded corners, which could indicate their specific location in the original construction from which they were removed (Juszczyk 2011, 119-123).

The blocking wall of chamber 3 was found intact. It was mainly built of mud bricks, though some red ones measuring $40 \mathrm{~cm} \times 20 \mathrm{~cm} \times 10 \mathrm{~cm}$ were also used in its construction, which comprised eight courses of alternating headers and stretchers.

On the south-east side of the shaft, part of the blocking wall had been damaged by robbers. Nonetheless, the remains that were found in place helped in understanding the technique used to build this wall, which proved to be analogous to that used for the blocking wall of chamber 3. However, the wall that blocked chamber 2 was set on foundations composed of a rowlock course followed by alternate courses of headers and stretchers.

During excavation of the main chamber (Ch. 1) [Fig. 3.61], a disarticulated human skeleton was noted on the 

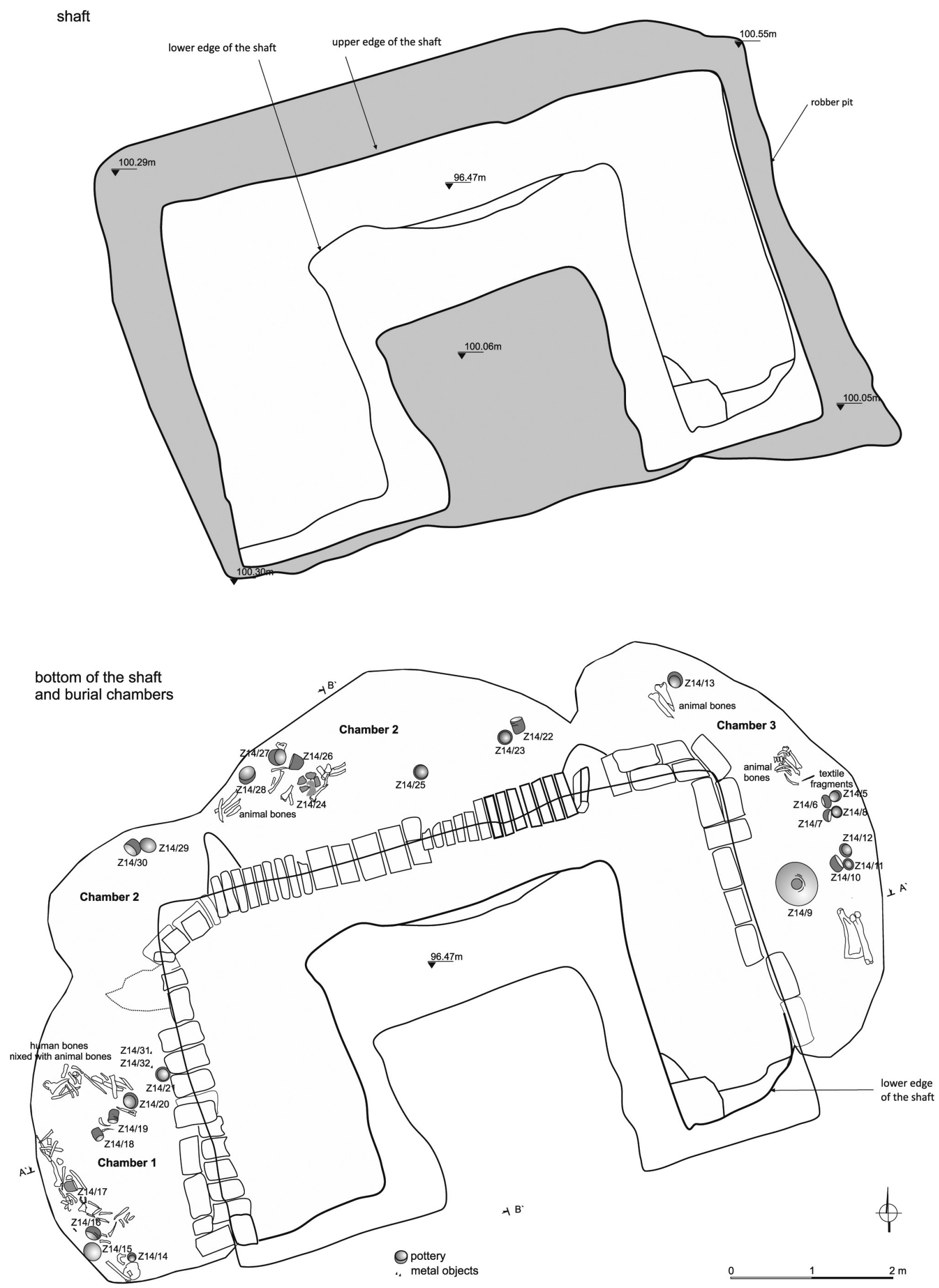

FIGURE 3.59A Tumulus 14, ground plan

DRAWN BY E. SKOWROŃSKA, J. BROCHOCKI, K. SOLARSKA, DIGITISED BY

E. CZYŻEWSKA-ZALEWSKA, K. SOLARSKA, J. BROCHOCKI 

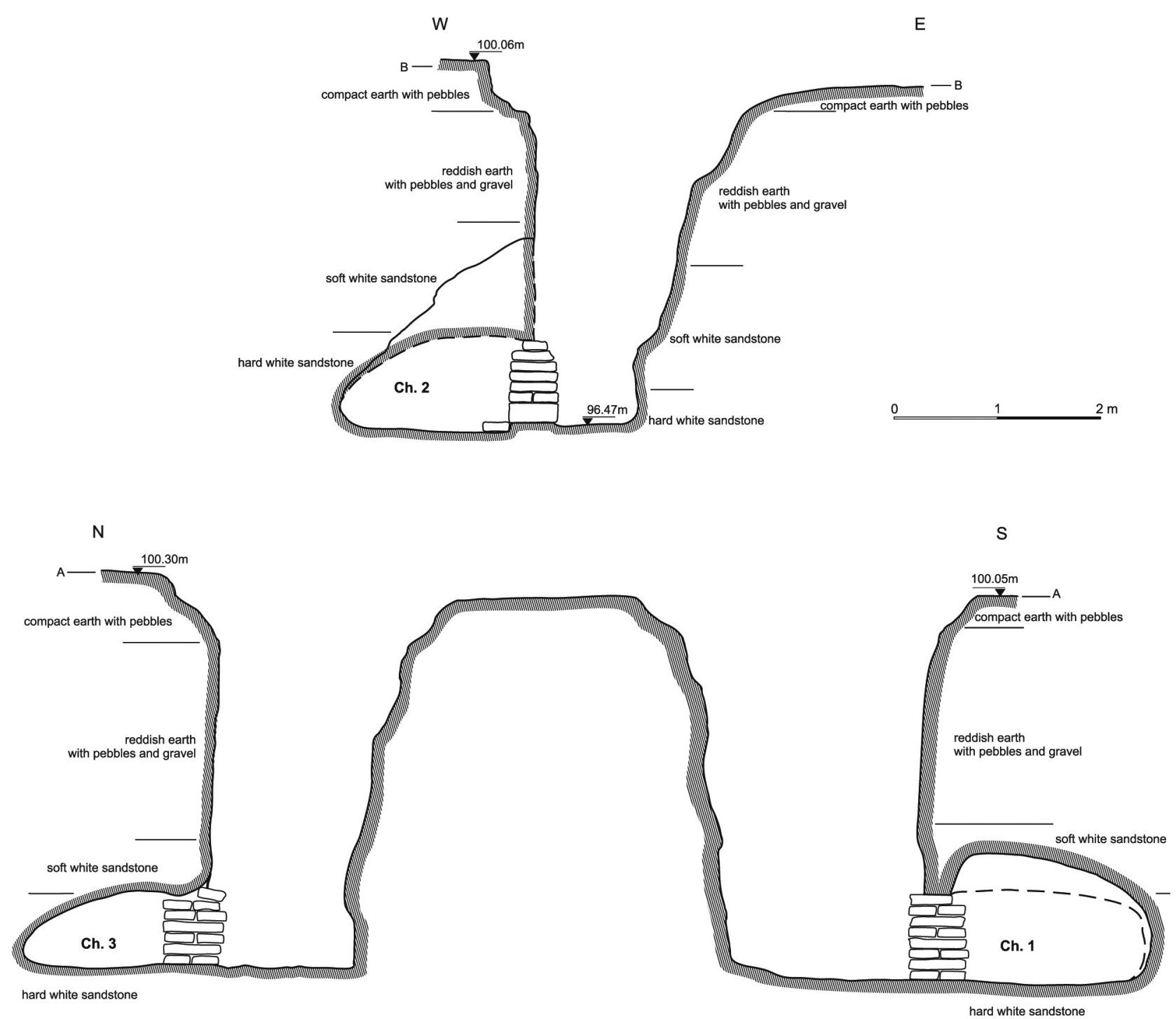

FIGURE 3.59B Tumulus 14, cross-sections of the tumulus DRAWN BY E. SKOWROŃSKA, J. BROCHOCKI, K. SOLARSKA, DIGITISED BY E. CZYŻEWSKA-ZALEWSKA, K. SOLARSKA, J. BROCHOCKI

south-west side of the chamber, with the detached skull cast aside close to the west wall of the burial. Large cattle bones and some iron nails were observed scattered throughout the burial chamber. Other grave offerings that apparently had not been of any interest to the robbers comprised eight small wheel-made red vessels (four cups and four bowls), which were intermingled amongst the human and animal bones.

The location of the disturbed human skeleton clearly indicates that the body was deposited on the west side of the burial chamber in keeping with the rite of inhumation noted at this cemetery in type I and II tumuli, where the body was placed either on a wooden frame or directly on the ground, in contracted position with head due east, facing north.
Chamber 2 [Fig. 3.62] is hewn into part of the western wall, where it adjoins chamber 1, and extends into the northern wall, where it borders chamber 3 [Fig. 3.63]. It is interconnected with both chambers 1 and 3 through a small hole of about $0.30 \mathrm{~m}$ made at floor level. This chamber was found filled with debris as a result of its ceiling having split. Thorough cleaning of the chamber revealed the presence of burial offerings represented by nine wheelmade pottery vessels divided into four groups aligned east-west. These comprise three cups and six bowls. There was also a collection of cattle bones on the north-west side, near the rear wall of the chamber.

The last burial chamber (Ch. 3 ) is partly cut into the north wall of the shaft, while the larger part is cut into the east wall. It measures $1.60 \mathrm{~m}$ in length along its east- 


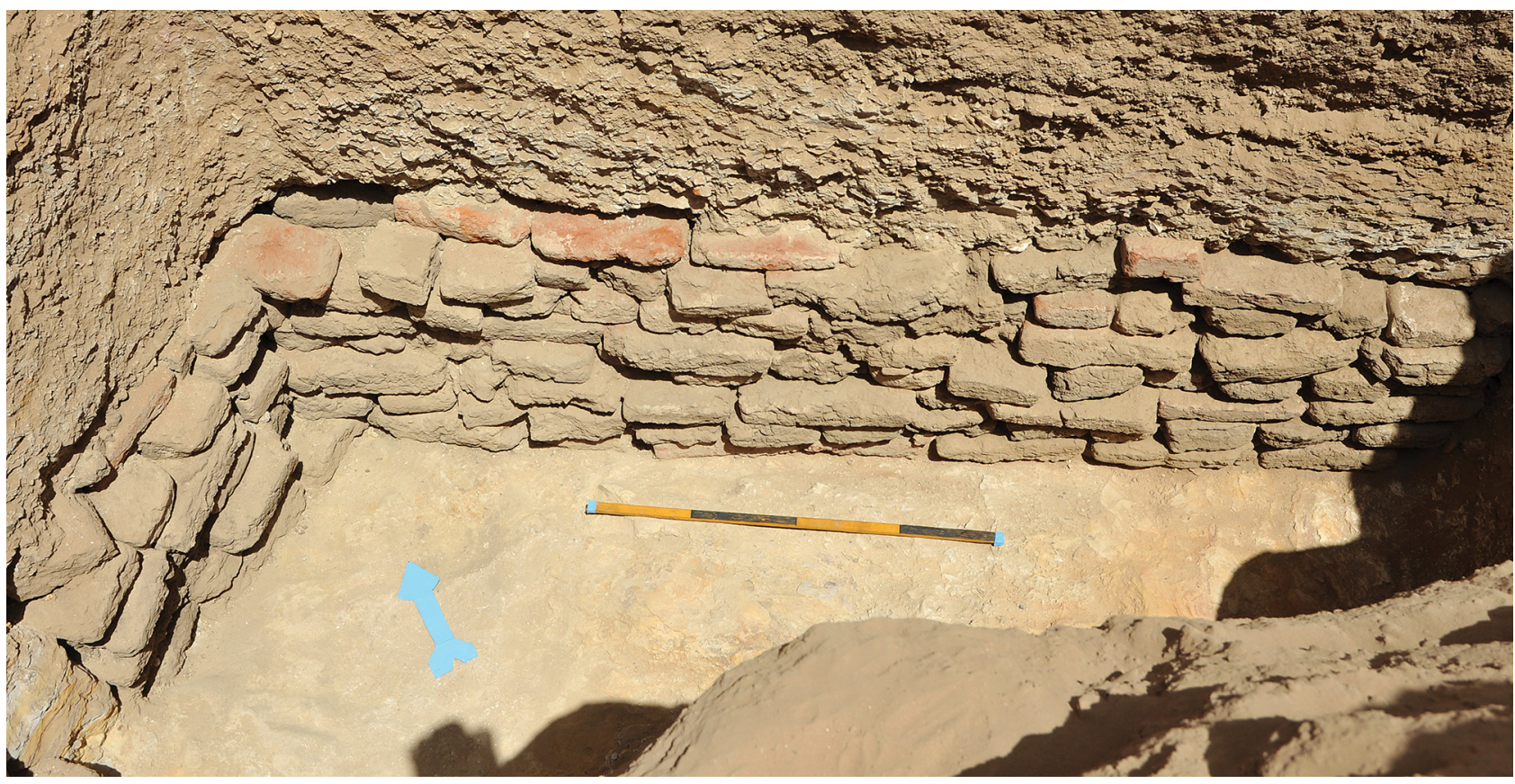

FIGURE 3.60 Tumulus 14, blocking wall of chamber 3 рното ву т. WOJTCZAK

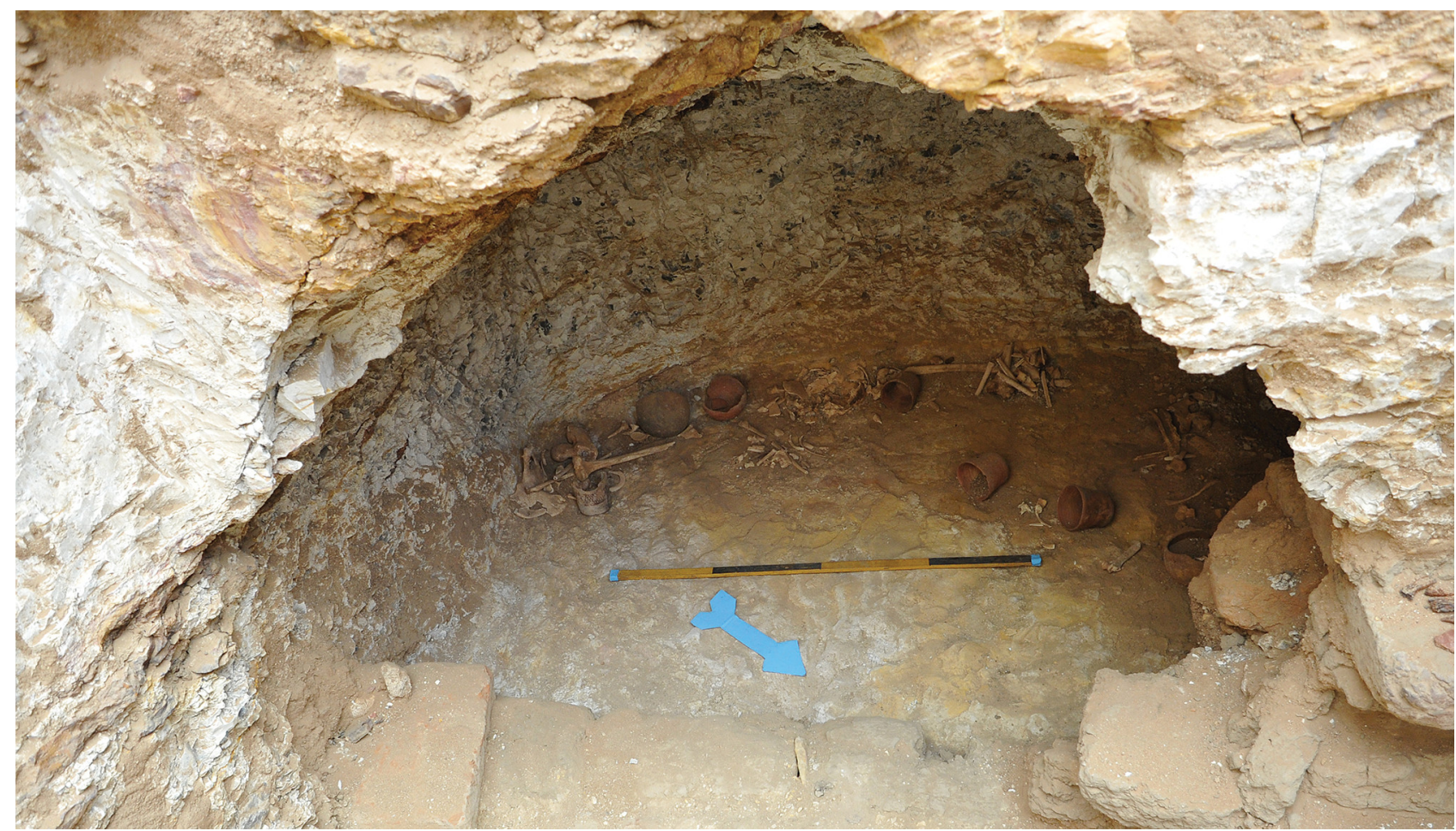

FIGURE 3.61 Tumulus 14, view of the east side of the main burial chamber (Ch. 1), showing the robber pit on the east side Рното вY т. WOJTCZAK 


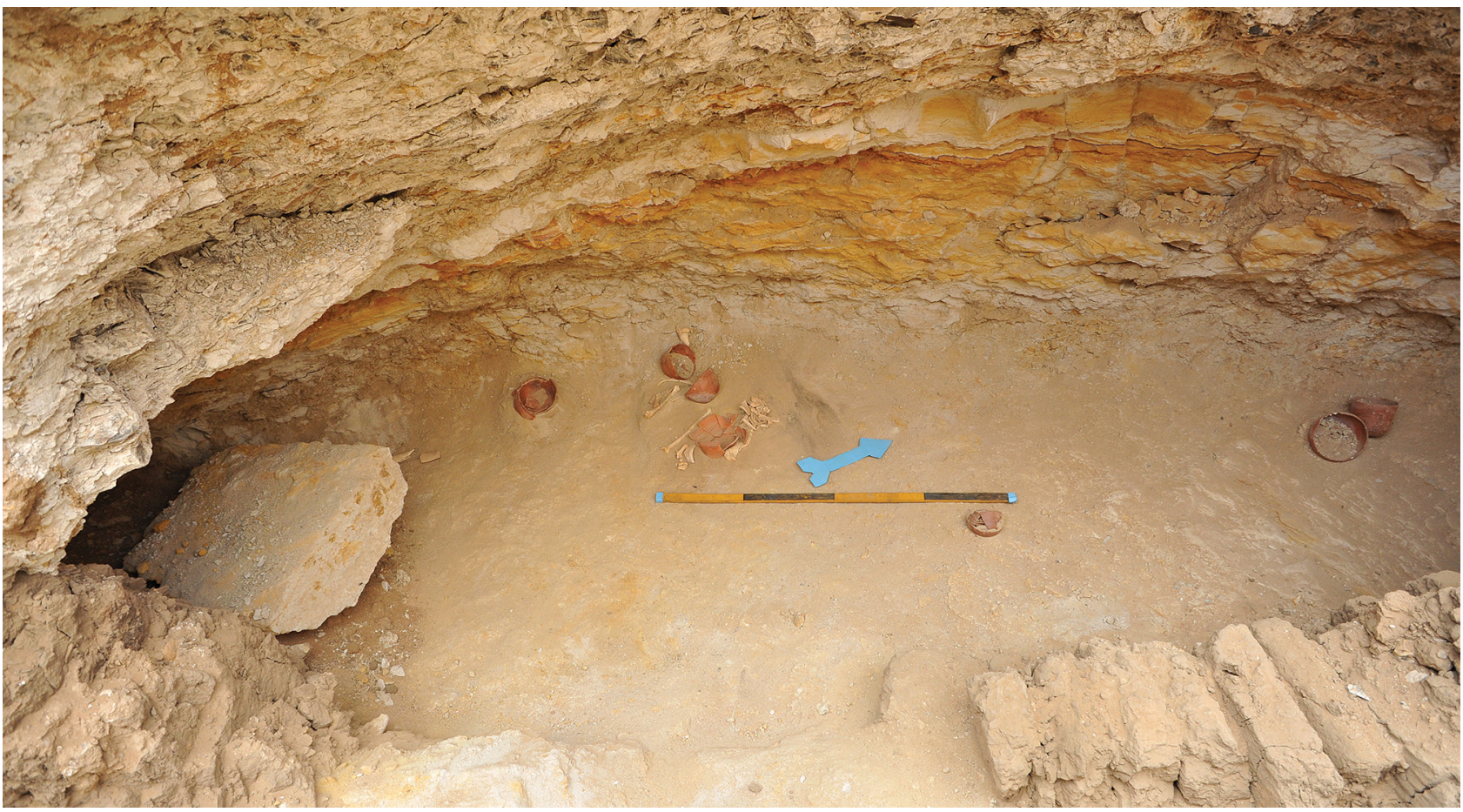

FIGURE 3.62 Tumulus 14, view of chamber 2 after excavation-note the fallen slab Рното ву т. WOJTCZAK

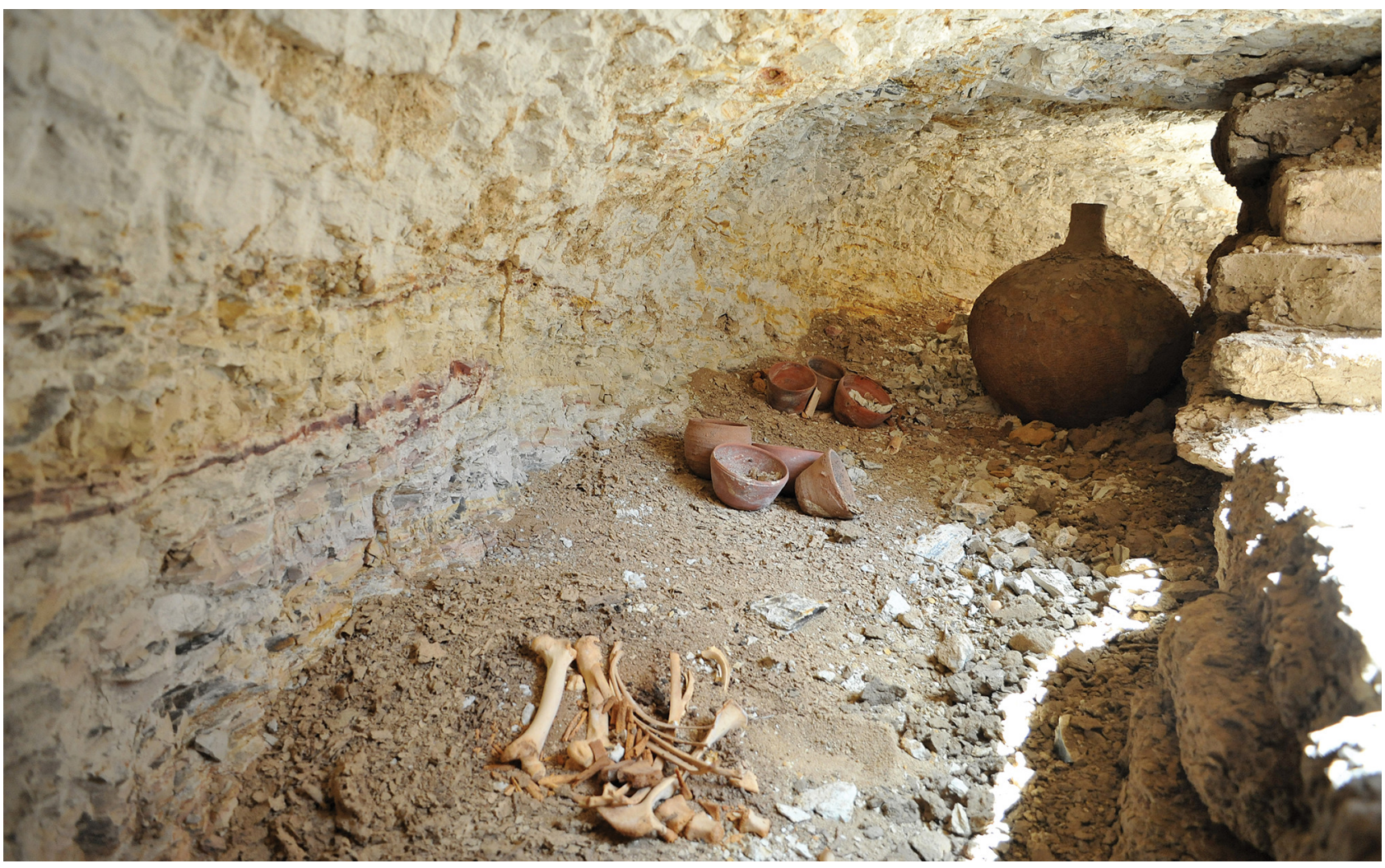

FIGURE 3.63 Tumulus 14, view of the grave goods in chamber 3 Рното вY т. WOJTCZAK 


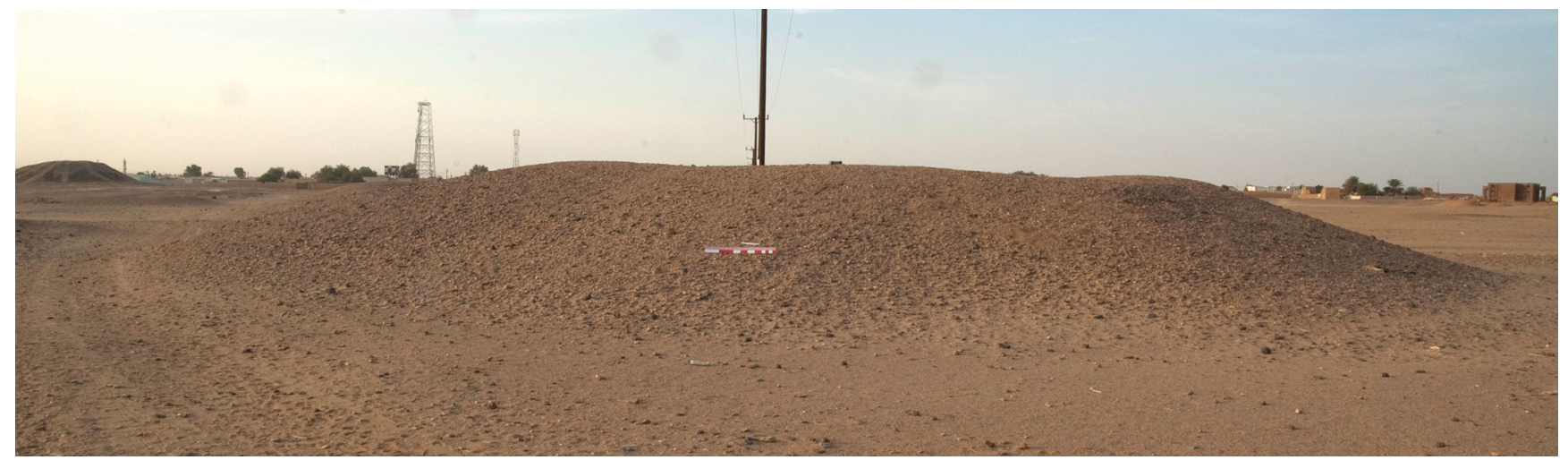

FIGURE 3.64 Tumulus 15, view of the superstructure, looking south PHOTO BY R. MAHLER

west axis by $1.20 \mathrm{~m}$ in width, and $4.90 \mathrm{~m}$ in length along its north-south axis by $1.30 \mathrm{~m}$ in width. This undisturbed chamber was furnished with eight wheel-made vessels consisting of four small cups and three medium-size bowls, all of which were deposited near the rear wall of the chamber. On the opposite side, a handmade beer jar was found close to the blocking wall of the chamber. The last vessel is a wheel-made bowl found in the northern extension of the chamber. In addition to the pottery, the chamber also contained other offerings such as cattle meat; large bones were recorded at the south-east side of the chamber and in its central part as well as at the north end.

\subsection{Tumulus 15}

Tumulus 15 lies in the central part of the necropolis. It is a circular mound built from a mixture of earth and gravel with a diameter of about $30 \mathrm{~m}$. The mound measures $1.87 \mathrm{~m}$ high on the north side, $1.70 \mathrm{~m}$ on the south, and $1.17 \mathrm{~m}$ on the west, reaching its maximum height of about $2.25 \mathrm{~m}$ on the east side. The superstructure of T.15 identifies it as a variant of type II burials because it does not have the flat top characteristic of this category [Fig. 3.64].

The substructure features a vertical shaft with a Ushaped ground plan and a pier projecting from the east wall. The top of the shaft measures $5.80 \mathrm{~m}$ on the west side, $5.70 \mathrm{~m}$ on the east, $3.70 \mathrm{~m}$ on the north, and $3.50 \mathrm{~m}$ on the south side. The upper part of the pier measures $1.75 \mathrm{~m}$ on the north side, $1.55 \mathrm{~m}$ on the west, and $1.55 \mathrm{~m}$ on the south side. At the bottom, the shaft is slightly narrower, measuring $3.14 \mathrm{~m}$ on its north side, $3.10 \mathrm{~m}$ on the south, and $5.05 \mathrm{~m}$ on the west side, while the pier dimensions reach $1.40 \mathrm{~m}$ on the north side, $2.20 \mathrm{~m}$ on the west, and $2.10 \mathrm{~m}$ on the south side. The depth of the shaft ranges from $3.10 \mathrm{~m}$ at the south-east end to $3.25 \mathrm{~m}$ at the south-west end. Access to the bottom of the shaft was provided by two steps. The first was made in the south-west corner of the northern wing of the shaft, about $2 \mathrm{~m}$ below the original ground surface, while the second was made on the south-west corner of the pier, at about $1.50 \mathrm{~m}$ below the original ground surface [Fig. 3.65].

Once more at this necropolis there was further confirmation that the existence of a depression on top of a mound attests to looting. Excavation of the fill in the south wing of the shaft revealed fragments of mud- and red bricks from the dismantled blocking walls of the burial chamber [Fig. 3.66]. Towards the bottom, amongst the earth, wind-blown sand, and debris, pottery vessels comprising one small table amphora, a locally made bottle, cups and fragmented footed bowls, as well as some large pieces of animal bone, were recorded. In the north wing, at a depth of about $0.70 \mathrm{~m}$ below the original ground surface, some fragments of mud- and red bricks appeared. Traces of blue paint on white plaster were discernible on some of the red bricks, while others had been specially shaped with rounded ends or angular cuts to fulfil certain structural needs (Juszczyk 2011, 120-123, Pls. 17-19). At the bottom of the shaft three side burial chambers were noted in the south, west, and north sides. Mainly mud bricks were used to build the chamber blocking walls, but some red bricks were also noted. Chamber 1, the main burial niche, was cut into the south wall of the shaft. It has a maximum length of $5.25 \mathrm{~m}$ and measures $1.95 \mathrm{~m}$ in width and $1 \mathrm{~m}$ in height at the entrance. The chamber was sealed by a mud-brick wall $0.95 \mathrm{~m}$ high, which appeared to have been built in successive phases in unbonded sections. Although it consisted of courses of rowlocks and stretchers similar to those noted in other graves, it exhibited a total lack of building skills [Fig. 3.67 top].

Robbers had destroyed the east side of the blocking wall. As a result, the chamber was badly damaged, its roof had partially collapsed, and it was found filled with debris. On the east side of the chamber a concentration of pot- 
shaft

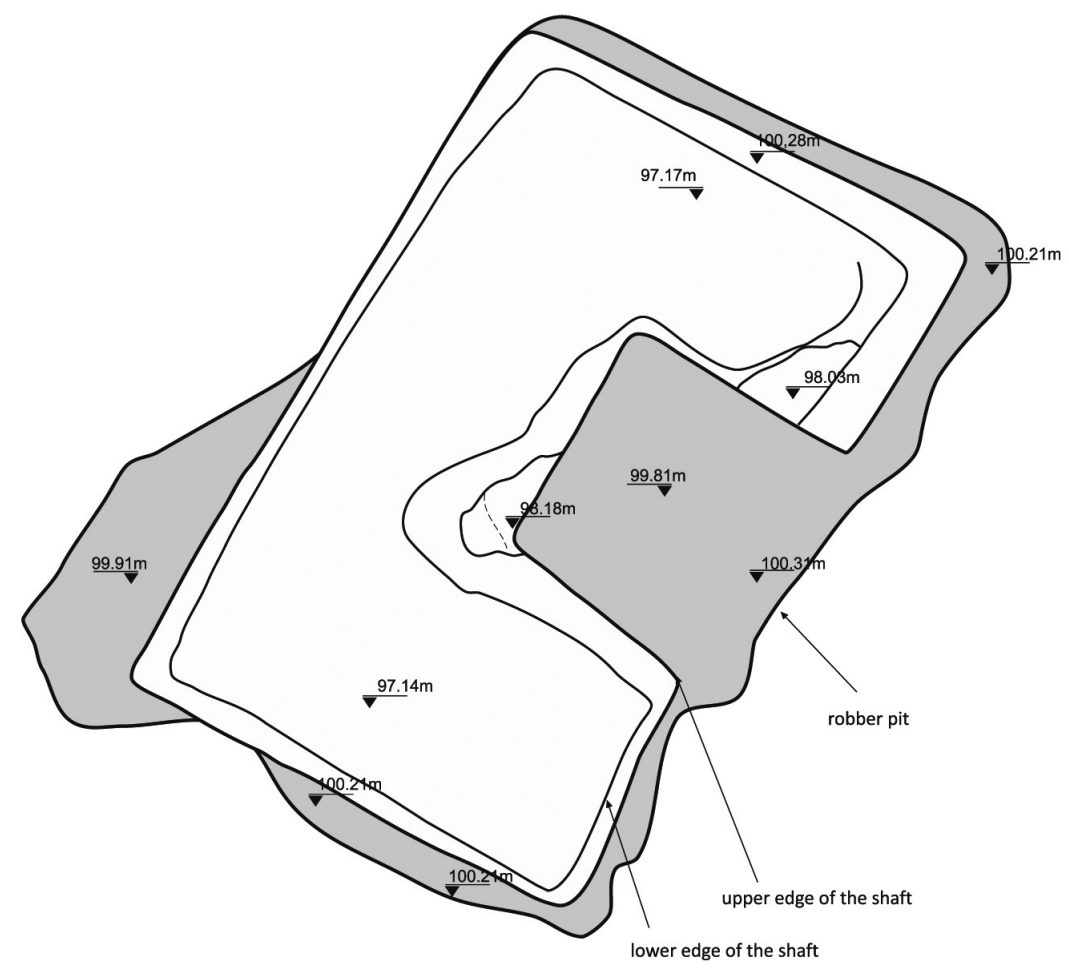

bottom of the shaft and burial chambers

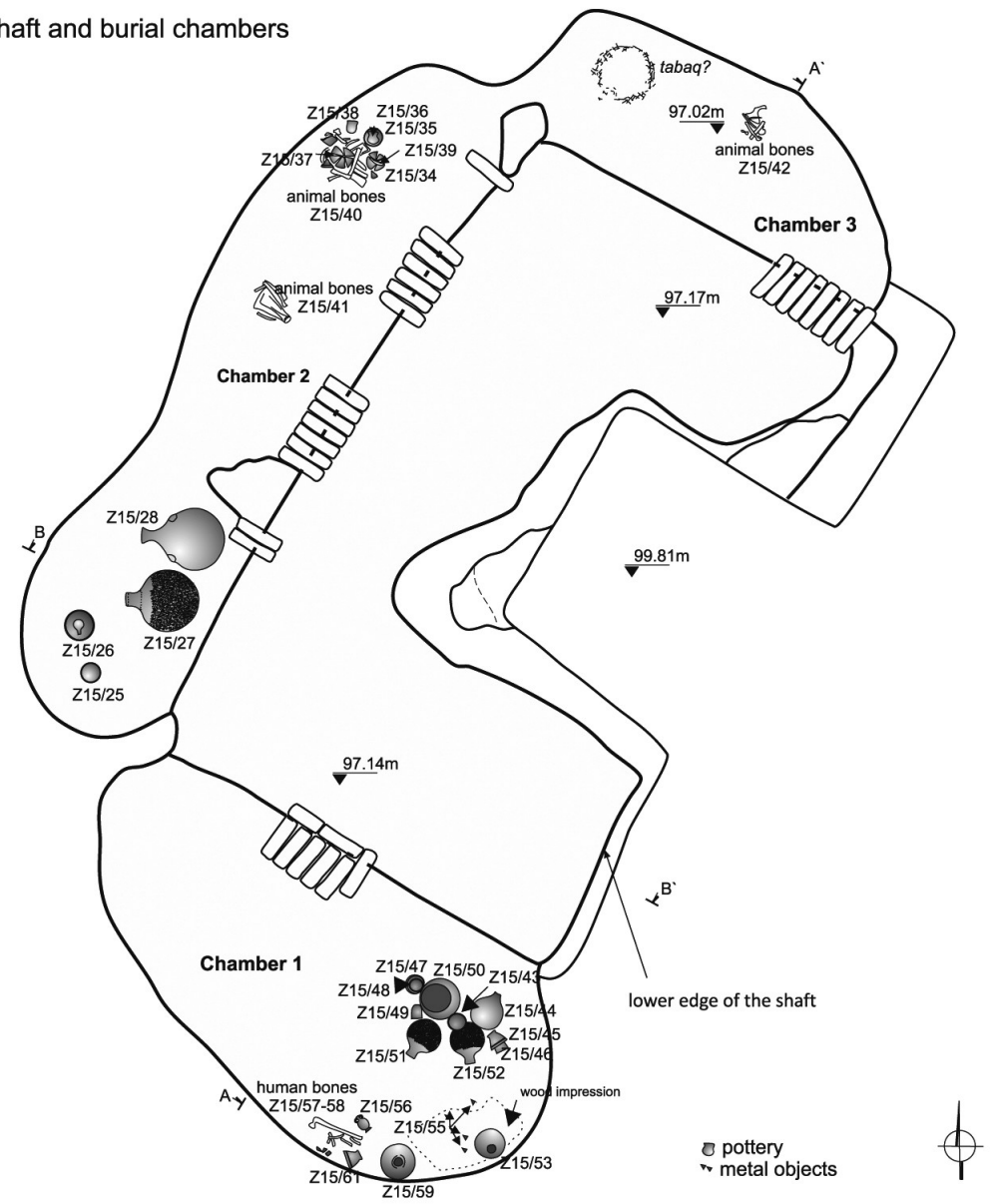

9

FIGURE 3.65A Tumulus 15, ground plan

DRAWN BY E. SKOWROŃSKA, A. GŁĄB, DIGITISED BY U. IWASZCZUK, E. CZYŻEWSKAZALEWSKA 

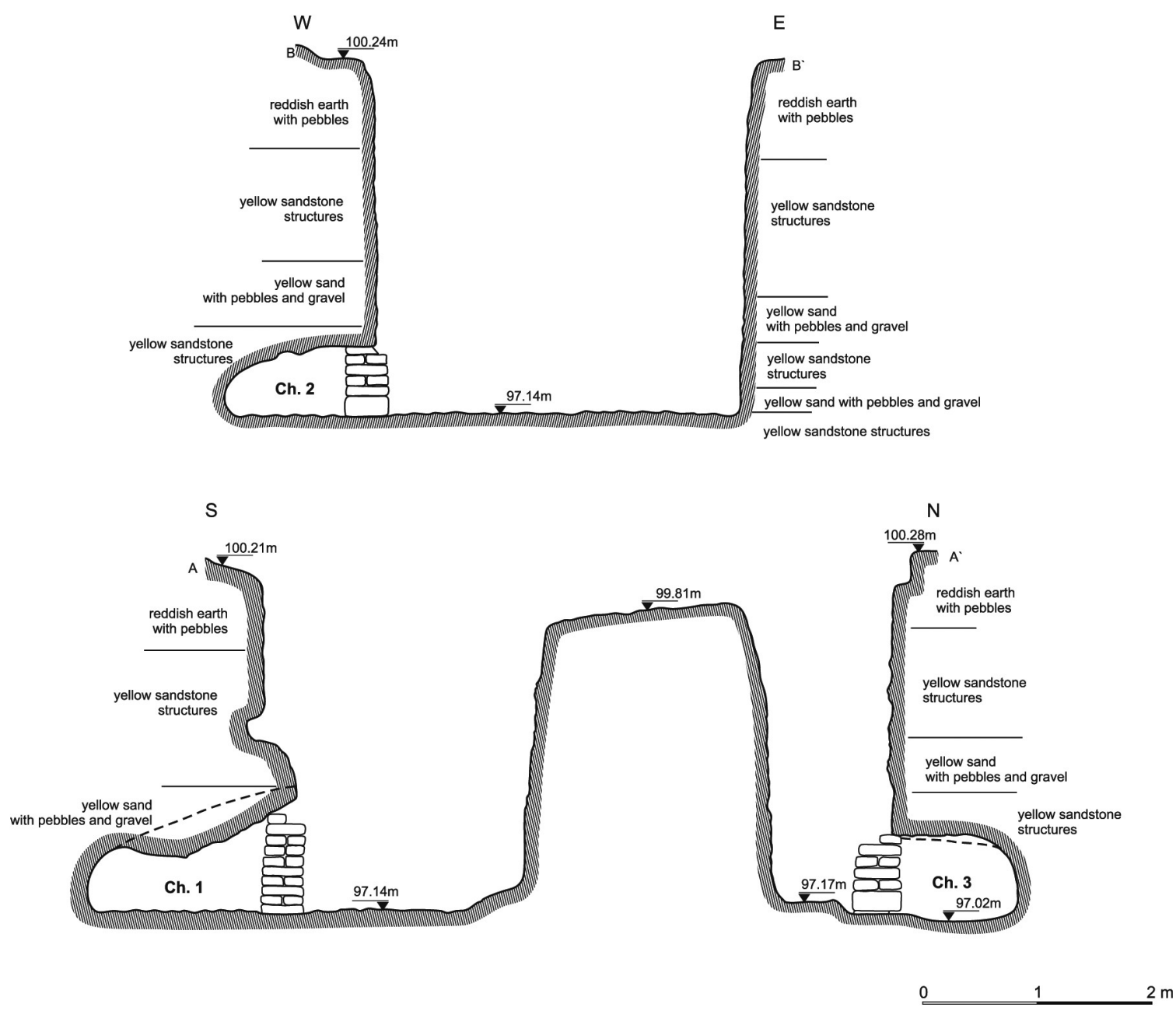

FIGURE 3.65B Tumulus 15 , cross-sections of the tumulus DRAWN BY E. SKOWROŃSKA, A. GŁĄB, DIGITISED BY U. IWASZCZUK, E. CZYŻEWSKAZALEWSKA

tery vessels was recorded, consisting of five beer jars, four hemispherical bowls, one finely made footed bowl, one neckless storage pot with a rounded body, three cups, and a small table amphora. Jumbled fragments of human and animal bones were also found in the same area [Fig. 3.68]. Other finds recorded in this eastern part of the chamber included fragments of iron nails and traces of decayed organic material (wood) forming a rectangle on the floor of the chamber-remnants of what may have been a wooden bier. The discovery of these three elements in one place indicates that the body had been placed on a bier located on the east side of the burial chamber, a practice which has been noted in several burials at El-Zuma. Chamber 2 adjoins chamber 1 from the west, but they are not interconnected. The blocking built along the west wall was about $0.60 \mathrm{~m}$ high and reinforced from the outside by an additional layer of bricks [Fig. 3.67 middle]. The removal of these bricks revealed that a 5.40-m-long chamber had been cut into the west wall. It had two entrances separated by a pillar hewn from the bedrock. The south side is about $1.10 \mathrm{~m}$ wide, while the north side is about $2.70 \mathrm{~m}$ wide. The narrowest part is in the middle of the chamber, between the pillar and the inner (west) edge of the niche, which does not exceed $0.70 \mathrm{~m}$. One chamber with two entrances separated by a rock-hewn rather than a constructed pillar is a rare but nonetheless quite well-known practice of this period, noted not only in the Dongola Reach but also in other regions, such as the Atbara-Berber district. The nearest analogies for this type of chamber were excavated in Berber by Lenoble (1991, 167-169, Figs. 1, 2) and at Akad near Atbara by Mohamed Faroug (Faroug and Tsakos 2005, 62-71, Fig. 2; Faroug, Saeed, and Tsakos 2007, 98106, Figs. 1, 2). At the El-Zuma cemetery this is the first recorded instance of such a feature in a type II burial. A similar example was noted in Tumulus 87 at Tanqasi, on the opposite bank of the Nile, excavated by Godlewski in 


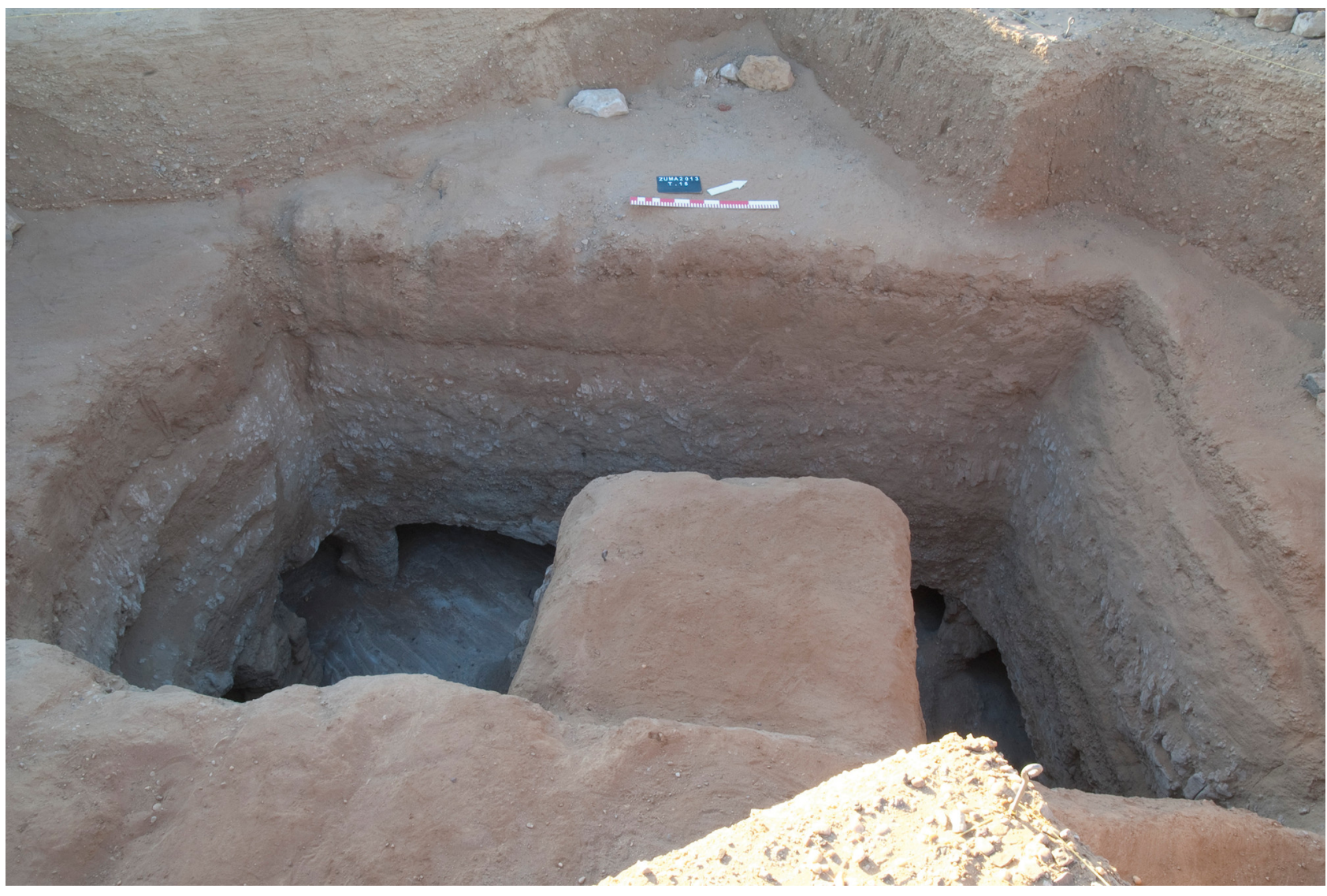

FIGURE 3.66 Tumulus 15, view of the U-shaped shaft, looking west PHOTO BY R. MAHLER

2006. The only difference between the two burials is that the chamber in El-Zuma is a secondary one located on the west side, while at Tanqasi the double entrance led to the main burial chamber, cut into the south wall of the shaft (Godlewski 2008, 469-476). Although the chamber was found untouched, nature had contrived to destroy parts of the roof, from which some blocks had fallen onto the grave offerings [Fig. 3.69].

Beneath the fallen debris, two beer jars, one bowl, and one jug were uncovered in situ at the south side of the chamber. In the middle of the chamber, a pile of animal bones was noted. At the north side three bowls and two cups were recorded along with some animal bones. Chamber 3 , which occupies the north side of the shaft, is interconnected with chamber 2 by a small hole about $0.40 \mathrm{~m}$ in height and $0.25 \mathrm{~m}$ in width, dug out at floor level through the wall that separates the two chambers. This was the first recorded instance of such a practice at the El-Zuma burial ground (the interconnection of all burial niches in a grave, in particular the main burial chamber and the one directly adjacent to it, is a common practice). The chamber was sealed by a mud-brick wall built in analogous fashion to the walls of the other two chambers [Fig. 3.67 bot- tom]. The $0.70-\mathrm{m}$-high blocking was found intact, as was the chamber. This is comparable, for example, to the situation in T.2, where both chambers 2 and 3 were untouched by the tomb robbers (Mahmoud El-Tayeb 2007, 71-85). The maximum length of the chamber reaches $2.70 \mathrm{~m}$, while its width is only $1.05 \mathrm{~m}$, with a height of about $0.75 \mathrm{~m}$. The modest offerings inside the chamber comprised some fragments of animal bones deposited on the east side, while on the opposite side there were traces of what could have been a decayed organic object, probably a basket containing an unidentified material. For more information see Mahmoud El-Tayeb, Skowrońska, and Czyżewska 2016, $114-117$.

\subsection{Tumulus 23}

Tumulus 23 lies about $100 \mathrm{~m}$ north of T.2. It was classified as a type II superstructure with a flat top constructed of earth and gravel, the sides revetted with rough stones [Fig. 3.70]. Its external diameter reached $20 \mathrm{~m}$ and the maximum preserved height did not exceed $0.80 \mathrm{~m}$. The large depression in the middle of the mound was taken as evidence of plundering, and this assumption was corroborated when a robber pit was revealed in the northern 

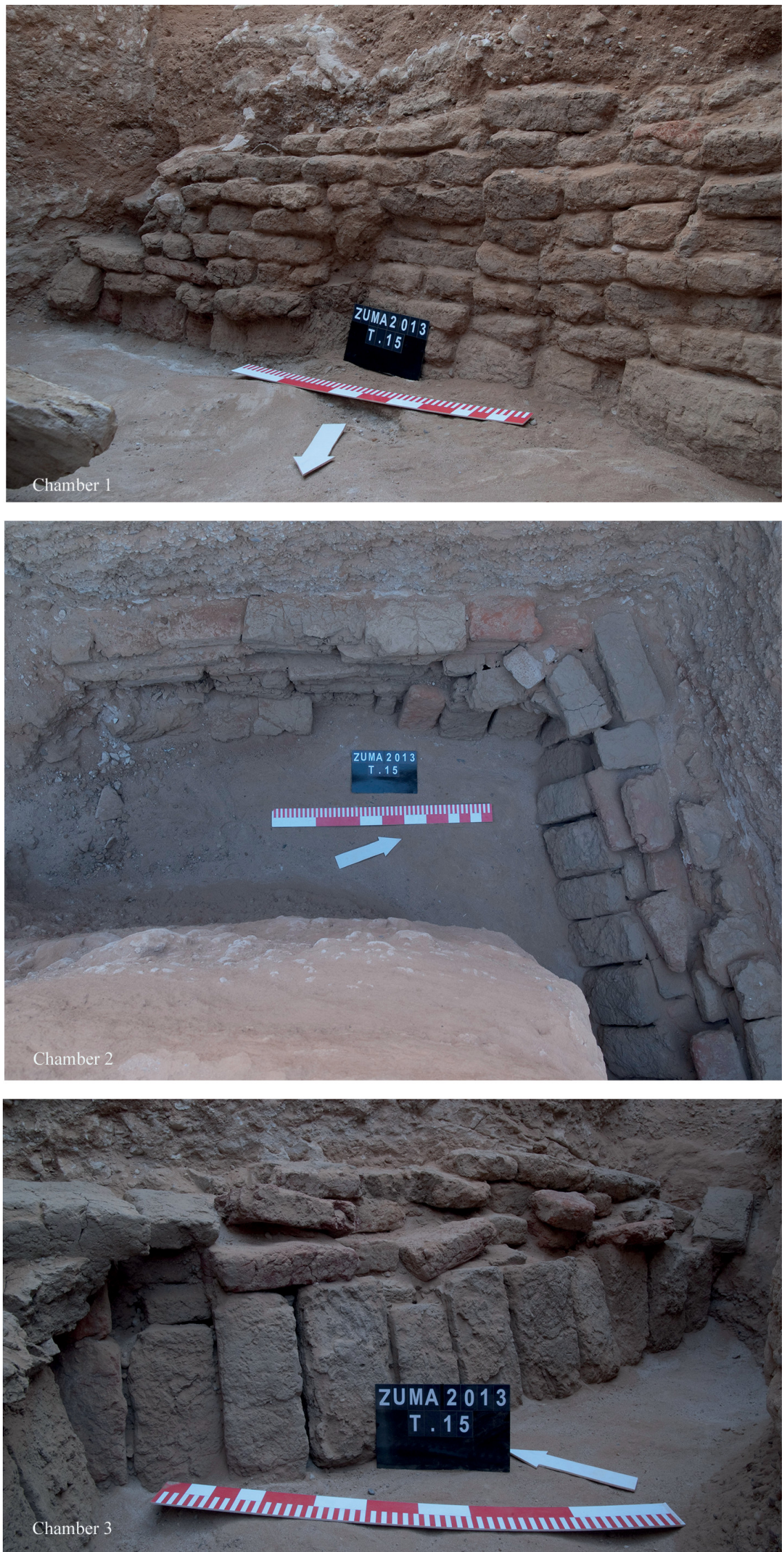

FIGURE 3.67 Tumulus 15, view of the blocking wall of chamber 1 (top), chamber 2 (middle) and chamber 3 (bottom)

PHOTOS BY E. SKOWROŃSKA 


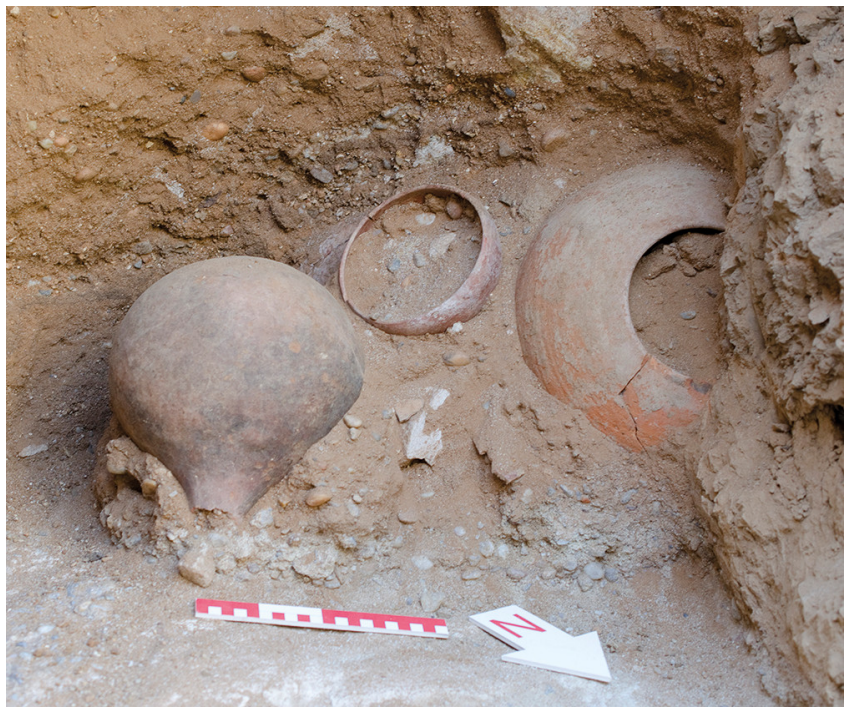

FIGURE 3.68

Tumulus 15 , chamber 1 , view of the grave offerings on its east side PHOTO BY E. SKOWROŃSKA

trench wall once excavation began. The unearthed shaft appeared to be of the same type as the one in T.2. While sharing a similar plan [Fig. 3.71], orientation and dimensions, this tumulus differed from T.15 in that it had only two side chambers cut at the bottom of the shaft [Fig. 3.72].

The main chamber (Ch. 1), measuring $2.00 \mathrm{~m} \times 1.50 \mathrm{~m}$ $\times 0.60 \mathrm{~m}$, was cut into the south wall of the shaft, and the other chamber was cut into the west wall. Chamber 1, presumably containing the main burial, had been plundered; the mud-brick blocking had been removed and the contents left upturned inside. Excavation was hindered by a hard and compact reddish soil that had filled the chamber at a later date. Only one human leg bone was discovered amongst some disturbed and partly smashed pottery vessels (18 in all), comprising cups, bowls, beer jars, a table amphora, and a pot stand [Fig. 3.73 top]. Characteristically, most of the beer jars were of medium size. The number and diversity of vessel forms indicates that this burial chamber had been richly furnished. Although we cannot be sure what the full set of grave furnishings originally consisted of, the absence of weapons, personal adornments, and metal objects should be noted. The western chamber measured $3.00 \mathrm{~m}$ in length, $1.5 \mathrm{om}$ in width and not more than $0.50 \mathrm{~m}$ in height. The sandstone blocks sealing the chamber were intact except for a small hole at the southern end, through which the robbers apparently surveyed the chamber in search of the main burial, where more precious goods were to be expected. Some of the vessels were broken, others apparently moved from their original position. Upon excavation, chamber 2 [Fig. 3.73 bottom]

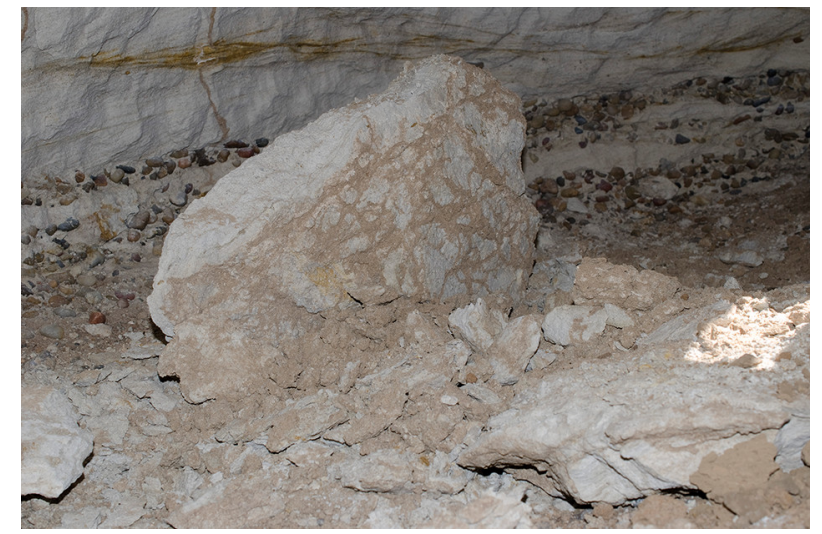

FIGURE 3.69

Tumulus 15, view of the collapsed ceiling of the chamber PHOTO BY E. SKOWROŃSKA

proved to be a repository for grave goods alone. The offerings consisted of vessels of various shapes, mainly cups and bowls, and animal bones, the arrangement of these items following that already recorded in T.2. Eleven vessels were assembled in one group and four vessels in another group, both associated with animal bones. The third group consisted of three vessels. Another three vessels, making up a total of 21, were found broken and displaced. For more information see Mahmoud El-Tayeb 2005, 394-397; Klimaszewska-Drabot and Mahmoud ElTayeb 2014.

\subsection{Tumulus 24}

Tumulus 24 lies on the north-east side of the cemetery, between T.15 to the north and T.19 and T.2O slightly to the west. The tomb has a rounded superstructure, built from a mixture of sandy earth and gravel. It has a diameter of about $23.00-24.65 \mathrm{~m}$. The top centre features a distinct circular depression, which undoubtedly attests to earlier plundering activity. The south-east side of the mound is markedly higher than the rest. Thus, the preserved height on the south side of the mound is $1.10 \mathrm{~m}$, while on the east it reaches 1.60 m [Fig. 3.74].

The fact that the mound is higher on one side seems to be an intentional feature rather than an inadvertent result of robber activity. Three other instances of superstructures which are evidently higher on one side have been noted at the El-Zuma cemetery, namely T.11, which lies on the north-west side of the cemetery, and T.14 and T.15, to the north-east of T.11. Based on these three tumuli, one would assume that the superstructures were built 


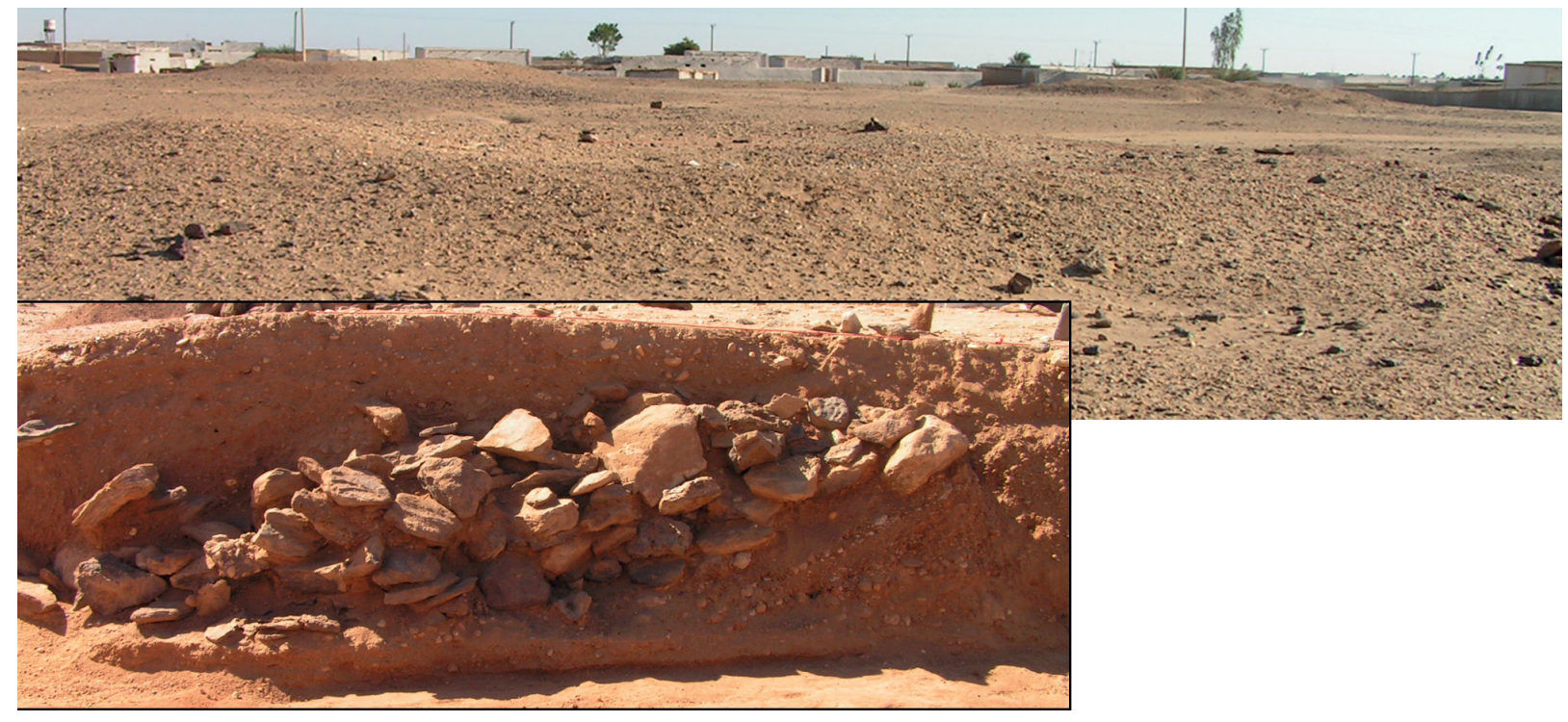

FIGURE 3.70 Tumulus 23, view from the superstructure of the tumulus and west section of the test trench, showing the stone slabs that covered the original mound, facing west РнОто вY А. ОВєUSKI

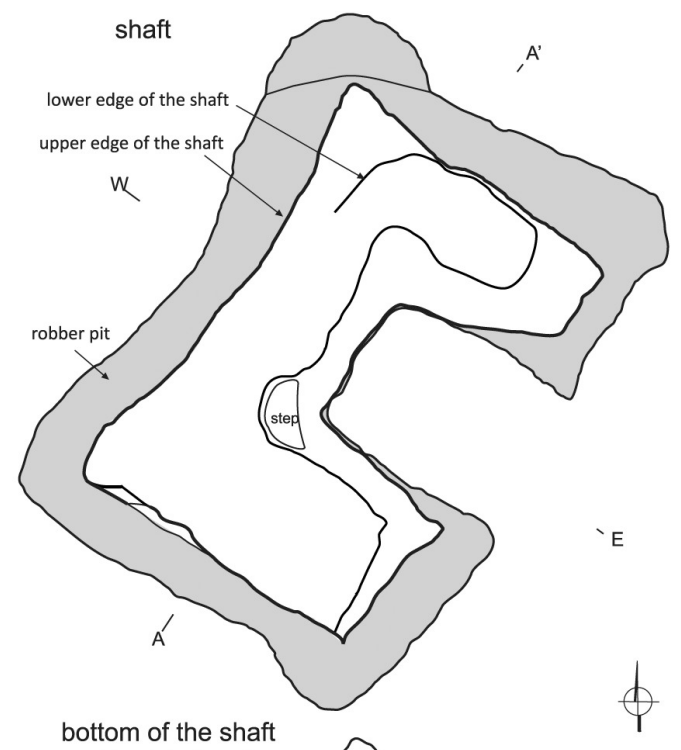

W

E
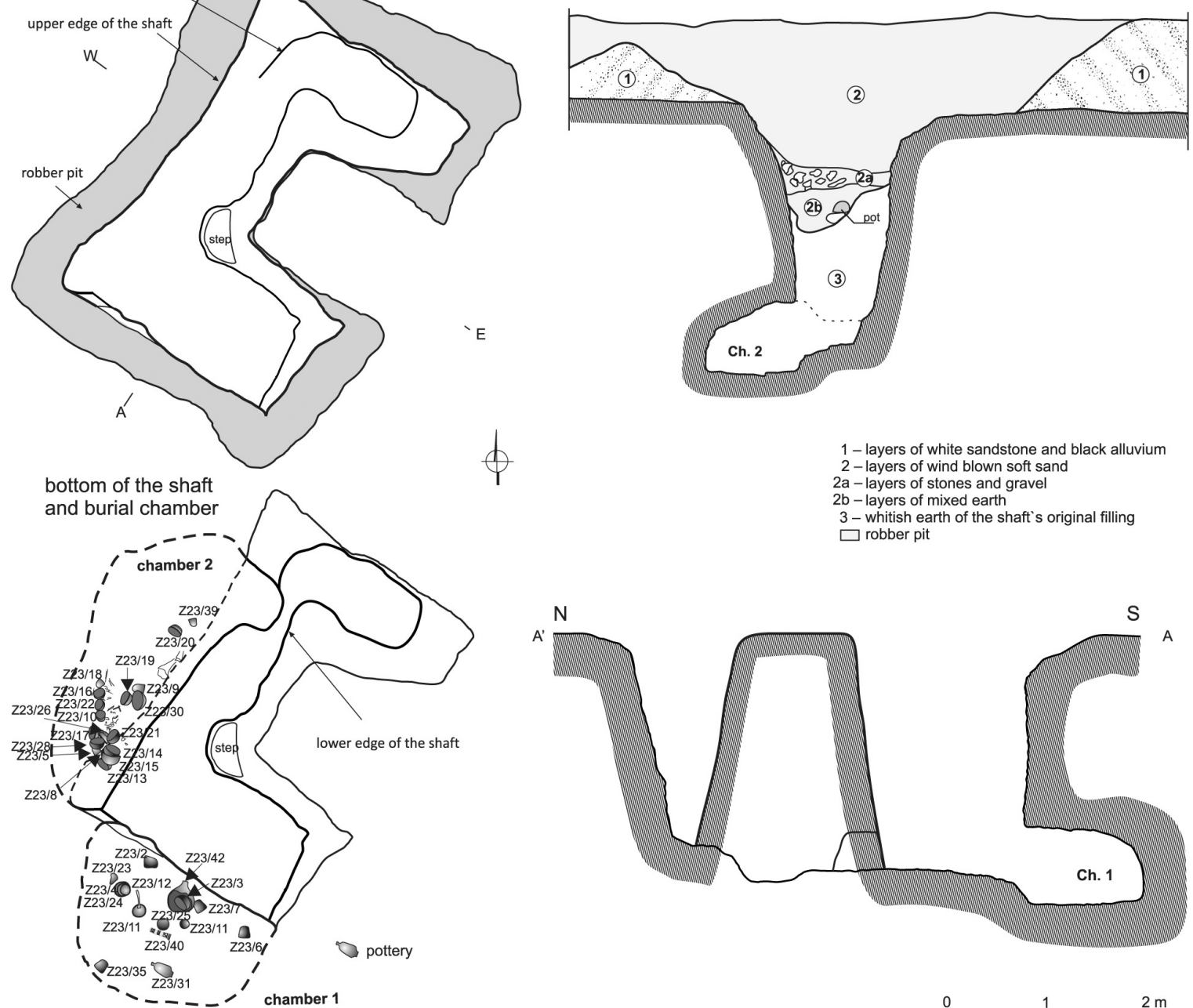

1 - layers of white sandstone and black alluvium 2 -layers of wind blown soft sand

2a - layers of stones and grave

3 - whitish earth of the shaft's original filling

N

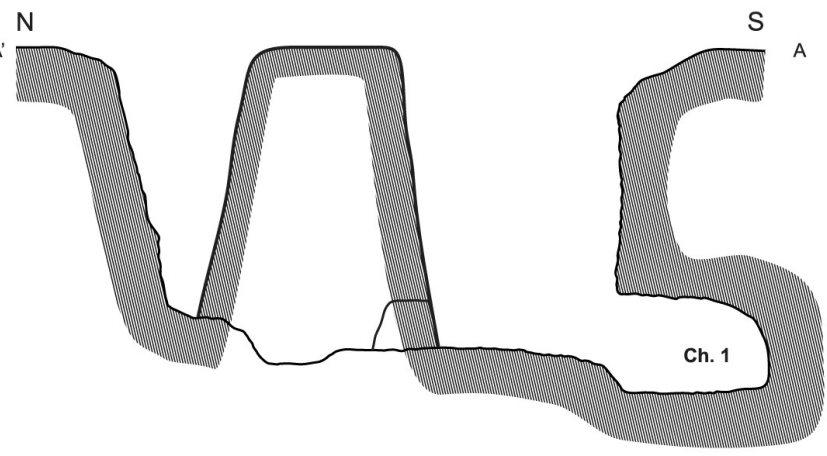

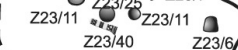

Z23/35 Z23/31, ', chamber

FIGURE 3.71 Tumulus 23, general plan and cross-sections

DRAWN BY A. OBEUSKI, U. WICENCIAK, DIGITISED BY M. PUSZKARSKI 


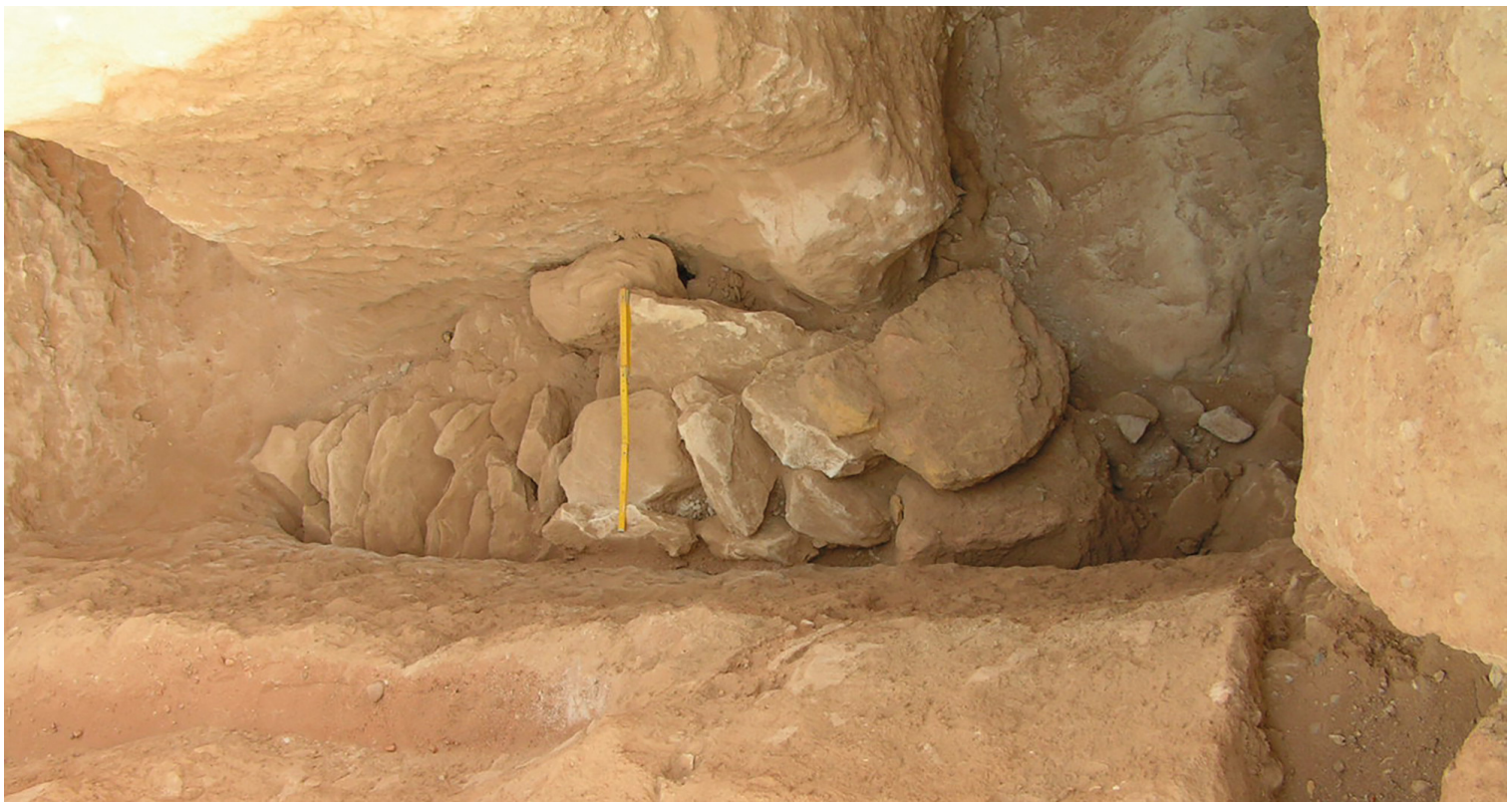

FIGURE 3.72 Tumulus 23, view of the stone slabs blocking chamber 2 PHOTO BY А. OВєUSKI
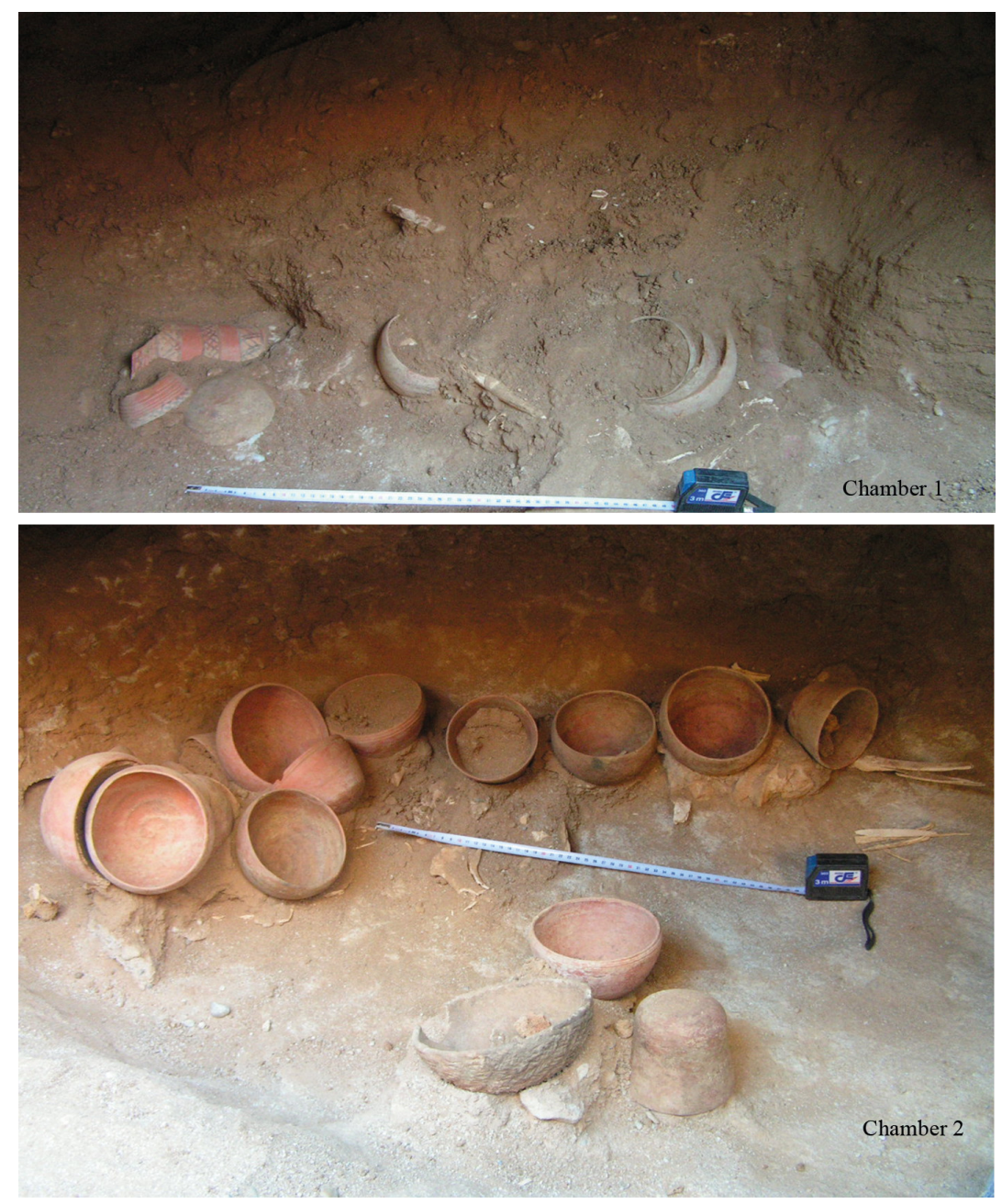

FIGURE 3.73 Tumulus 23, view of the grave goods in chamber 1, facing west (top) and chamber 2, facing west (bottom)

PHOTOS BY H. KOŹMIŃSKA-SOWA 


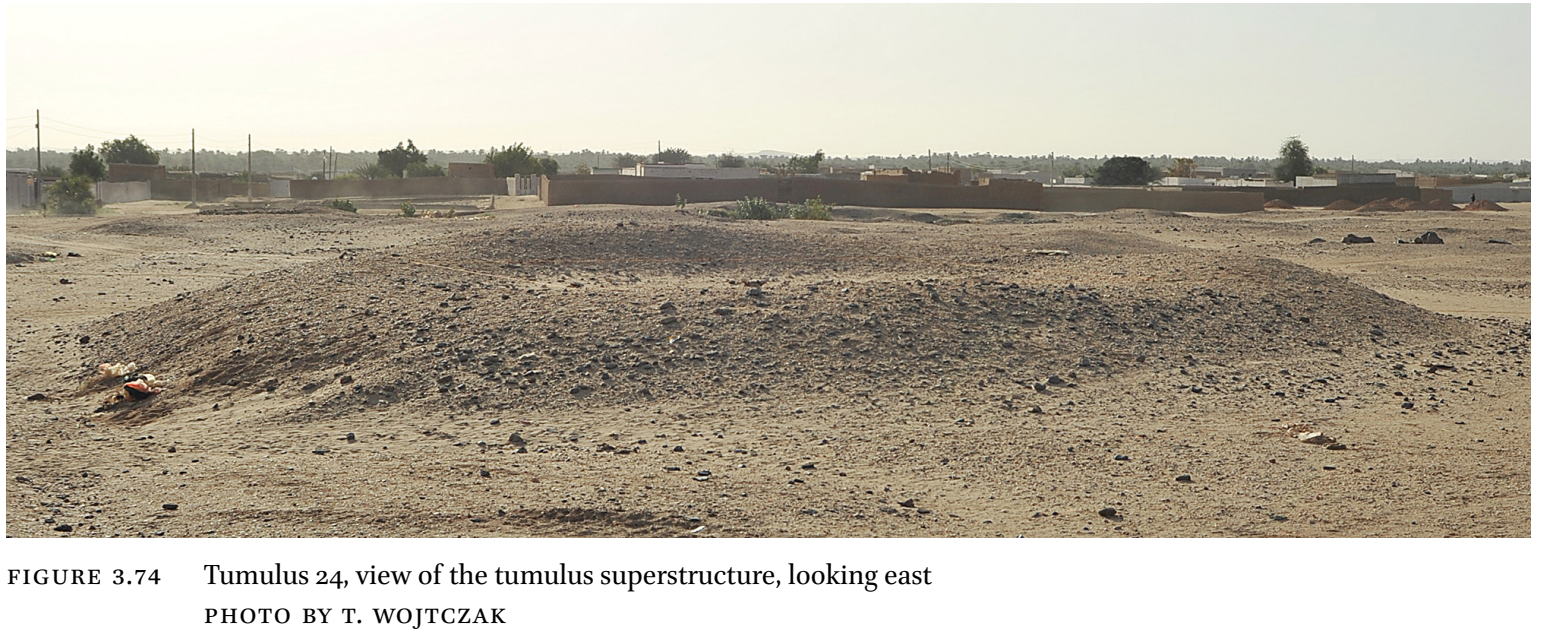

higher on one side deliberately rather than accidentally. The closest analogy for this type of burial comes from the Fourth Nile Cataract region, where examples were recorded at two cemetery sites discovered by the Gdańsk archaeological mission. The first lies near Elashameen village (site HP 595). The second cemetery site (HP 610) is located in the vicinity of Hager Zerga village (Kołosowska 2010, 94, Fig. 8).

On the ground surface the shaft presented a simple rectangular outline [Fig. 3.75] measuring $3.5 \mathrm{O} \mathrm{m}$ on the north side, $3.40 \mathrm{~m}$ on the south, $5.30 \mathrm{~m}$ on the east, and $5.05 \mathrm{~m}$ on the west side. A pier with sides measuring about $1.50 \mathrm{~m}(\mathrm{~N})$, $1.50 \mathrm{~m}(\mathrm{~S})$, and $1.6 \mathrm{om}(\mathrm{W})$ was revealed projecting from the east wall, affording the shaft a U-shaped plan. The shaft has a maximum depth of 3.6o m [Fig. 3.76].

At the bottom of the shaft, four burial chambers in an unusual layout were recorded cut into the western, southern, and eastern walls of the shaft, extending into part of the southern side of the pier [see Fig. 3.75]. Chamber 1, usually the main burial niche, was cut into the full length of the southern wall, as was the common practice [Fig. 3.77 bottom]. Yet, in the case of T.24, there is a unique feature in the construction of this niche. The chamber was partially cut into the eastern half of the southern side of the shaft, curving around towards the short east wall and terminating in the southern side of the pier. Thus, the final plan of the chamber resembled a reversed $C$ shape, measuring about $3.20 \mathrm{~m} \mathrm{~N}-\mathrm{S}$, about $2.30 \mathrm{~m} \mathrm{E}-\mathrm{W}$, and $1.40 \mathrm{~m} \mathrm{~N}-\mathrm{S}$. No similar construction of the main burial chamber had previously been noted in this type of tomb. Chamber 2, adjoining chamber 1 from the west side of the same southern wall of the shaft, measures $1.72 \mathrm{~m}$ in length, $1.15 \mathrm{~m}$ in width, and $0.95 \mathrm{~m}$ in height. The two chambers are interconnected through a small hole about $0.15 \mathrm{~m}$ in width, made at floor level. A similar hole of the same width also interconnects chambers 2 and 3 .
There are two more side chambers: chamber 3, measuring $1.70 \mathrm{~m}$ in length, $0.70 \mathrm{~m}$ in width, and $0.90 \mathrm{~m}$ in height, and chamber 4 , measuring $3.10 \mathrm{~m}$ in length by $1.10 \mathrm{~m}$ in maximum width. Both are hewn into the long west wall of the shaft, but because of concerns about the instability of the chambers' ceilings no attempts were made to verify if there is a connecting hole between the neighbouring chambers 3 and 4 .

The burial chambers were sealed with mud bricks bonded with sandy lime mortar [Fig. 3.78]. The blocking wall of the secondary chamber 3 was the only one that had not been damaged by grave robbers. It is about $1.15 \mathrm{~m}$ long and $0.70 \mathrm{~m}$ high. The blocking wall was built on a foundation of mud bricks in which the headers were set on edge, upon which four courses of alternating headers and stretchers were laid. The blocking wall of chamber 1 had been disturbed on the north-east side of the southern section as well as its eastward extension and the southern side of the pier. Excavation of the four burial chambers revealed that apart from chamber 3 , the other three niches had been heavily looted and disturbed. When clearing the shaft of debris and earth fill, a wall about $1.30 \mathrm{~m}$ high and $1.05 \mathrm{~m}$ wide, roughly built of mud bricks and sandstone chunks, was found blocking the northern wing of the shaft [Fig. 3.79]. A large heap of mudbrick debris and sand was accumulated behind the east side of the wall. Most probably this wall had been erected by the grave robbers to prevent the fallen material from pouring into the nearest chambers during the robbery.

Although three of the four chambers had been looted in the past, nonetheless, what was left behind can also throw some light on the funerary traditions at this burial ground. It is obvious that the construction of chamber 1 is far removed from the known practice of burial recorded in tumuli designated as types I and II at El-Zuma. Moreover, 


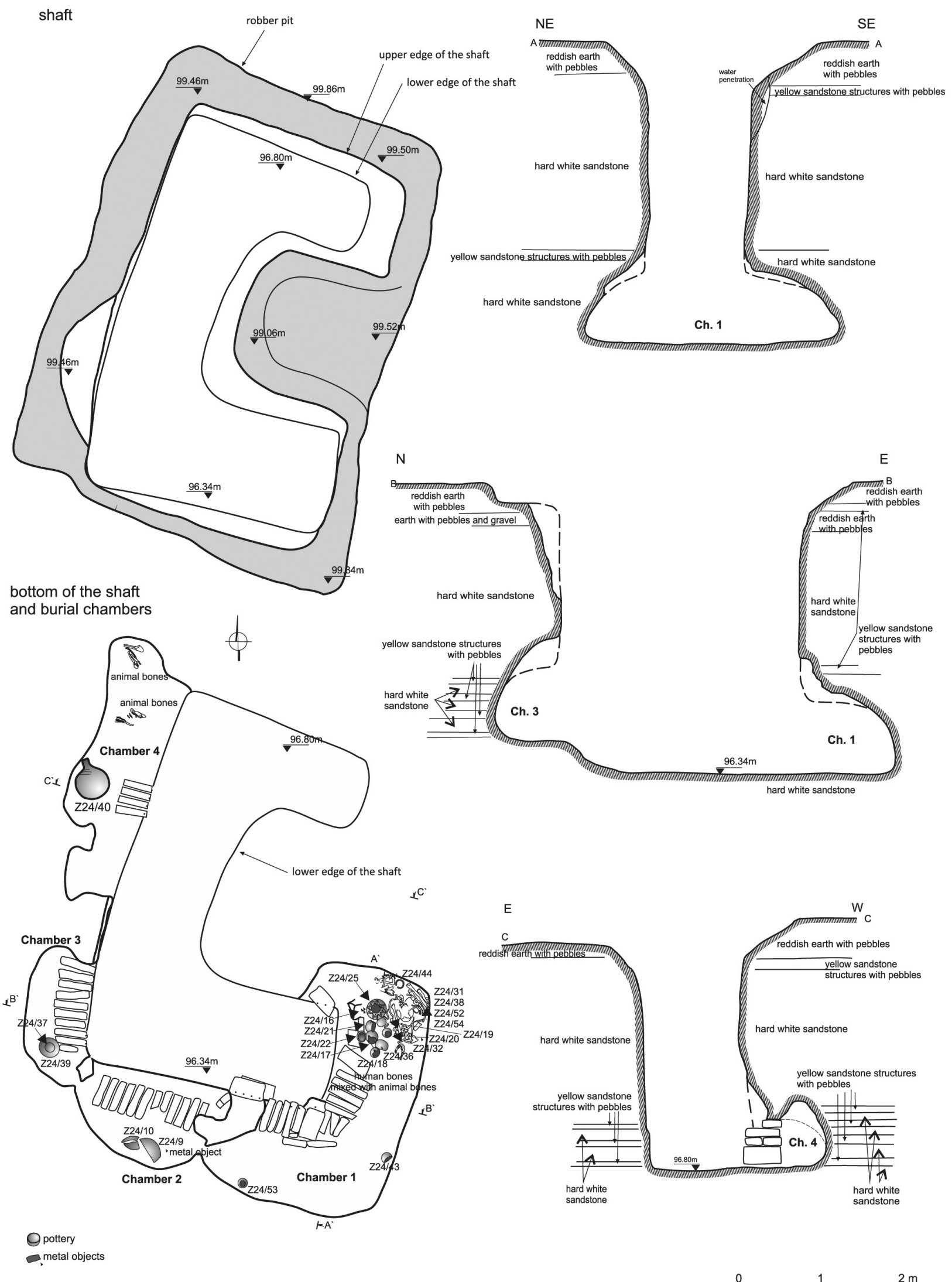

FIGURE 3.75 Tumulus 24, general plan and cross-sections

DRAWN BY E. SKOWROŃSKA, J. BROCHOCKI, DIGITISED BY J. BROCHOCKI,

E. CZYŻEWSKA-ZALEWSKA 


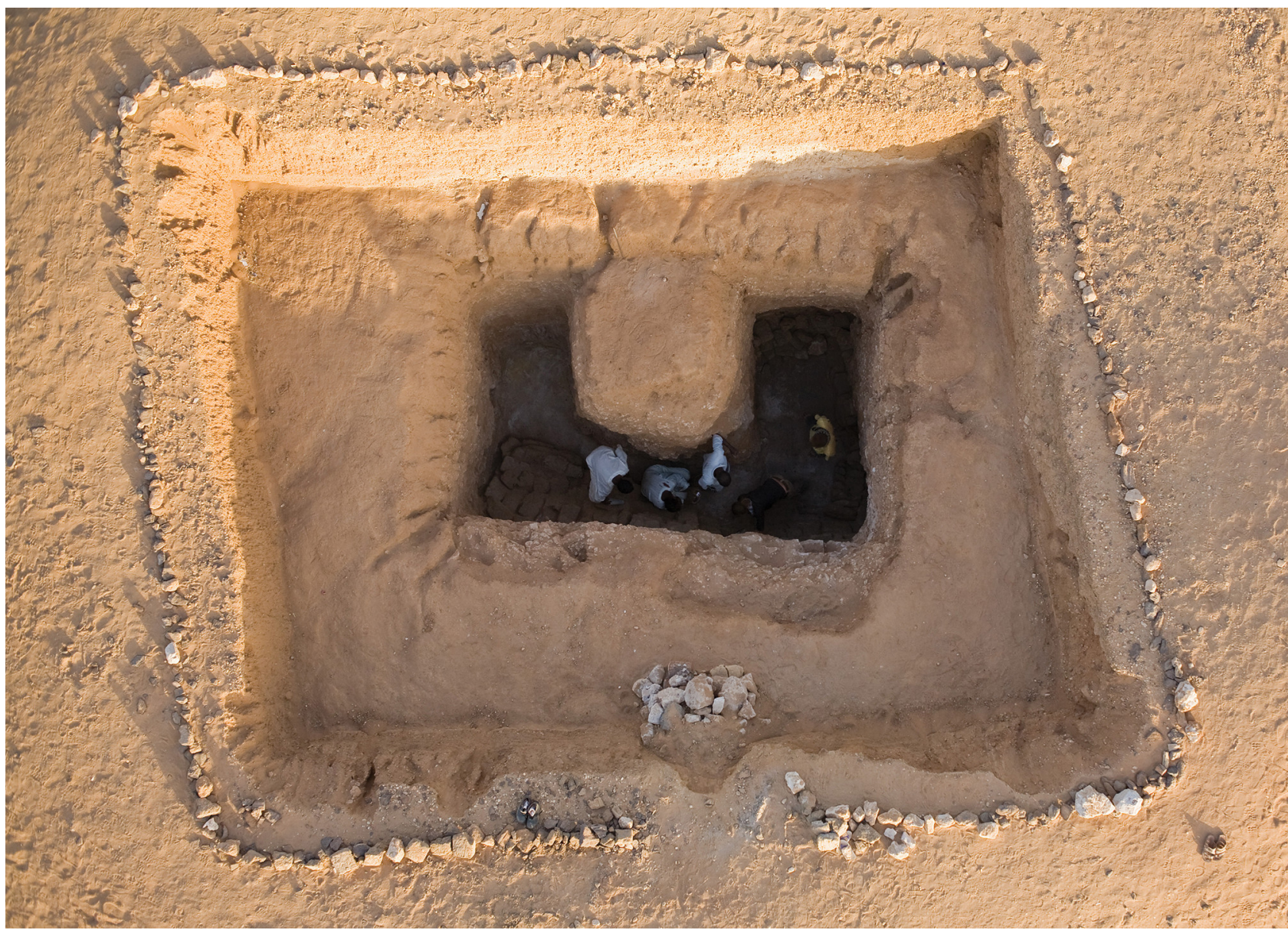

FIGURE 3.76 Tumulus 24, aerial view of the shaft

PHOTO BY M. BOGACKI

excavation of T.24 revealed that even the last resting place of the grave's occupant was completely different from the well-established inhumation customs of the period. The north-east corner of chamber 1 was found to contain a mixed-up pile of disarticulated human and animal bones, in addition to iron nails, a knife, decayed wood fragments, unidentified metal objects, metal fittings, faience and quartz beads, plus a copper-alloy ferrule, which might have been part of a decorative object [see Fig. 3.77 top left]. The human long bones, skull, iron nails, and traces of decayed wood in this pile indicate that the body might have been placed on a wooden frame on the east side of the main chamber (Ch. 1). However, the limited space available in the central eastern part of the niche suggests that the body was laid in contracted position, with head due north, facing west. Alternatively, another possibility is that the inhumation was carried out according to the wellknown practice noted in the southern main chamber of other type II tumuli, where the body was laid in contracted position, head to the east, facing north. Yet, careful examination of the pushed aside human bones and the other material shows that their arrangement was not the work of grave robbers, who usually left the plundered burial in a great state of disorder. One issue that remains unclear is whether or not this part of the chamber had been emptied intentionally to make way for another interment. The nearest parallel for this is burial 4 recorded at the cemetery in Hammur-Abbassiya (Mahmoud El-Tayeb 2003, 130-139, Figs. 8, 20, 21).

In the same north-east corner of chamber 1 , in front of the abovementioned pile, eight complete vessels were noted. They consist of three handmade cooking pots, one big decorated spouted bowl, two small bowls, and two cups [see Fig. 3.77 top right]. Meanwhile, the southern part of chamber 1 yielded two small vessels (a wheelmade red slipped bowl and a red cup) in addition to some iron nails, metal fittings, beads, and scattered pieces of animal bone. Chamber 2 appeared to have been thoroughly plundered. It was found filled with red sand that concealed some beer jar sherds distributed across several layers. In contrast, chamber 3 , which had not been ransacked, nonetheless appeared to contain only one beer 

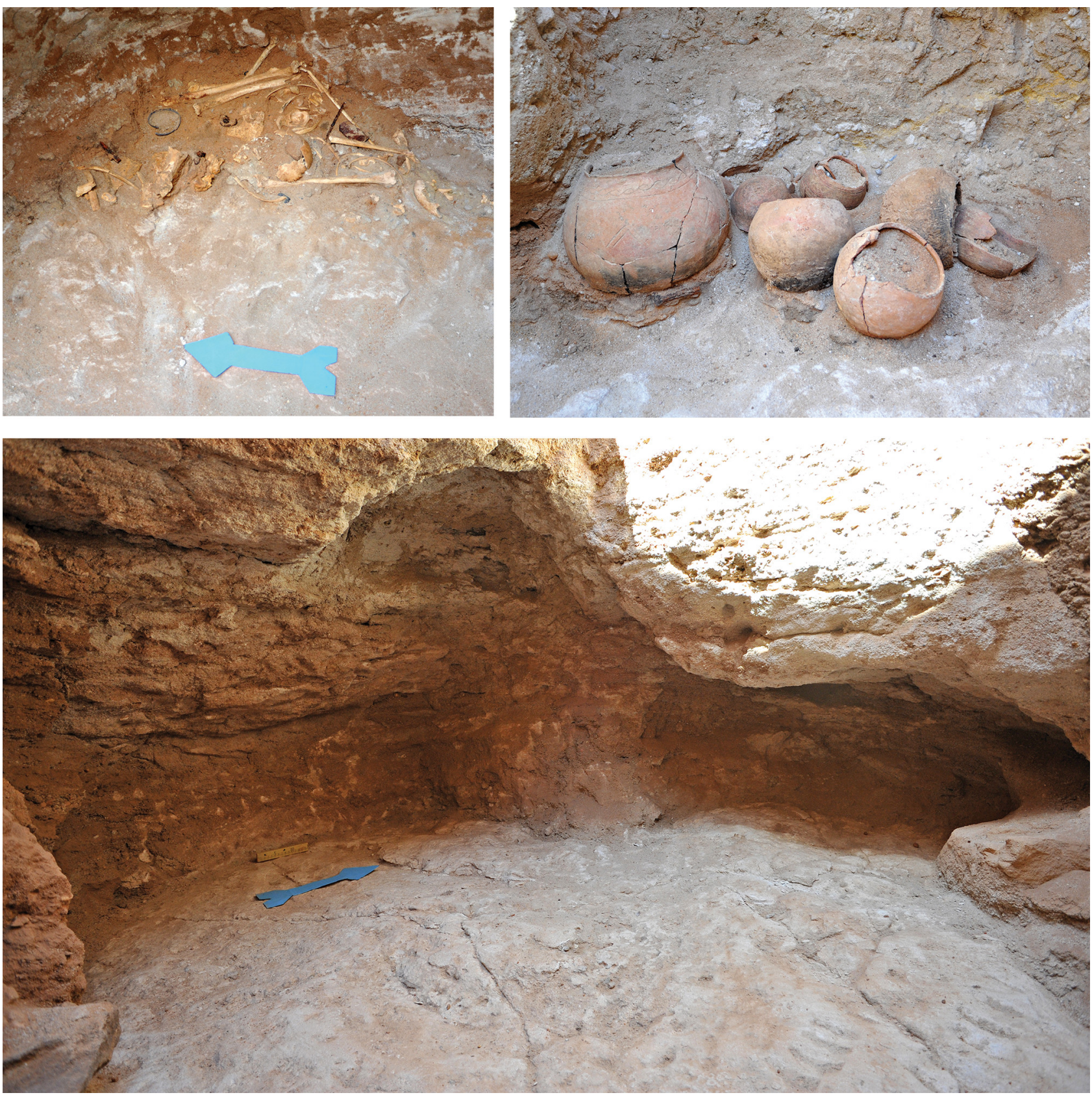

FIGURE 3.77 Tumulus 24, view of the piled-up bones and mixed material (top left) and pottery vessel at the north-east side of chamber 1 (top right); view of chamber 1 with the eastern annexe (bottom)

PHOTOS BY E. SKOWROŃSKA

jar with a wheel-made cup placed upside down over its rim [see Fig. 3.8o top]. This jar is decorated with a matimpressed pattern and a red slipped stripe on its shoulder. The third target for the robbers was chamber 4 , in which a heap of cattle bones was noted at the northern end of the chamber, and a large beer jar was located in the central part, near the demolished blocking wall [see Fig. 3.8o bottom]. Once again, the plundering of these chambers confirms the fact that the grave robbers were well organized, specialized gangs who knew exactly what they were looking for and where to find it, in particular the main chamber where the deceased was buried.

\subsection{Tumulus 25}

The medium-sized tumulus 25 lies at the north-eastern edge of the burial field. It is a relatively low, flat-topped mound about $21.50 \mathrm{~m}$ in diameter with a preserved height not exceeding $1 \mathrm{~m}$ [Fig. 3.81]. The mound consists of earth mixed with gravel. A recognizable depression at the top of the mound is proof of plundering. The burial shaft 


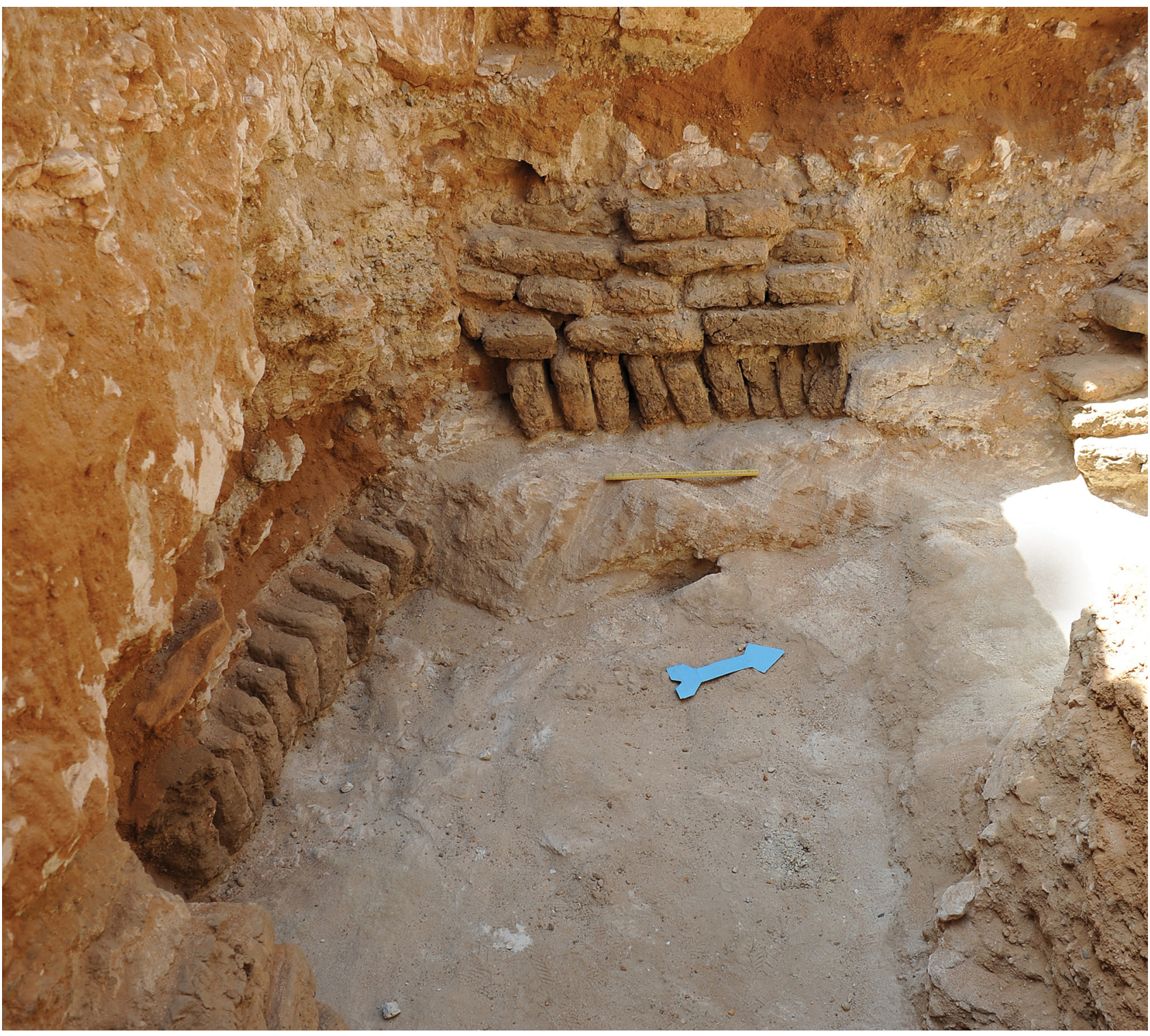

FIGURE 3.78 Tumulus 24, view of the mud-brick blocking walls of chambers 2 and 3 PHOTO BY S. MAILLOT

resembles that of another tumulus (T.5), but the U-shaped plan with equal sides was cut into solid ground [Fig. 3.82]. At the top, the shaft measures $4.34 \mathrm{~m} \times 3.08 \mathrm{~m}$, and at the bottom, about $4.28 \mathrm{~m} \times 3.08 \mathrm{~m}$, with a maximum depth of about $2.38 \mathrm{~m}$ on the northern side and $2.50 \mathrm{~m}$ on the southern side [Fig. 3.83]. At the bottom of the shaft there are three niches hewn into the south and west walls. Chamber 1 , cut into the south wall, measures $2.40 \mathrm{~m} \times 1.20 \mathrm{~m}$ $\times 0.69 \mathrm{~m}$. The other chambers, 2 and 3 , were cut side by side with an arch-like opening in between. The former was $2.35 \mathrm{~m} \times 0.74 \mathrm{~m} \times 0.67 \mathrm{~m}$, the latter $2.32 \mathrm{~m} \times 1.04 \mathrm{~m} \times$ $0.67 \mathrm{~m}$. The three chambers were sealed with walls of large mud bricks $(44 \mathrm{~cm} \times 22 \mathrm{~cm} \times 13 \mathrm{~cm})$, each wall measuring $0.60-0.70 \mathrm{~m}$ in width. That of chambers 2 and 3 was found intact, but the wall blocking the entrance to cham- ber 1 appeared to have been disturbed directly above the east end and partly repaired at a later time. It is worth noting that rare instances of chamber blocking walls being repaired after plundering were observed in the Fourth Cataract region (in the Gdańsk Archaeological Museum Expedition's concession area on the right bank of the Nile).

Excavation of the burial chamber revealed only some disarticulated human bones and the skull of an adult. Finds included two medium-sized beer jars, a broken cup, an iron arrowhead, and a few beads [Fig. 3.84 top]. Chambers 2 and 3 held grave offerings. The first one (Ch. 2 ) contained some animal bones deposited in the centre and at the southern end of the chamber. Eleven pottery vessels were noted here: three handmade bowls, found broken, 


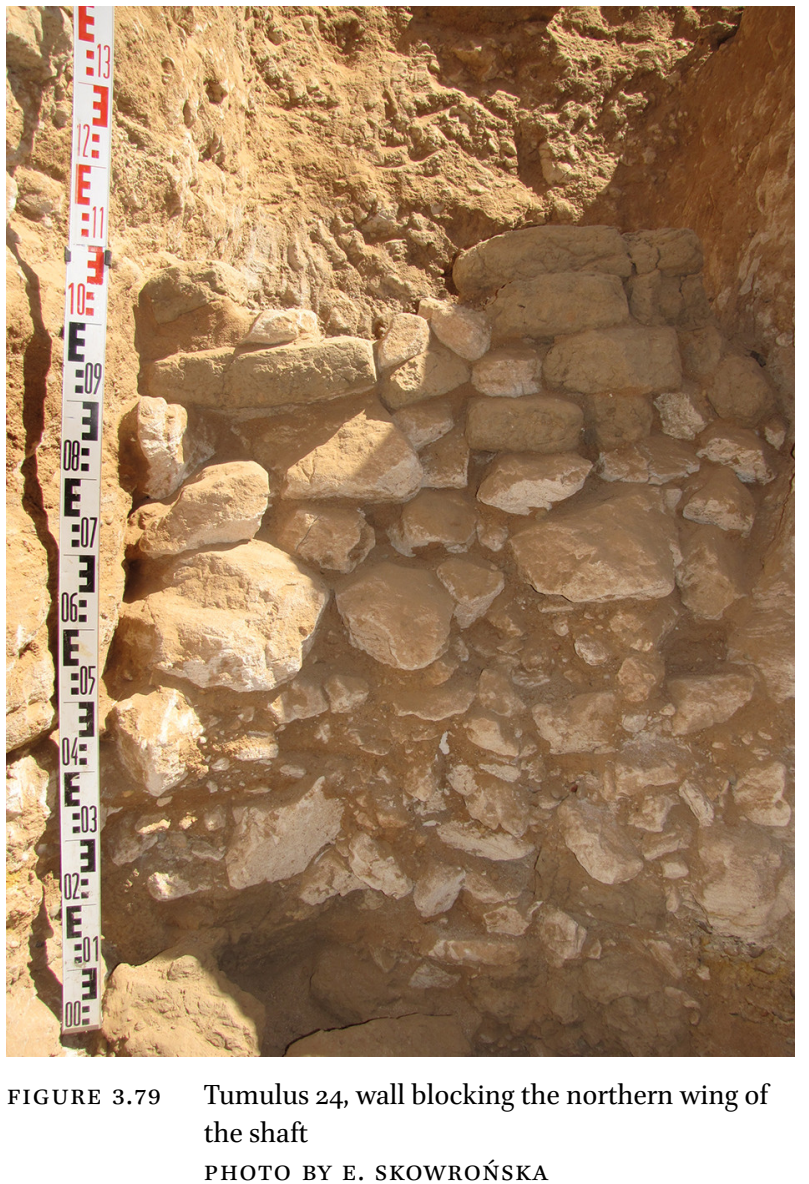

and eight intact wheel-made bowls. In the centre of chamber 3 there was a pile of animal long bones and 16 pottery vessels [Fig. 3.84 bottom]. Eleven of these (six bowls and five cups) were wheel-made. The other five were handmade globular beer jars. Traces of a fire containing small lumps of charcoal were observed on the top of the pier close to its south-eastern end. These remains were found buried beneath an undisturbed part of the original superstructure, so the fire could well have been part of a funeral ceremony, although there can be no certainty of this. Evidence of fires has been observed near the edges of burial shafts from the same (post-Meroitic) period at the ElKadada cemetery in Central Sudan. For more information see Mahmoud El-Tayeb 2010b, 470-474.

\subsection{Tumulus 26}

This tumulus is located on the far north-east fringes of the cemetery. The superstructure is a rounded mound built of earth, gravel, and chunks of rough black stone and sandstone. It has a diameter of $30.80 \mathrm{~m}$ and its maximum preserved height does not exceed $1.40 \mathrm{~m}$ [Fig. 3.85]. This very low height is a result of the severe destruction inflicted on the mound in the past by grave robbers and in recent times by people who have used it as a source of building mater- ial, as clearly evidenced by the top of what remains of the burial superstructure.

On the original ground surface, the shaft presented a simple rectangular outline aligned north-east-southwest, its sides measuring $4.00 \mathrm{~m}(\mathrm{~N}), 6.80 \mathrm{~m}(\mathrm{E}), 3.90 \mathrm{~m}(\mathrm{~S})$ and $6.20 \mathrm{~m}(\mathrm{~W})$. However, a pier projecting from the east wall gave the shaft a U-shaped plan [Fig. 3.86]. At the top of the pier its sides measure $2.40 \mathrm{~m}(\mathrm{~N}), 2.60 \mathrm{~m}(\mathrm{~W})$ and $2.10 \mathrm{~m}(\mathrm{~S})$, while its base is larger. At the bottom of the shaft four side chambers are hewn into three walls of the shaft [Fig. 3.87]. The main chamber (Ch. 1) occupies the southern wall. Chambers 2 and 4 are cut into the west wall, while chamber 3 is cut into the north wall and part of the west wall, forming a roughly L-shaped plan. All four chambers are interconnected by holes made at floor level in their adjoining walls.

The burial chambers were sealed by solid walls built mainly of mud bricks, in some cases capped by a single course of reused red brick.

The blocking wall of the main burial chamber 1 [Fig. 3.88 top] was damaged in the south-west corner of the shaft by robbers and rainwater. These two destructive factors in combination with the weak geological makeup of this part of the cemetery, comprising soft sandstone and 

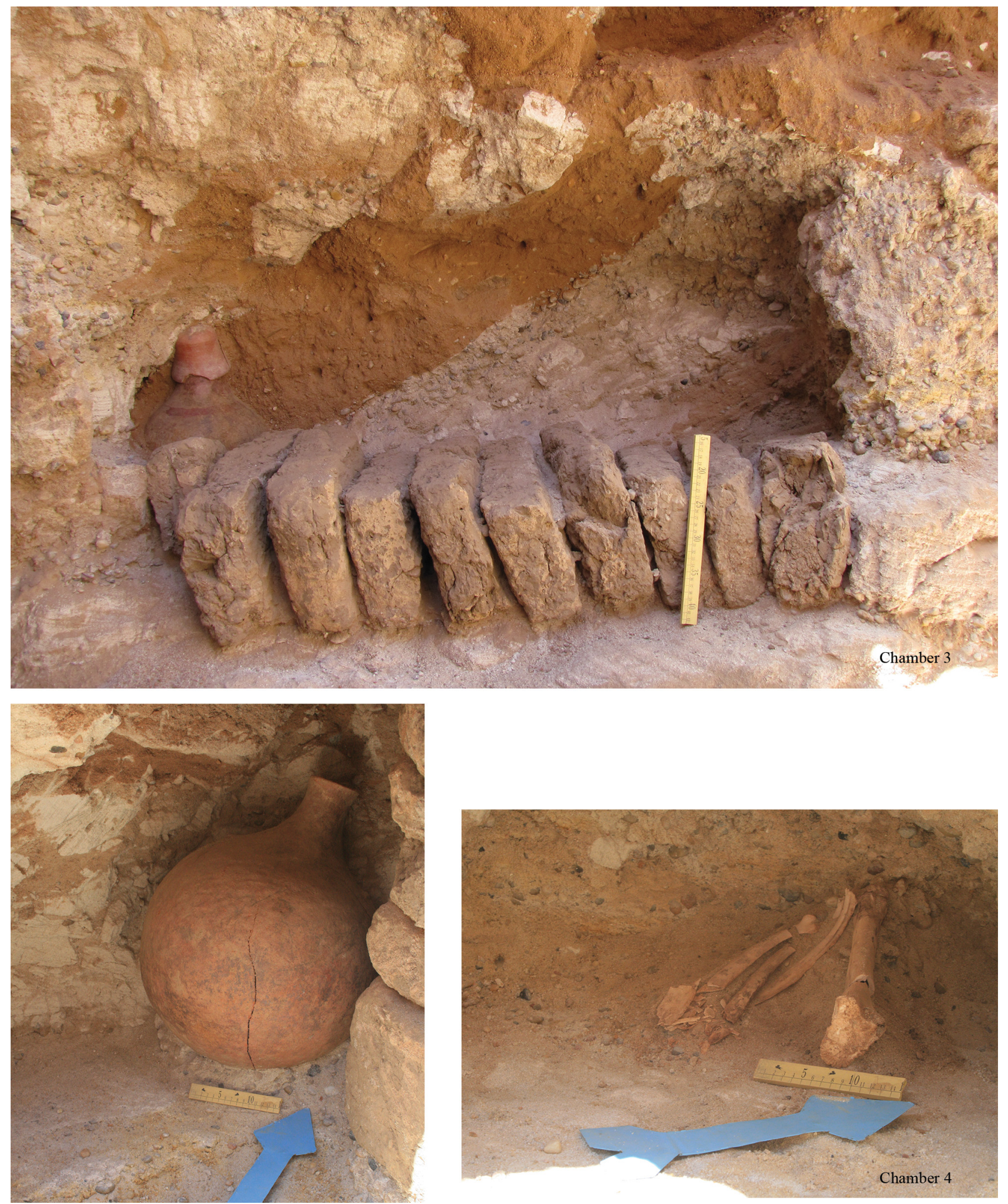

FIGURE 3.80 Tumulus 24, view of chamber 3 looking west (top); part of the grave goods in chamber 4 (bottom)

PHOTOS BY E. SKOWROŃSKA 


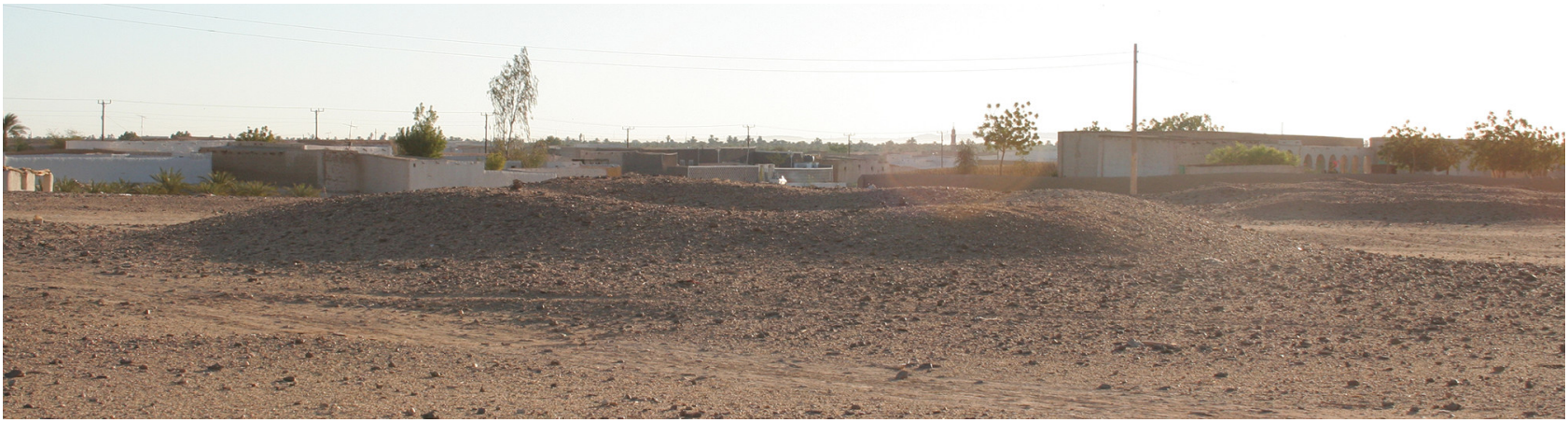

FIGURE 3.81 Tumulus 25, view of the superstructure, looking east PHOTO BY K. KOTLEWSKI

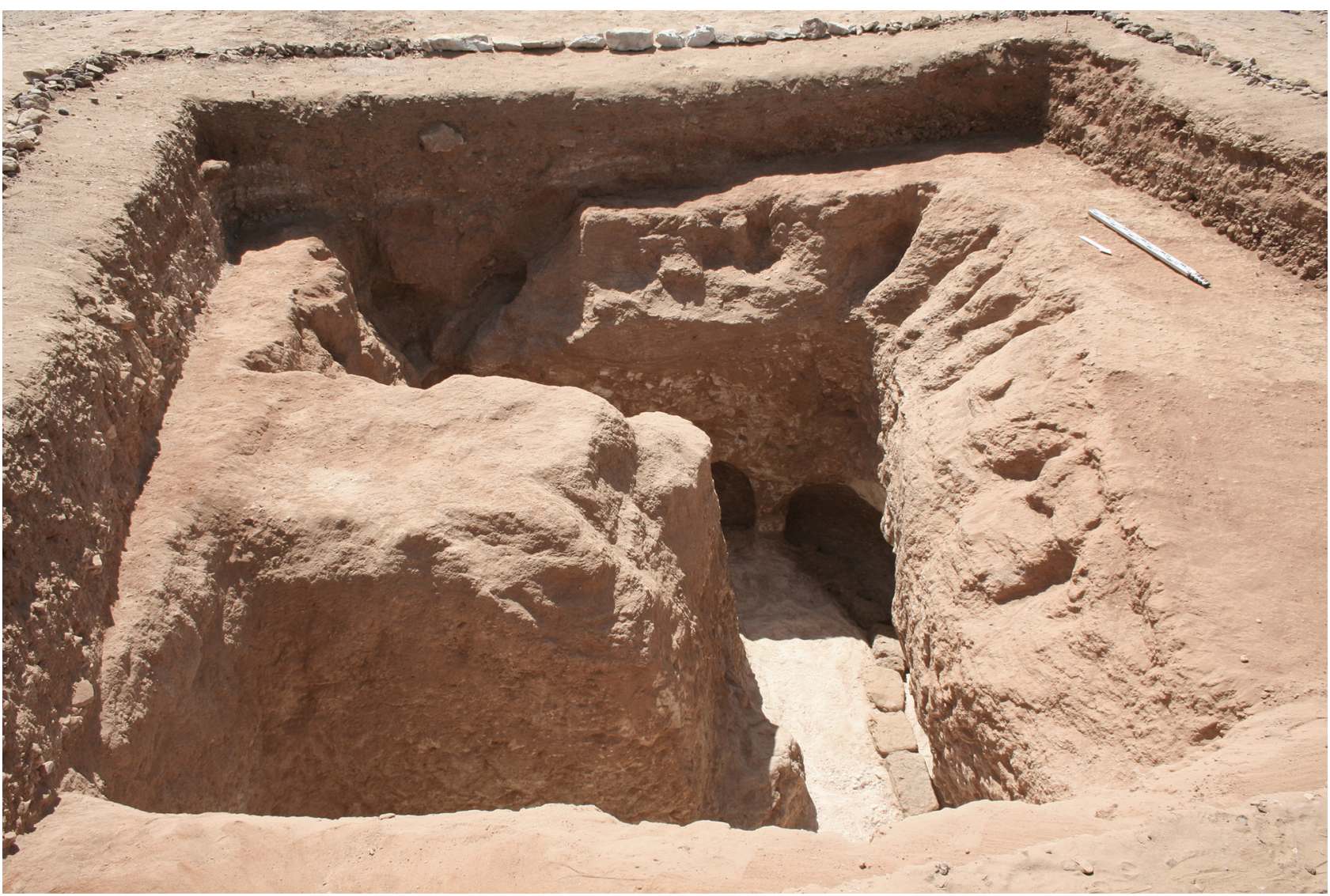

FIGURE 3.82 Tumulus 25, view of the shaft, looking south-note the effect of robber activity on the south wall

PHOTO BY K. KOTLEWSKI

fragile limestone, caused further problems, leading to the partial collapse of the chamber's ceiling. This in turn seriously damaged the blocking wall, especially its south-east side, where only four courses of the wall were left in place, revealing that the bricks had been laid in alternate rows of headers and stretchers, on a foundation consisting of two mud bricks, measuring about $42 \mathrm{~cm} \times 20 \mathrm{~cm} \times 10 \mathrm{~cm}$, laid as stretchers, making the width of the blocking wall about $40 \mathrm{~cm}$.
The full length of the wall till it reaches the blocking wall of chamber 2 is about $3.20 \mathrm{~m}$ with a height of $0.80 \mathrm{~m}$. Both chambers 2 and 4 were closed off by one wall built along the west side of the shaft and measuring $4.70 \mathrm{~m}$ in length with a preserved height of no more than four courses $(0.40 \mathrm{~m})$, though it originally probably consisted of about 6-7 brick courses (o.6o-0.70 m high).

The L-shaped northern chamber 3 was blocked by a wall of mud bricks made up of seven courses (0.70 m) laid in 


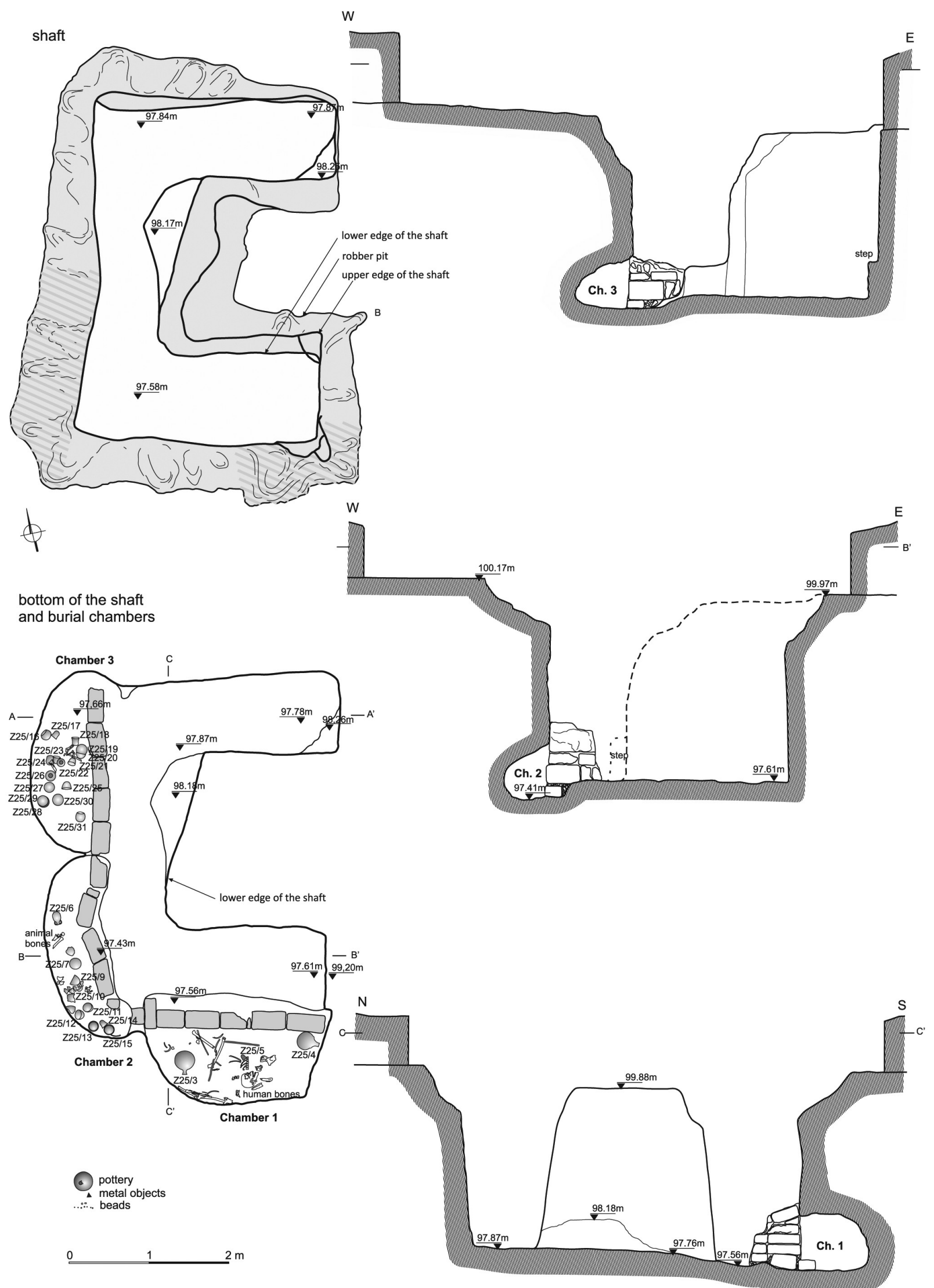

FIGURE 3.83 Tumulus 25, ground plan and cross-sections DRAWN BY A. BEASZCZYK, M. WYBIERALSKA, E. KLIMASZEWSKA-DRABOT, DIGITISED BY M. PUSZKARSKI 

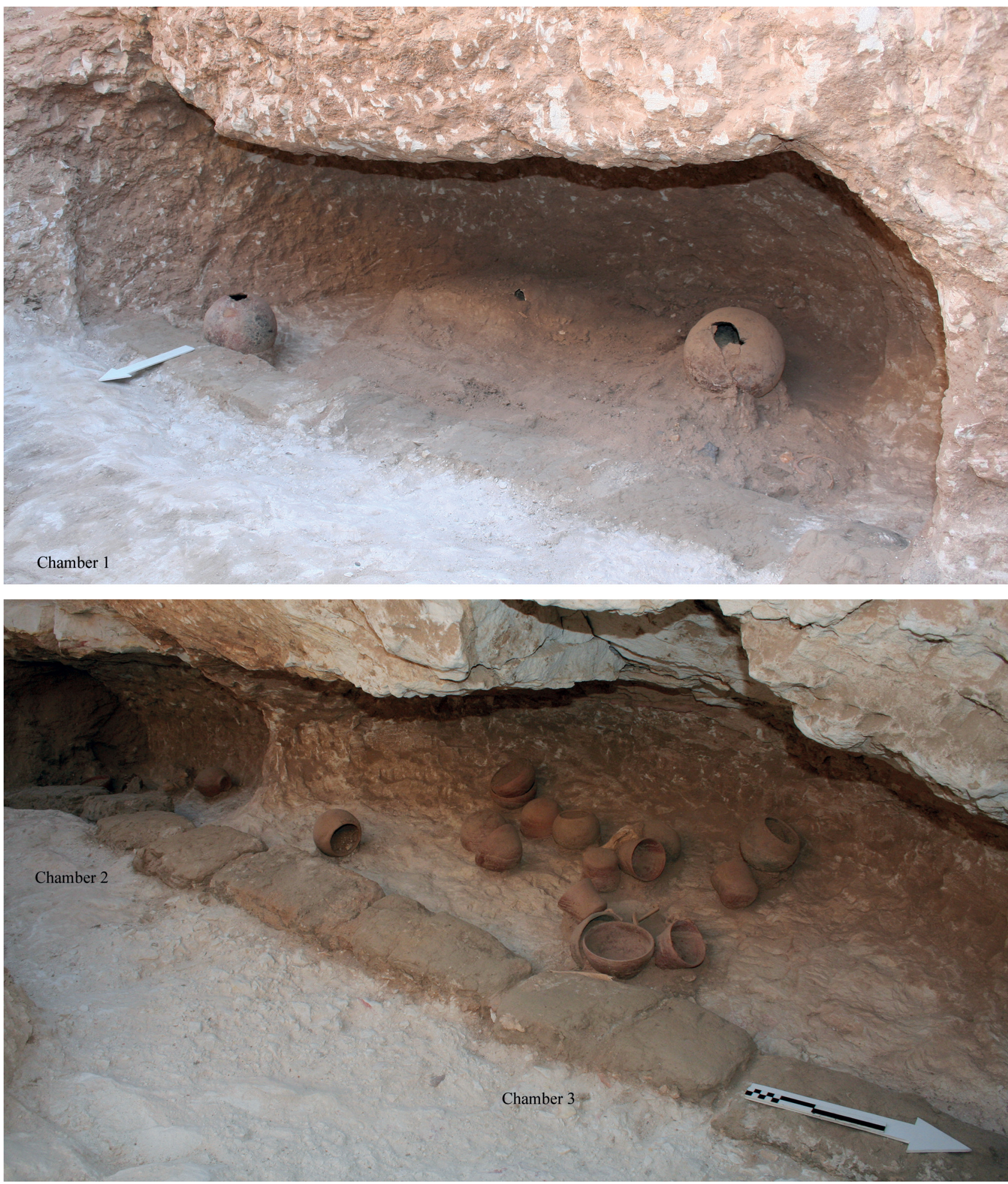

FIGURE 3.84 Tumulus 25, view of scattered grave goods in chamber 1 (top); view of the excavated chambers 2 and 3 (bottom) PHOTOS BY K. KOTLEWSKI 


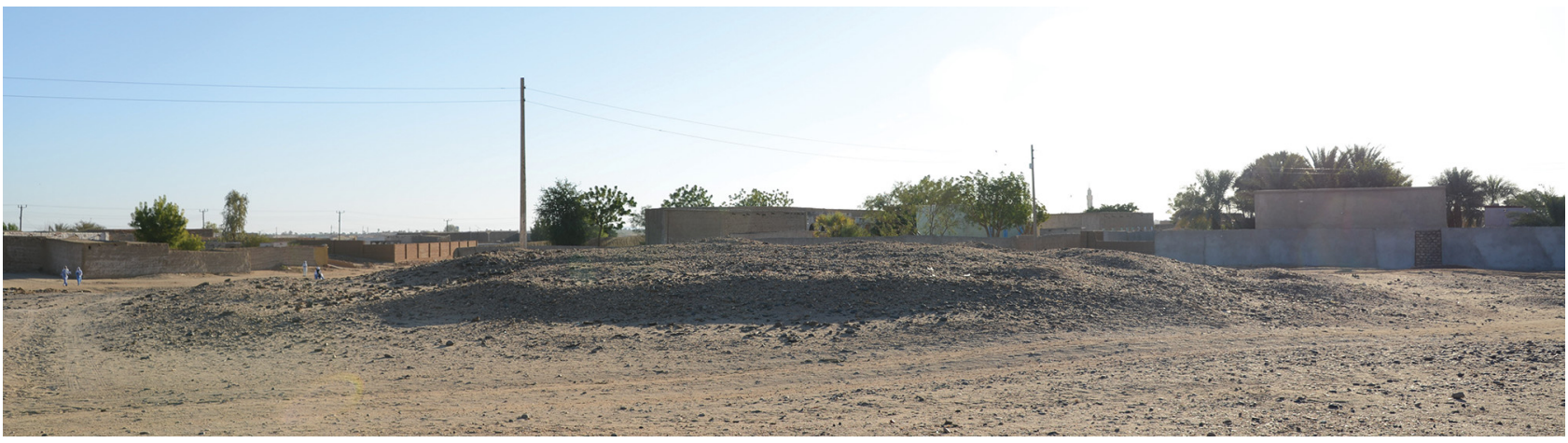

FIGURE 3.85 Tumulus 26, view of the superstructure, looking east PHOTO BY A. KAMROWSKI

a similar technique to the one used in the other walls of chambers 1, 2 and 4. However, in the last course both mudand fired bricks had been used to complete the wall. The north-west side of the $3.20 \mathrm{~m}$-long wall had been disturbed by grave robbers [Fig. 3.88 bottom].

The oval-shaped main southern chamber 1 measures $3.90 \mathrm{~m}$ in length $(\mathrm{E}-\mathrm{W}), 1.40 \mathrm{~m}$ in width $(\mathrm{N}-\mathrm{S})$, and $0.8 \mathrm{om}$ in height. The chamber was found filled with reddish soil, especially in the east and central parts, as a result of robber action that had damaged the blocking wall [Fig. 3.89 top]. Some disturbed human bones were observed scattered on the east side of the chamber. These comprised a pelvis, broken femurs, and a fragment of skull. Furthermore, on this same east side several faience beads were recorded, as well as wood fragments, metal fittings, and some nails. No doubt, these finds attest to the fact that the deceased was buried according to the funerary traditions that were followed at this cemetery in the second phase of the Early Makurian period (AD 450-550), one of the most notable features of which was the location of the body on the east side of the chamber, laid on a wooden frame, most probably in a contracted position, head due east, facing north. The central part of the chamber was not fully excavated due to the fragile state of the ceiling and its partial delamination. Nonetheless, a number of vessels, including cups, bowls, and a single amphora, were recorded alongside wood remains and a pile of cattle bones. The west side of the chamber yielded a few vessels represented by wheel-made cups and bowls, and handmade bowls.

Chamber 2 is a small oval shape, measuring $2.10 \mathrm{~m} \times$ $1.05 \mathrm{~m}$. As already mentioned, its mud-brick blocking wall was part of one long wall built to seal all of the four side niches. The northern side of the chamber was found destroyed; however, despite this destruction, a collection of large animal bones was noted together with 25 various types of vessels, mostly cups and bowls, with one bowl even being found in the hole connecting chamber 2 and chamber 4 [Fig. 3.89 bottom].

The L-shaped chamber 3, which occupies the northern and part of the western side of the shaft, measures $3.65 \mathrm{~m}$ $(\mathrm{E}-\mathrm{W}) \times 1.70 \mathrm{~m}(\mathrm{~N}-\mathrm{S}) \times 0.6 \mathrm{om}$ in height. The blocking wall of this chamber had been dismantled on the north-west side, while its longer, northern, part remained untouched by the plunderers. The chamber was excavated slowly and conditions were complicated by the collapse of the weak limestone roof. Despite this, after careful cleaning of the chamber a single bowl and some scattered animal bones were found at the north-west end, which had been disturbed by the robbers. Two large beer jars were found some distance from each other in the central part of the northern side of the chamber. Between these two beer jars was a decayed basket with a cover (Arabic: tabaq- طبق), containing some small unidentified seeds. Such an unusual grave offering has rarely been noted in other burial chambers, if at all (no parallel has been recorded to date). Another unusual practice was noted in the form of a small bowl beside some animal bones laid on what appeared to be a mat made of organic material, which was found in a badly decayed state [Fig. 3.9o].

\subsection{Tumulus 16}

Tumulus 16 is situated in the central part of the site, between T.9, T.15, and T.20 [see Fig. 1.2]. This round, flattopped mound is slightly smaller than T.9, with a maximum height of about $1.10 \mathrm{~m}$ and a diameter of about $20 \mathrm{~m}$ [Fig. 3.91]. The stone ring encircling the mound was not examined [Fig. 3.92]. The superstructure covered a rectangular burial shaft measuring $2.85 \mathrm{~m}$ to $2.95 \mathrm{~m}$ (north and south walls respectively) by $4.35 \mathrm{~m}$ to $4.25 \mathrm{~m}$ (east and west walls respectively; the east wall being the one most damaged by looting), which narrows towards the bottom [Fig. 3.93]. A step was hewn in the bedrock at the bottom of the shaft by the east wall. The main chamber (Ch.1) was 


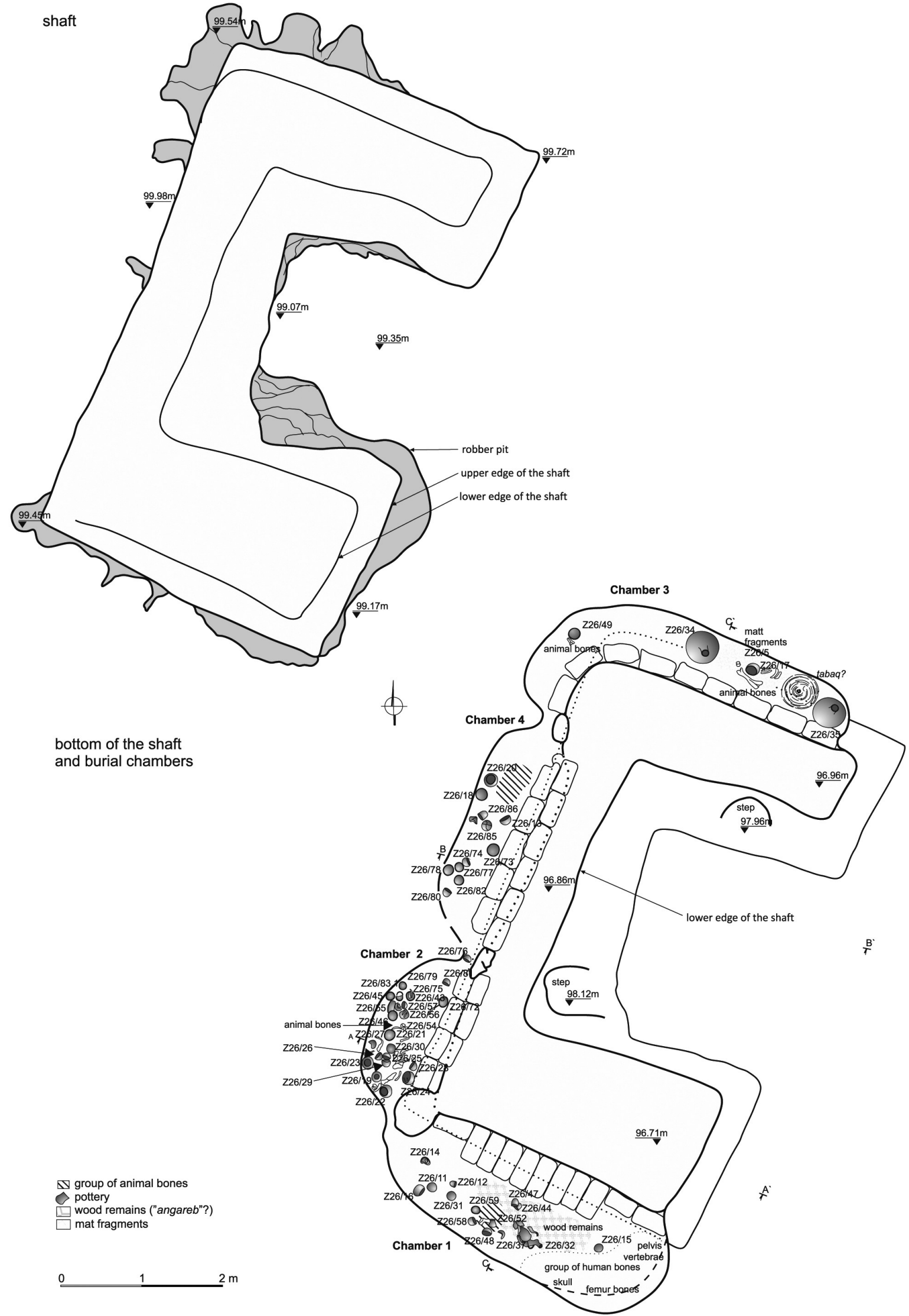

FIGURE 3.86A Tumulus 26 , ground plan DRAWN BY K. JUSZCZYK-FUTKOWSKA, DIGITISED BY E. CZYŻEWSKA-ZALEWSKA 

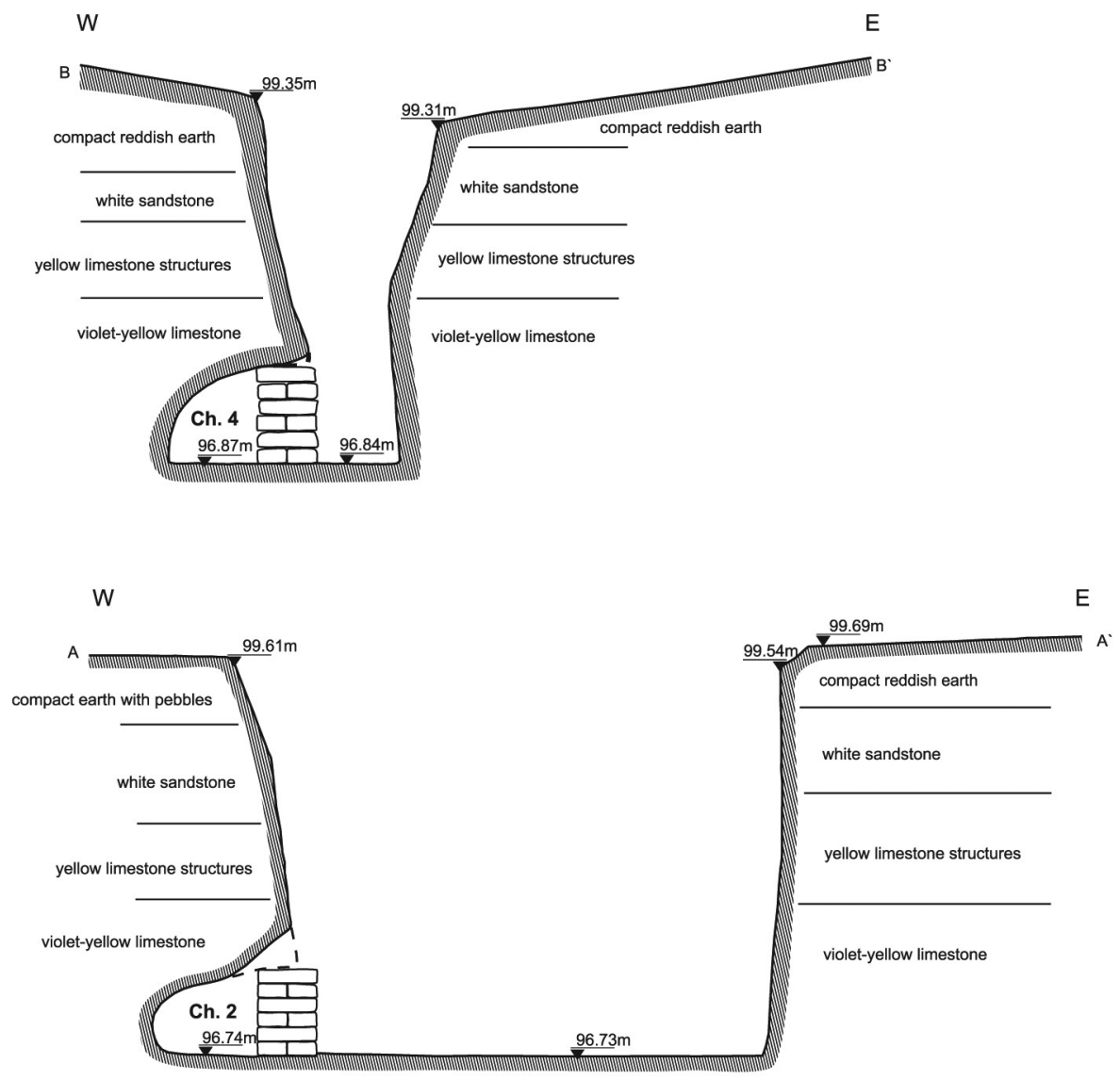

S

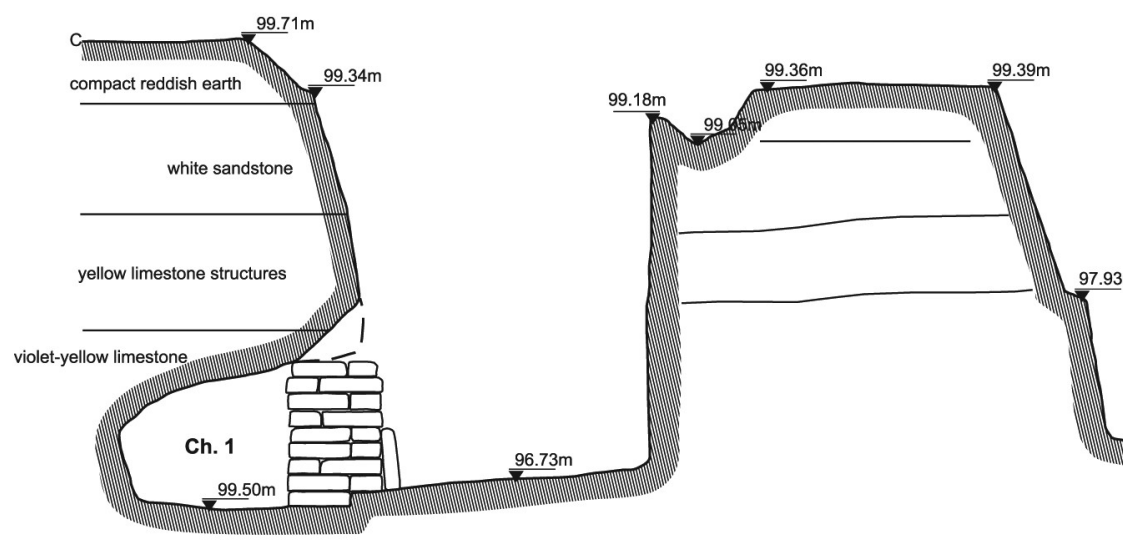

$\mathrm{N}$

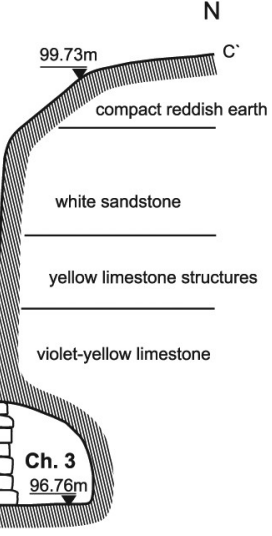

FIGURE 3.86B Tumulus 26, cross-sections of the tumulus

DRAWN BY K. JUSZCZYK-FUTKOWSKA, DIGITISED BY E. CZYŻEWSKA-ZALEWSKA 


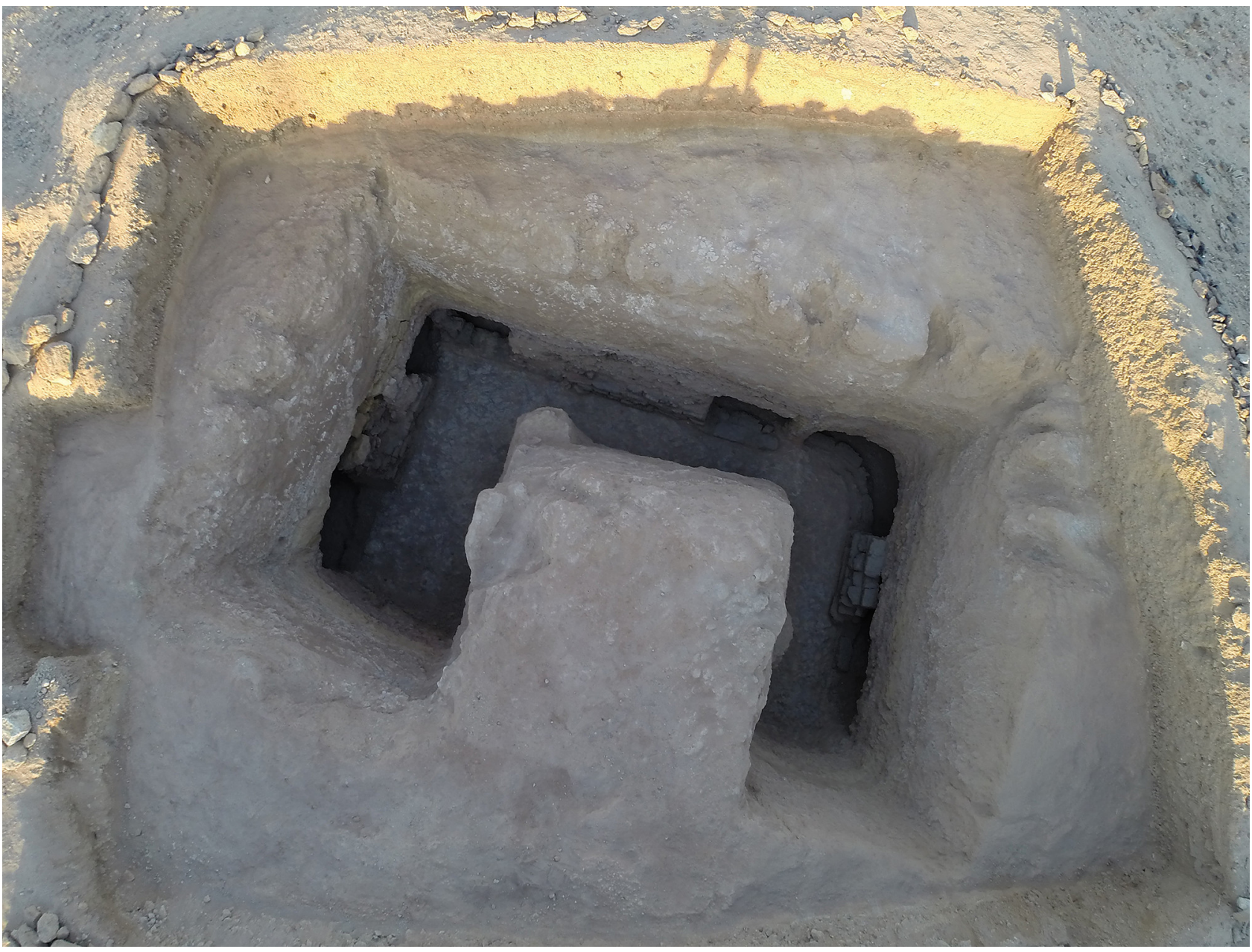

FIGURE 3.87 Tumulus 26, aerial view of the U-shaped shaft Рното вY T. WOJTCZAK

cut into the south-western side of the shaft; the front part was found collapsed, presumably because of the ancient break-in, which left dangerous cracks in the west wall of the chamber. This chamber measured $2.40 \mathrm{~m} \times 1.40 \mathrm{~m}$ $\times 0.78 \mathrm{~m}$, while chamber 2 , a secondary niche cut into the north-western side of the shaft, measured $1.65 \mathrm{~m} \times$ $1.20 \mathrm{~m} \times 0.55 \mathrm{~m}$. The two chambers were interconnected by a small opening, about $0.40 \mathrm{~m}$ wide, in a manner similar to other burials of types I and II at the El-Zuma cemetery [Fig. 3.94].

The entrances to both chambers had been blocked with mud bricks (average size $37 \mathrm{~cm} \times 18 \mathrm{~cm} \times 8 \mathrm{~cm}$ ), which were found scattered at the bottom of the shaft. The blocking wall was $2.10 \mathrm{~m}$ long in the case of the main chamber and $1.40 \mathrm{~m}$ in that of the side chamber. The height could not be estimated easily. The lowest course of the blocking of the main chamber was a rowlock course. The fill of the main chamber [Fig. 3.95 top], which showed evidence of heavy plundering, contained two handmade beer jars, found at opposite ends of the chamber, as well as disarticulated and jumbled human bones, including vertebrae, ribs, long bones and a broken pelvis, in addition to a broken skull next to the beer jar at the southern end, indicating that this was the main burial chamber. Two small metal objects, an iron cross and a copper-alloy bell, were found near the skull (for a catalogue of metal artefacts and discussion, see Volume III, Chapter 5). Some large animal bones, probably of cattle, were found heaped near the second beer jar at the northern end of the chamber. The fill of the side chamber (Ch. 2) contained only some cattle bones [Fig. 3.95 bottom]. There is reason to believe that this chamber was intended solely for grave offerings. More small objects were found in front of the main chamber. These were mostly metal artefacts comprising a number of iron arrowheads and fragments of a broken spear blade, as well as different types of beads, all found scattered amongst the dismantled mud bricks of the chamber blocking. For more information see Mahmoud El-Tayeb, Juszczyk-Futkowska, and Czyżewska 2014, $363-365$. 

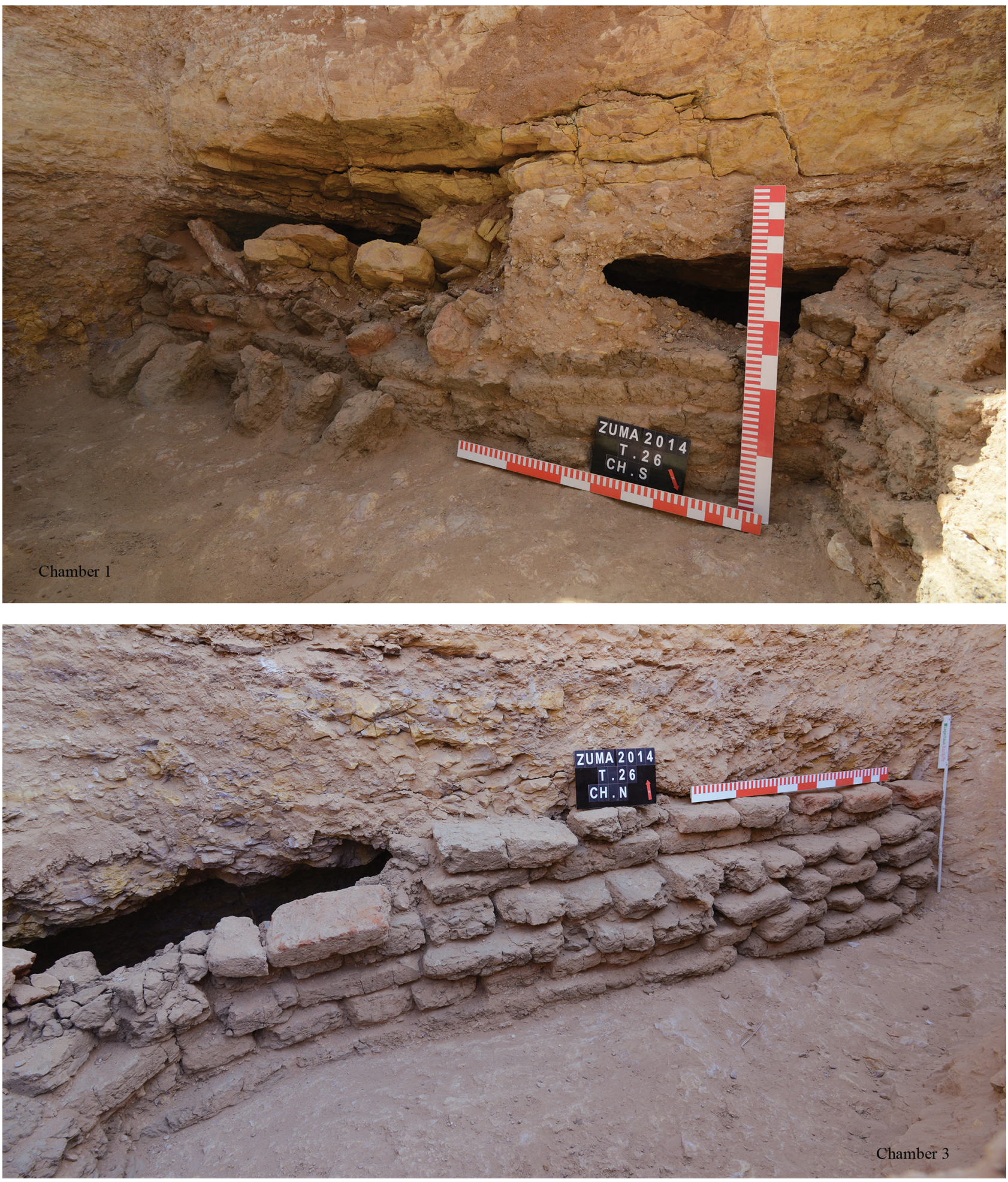

FIGURE 3.88 Tumulus 26, view of the disturbed chamber 1 (top); view of the blocking wall of chamber 3 (bottom)

PHOTOS BY A. KAMROWSKI 

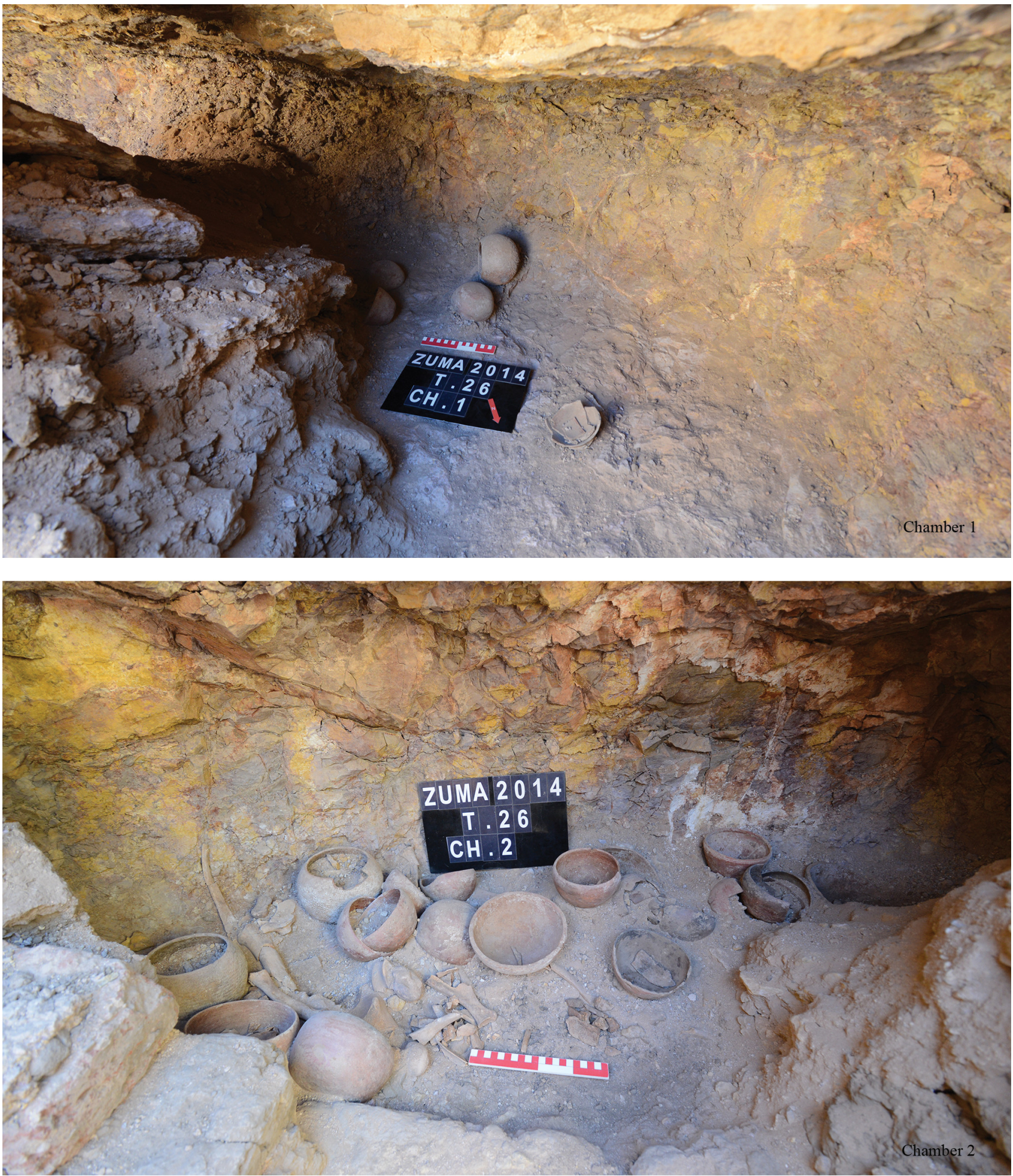

FIGURE 3.89 Tumulus 26, view of plundered and disturbed southern part of chamber 1 (top); grave goods in chamber 2 (bottom) PHOTOS BY A. KAMROWSKI 

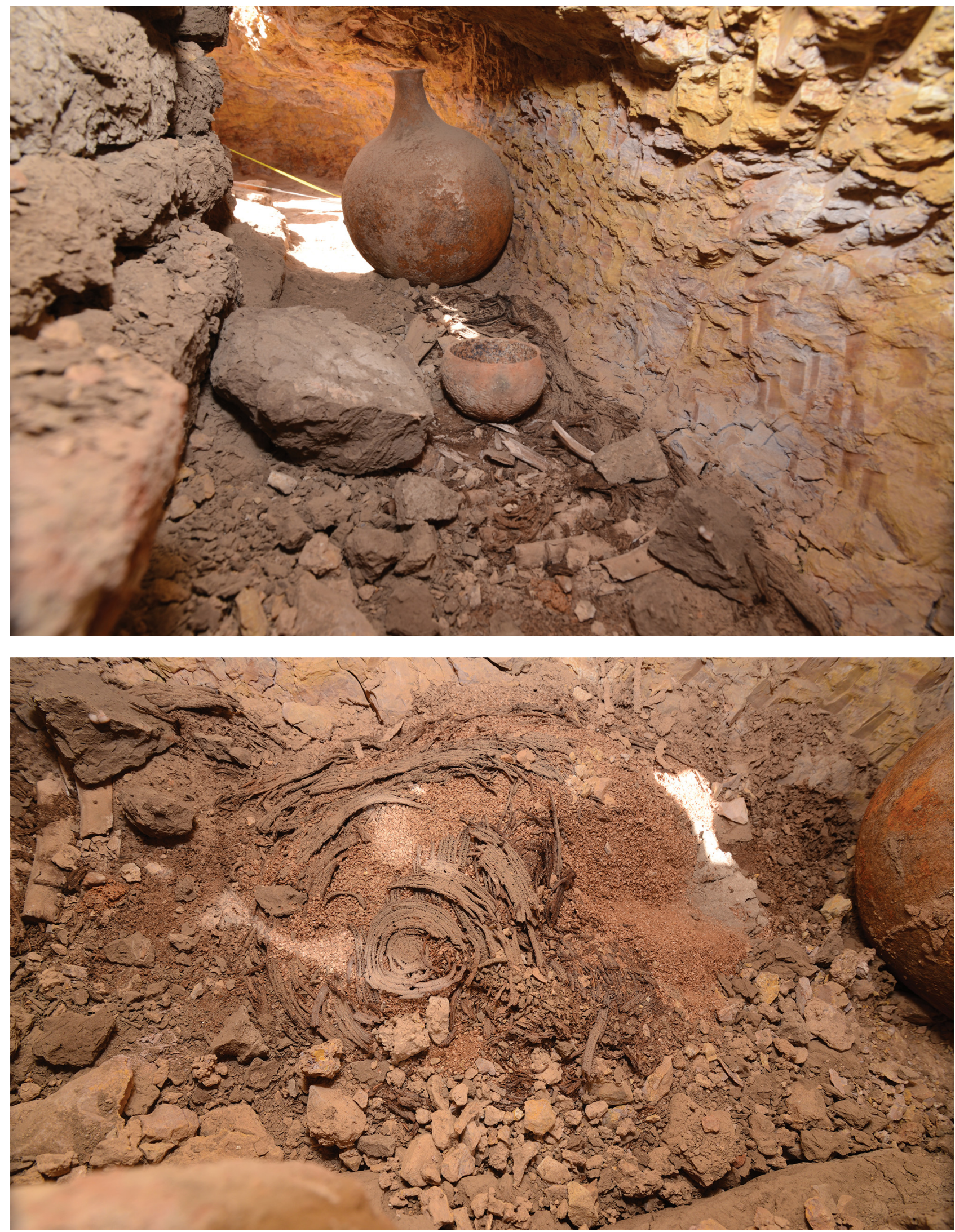

FIGURE 3.90 Tumulus 26 , view of grave goods in chamber 3 during excavation, facing north-east PHOTOS BY A. KAMROWSKI 


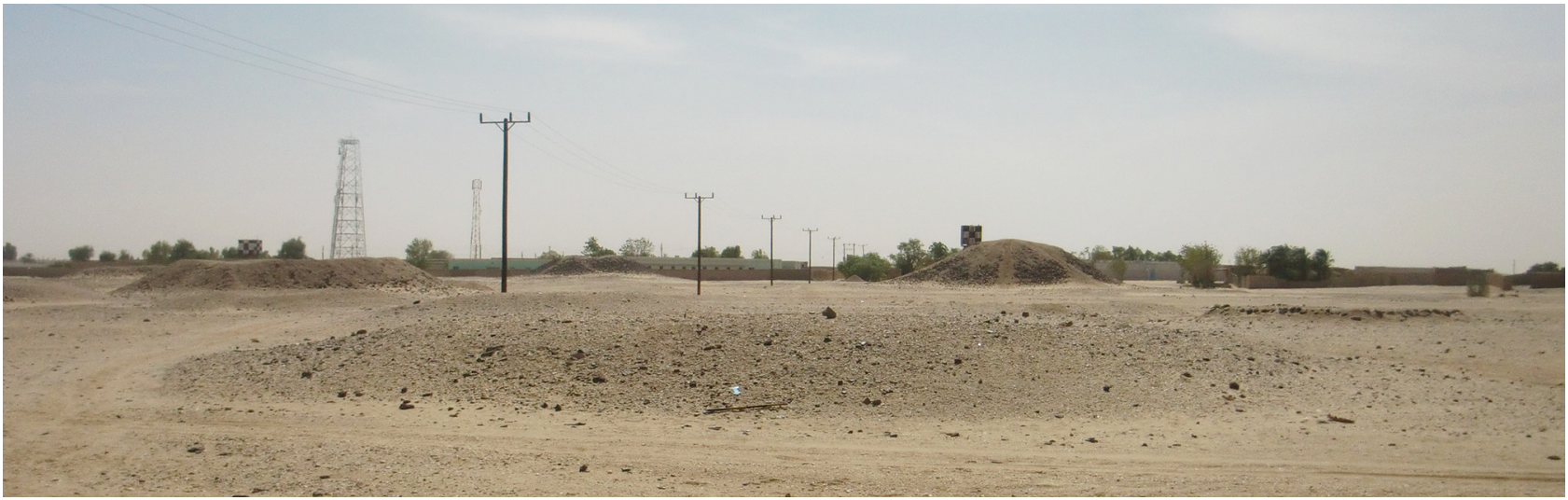

FIGURE 3.91 Tumulus 16, superstructure, looking south РНОто вY О. ВIAєOSTOCKA
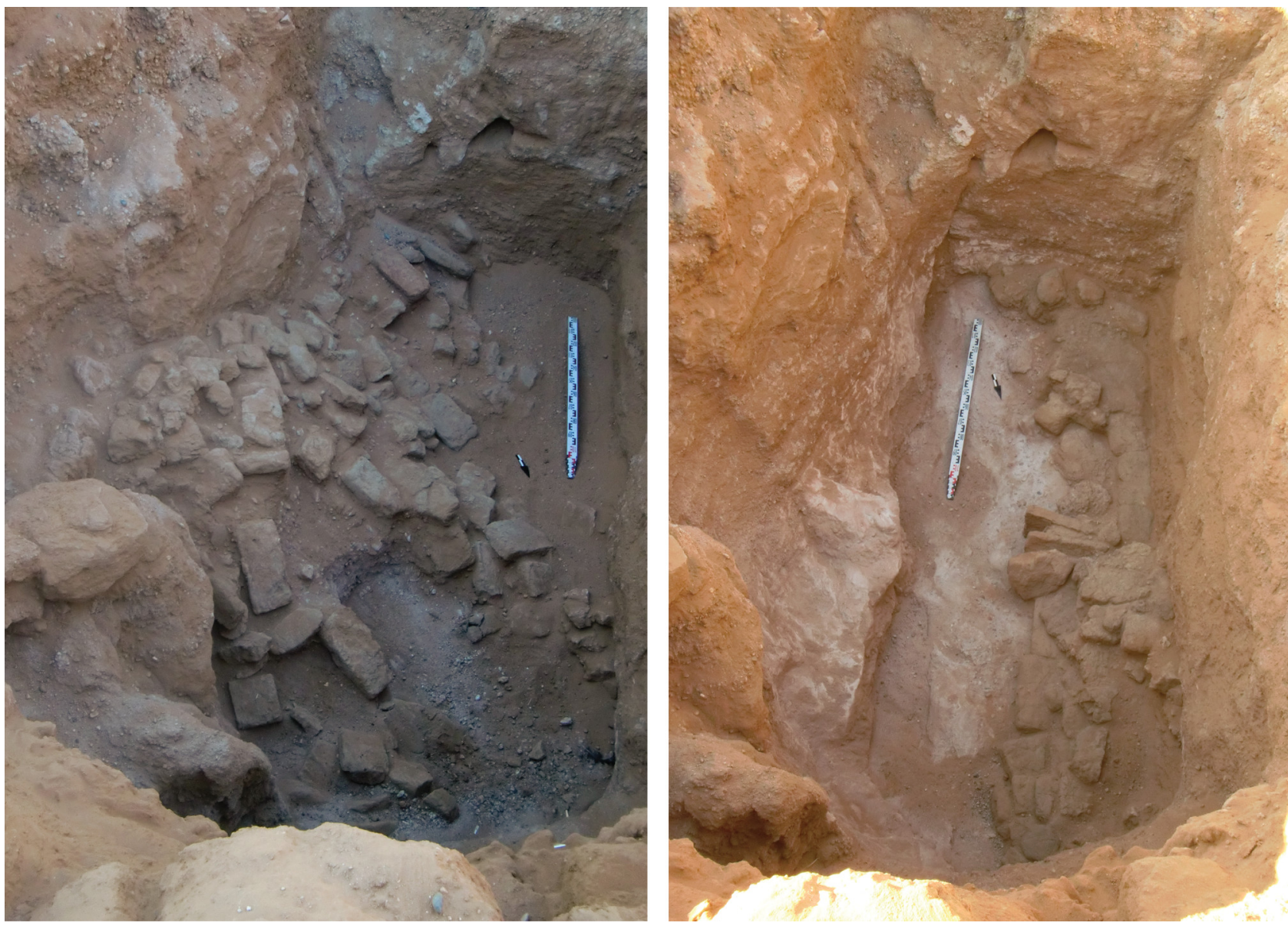

FIGURE 3.92 Tumulus 16, view of the dismantled bricks of the chambers' blocking walls, thrown against the east wall of the shaft (left); view of two blocking walls of the burial chambers cut into the west wall of the grave shaft (right)

РноTOS BY O. BIAŁOSTOCKA 


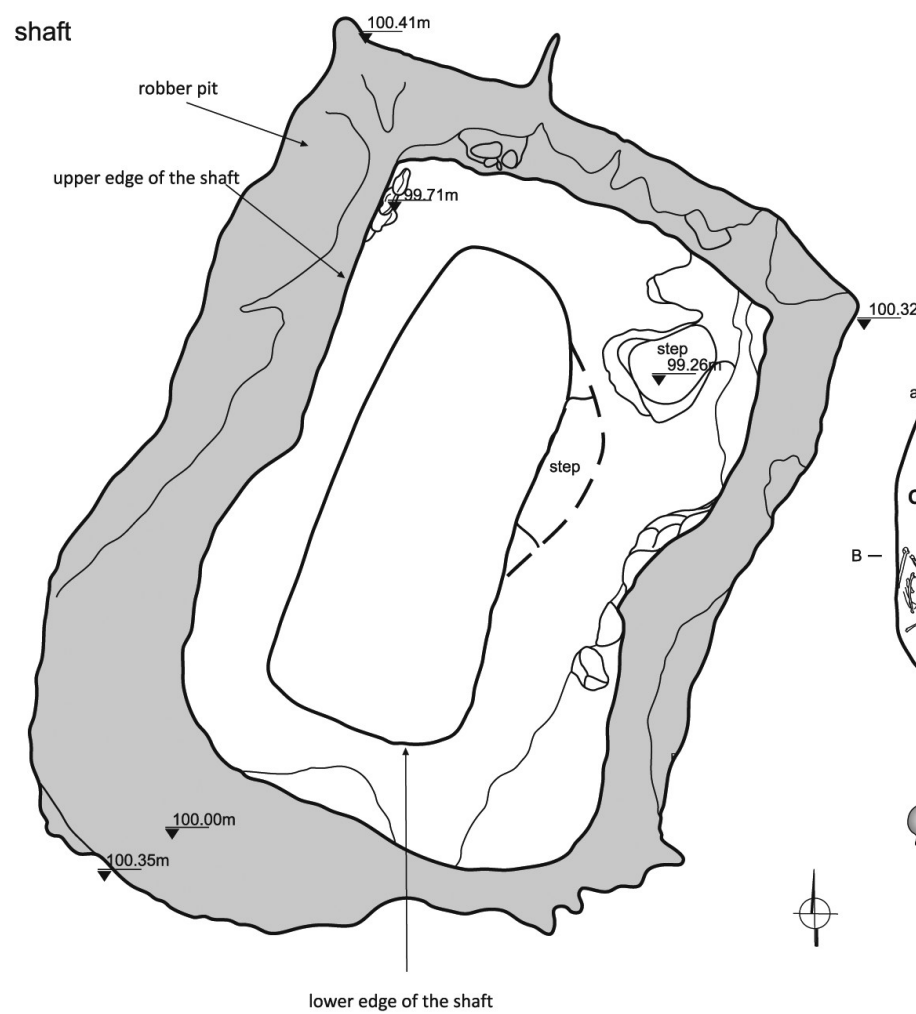

bottom of the shaft
and burial chambers
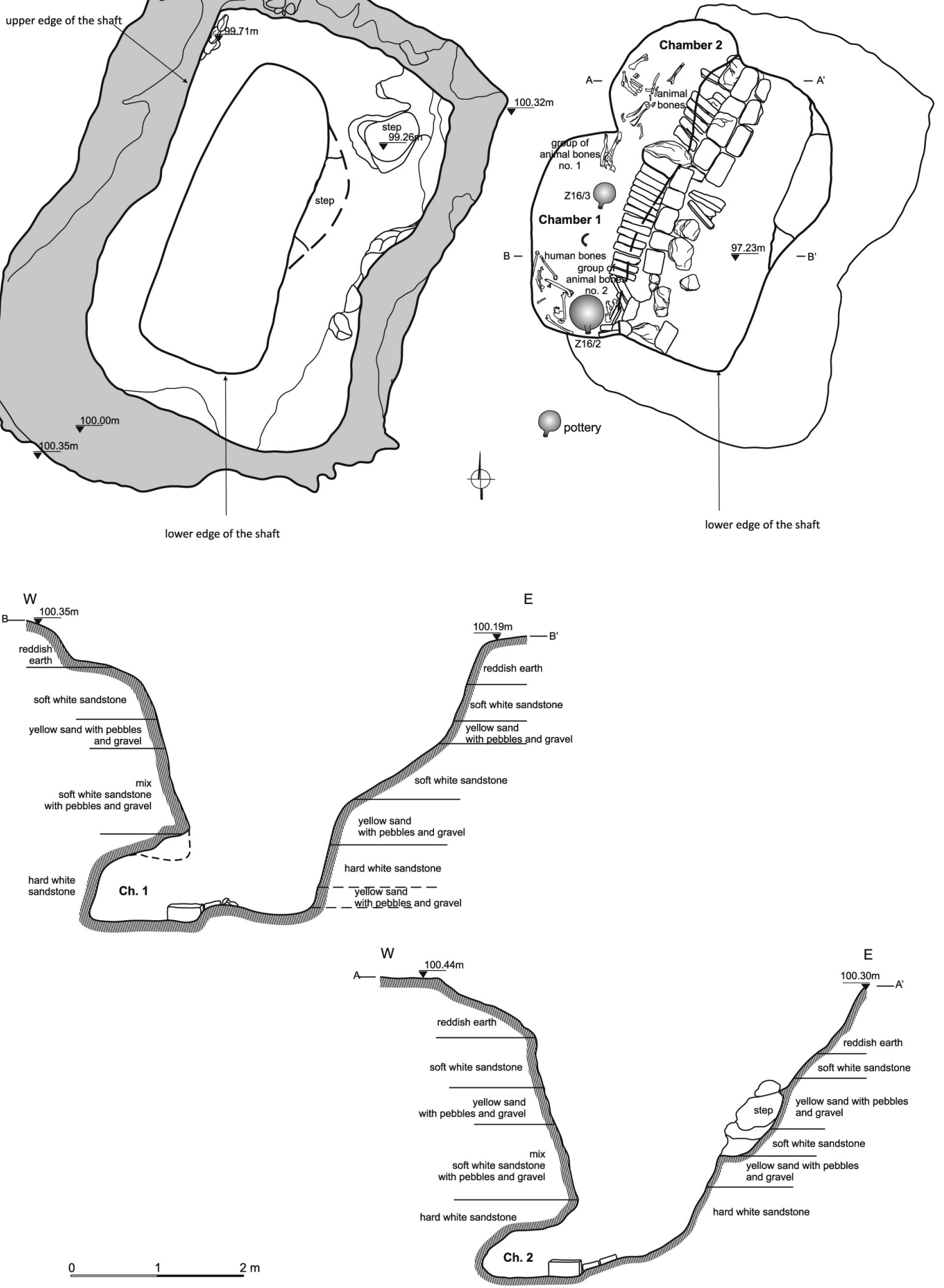

FIGURE 3.93 Tumulus 16, ground plan and cross-sections of the burial DRAWN BY K. JUSZCZYK-FUTKOWSKA, E. CZYŻEWSKA-ZALEWSKA, E. KLIMASZEWSKADRABOT, DIGITISED BY E. CZYŻEWSKA-ZALEWSKA 


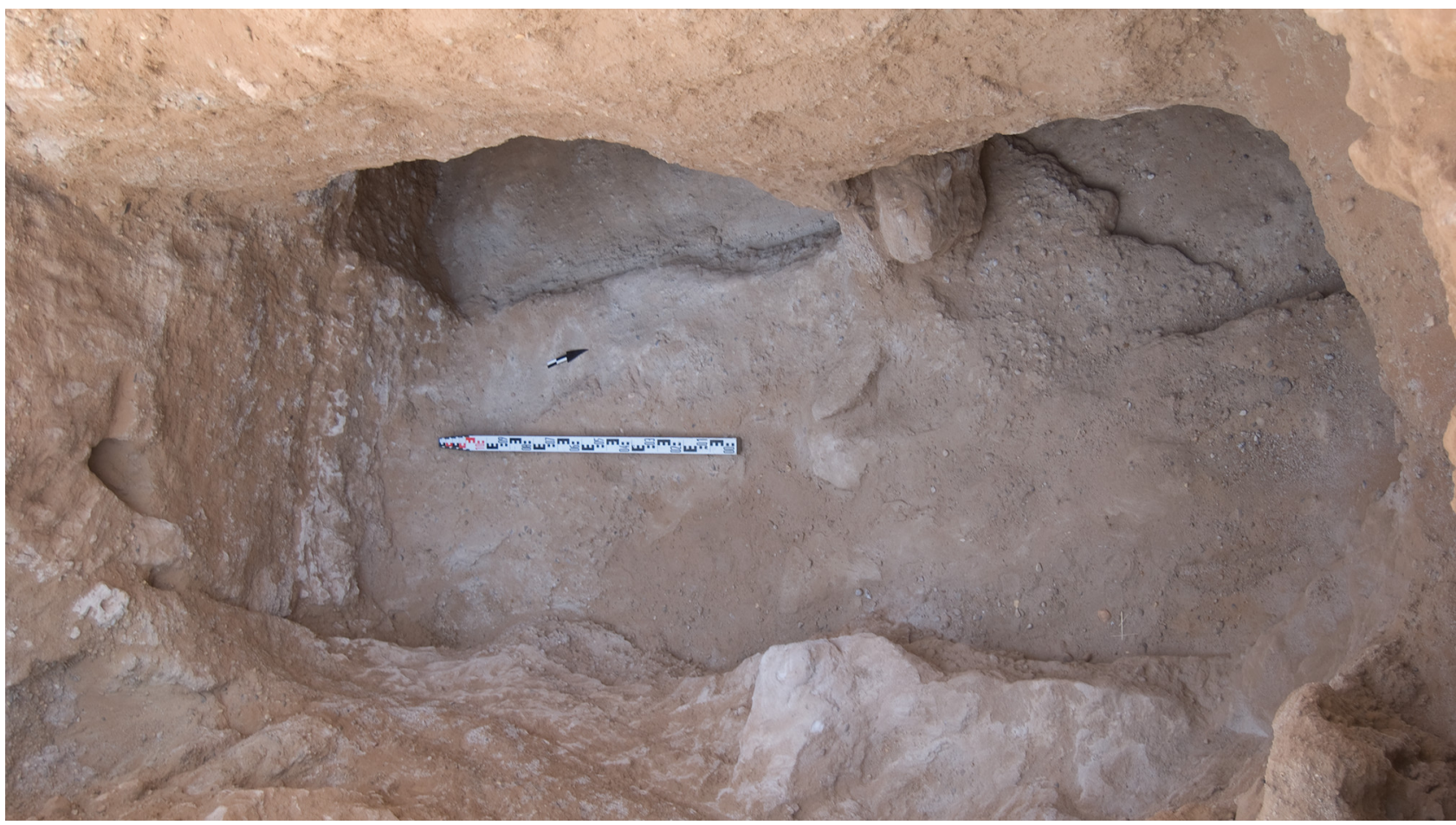

FIGURE 3.94 Tumulus 16, shaft, view of the rectangular shaft with two entrances to chambers 1 and 2 PHOTO BY O. BIAŁOSTOCKA

\subsection{Tumulus 9}

Situated in the central part of the site, between T.16 to the east and T.11 and T.1o to the west [see Fig. 1.2], this round, flat-topped mound has a maximum height of about $1.80 \mathrm{~m}$, and an E-W diameter of 24.50 m [Fig. 3.96]. The L-shaped burial shaft (disturbed in the upper part by looting) is only the second of its kind to have been found at this cemetery; the first example was observed in T.11, which was excavated in 2009 (Mahmoud El-Tayeb and Czyżewska 2011). A parallel is known from the cemetery in Abkur, where tumulus T.1 had an L-shaped burial shaft, 3.30 m deep on the south and $3.60 \mathrm{~m}$ on the north side when measured from the ground surface around the tumulus (Kirwan 1939; Żurawski 2003, 220; Juszczyk 2011, 119-121). Two steps were hewn from the rock by the east wall of the burial shaft [Fig. 3.97 left] in a manner typical of El-Zuma tombs: one in the north-east corner of the shaft, and the other following the angle of the $\mathrm{L}$ shape at a depth of $2.20-2.50 \mathrm{~m}$. The red bricks which were found in the fill were reused to block each of the three chambers of this tomb. The bricks measured $33 \mathrm{~cm} \times 17 \mathrm{~cm} \times 8 \mathrm{~cm}$ and $36 \mathrm{~cm} \times 18 \mathrm{~cm} \times 5 \mathrm{~cm}$ [Fig. 3.98].

The difference in their shape and size, as well as traces of coarse white plaster or mortar, suggest that they had been taken from various parts of an unidentified Meroitic structure. The blocking wall of the main chamber (Ch. 1) was $3.30 \mathrm{~m}$ long and about $0.60 \mathrm{~m}$ high. It consisted of six courses bonded with mud mortar. The bricks were laid in rows of alternating headers and stretchers, set on a lowermost rowlock course [Fig. 3.99] faced with shiners (bricks set on the long narrow side with the broad face exposed). The second chamber was blocked with a wall of the same height but shorter (2.10m long), consisting of five courses. A rowlock course was laid at the bottom and top of this wall, with a course of headers between two courses of stretchers in the middle. Blocking the third chamber was a wall $1.40 \mathrm{~m}$ long and about $0.75 \mathrm{~m}$ high, consisting of seven single-thickness courses of alternating headers and stretchers; the bottom course was level with the same course in the blocking walls of the other two chambers. Chambers 2 and 3 shared a red-brick facade, approximately $3.80 \mathrm{~m}$ long. Three chambers were cut into the sides of the burial shaft: the main chamber into the south side, and chambers 2 and 3 into the west side. The dimensions of the chambers were as follows: chamber $1-$ L. $3.70 \mathrm{~m}, \mathrm{~W}$. $1.50 \mathrm{~m}, \mathrm{H}$. o.65 m; chamber 2 -L. $2.40 \mathrm{~m}, \mathrm{~W}$. 1.30 m, H. o.6o m; chamber 3-L. 3.0o-1.8o m, W. 1.40 m, H. $0.75 \mathrm{~m}$. Passages were cut between the chambers, the one from the main chamber to the second chamber was $0.40 \mathrm{~m}$ wide, while the one from the second chamber to the third was just a narrowing of their shared space, which rendered both chambers kidney-shaped in plan [see Fig. 3.98]. The passages, as was mentioned earlier, could have been of symbolic significance, allowing the soul of the grave occupant to move freely between the chambers. Exploration was hindered by the poor geological structure of the bed- 

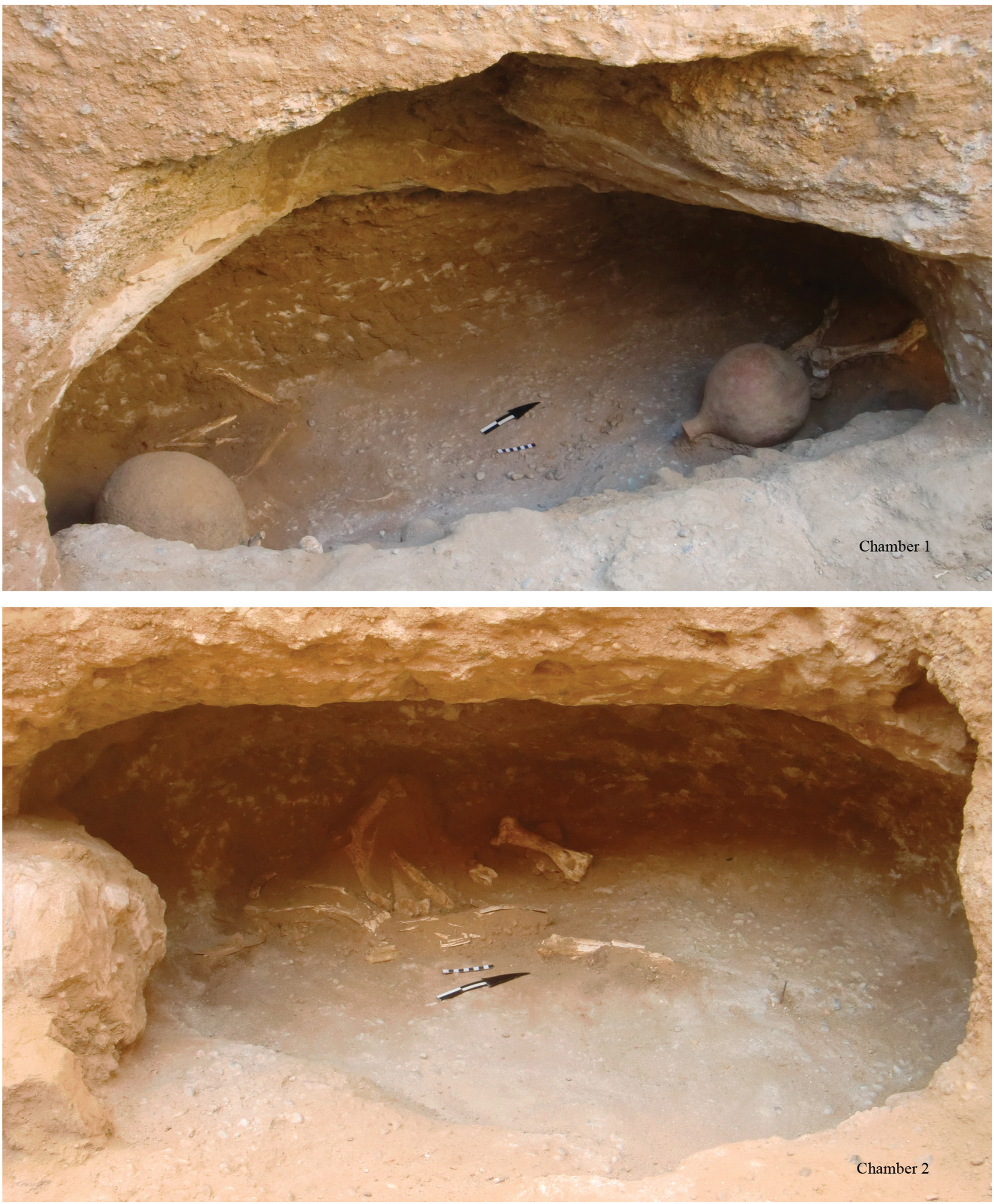

FIGURE 3.95 Tumulus 16, view of chamber 1 with pottery offerings and disturbed human skeleton (top); animal bones in chamber 2 (bottom)

PHOTOS BY O. BIAєOSTOCKA 


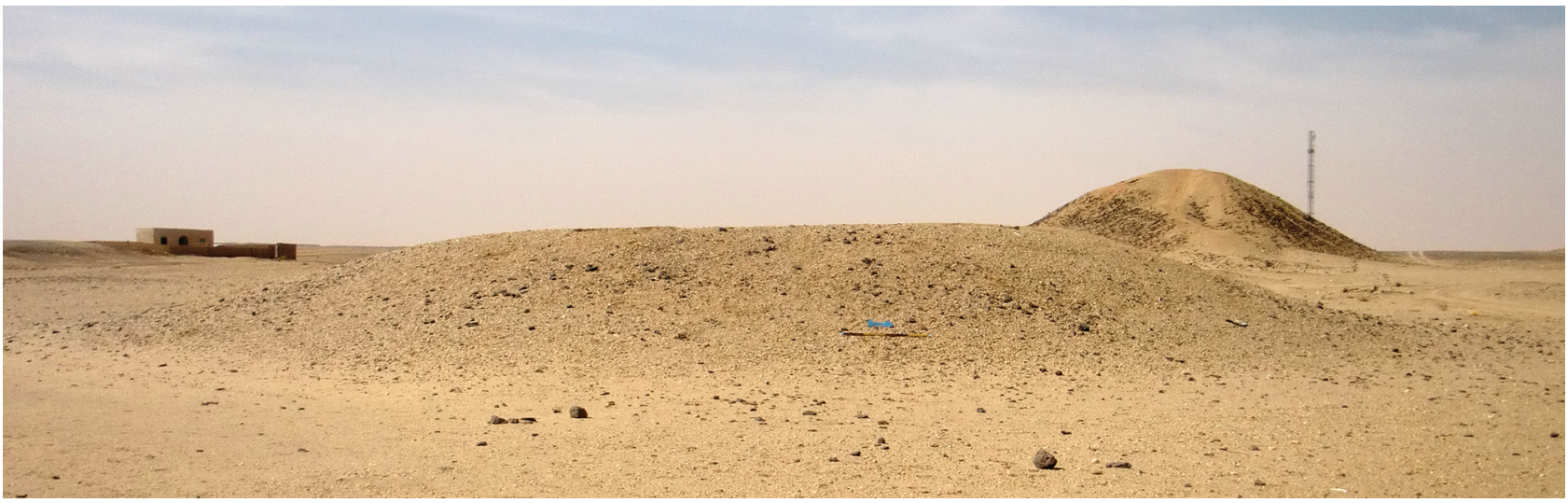

FIGURE 3.96 Tumulus 9, view of the mound, looking west PHOTO BY E. CZYŻEWSKA-ZALEWSKA
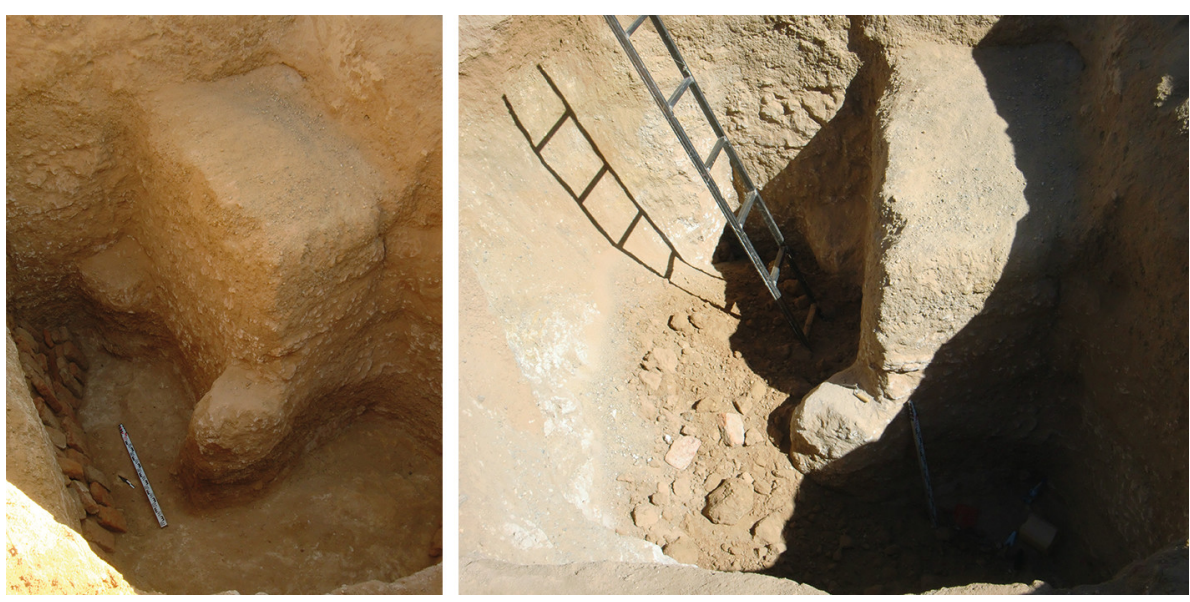

FIGURE 3.97 Tumulus 9, view of the L-shaped shaft with steps cut in the wall (left); view of the lower part of the shaft showing the collapsed ceilings of chambers 2 and 3 , facing west (right)

PHOTOS BY E. CZYŻEWSKA-ZALEWSKA

rock, which resulted in the intermittent crumbling of the walls of the shaft, especially the west wall, during excavation [Fig. 3.10o]. A robber pit of irregular shape had been dug into the top centre of the mound, directly above the burial shaft and chambers, damaging especially the west wall of the shaft. The fill in the southern part of the shaft yielded concentrations of red bricks presumed to be from the destroyed blocking wall of chamber 1 and probably also chamber 2 (possibly only the outer facing [Fig. 3.10o right]). Two vessels and fragmentary human bones were found among the bricks by the main chamber, indicating that the burial had been plundered. The main chamber had been penetrated through a robber pit in the ceiling at its eastern end. Scattered human bones (pelvis, long bones and ribs) were found in the central part, as well as two cups and remains of nails. The original orientation of the burial was suggested by human teeth found lying in the south-east corner of the chamber. Two beer jars were found in the fill of the second chamber and one in the fill of the third. The third chamber may have been plundered at some point. For more information see Mahmoud El-Tayeb, Juszczyk-Futkowska, and Czyżewska 2014, $360-363$.

\subsection{Tumulus 11}

Tumulus 11, built from a mixture of earth and gravel, measures about $27 \mathrm{~m}$ in diameter. At first glance it appeared to have a flat top, yet closer examination revealed that its preserved height from south to north ranges from $1.50 \mathrm{~m}$ to $2.00 \mathrm{~m}$, a feature not observed among the earlier excavated tumuli of the same group [Fig. 3.101]. A large central depression at the top of the mound clearly indicated that the burial had been plundered. Therefore, a trench measuring $6 \mathrm{~m} \times 6 \mathrm{~m}$ was opened in this area to allow excavation of the burial shaft. The task was not easy because of the problems caused by the coarse geological deposits in 


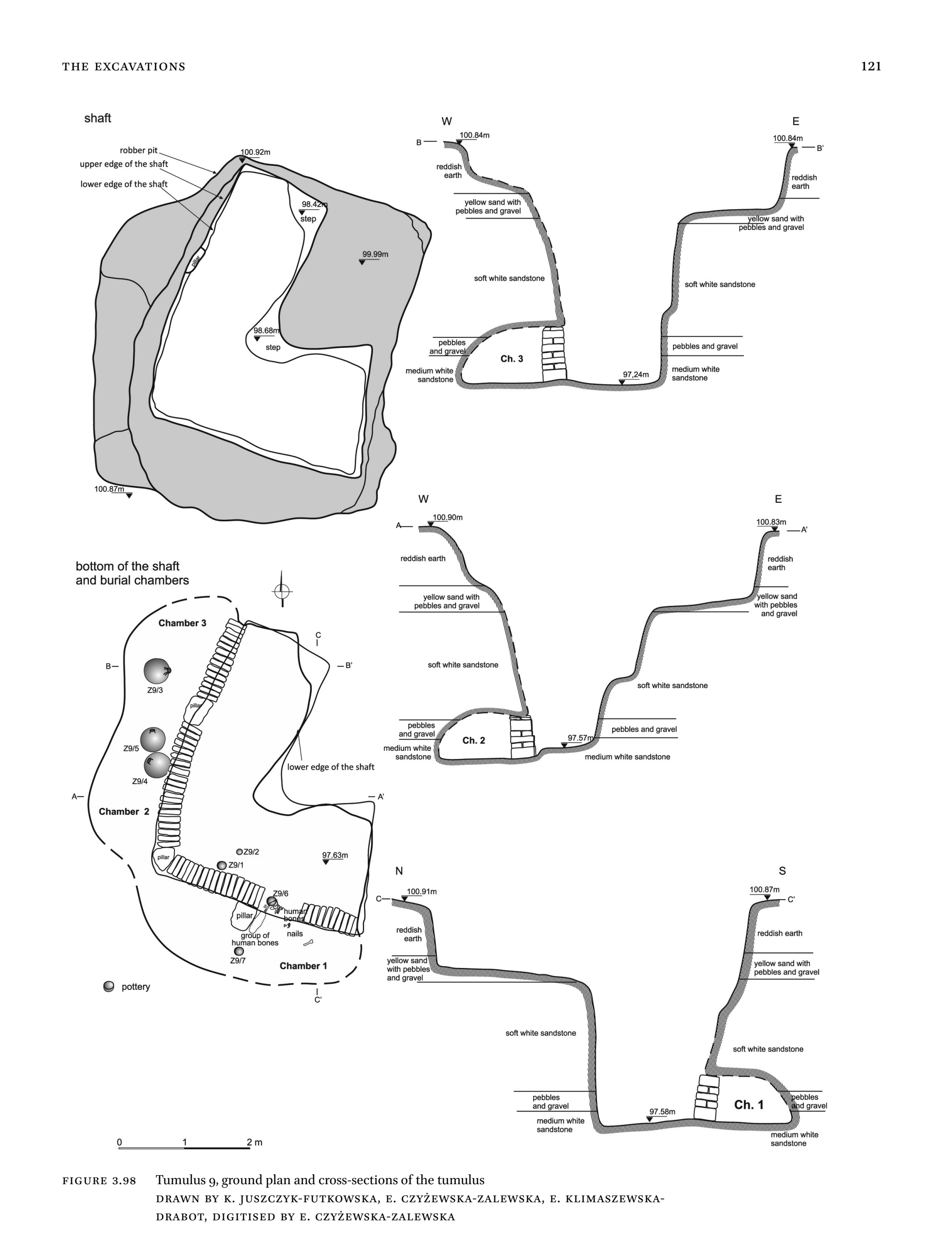



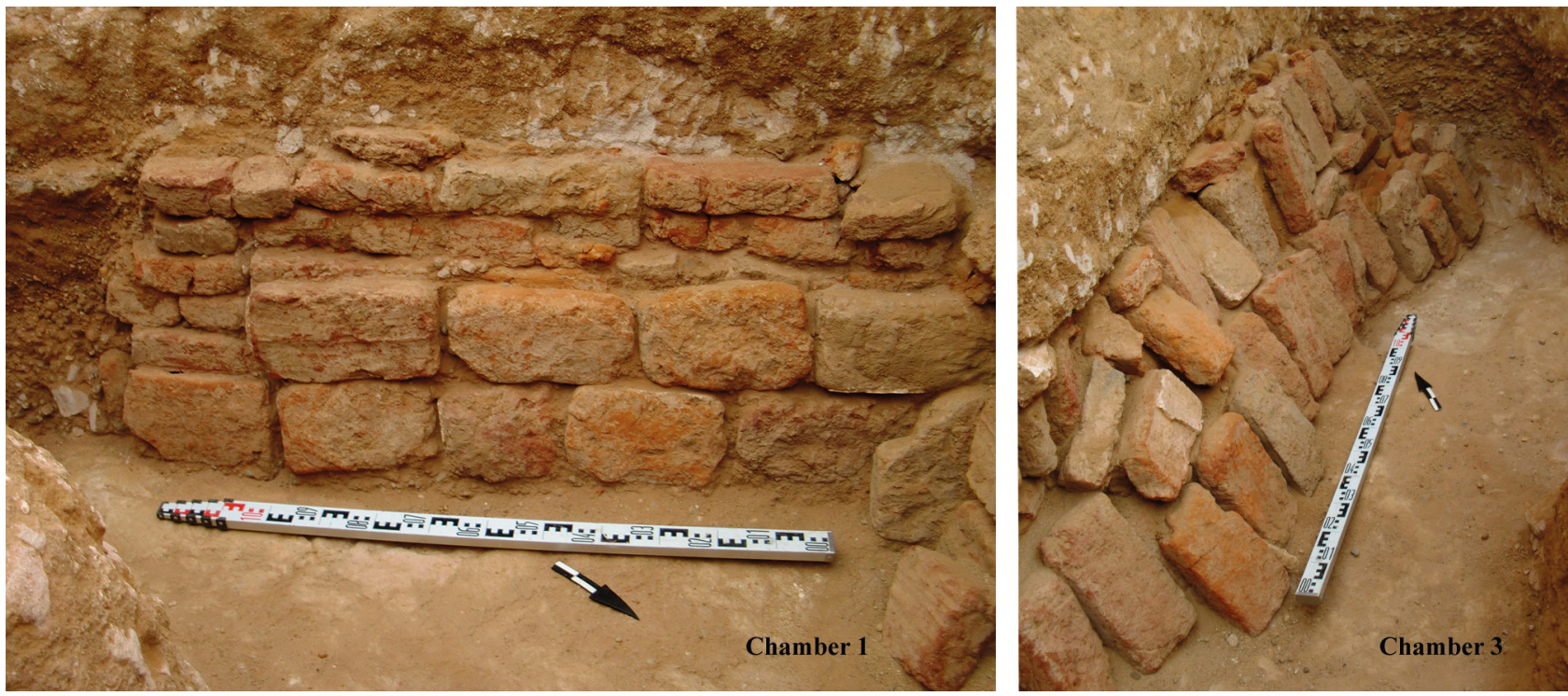

FIGURE 3.99 Tumulus 9, brick courses in the walls of the main chamber 1 (left), and chamber 3 (right) PHOTOS BY E. CZYŻEWSKA-ZALEWSKA
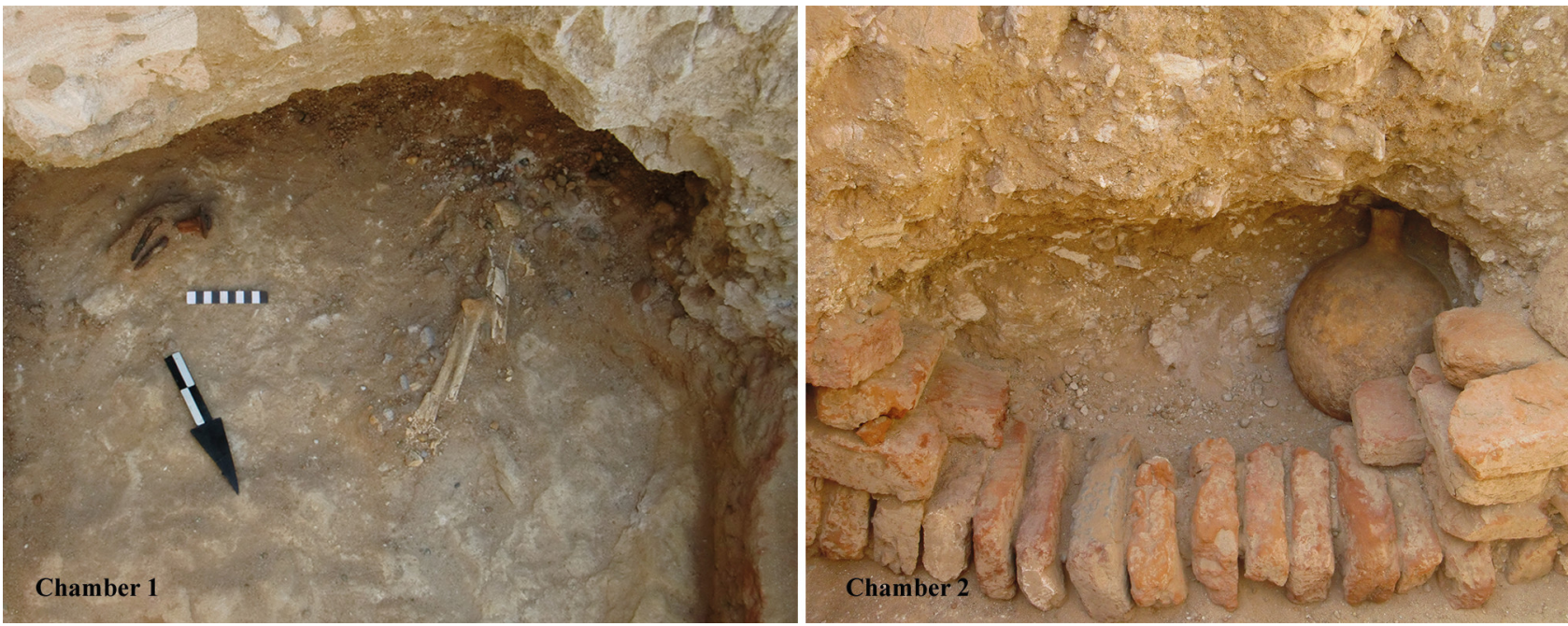

FIGURE 3.100 Tumulus 9, view of the plundered chamber 1 (left); view of chamber 2, facing west (right)

PHOTOS BY E. CZYŻEWSKA-ZALEWSKA

this part of the cemetery. The first $0.30 \mathrm{~m}$ from the ground surface consisted of loose reddish earth with gravel, followed by $0.40 \mathrm{~m}$ of relatively compact yellow sandstone, a layer of yellow sand mixed with pebbles and gravel, a layer of whitish-grey soft sandstone, and finally the lowermost stratum, consisting of hard white sandstone. The upper part of the shaft had been much disturbed by robbers who created a pit of irregular shape.

Unexpectedly, the original shape of the shaft was revealed to be of a quite rare type [Fig. 3.102] so far only noted at two sites: Firka in northern Nubia and Abkur in the Dongola Reach (Kirwan 1939, 4, Pl. v; Żur- awski 2003, 222-224). The longer side of the L-shaped shaft is aligned east-west and measures $2.95 \mathrm{~m} \mathrm{(S),} 1.55 \mathrm{~m}$ $(\mathrm{E}-\mathrm{W})$ and $1.70 \mathrm{~m}(\mathrm{~N})$; the shorter side is oriented northsouth and measures $2.75 \mathrm{~m}(\mathrm{~W}), 1.40 \mathrm{~m}(\mathrm{~N}-\mathrm{S})$ and $1.10 \mathrm{~m}$ (E). The shaft has a maximum depth of about $4.95 \mathrm{~m}$ [Fig. 3.103]. Two side chambers were found at the bottom of the shaft. The main burial niche was hewn into the south wall of the longer side, while the offering chamber was cut into the west wall of the shaft's shorter side. The neighbouring chambers are interconnected by a small hole made in the dividing wall, at floor level. Both chambers were originally blocked with solid 


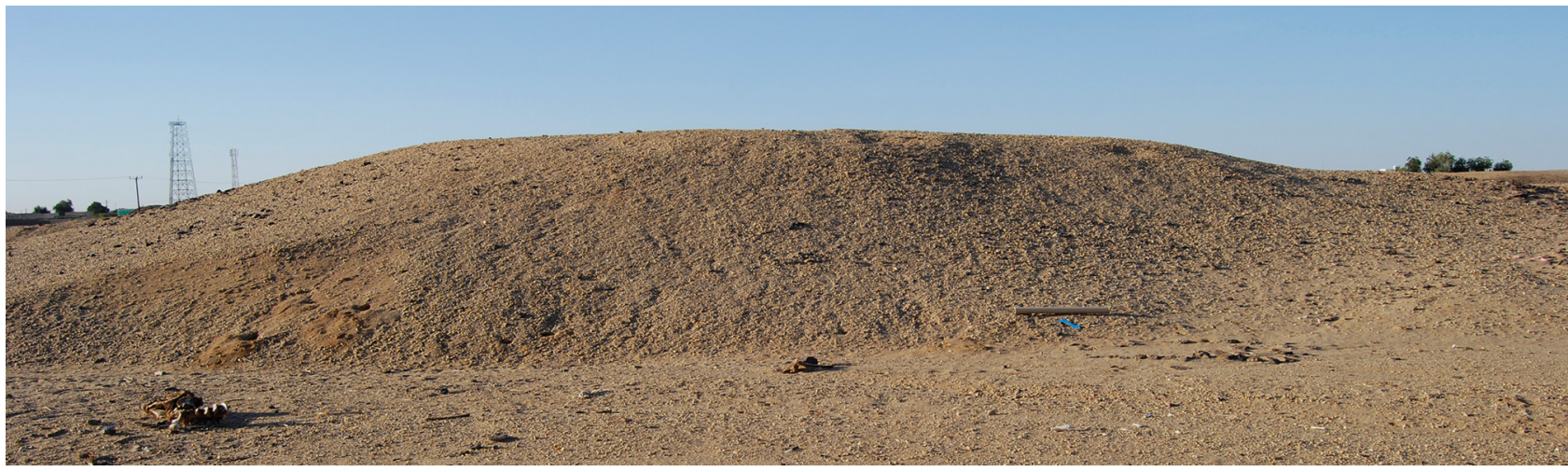

FIGURE 3.101 Tumulus 11, superstructure, looking south Pното BY O. BIAŁOSTOCKA

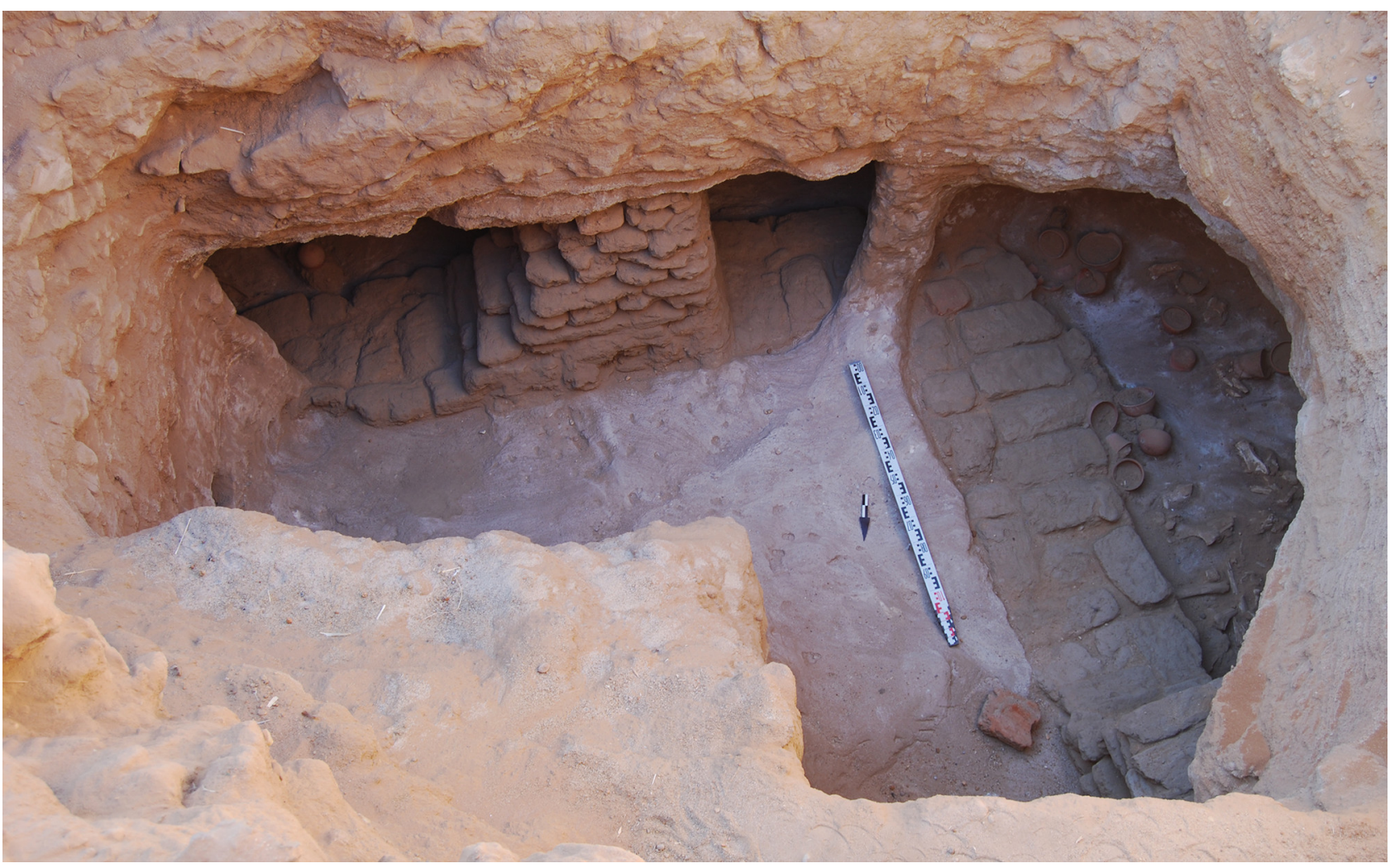

FIGURE 3.102 Tumulus 11, view of the L-shaped shaft, facing south РНОTO BY O. BIAŁOSTOCKA

walls built of large mud bricks, in places mixed with some red bricks. Despite these precautions, both were plundered.

The robbers gained access to the main chamber (Ch. 1) through the dismantled eastern side of the blocking wall [Fig. 3.104]. A disarticulated human skeleton was found inside the chamber; however, due to its poor state of preservation, it was not easy to determine either the position or the orientation of the deceased. This chamber was probably richly furnished, as attested by 12 com- plete pottery vessels that were left behind by the grave robbers. These comprise four bowls and five cups, all of wheel-made red ware, and one large handmade bowl [Fig. 3.105 top]. Apart from the pottery vessels, a concentration of animal bones was found at the west side of the chamber, as well as some blue faience beads, and an eroded iron fragment, probably from the blade of a knife which was found beside the human bones. Chamber 2 , on the west side of the shaft, was set aside exclusively for funerary offerings. It contained 17 complete ves- 

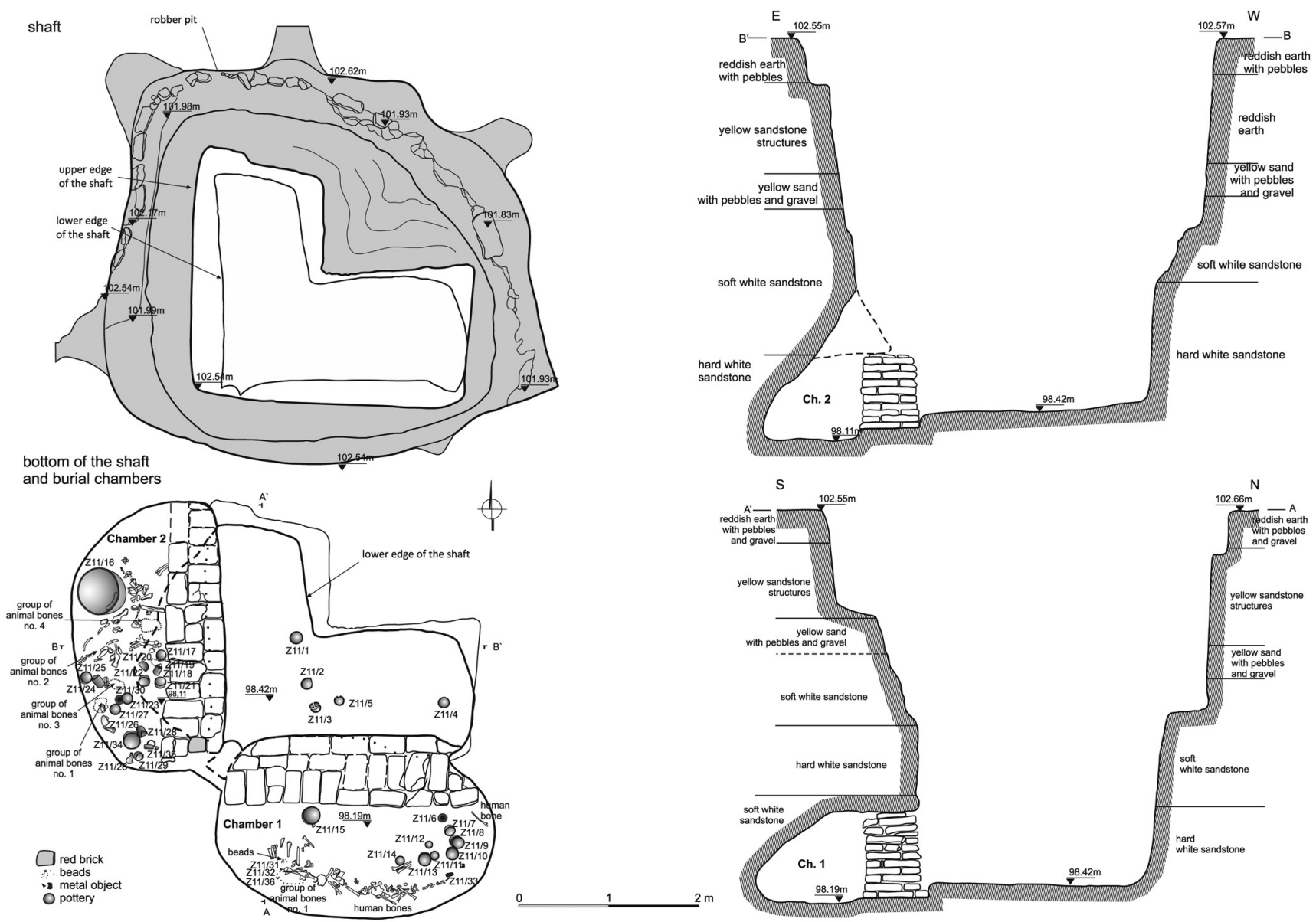

FIGURE 3.103 Tumulus 11, ground plan and cross-sections

DRAWN BY K. JUSZCZYK-FUTKOWSKA, E. CZYŻEWSKA-ZALEWSKA, E. KLIMASZEWSKA-

DRABOT, DIGITISED BY E. CZYŻEWSKA-ZALEWSKA

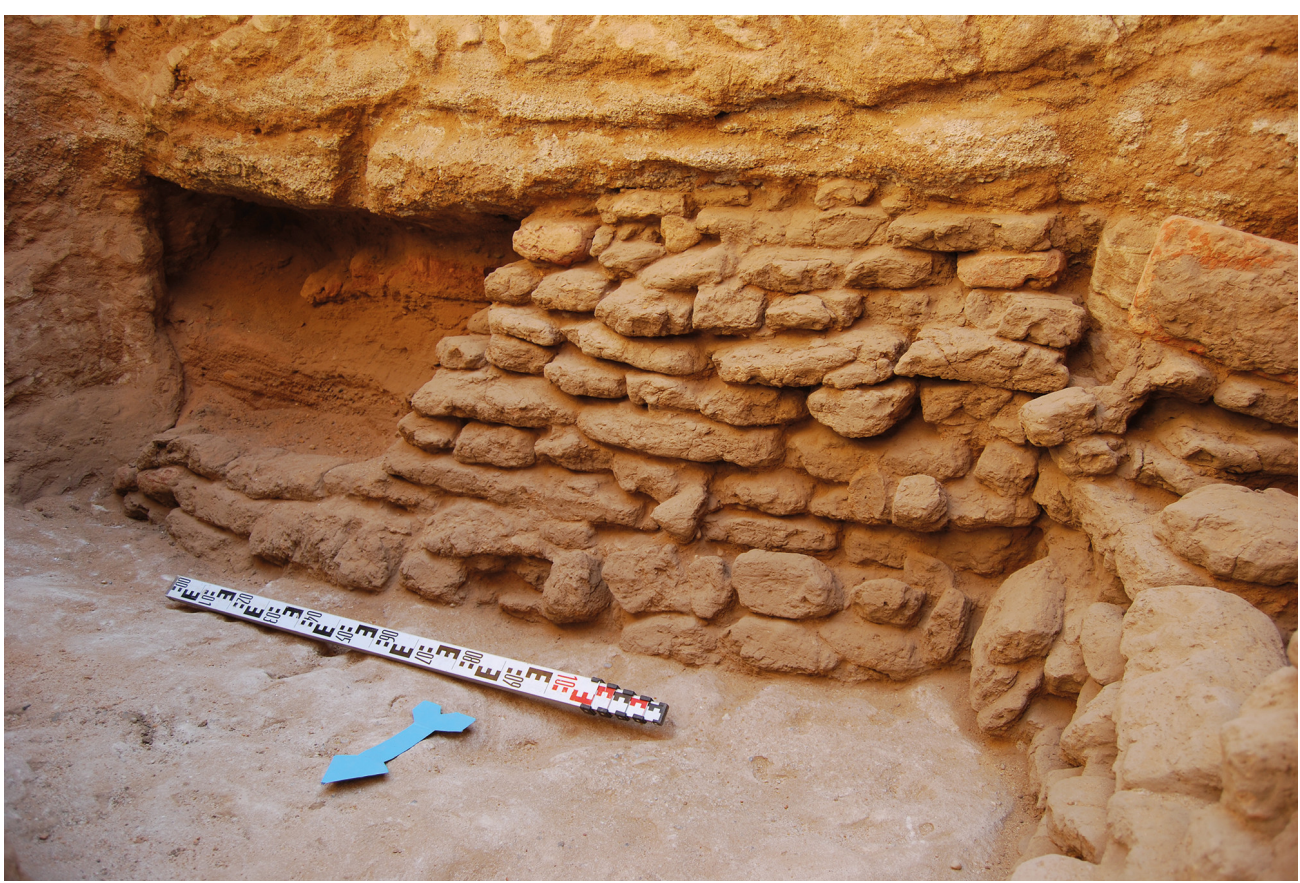

FIGURE 3.104 Tumulus 11, view of the blocking wall showing the robber hole in the east side РНОТО ВY О. ВIAŁOSTOCKA 

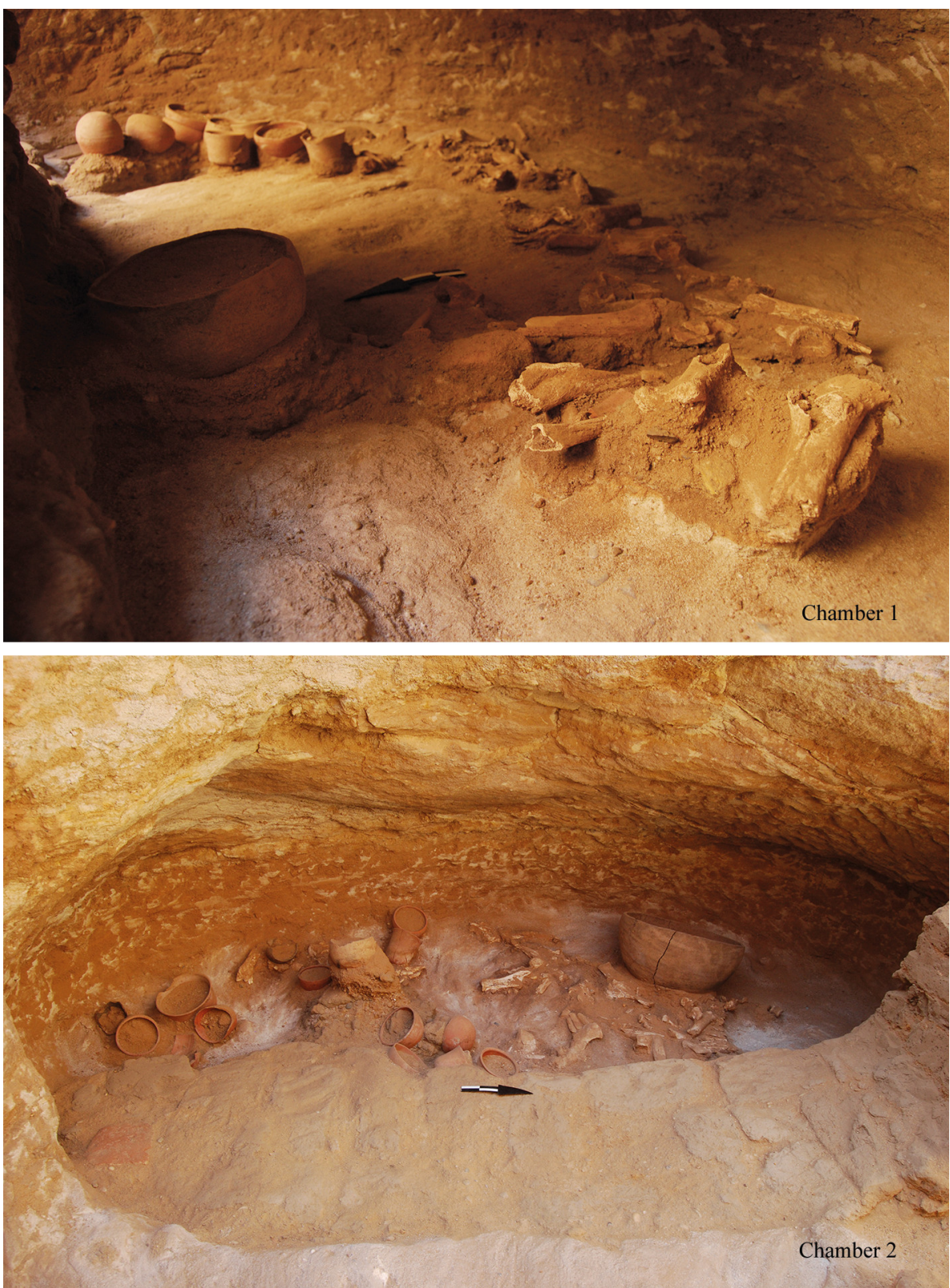

FIGURE 3.105 Tumulus 11, view of grave goods in chamber 1, facing east (top); view of the funerary offerings in the west chamber 2 (bottom) PHOTOS BY O. BIAŁOSTOCKA

sels: 10 bowls and four cups of wheel-made red ware and three handmade vessels, consisting of one black beer jar, one cooking pot, and a very large basin containing animal bones. Animal bones, probably of cattle and sheep/goat, were also found arranged in four groups extending from south to north [Fig. 3.105 bottom]. For more information see Mahmoud El-Tayeb and Czyżewska 2011, 1-16.

\section{Type III Tumuli}

\subsection{Tumulus 10}

Tumulus 10 is made of similar material to that used in the construction of all the other mounds at the cemetery. It has a diameter of about $18.30 \mathrm{~m}$ and a preserved height of up to $1.20 \mathrm{~m}$ [Fig. 3.106]. The substructure is characterized by a slightly deformed rectangular shaft, its sides measuring $3.24 \mathrm{~m}(\mathrm{~W}), 3.14 \mathrm{~m}(\mathrm{E}), 2.02 \mathrm{~m}(\mathrm{~N})$ and $1.99 \mathrm{~m}(\mathrm{~S})$ on the ground surface, with a depth of about $2.60 \mathrm{~m}$. The shaft is provided with a single burial chamber measuring $3.32 \mathrm{~m}$ $\times 1.40 \mathrm{~m} \times 0.90 \mathrm{~m}$ [Fig. 3.107]. The large stone slabs that 


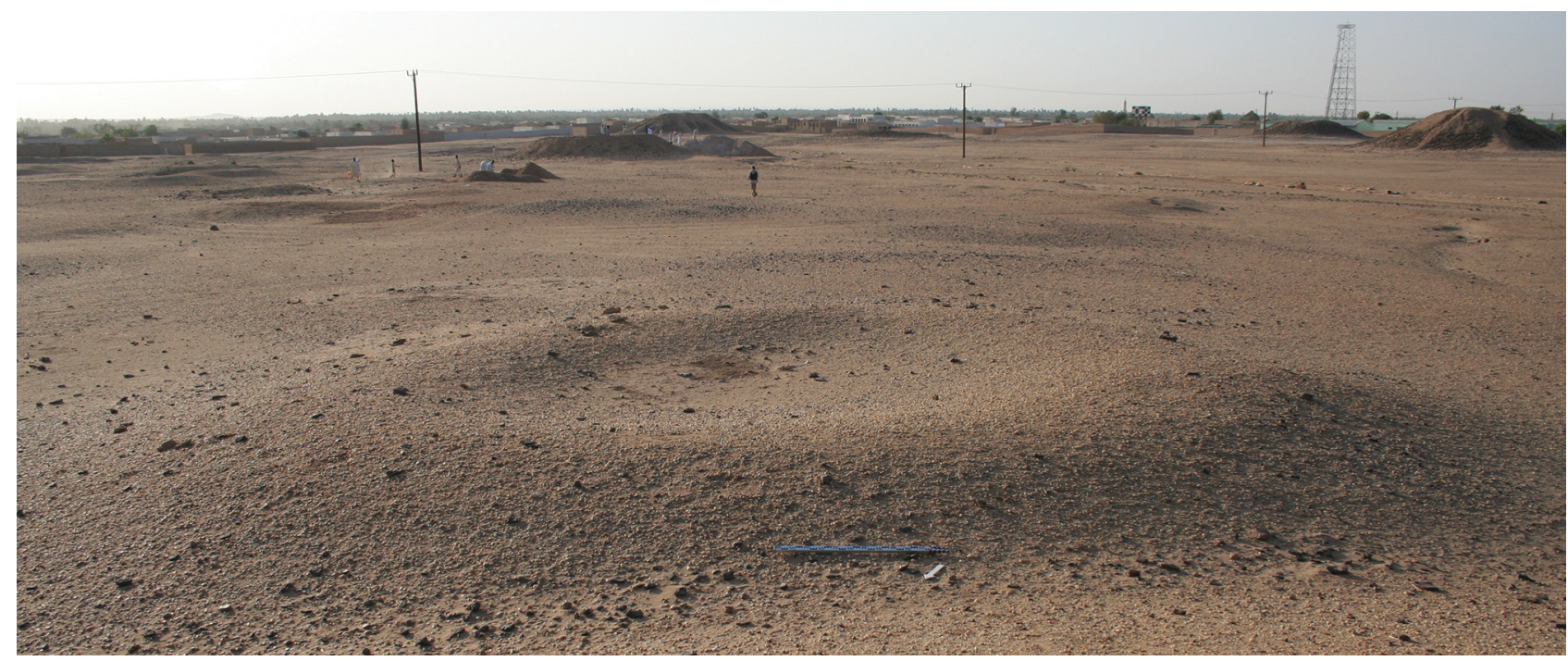

FIGURE 3.106 Tumulus 10, view of the superstructure, looking south PHOTO BY K. KOTLEWSKI

were used to seal the chamber were found dismantled and scattered around the bottom of the shaft [Fig. 3.108]. Several broken fragments of pottery vessels recorded in the shaft fill attest to the fact that the burial chamber was heavily looted.

Fragments of human skull were noted in the centre of the burial chamber, mixed with some animal bones, while more of the latter were also recorded at the southern end of the chamber [Fig. 3.109].

Although the burial chamber had been badly rifled, 27 complete pottery vessels of different forms were, nonetheless, found inside it. These comprise wheel-made cups, bowls, and bottles, as well as handmade beer jars and cooking pots. Moreover, it contained many fragments of badly corroded metal objects, including a number of complete and fragmentary arrowheads, some barbless and others with a single barb, in addition to broken knives and spears.

Several adornments left behind by the robbers in the ransacked grave are represented by a fragment of silver chain, teardrop-shaped beads made of black stone, and rounded red agate beads as well as some made of faience. For more information see Mahmoud El-Tayeb 2010b, 474476.

\subsection{Tumulus 17}

Tumulus 17 is a very low mound with a preserved height of about $0.45 \mathrm{~m}$ and a maximum diameter of $10 \mathrm{~m}$ [Fig. 3.110]. The mound is built from a mixture of sand and gravel and is surrounded by a stone ring about $3.60 \mathrm{~m}$ in diameter, which originally demarcated the limit of the mound. It is located between T.18 and T.19, in the central part of the cemetery [see Fig. 1.2]. The geological deposits in this part of the burial ground are quite different. The surface is covered with aeolian sand overlying a mixture of small stones in addition to gravel and reddish soil that forms a stratum of about $2.31 \mathrm{~m}$ thick down to the bottom of the shaft. The floor at the bottom consists of a compact layer of black gravel and whitish-greyish sand. The robbers had dug a large hole, about $2 \mathrm{~m}$ wide, at the top of the mound, but it seems that they missed the centre of the shaft as well as the blocking wall.

The shaft is aligned north-south and has a trapezoid plan [Fig. 3.111] that measures $1.34 \mathrm{~m} / 1.80 \mathrm{~m}(\mathrm{E} / \mathrm{W})$ by $0.98 \mathrm{~m} / 0.86 \mathrm{~m}(\mathrm{~N} / \mathrm{S})$ at ground level, narrowing towards the bottom to $1.24 \mathrm{~m} / 1.45 \mathrm{~m}(\mathrm{E} / \mathrm{W})$ by $0.70 \mathrm{~m} / \mathrm{o} .80 \mathrm{~m}(\mathrm{~N} / \mathrm{S})$. A single burial chamber is cut into the west wall of the shaft, measuring $2.40 \mathrm{~m}$ in length, $0.80 \mathrm{~m}$ in width and only $0.52 \mathrm{~m}$ in height [Fig. 3.112]. The robbers had dug into part of the west wall and removed some of the stones of the blocking wall from the south-west corner of the shaft. Thus, they reached the burial chamber and badly damaged the human skeleton inside it. Although the skeleton was greatly disturbed, fragments of leg and foot bones indicate that it may have originally been laid on its right side, in a contracted position, with head due north-west, facing south. The grave goods consisted of two complete handmade beer jars, a large brown one located at the northern end of the chamber and a smaller one of black ware deposited at the opposite (southern) end [Fig. 3.113]. An iron ring and a group of about nine badly corroded iron arrowheads were also found. Further finds included about 88 beads of different materials such as quartz, agate, faience, and probably ivory or bone. Fragments of beer jars used by the robbers as scrapers/digging 


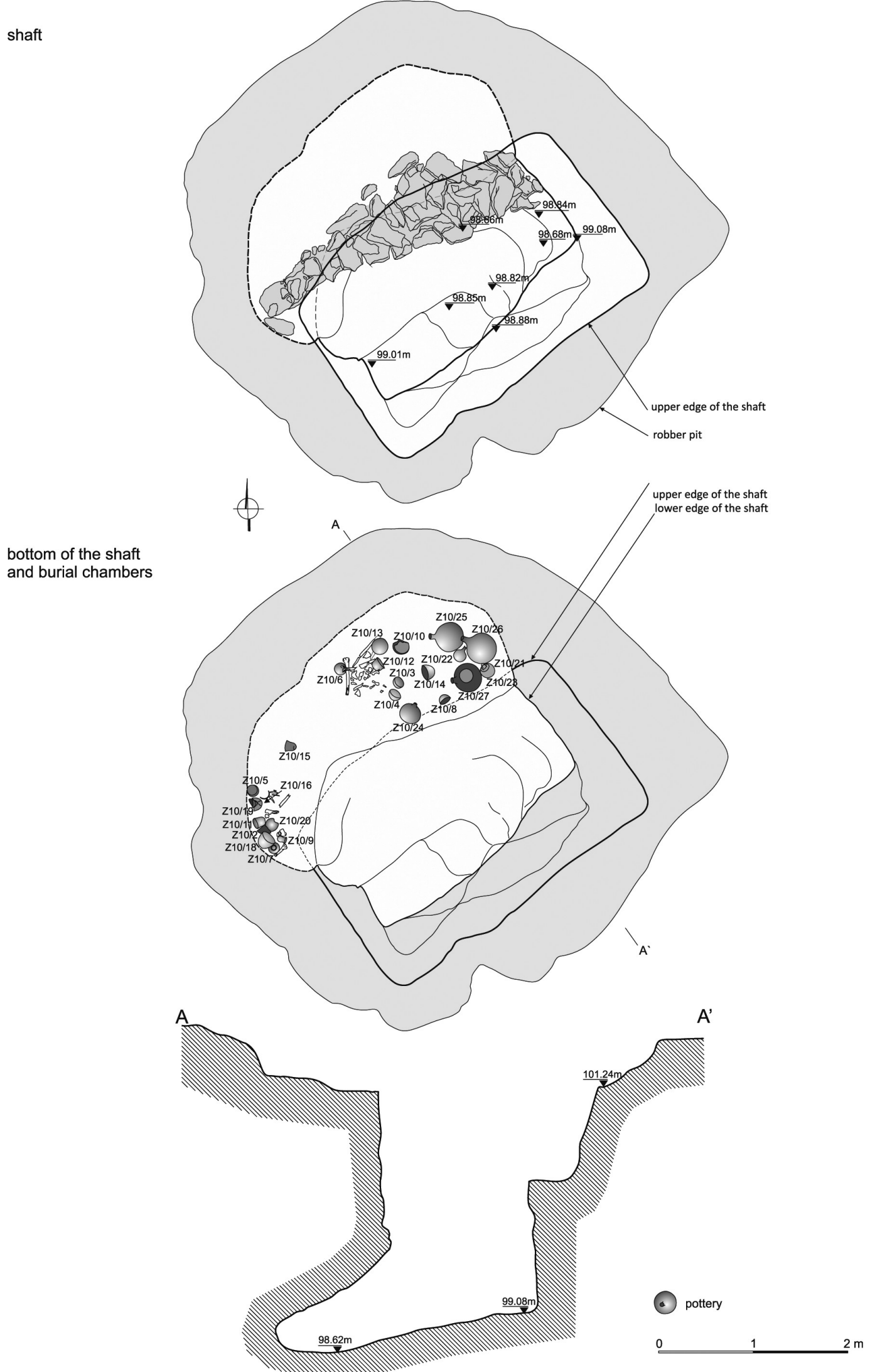

FIGURE 3.107 Tumulus 10, ground plan and cross-section of the burial shaft DRAWN BY K. OCHNIO, A. BŁASZCZYK, E. KLIMASZEWSKA-DRABOT, M. WYBIERALSKA, DIGITISED BY M. PUSZKARSKI 


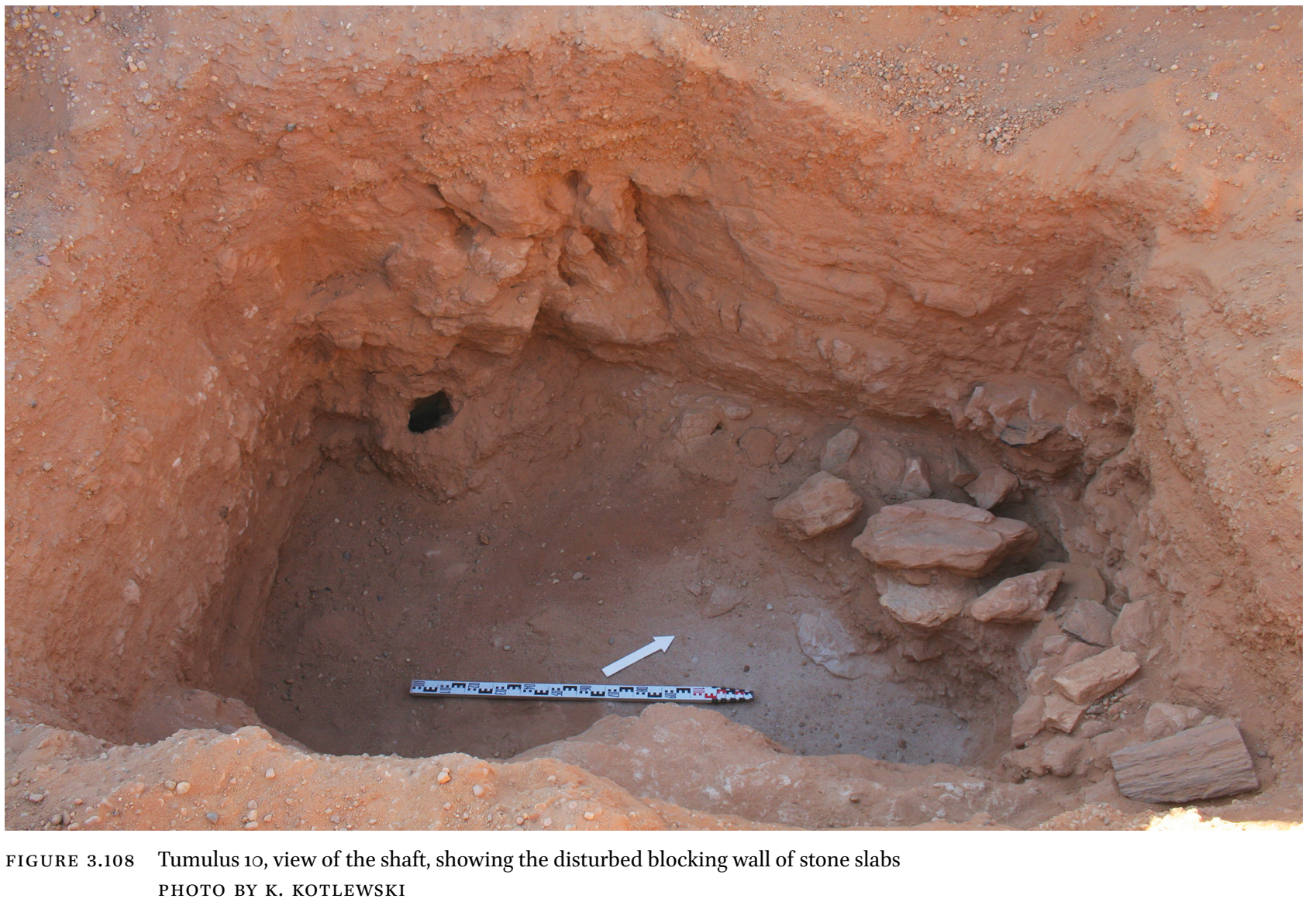

tools (see Volume II, chapter 4.3) were found in the shaft fill as well as in the burial chamber itself. For more information see Mahmoud El-Tayeb and Czyżewska 2011.

\subsection{Tumulus 18}

Tumulus 18 is a very low, flat-topped mound with a diameter of about $10 \mathrm{~m}$ and a preserved height of no more than $0.35 \mathrm{~m}$ [Fig. 3.114]. Like T.22, this mound is also built from a mixture of earth and fine gravel. Its substructure presented a trapezoidal outline at ground level, measuring $1.30 \mathrm{~m} / 1.20 \mathrm{~m}(\mathrm{~N} / \mathrm{S})$ by $1.30 \mathrm{~m} / 1.90 \mathrm{~m}(\mathrm{E} / \mathrm{W})$ [Fig. 3.115]. This marked the top of a vertical shaft about $1.55 \mathrm{~m}$ in depth, provided with a side niche cut into the west wall of the shaft [Fig. 3.116 left]. The niche measures $1.8 \mathrm{om} \times 0.6 \mathrm{om}$ $\times 0.5^{2} \mathrm{~m}$. Its entrance was originally sealed with large slabs of rough stones that were found dismantled and scattered in the direction of the opposite (east) wall of the shaft. Thus, the burial chamber had been penetrated and badly rifled [Fig. 3.117]. Nevertheless, inside the plundered burial chamber the robbers left behind a disarticulated human skeleton and some pottery, namely three bottles, one shallow bowl, two wheel-made cups, and two beer jars, one complete and the other fragmented. For more information see Mahmoud El-Tayeb 201ob, 474-476.

\subsection{Tumulus 19}

Tumulus 19 is a low mound [Fig. 3.118] built from earth and fine gravel, surrounded at the base by a stone ring [Fig. 3.119]. It has a diameter of about $13.40 \mathrm{~m}$ and a maximum preserved height of about $0.47 \mathrm{~m}$. Like the substructure of T.18, the shaft of T.19 also has a trapezoid ground plan and a vertical shaft about $2.34 \mathrm{~m}$ deep, provided with one side chamber hewn into its west wall. This niche measures about $1.80 \mathrm{~m} \times 0.83 \mathrm{~m} \times 0.5^{2} \mathrm{~m}$ [Fig. 3.12o]. The entrance to the chamber was blocked with chunks of rough stone that were removed by robbers and piled up against the east wall of the shaft [Fig. 3.121].

As a result of looting, the burial chamber was left in a very bad state. The bones of a disarticulated human skeleton were found scattered across the centre of the chamber and its northern side. In addition to the broken pottery recovered from the shaft fill, four different vessels were found in fragmentary state inside the burial chamber. They comprised one handmade cup, one spouted bowl, one wheel-made bowl and one beer jar. The chamber also contained some arrowheads [Fig. 3.122]. For more information see Mahmoud El-Tayeb 2010b, 474-476. 

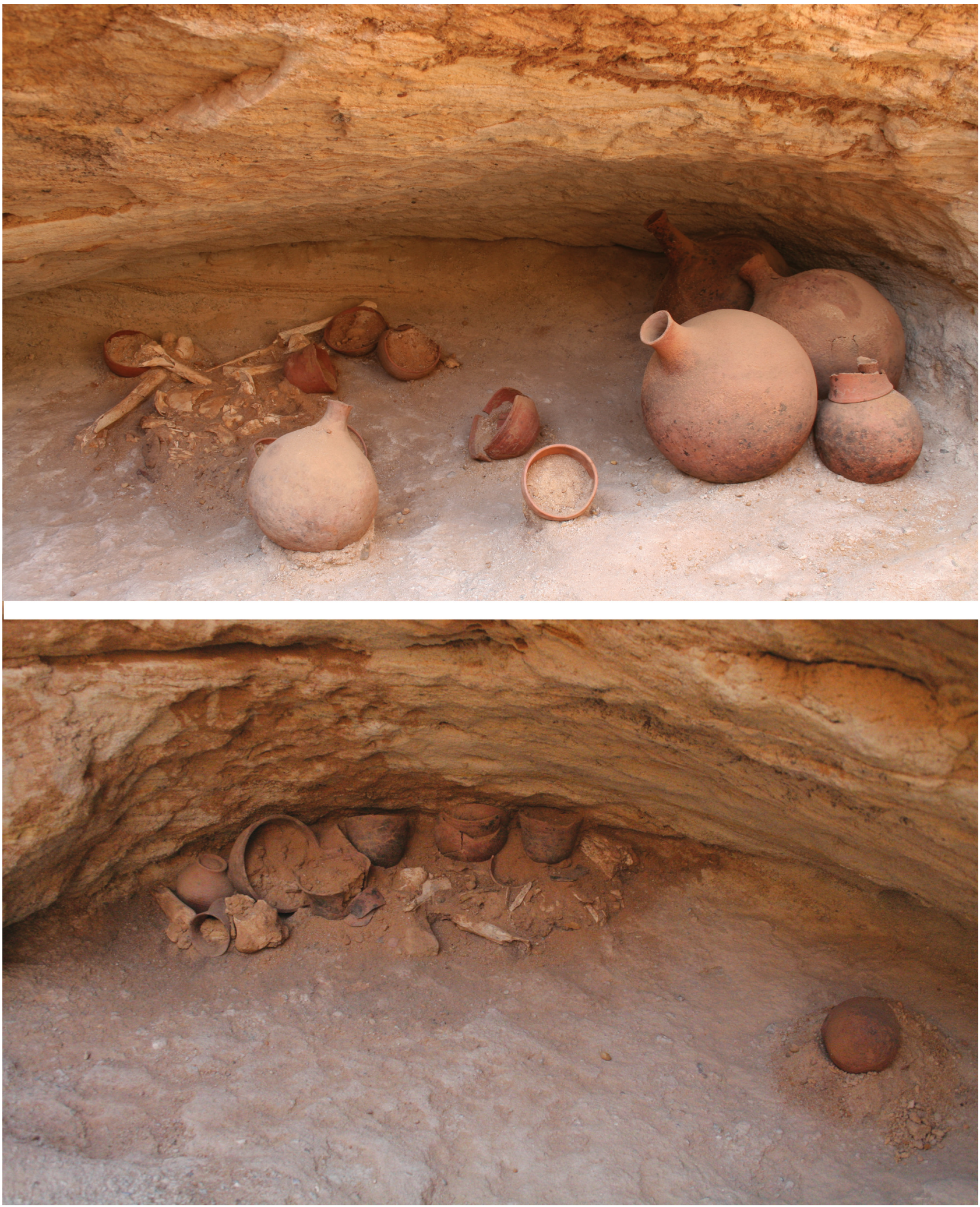

FIGURE 3.109 Tumulus 10, view of the central and northern part of the burial chamber, showing disarticulated human skeleton in the middle (top); southern part of the burial chamber with offerings of pottery and animal bones (bottom)

PHOTOS BY K. KOTLEWSKI 


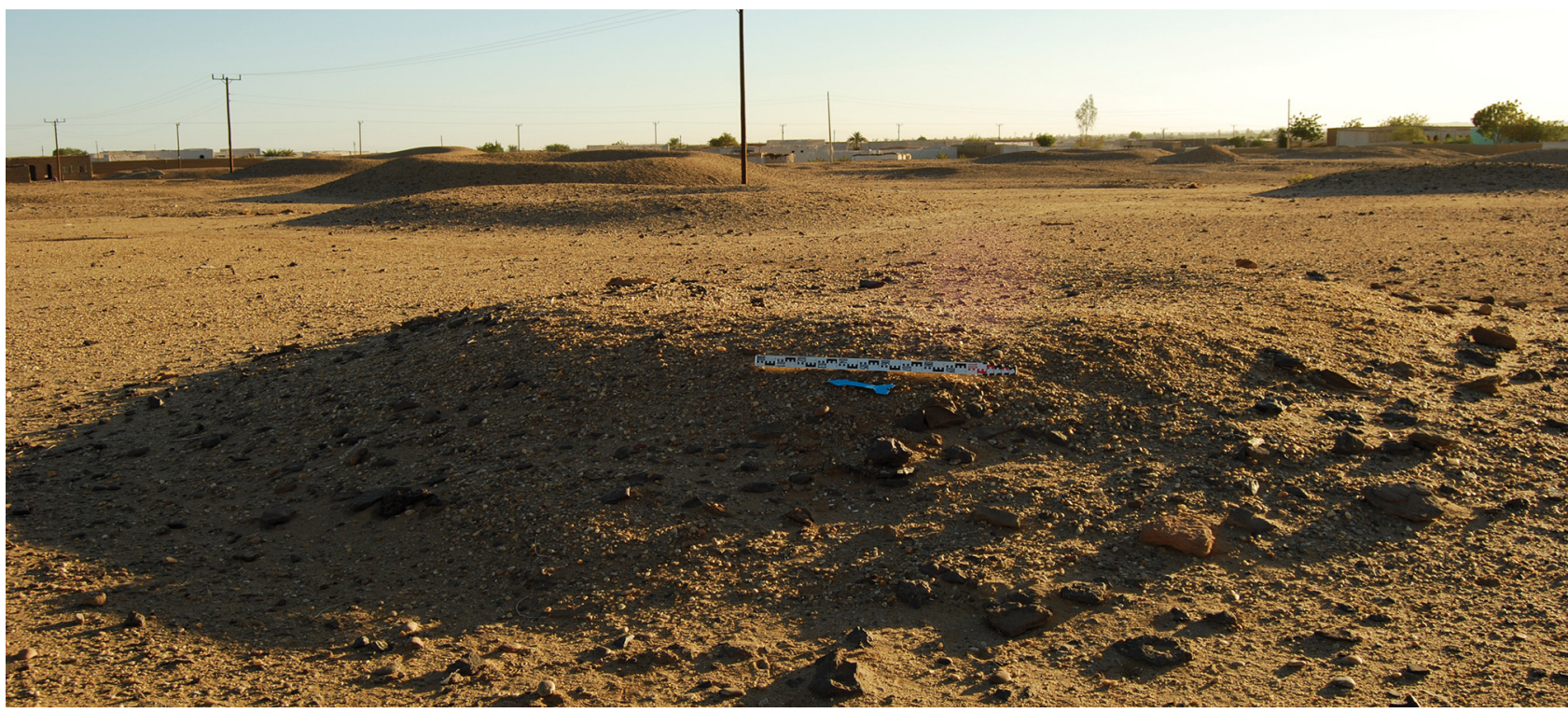

FIGURE 3.110 Tumulus 17, view of the superstructure, looking east РНОТО BY O. BIAŁOSTOCKA

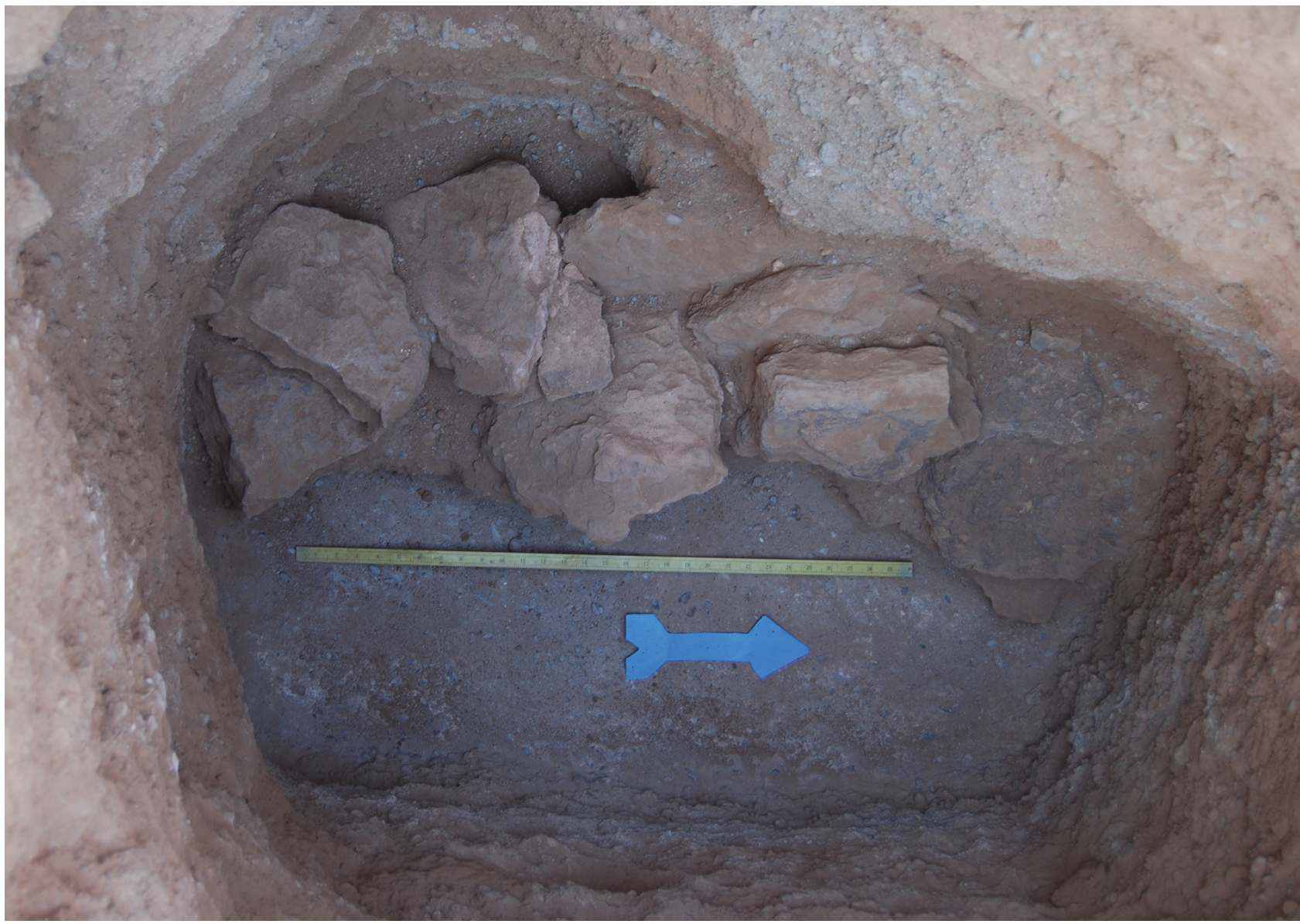

FIGURE 3.111 Tumulus 17, the burial shaft and stone slabs of the burial chamber's blocking wall РНОТО BY О. BIAŁOSTOCKA 


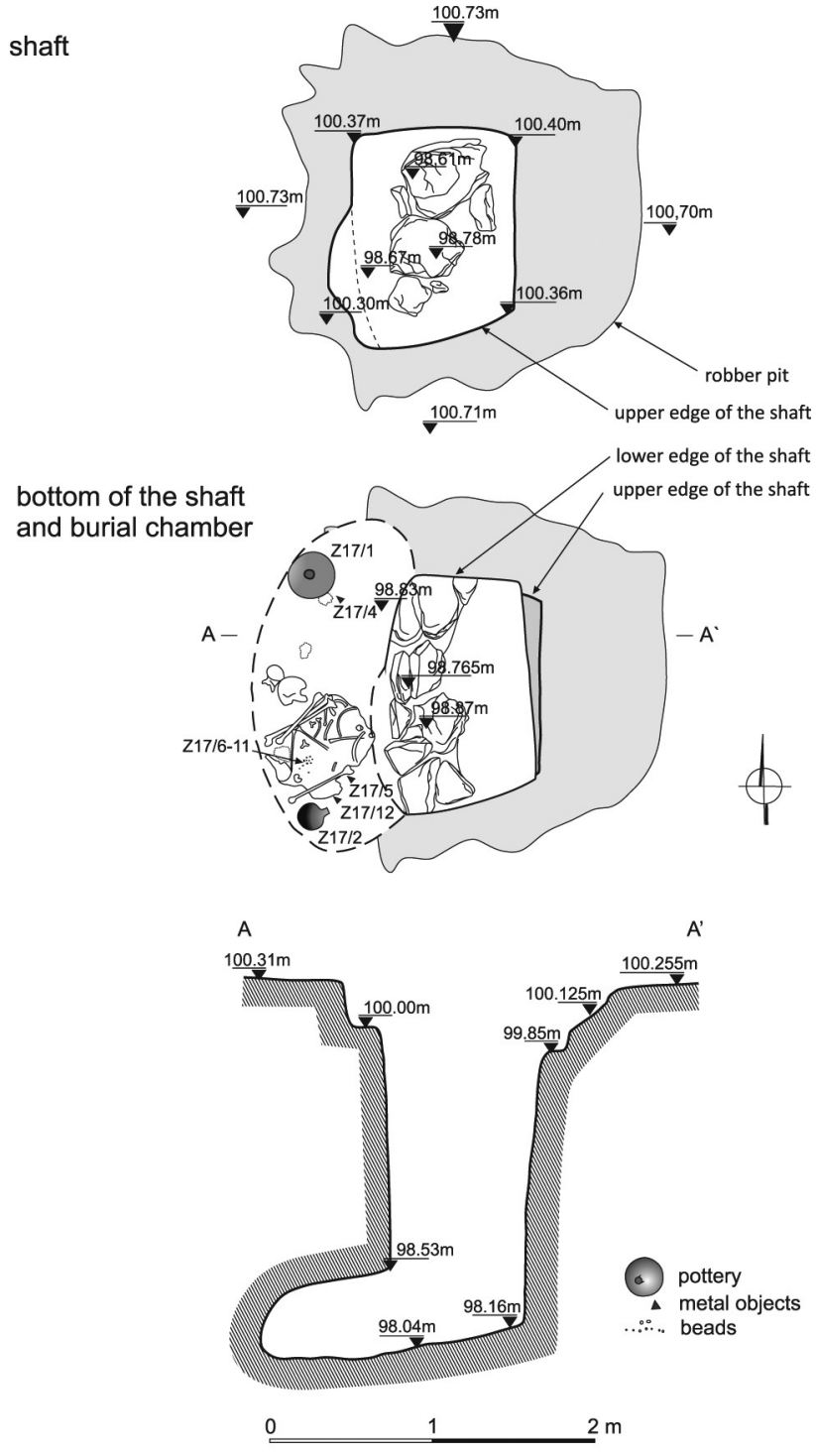

4.5 Tumulus 20

Tumulus 20 is situated in the central part of the site, in a group of three small tumuli (T.2O-T.22) assigned to type III [see Fig. 1.2]. This is a round, flat-topped mound with a maximum height of $0.70 \mathrm{~m}$ and a diameter of $13.50 \mathrm{~m}$ [Fig. 3.123]. It is encircled by a stone ring $9 \mathrm{~m}$ in diameter [Fig. 3.124]. The burial shaft is trapezoidal in plan and its sides are of similar dimensions from top to bottom: $0.85 \mathrm{~m}(\mathrm{~N}), 1.20 \mathrm{~m}(\mathrm{E}), 0.90 \mathrm{~m}(\mathrm{~S}), 1.50 \mathrm{~m}(\mathrm{~W})$ [Fig. 3.125]. It is $2.58 \mathrm{~m}$ deep and was cut into soft, friable sandstone. The burial chamber, oriented north-south, was hewn into the white sandstone bedrock off the west side of the burial shaft. Humidity inside the chamber coupled with the friability of the stone resulted in the collapse of the roof [Fig. 3.127]. The chamber had originally been sealed with a wall made from blocks of white sandstone (found in the fill). The bottom course of this wall, which would have been $1.50 \mathrm{~m}$ long and approximately $0.80 \mathrm{~m}$ wide,
FIGURE 3.112

Tumulus 17, ground plan and cross-section DRAWN BY E. CZYŻEWSKA-ZALEWSKA, E. KLIMASZEWSKA-DRABOT, DIGITISED BY E. CZYŻEWSKA-ZALEWSKA

consisted of two large sandstone boulders (each about o.6om long) [Fig. 3.126]. The tomb had evidently been plundered: traces of a robber shaft were observed at the top centre of the mound, encompassing the original shaft and part of the burial chamber. Human bones (including a skull), a substantial number of faience beads and a damaged vessel were found in the fill of the shaft, indicating that the body had been dragged from the chamber during the looting. Inside the chamber, the fill yielded three vessels, an abundance of faience beads and fragmented human bones. For more information see Mahmoud ElTayeb, Juszczyk-Futkowska, and Czyżewska 2014, 357-36o. 


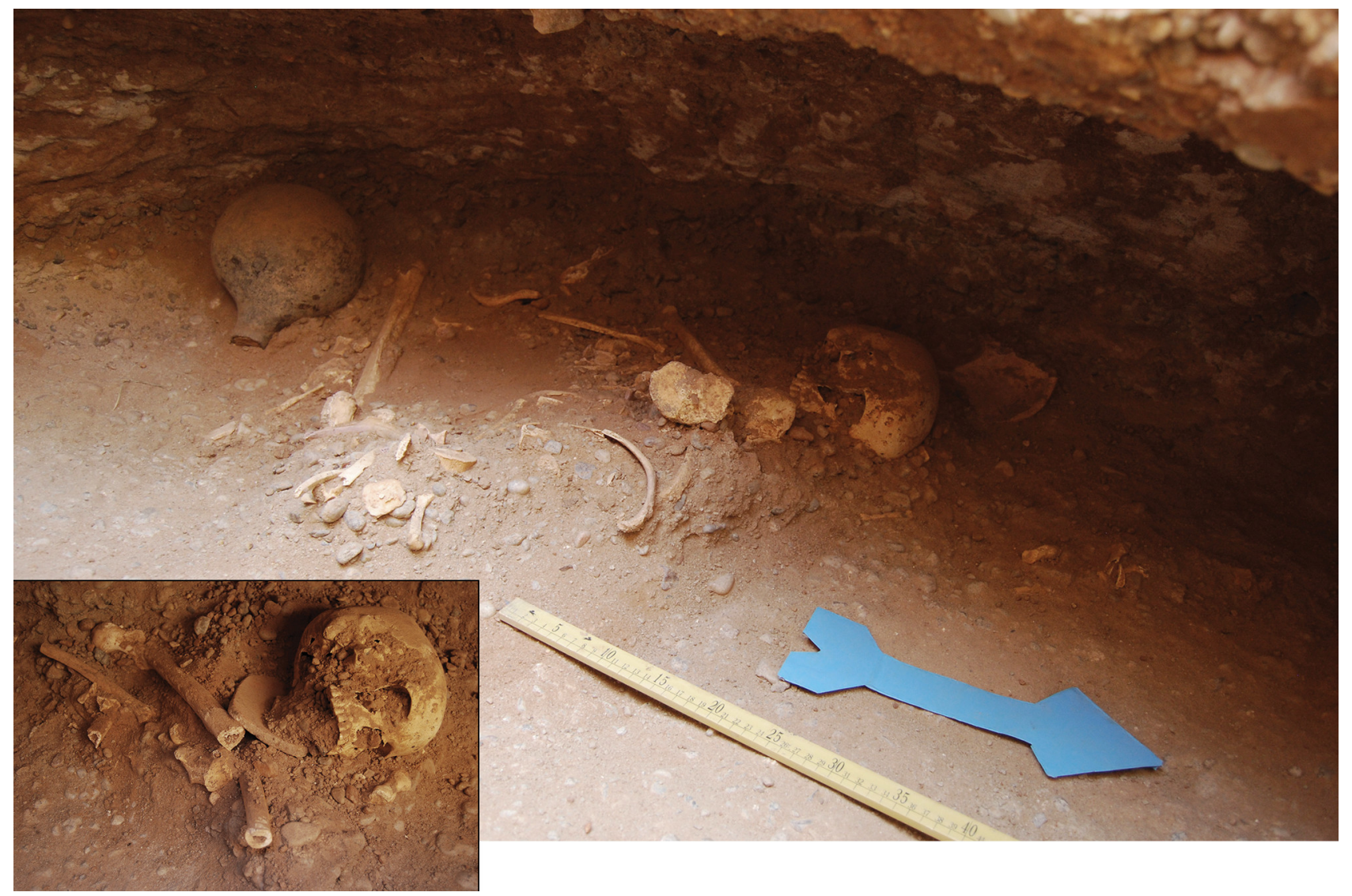

FIGURE 3.113 Tumulus 17, view of the burial chamber; inset: the damaged human skeleton РНОTO BY O. BIAŁOSTOCKA

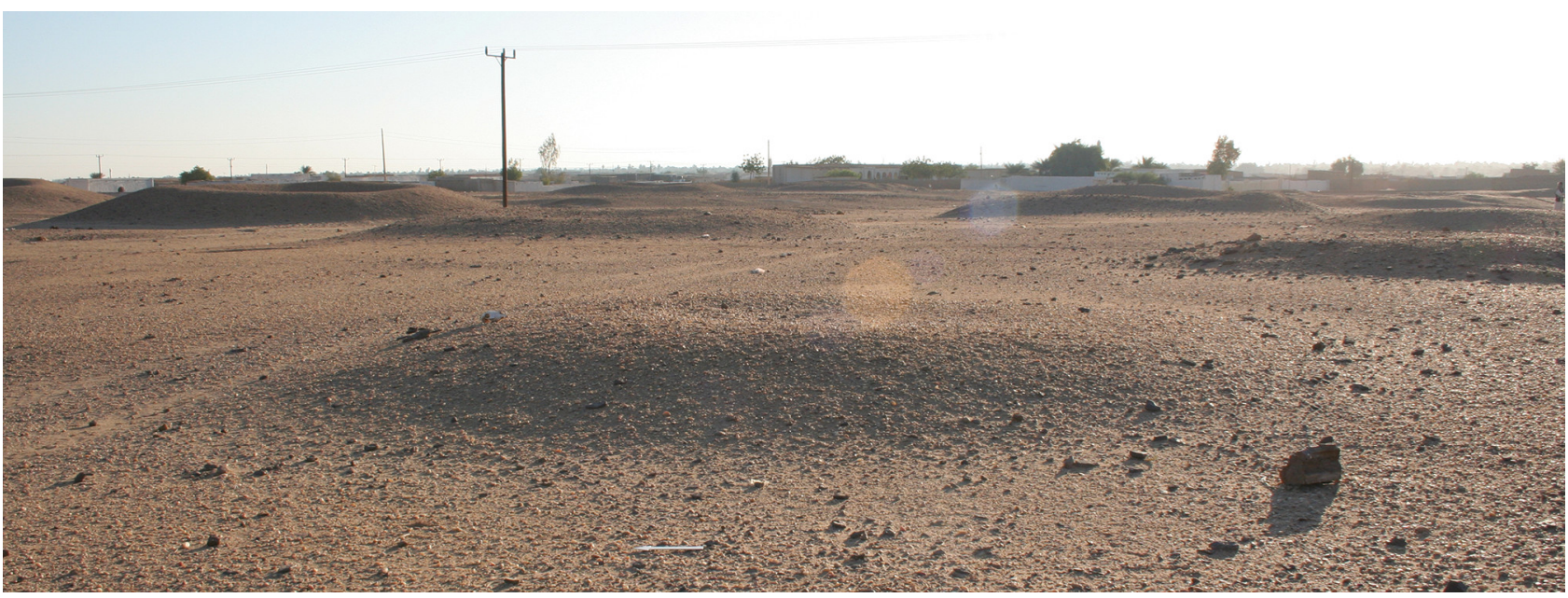

FIGURE 3.114 Tumulus 18, view of the superstructure, looking east РНОTO BY K. KOTLEWSKI 

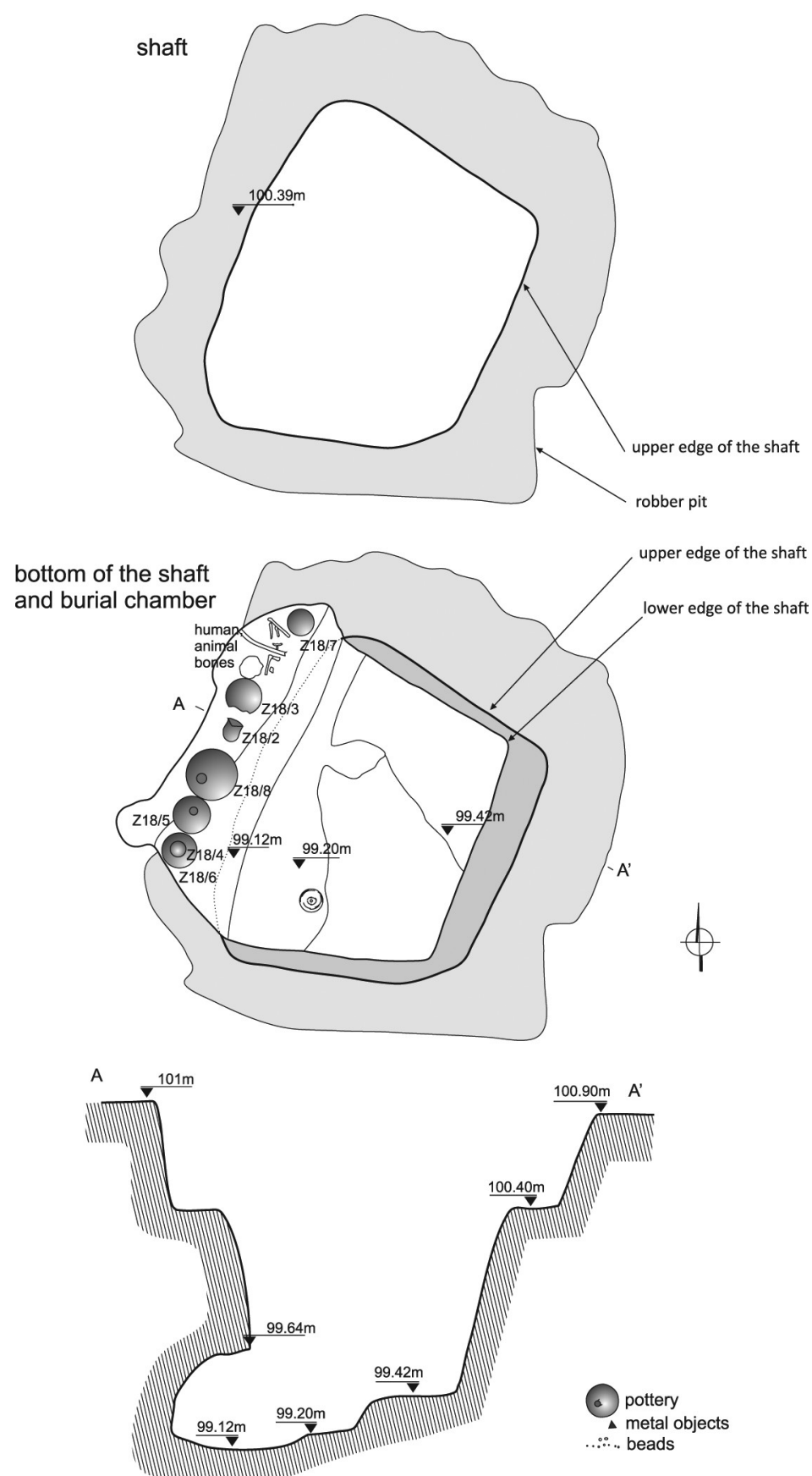

$\underline{0}$ $2 \mathrm{~m}$
FIGURE 3.115

Tumulus 18, ground plan and cross-section

DRAWN BY E. KLIMASZEWSKA-DRABOT, M. WYBIERALSKA,

K. KOTLEWSKI, DIGITISED BY M. PUSZKARSKI 

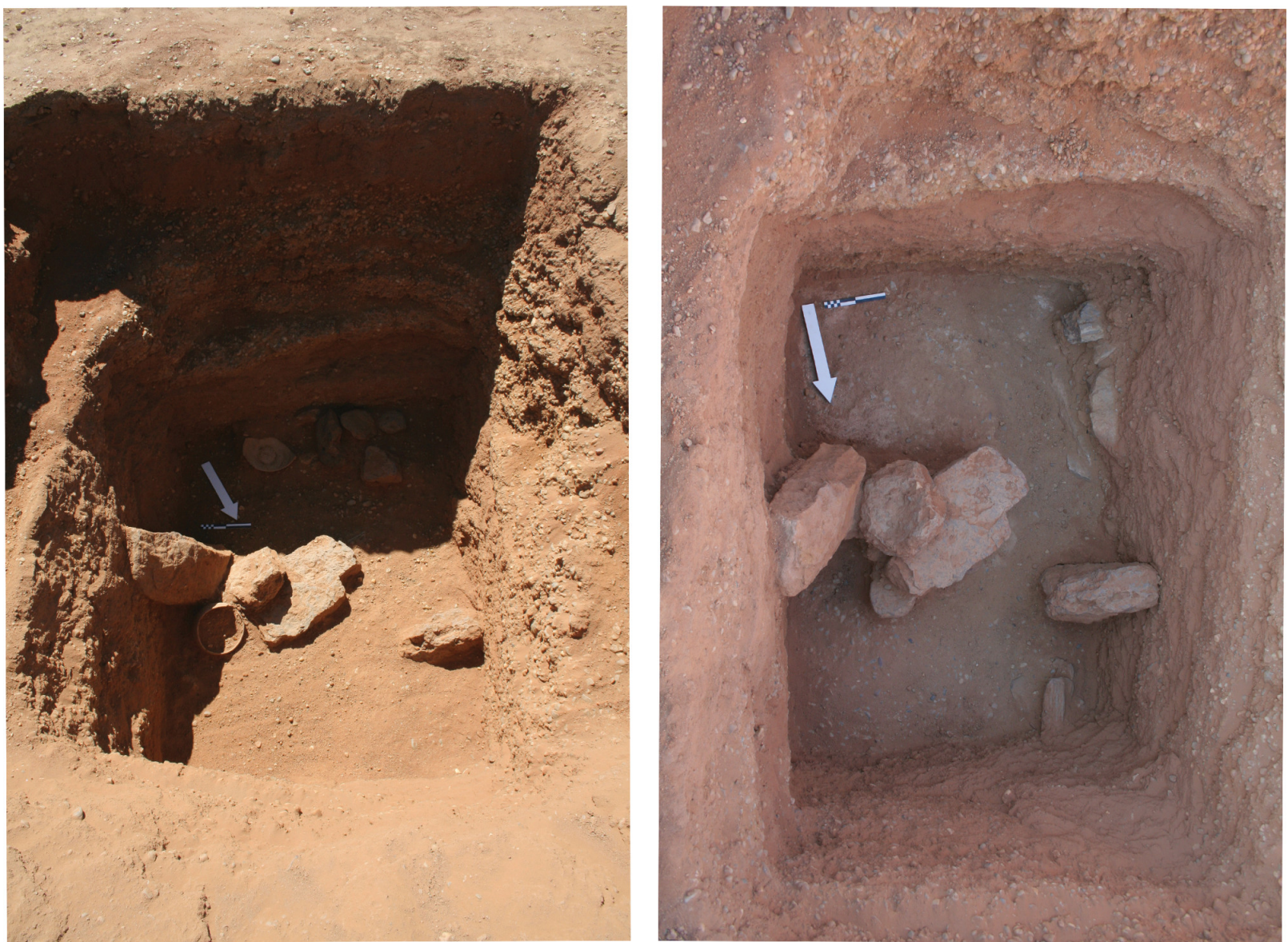

FIGURE 3.116 Tumulus 18, view of the burial shaft, showing the dismantled stone blocking wall and part of the grave goods (left); view of the cleaned shaft (right) PHOTOS BY K. KOTLEWSKI

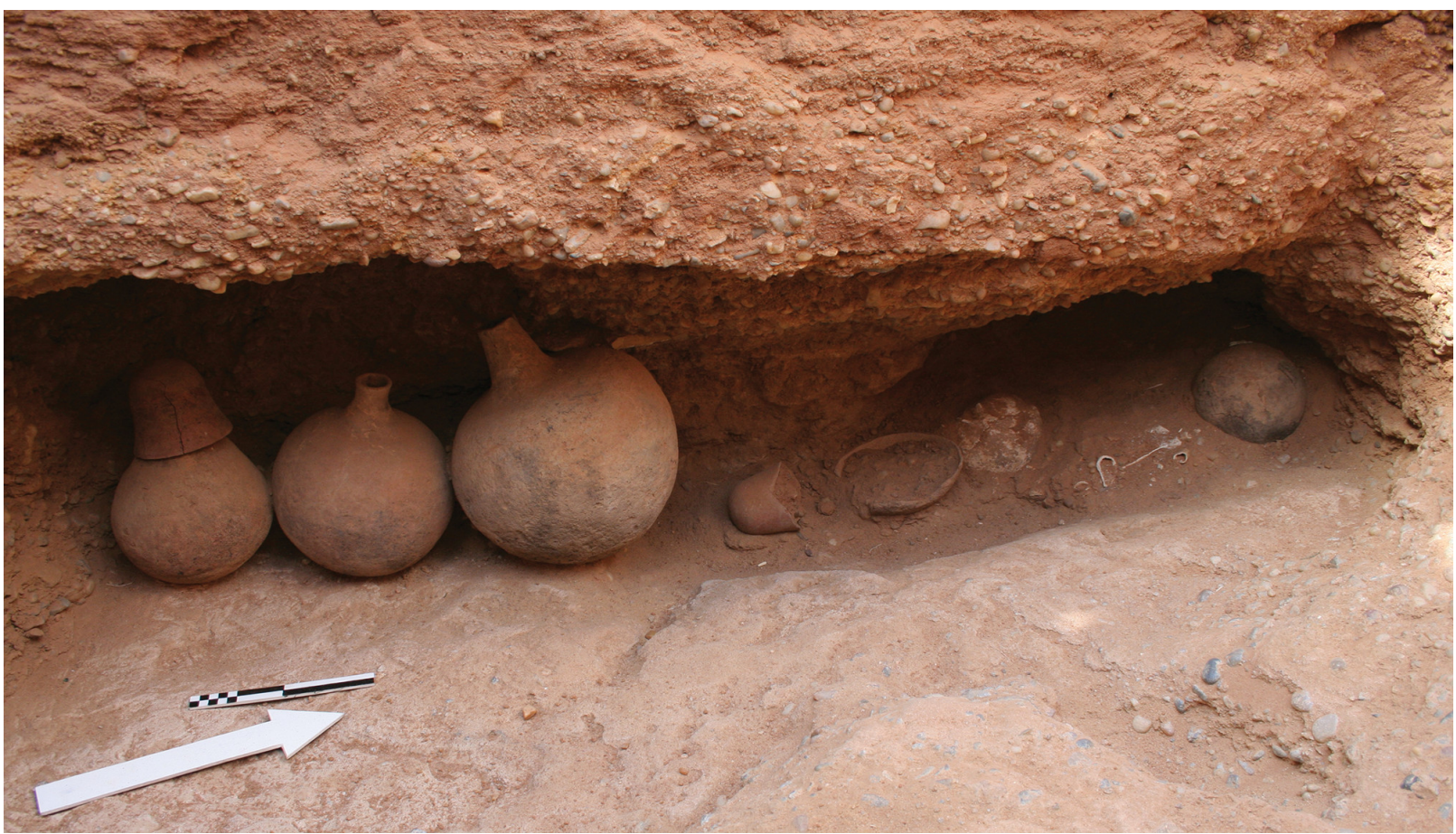

FIGURE 3.117 Tumulus 18, view of the burial chamber with grave goods and damaged skeleton РНОTO ВY К. КОTLEWSKI 


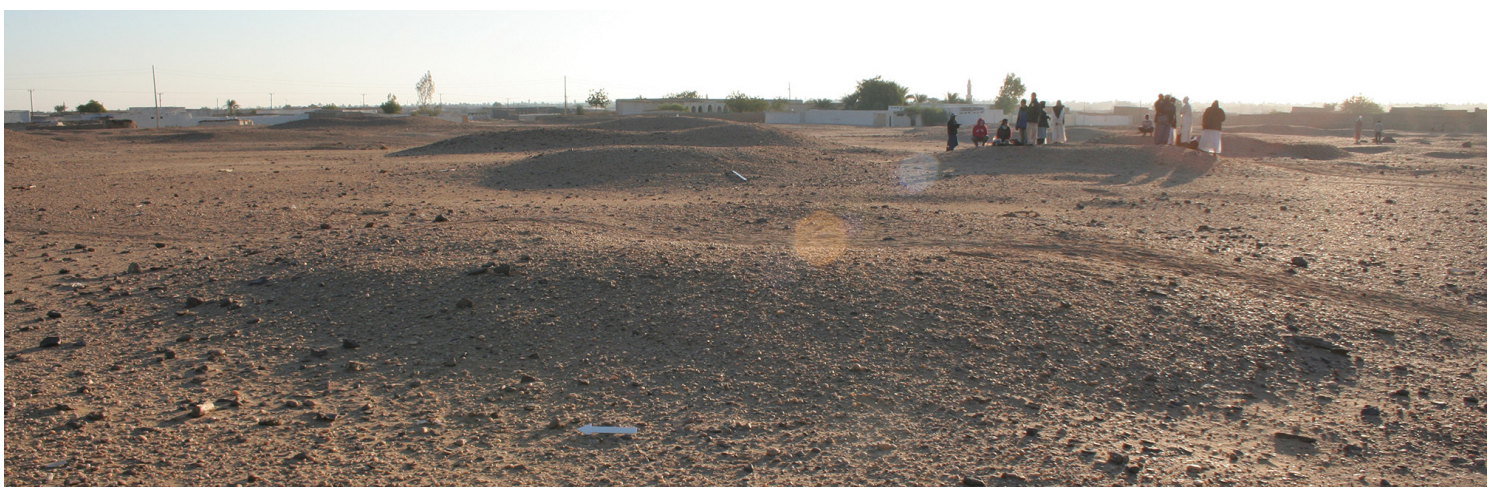

FIGURE 3.118 Tumulus 19, view of the partly disturbed superstructure, looking east РнОTO BY K. KOTLEWSKI

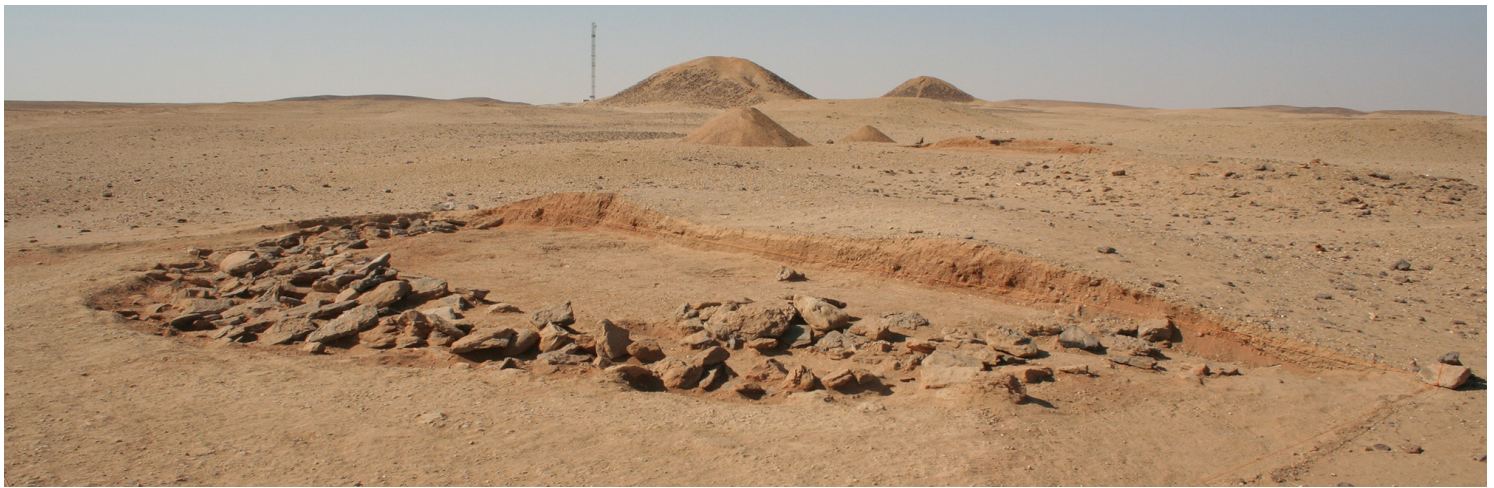

FIGURE 3.119 Tumulus 19, view of the stone ring around the superstructure, looking west РНОTO ВY К. КОTLEWSKI

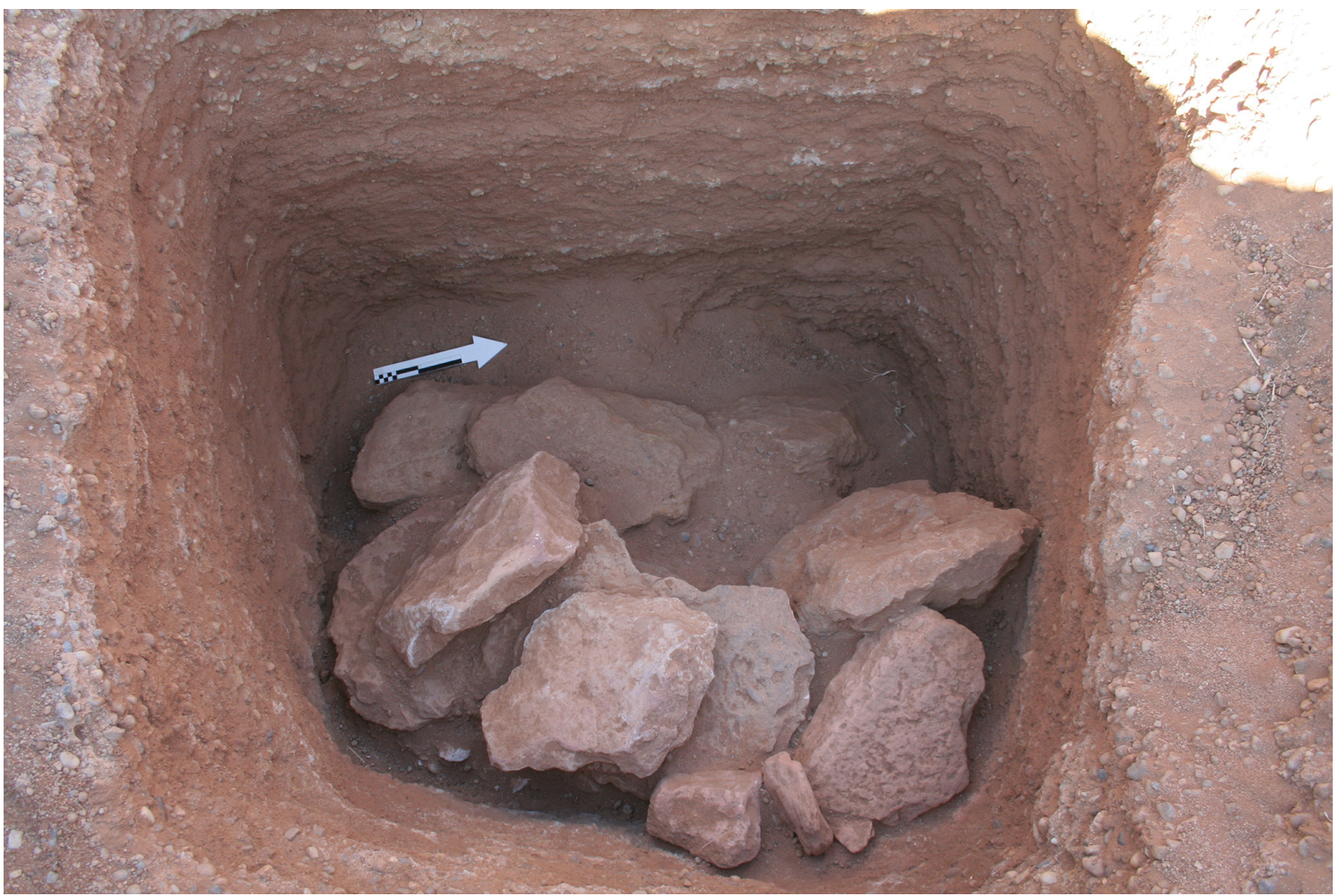

FIGURE 3.120 Tumulus 19, view of the dismantled stone blocking wall at the bottom of the trapezoidal burial shaft

PHOTO BY K. KOTLEWSKI 


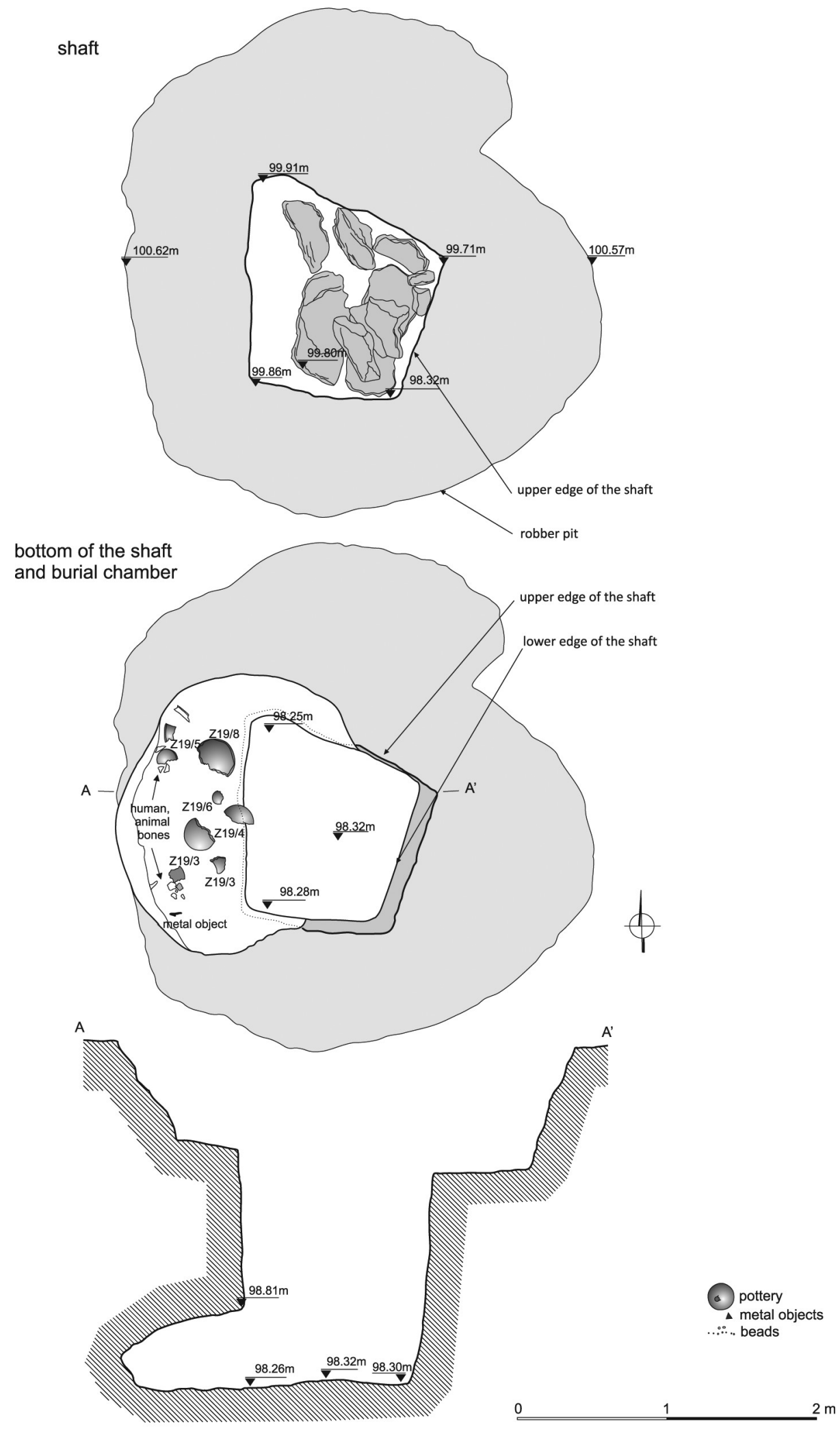

FIGURE 3.121 Tumulus 19, ground plan and cross-section

DRAWN BY A. BŁASZCZYK, K. OCHNIO, DIGITISED BY M. PUSZKARSKI,

E. CZYŻEWSKA-ZALEWSKA 


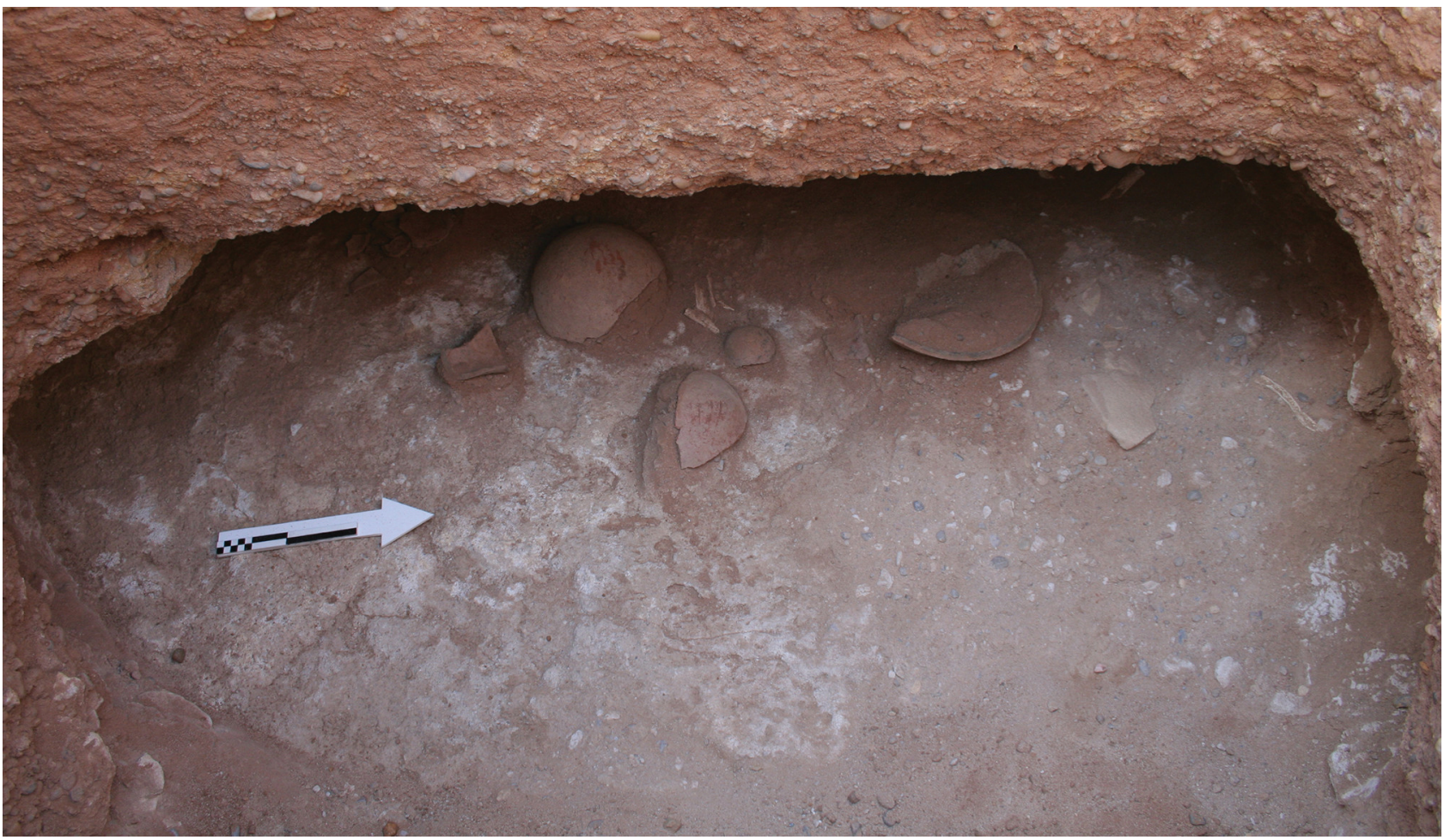

FIGURE 3.122 Tumulus 19, view of the plundered burial chamber РНОТО ВY К. КОTLEWSKI

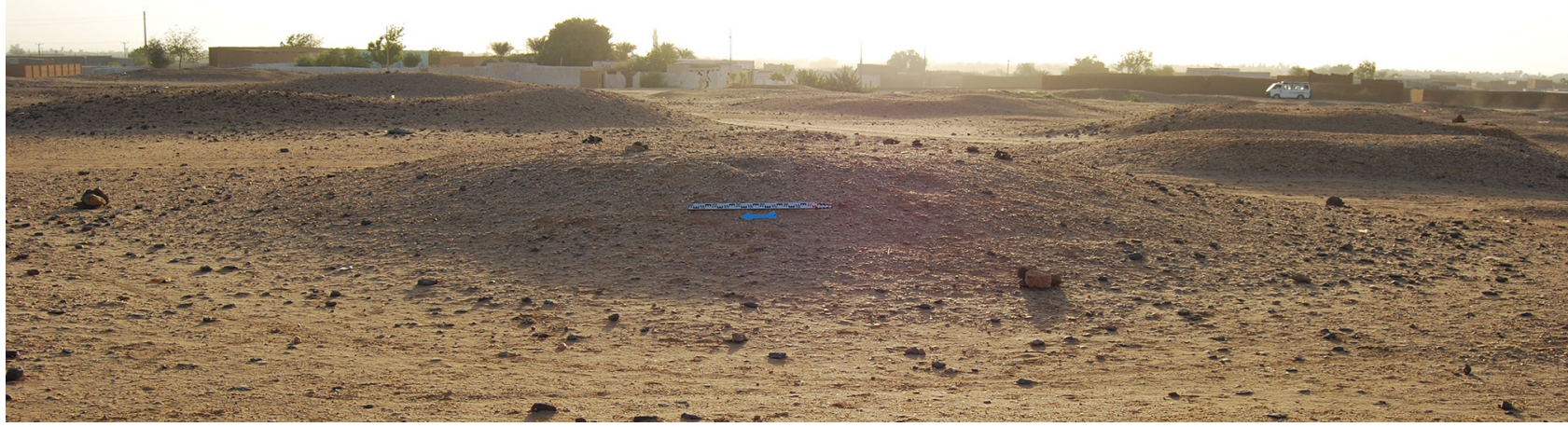

FIGURE 3.123 Tumulus 2O, view of the superstructure, looking east PHOTO BY E. CZYŻEWSKA-ZALEWSKA

\subsection{Tumulus 22}

Tumulus 22 lies roughly in the middle of the cemetery, about $20 \mathrm{~m}$ due west of T.23 [see Fig. 1.2]. It is a flat-topped mound, built from a mixture of sandy earth and gravel [Fig. 3.128]. The perimeter of the tumulus superstructure is demarcated at ground level by one course of rough sandstone chunks. The tumulus has a diameter of about $15 \mathrm{~m}$ and a preserved height not exceeding $0.50 \mathrm{~m}$. Like other tumuli of types II and III, this one had also been penetrated from the top.
The substructure of the tumulus appeared to be of a type prevalent in the Dongola Reach between the Third and Fourth Nile Cataracts during Phase I of the Terminal Meroitic period (post-Meroitic Phase I, AD 350$45^{\circ}$ ). It consists of a rectangular, vertical shaft provided with a single burial chamber hewn into the west wall of the shaft. The ground plan of the vertical shaft, which is aligned north-east to south-west, measures $2 \mathrm{~m} \times 1 \mathrm{~m}$, while its maximum depth is about $2.30 \mathrm{~m}$. The burial chamber is cut into the north-west wall of the shaft and mea- 


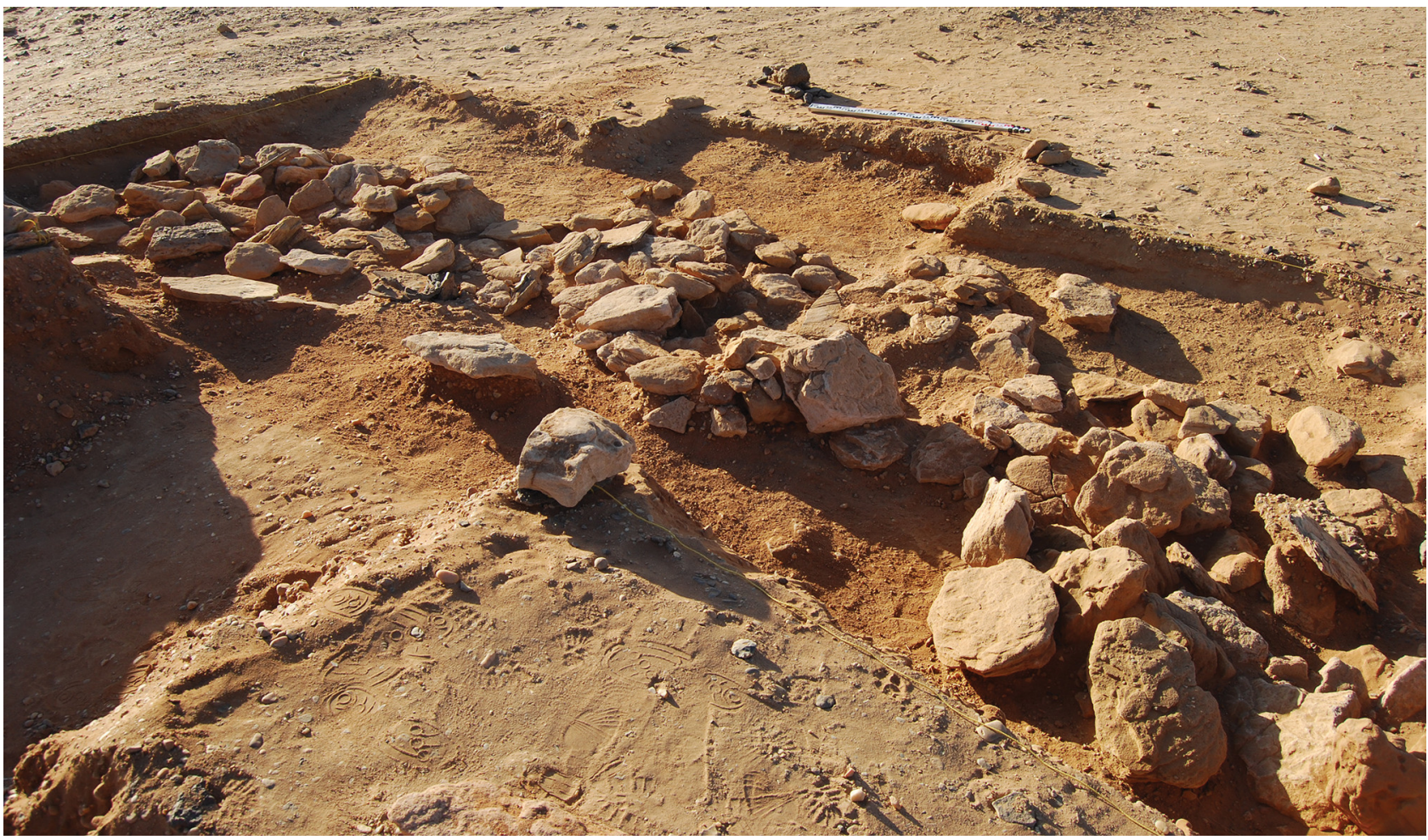

FIGURE 3.124 Tumulus 2O, view of the stone ring

Pното BY E. CZYŻEWSKA-ZALEWSKA

sures $1.55 \mathrm{~m}$ in length by $0.50-0.40 \mathrm{~m}$ in width by $0.50 \mathrm{~m}$ in height [Fig. 3.129]. The large stone slabs that blocked the chamber had been removed and thrown against the south-east wall at the bottom of the shaft [Fig. 3.13o]. It was evident that the chamber had been badly plundered [Fig. 3.131]. A human skeleton had been pulled out of the chamber and discarded against the east wall of the shaft while some of the soft tissues were still intact. This is attested by the fact that parts of the lower limbs were found articulated. Due to the state in which the human remains were found, it is quite hard to establish exactly where the body had originally been deposited. However, examination of the skeleton, the burial chamber, and its contents suggest that the deceased had been interred at the southern end of the chamber. In keeping with the funerary rites of the period, the body would have been laid in contracted position, on its right side with the head pointing south. Grave goods comprise six pottery vessels: two medium-size beer jars and two wheel-made red cups were recorded in situ at the northern end of the chamber, while another two red cups were found amongst the human bones at the bottom of the shaft.

It is worth highlighting that the rectangular vertical shaft with a side burial chamber is considered the standard type of burial construction in this region. It was often recorded in east-west alignment with a side niche cut into the south wall of the shaft. Nonetheless, differently aligned shafts and developments in burial niche construction of this same type have been noted at a number of cemetery sites in the Dongola Reach.

Examples were recorded at several sites in this region, including Tanqasi (Shinnie 1954, 66-86), El-Ghaddar (Phillips 1987, 35-41; Żurawski 1987: 41-46), HammurAbbassiya (Mahmoud El-Tayeb 1994, 65-79; 2003, 130139), El-Kassinger Bahry (Paner 1998, 115-132), and Jebel Kulgeili (Ali Mohammed and Hussein 1999, 6o-70).

\subsection{Tumulus 27}

Tumulus 27 lies at the far eastern edge of the cemetery. The mound is made from similar materials to those used in the construction of the earlier described tumuli [Fig. 3.132]. It has a diameter of about $10.5 \mathrm{Om}$ and a preserved height of only $0.67 \mathrm{~m}$ [Fig. 3.133]. The mound, in particular its western and northern parts, was severely damaged by grave robbers and their unsuccessful attempts to find the shaft. The substructure of the burial presented a trapezoidal outline at ground level marking the top of a vertical shaft with a lateral niche hewn into its west side. Both the shaft and niche were dug into the hard white sandstone which is predominant in this part of the cemetery. The ground plan of the shaft measures $1.20 \mathrm{~m} / 0.95 \mathrm{~m}(\mathrm{E} / \mathrm{W})$ by $0.85 \mathrm{~m} / 0.90 \mathrm{~m}(\mathrm{~N} / \mathrm{S})$, narrowing slightly towards the 


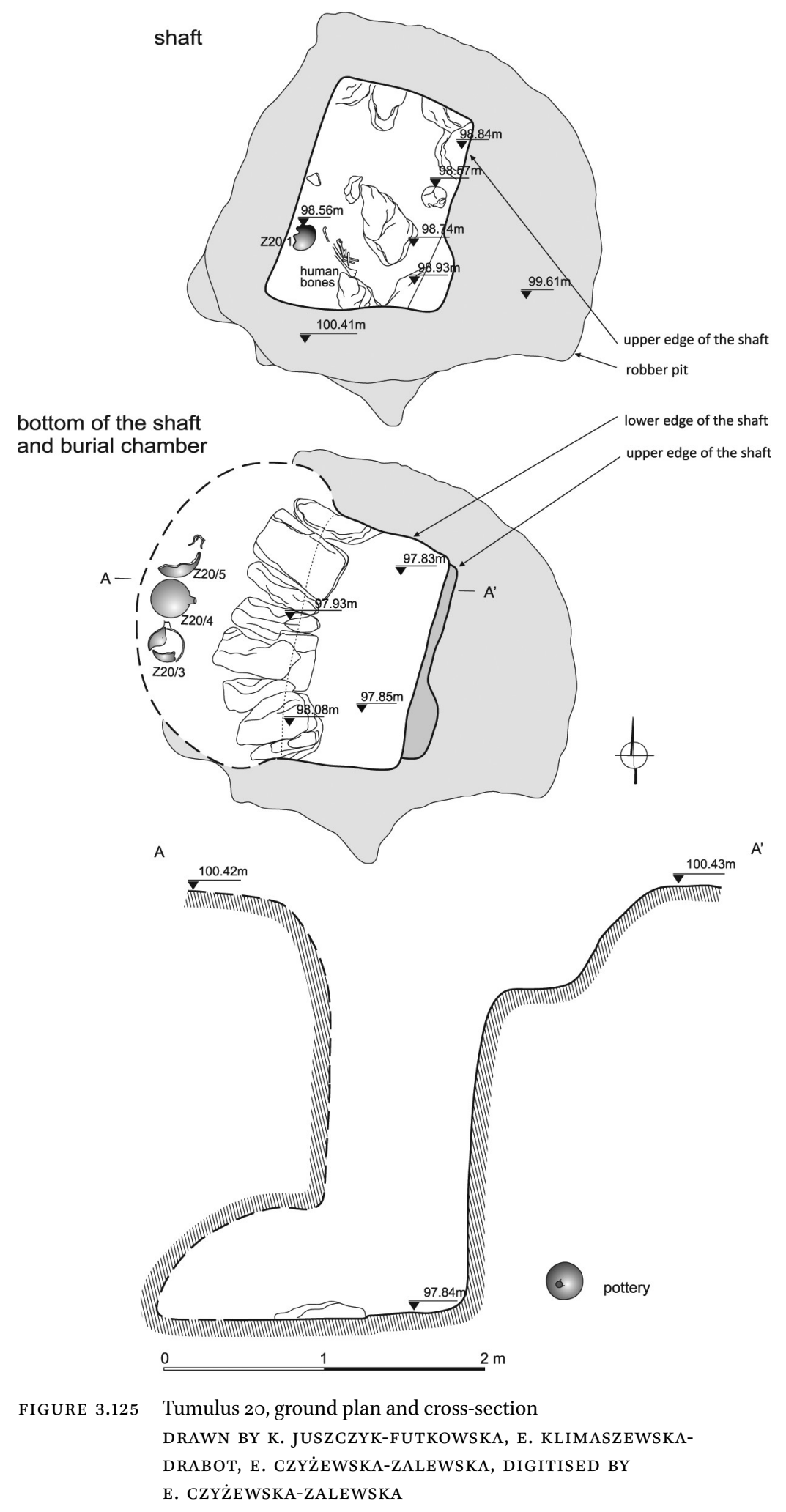



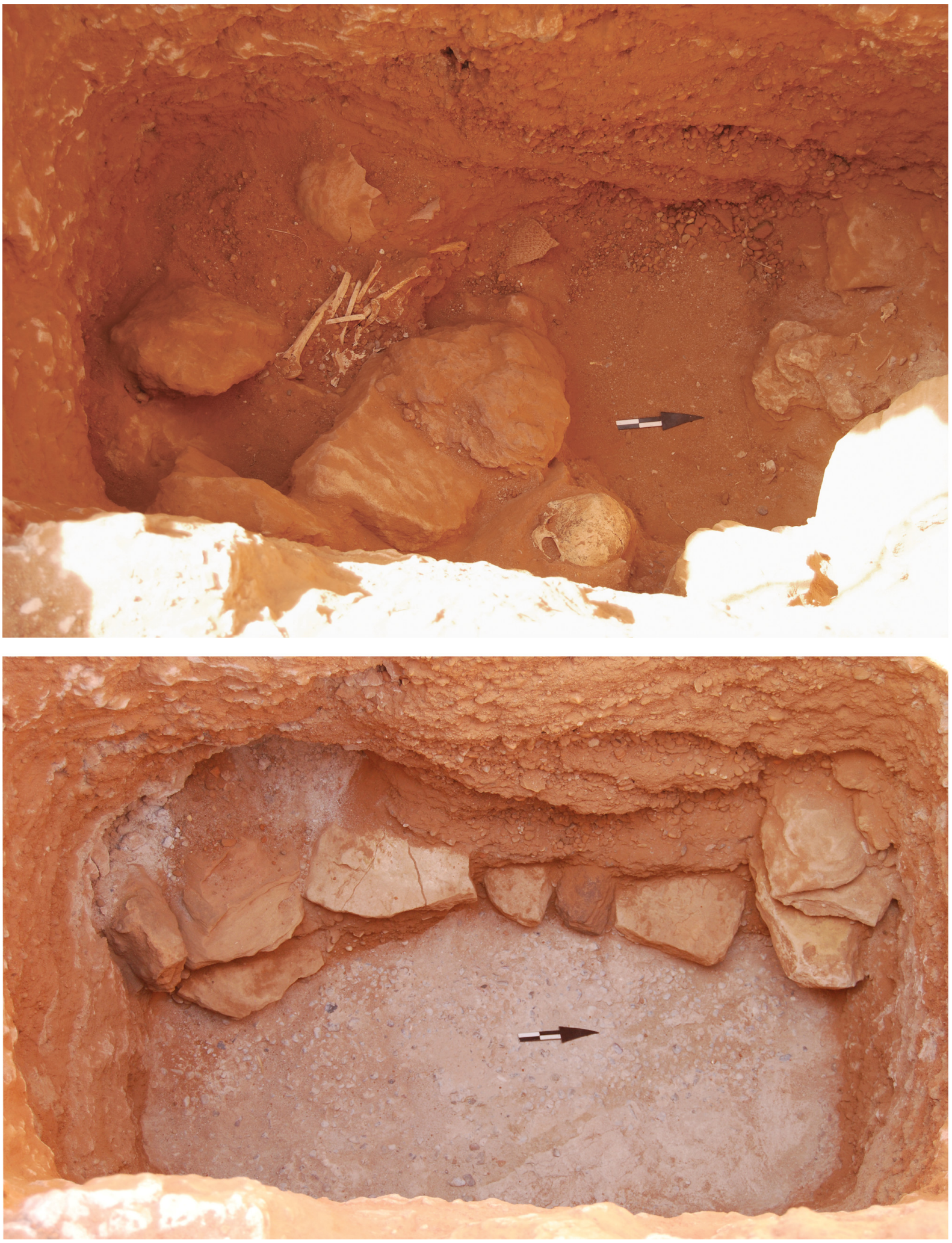

FIGURE 3.126 Tumulus 2o, view of the dismantled stone blocking wall and human bones pulled out of the burial chamber (top); view of the shaft with wall blocking the entrance to the burial chamber (bottom)

PHOTOS BY E. CZYŻEWSKA-ZALEWSKA 


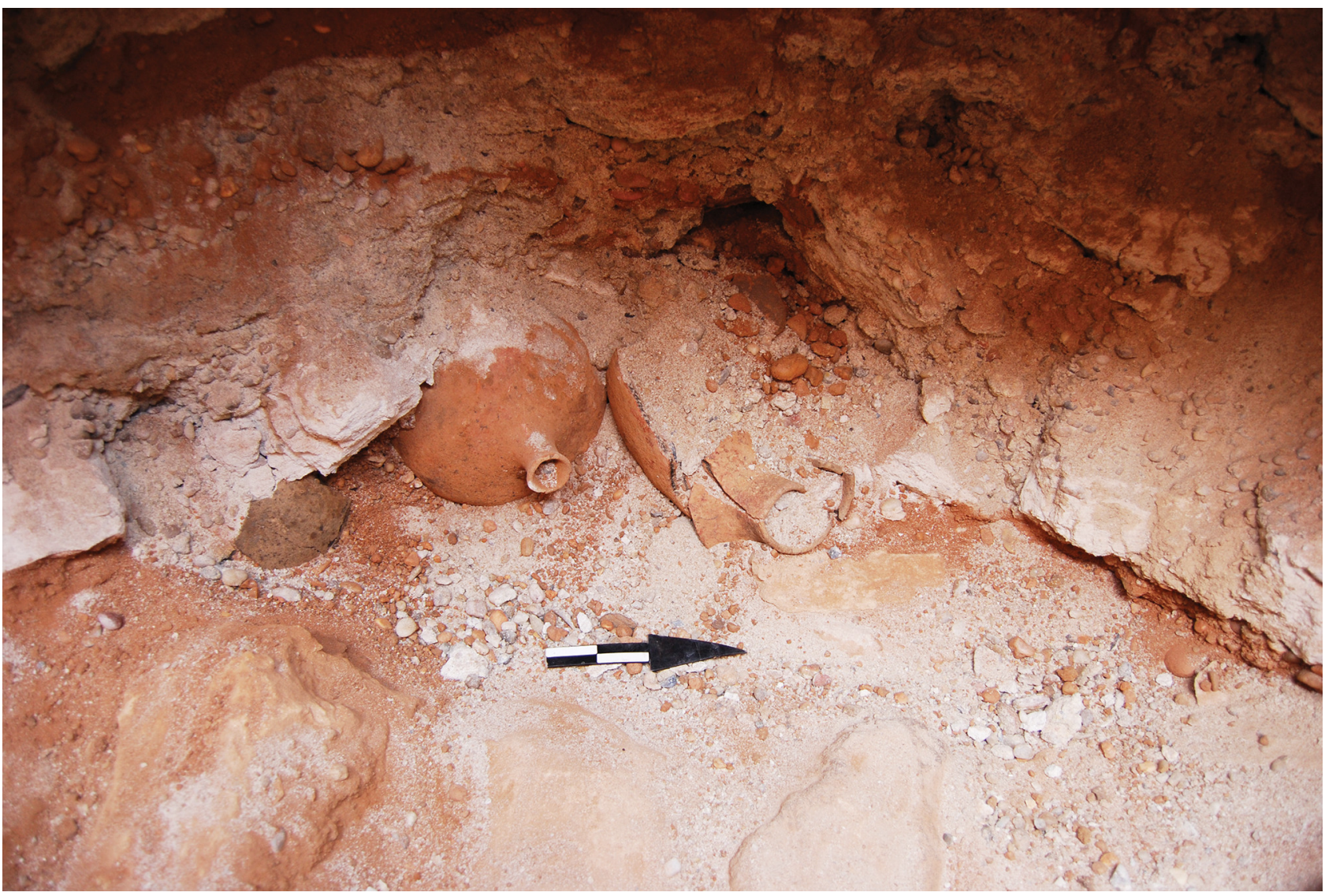

FIGURE 3.127 Tumulus 20, view of the burial chamber with collapsed roof PнОто BY E. CZYŻEWSKA-ZALEWSKA

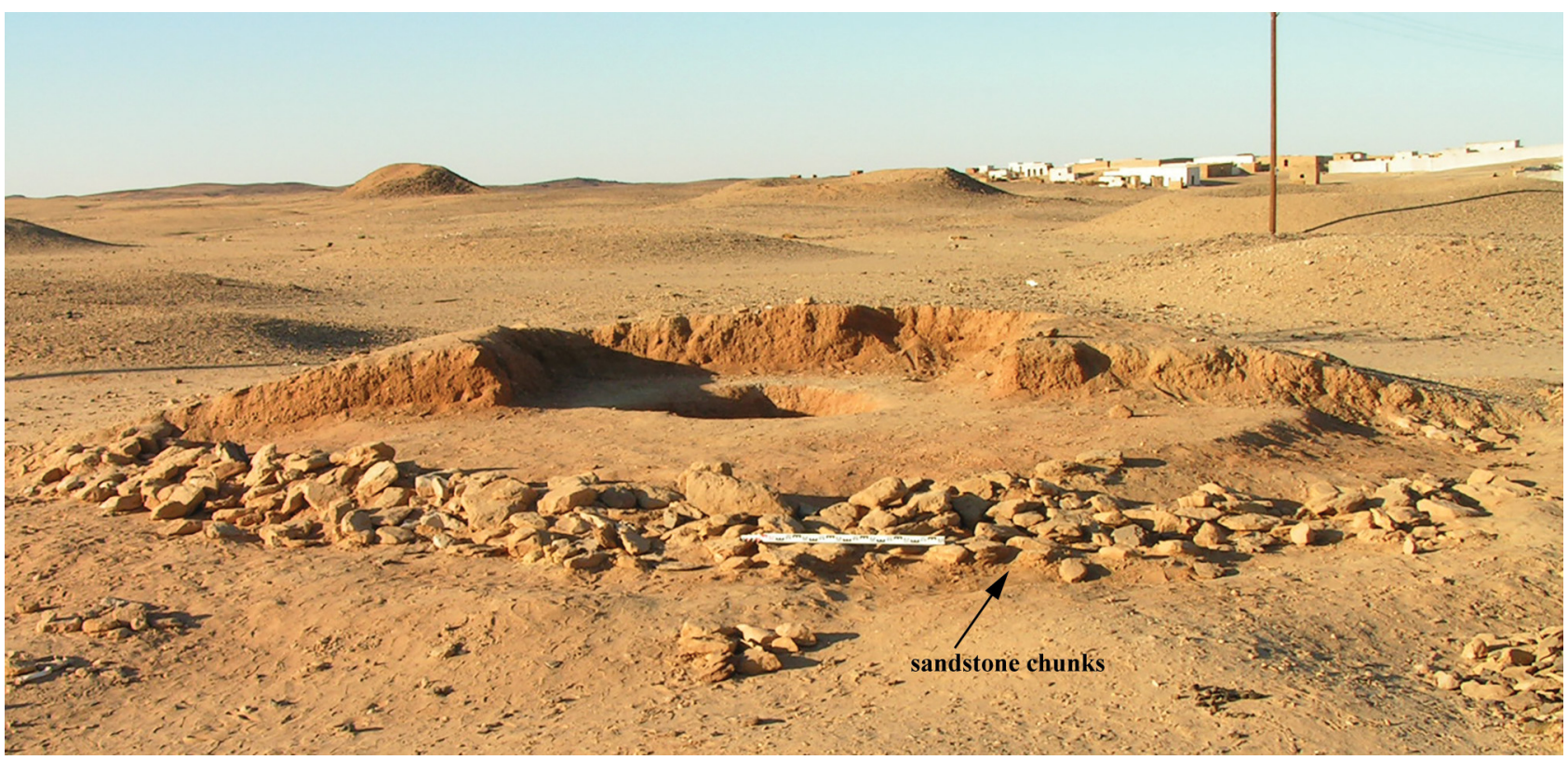

FIGURE 3.128 Tumulus 22, view of the partially excavated mound showing the stone-ring on the southern side of the superstructure

PHOTO BY MAHMOUD EL-TAYEB 


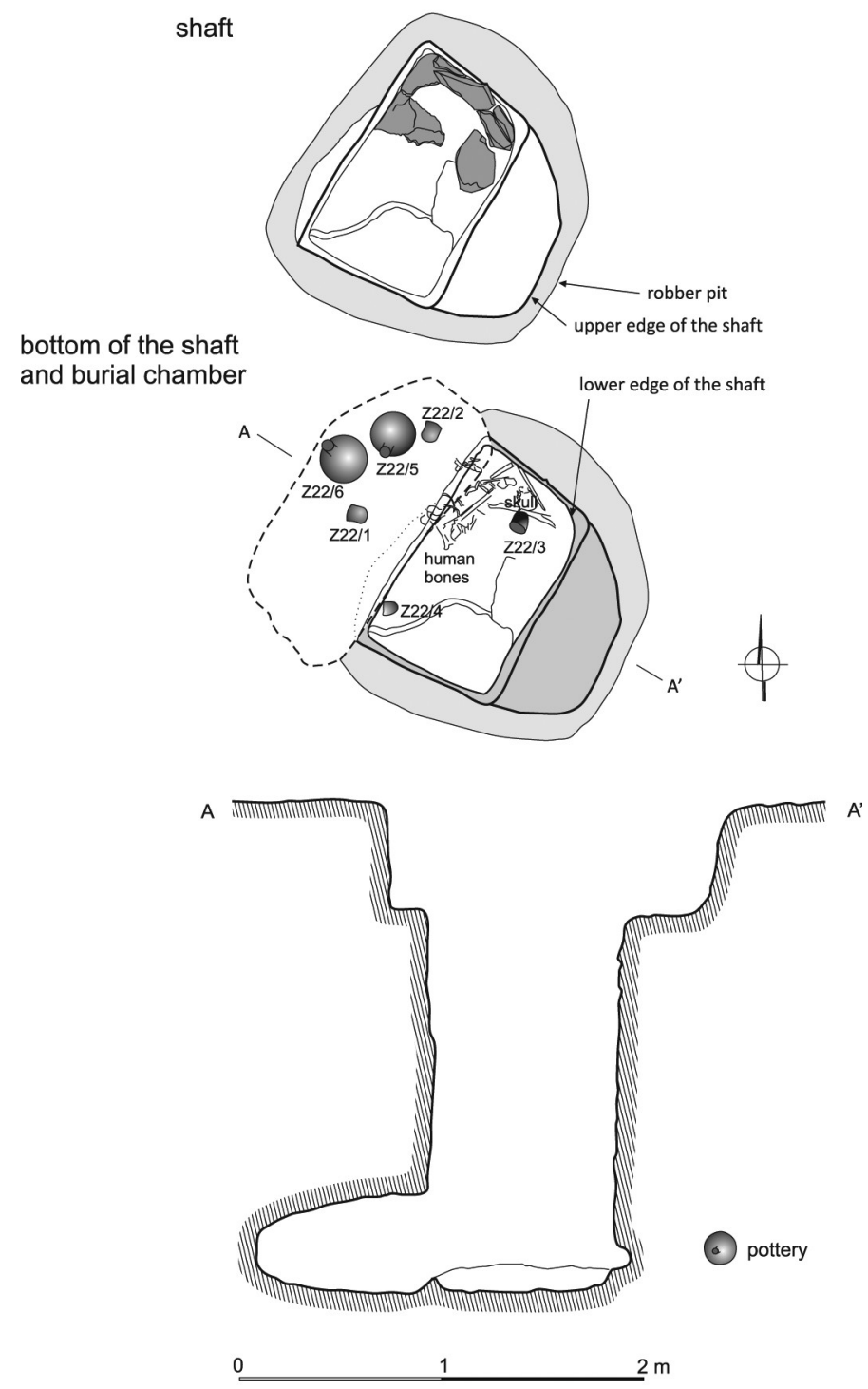

bottom to about $1.24 \mathrm{~m} / \mathrm{o} .80 \mathrm{~m}(\mathrm{E} / \mathrm{W})$ by $0.40 \mathrm{~m} / 0.40 \mathrm{~m}$ $(\mathrm{N} / \mathrm{S})$. The shaft has a maximum depth of no more than o.9o $\mathrm{m}$, while the burial chamber measures $1.90 \mathrm{~m} \times 0.75 \mathrm{~m}$ and is $0.44 \mathrm{~m}$ high. This small niche was blocked by large chunks of yellow sandstone, which appear to have been brought from another part of the cemetery. The robbers had only dismantled part of the south-west side of the blocking wall, discarding some of its stones in the shaft, an action that indicates that they had an idea about the burial tradition of the period and so were able to reach their target directly [Fig. 3.134].

A single, disarticulated human skeleton was strewn from north to south across the floor of the chamber. Due to the considerable disarray in which the skeleton was found, it is not easy to determine its original position or orientation with any degree of certainty. However, the small size of the chamber suggests that the body may have originally been laid in contracted position on its
FIGURE 3.129

Tumulus 22, ground plan and cross-section of the tumulus DRAWN BY A. OBŁUSKI, U. IWASZCZUK, H. KOŹMIŃSKA-SOWA, DIGITISED BY M. PUSZKARSKI, E. CZYŻEWSKA-ZALEWSKA

left side, aligned south-north with the head towards the south [Fig. 3.135].

The few objects found in the rifled burial chamber comprised pottery vessels, metal artefacts, and beads. Two vessels were deposited in the chamber: one large handmade beer jar located at the north end, and a small red wheelmade cup at the south end. A number of corroded iron arrowheads, some fragments of unidentified iron objects and a stone archer's ring were scattered amongst the pile of bones. In the same area, and particularly near the damaged skull, 101 beads made of different materials were found along with a faience scarab. The pottery sherds and scraper together with 14 arrowhead fragments recovered from the shaft had probably been dropped there by the grave looters. 

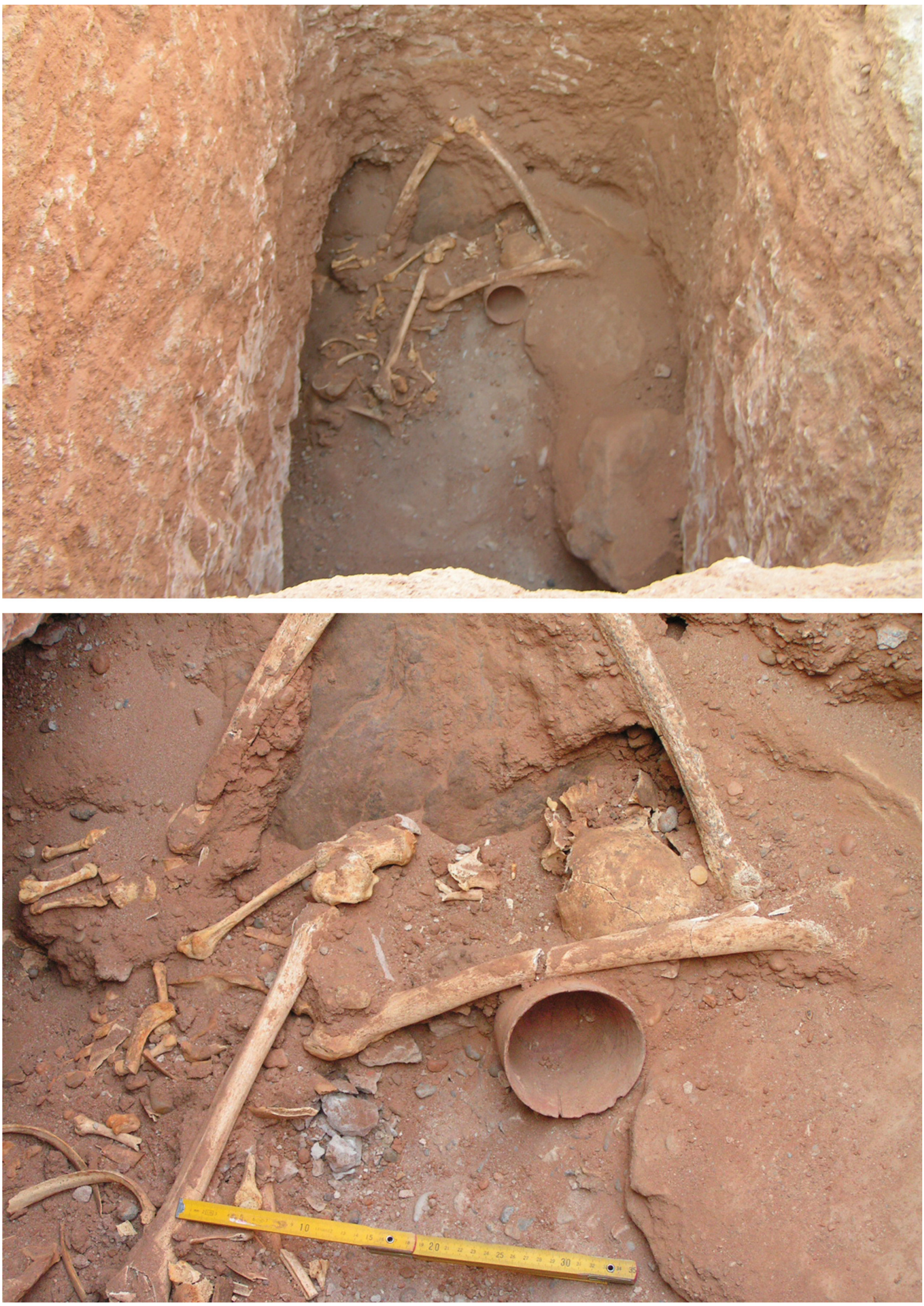

FIGURE 3.130 Tumulus 22, the burial shaft with disarticulated human skeleton and some grave goods PHOTO BY MAHMOUD EL-TAYEB 


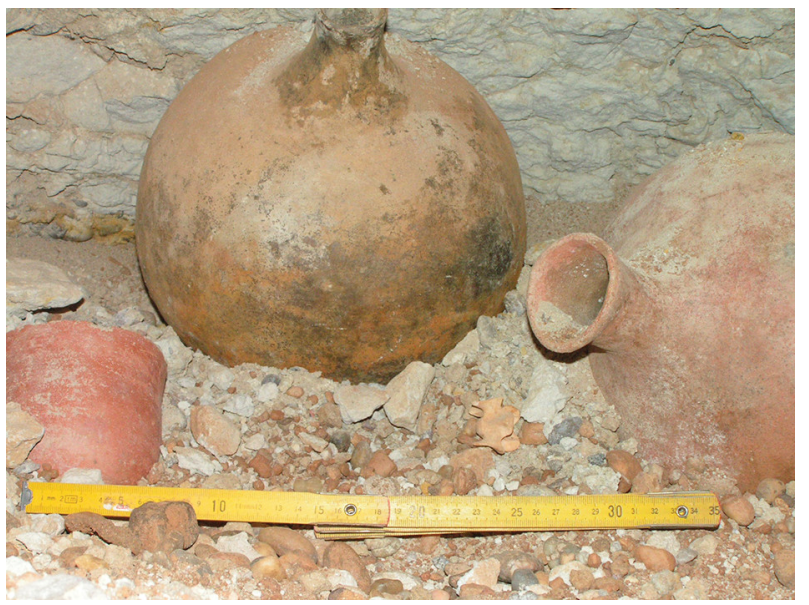

FIGURE 3.131 Tumulus 22, pottery vessels in the plundered burial chamber

PHOTO BY MAHMOUD EL-TAYEB

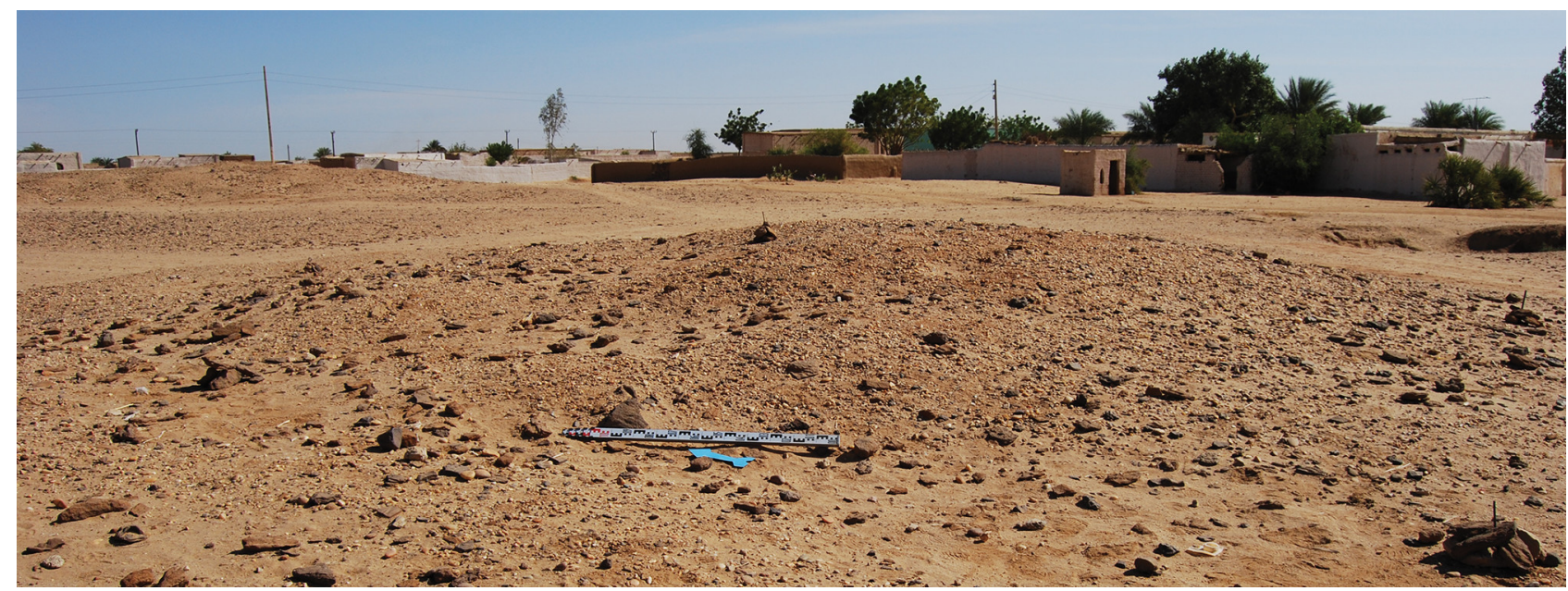

FIGURE 3.132 Tumulus 27, view of the superstructure, looking east Рното BY O. BIAŁOSTOCKA

\subsection{Tumulus 21}

Tumulus 21 is located in the central part of the cemetery, within a group of the smallest variety of tumuli (type III). It is a circular, flat-topped mound built from a mixture of earth and gravel. The mound has a diameter of about $12.5 \mathrm{om}$ and a preserved height not exceeding $0.6 \mathrm{om}$ [Fig. 3.136]. The excavation revealed that the mound had originally been surrounded by a stone ring about $11.50 \mathrm{~m}$ in diameter and about $2.00 \mathrm{~m}$ wide at ground level [Fig. 3.137]. This form of construction has been noted in all excavated burials of type III. Existence of a depression at the top centre of the mound indicates that the burial was plundered sometime in the past. In making their way to the bottom of the grave, the robbers dug a large, roughly square hole measuring about $2.60 \mathrm{~m} \times 2.55 \mathrm{~m}$ [Fig. 3.138]. Further cleaning revealed the original shape of the burial shaft [Fig. 3.139].
It has a rectangular ground plan with the long axis, unusually, aligned north-east to south-west. Its short sides measure $1.85 \mathrm{~m}(\mathrm{NE}-\mathrm{NW})$ and $1.9 \circ \mathrm{m}(\mathrm{SW}-\mathrm{SE})$, while the long sides measure $2.20 \mathrm{~m}$ (NW-SW) and $2.15 \mathrm{~m}$ (NE-SE). At a depth of $0.60 \mathrm{~m}$, a single step (in the form of a long bench) about $0.70 \mathrm{~m}$ wide is cut along the full length of the NE-SE side of the shaft. The maximum depth of the shaft is $2.60 \mathrm{~m}$. During the course of excavation, sandstone blocks of various sizes were noted at different levels inside the shaft. Amongst the debris one complete vessel was found, indicating that the burial had been rifled. In accordance with the construction tradition of type III tumuli, the vertical shaft was provided with a side niche at the bottom, albeit in an unusual location, as it is hewn into the north side of the NE-SW wall in a SW-NE alignment (usually the burial chamber in type III tumuli is located in the central part of the western wall of the shaft). The burial 


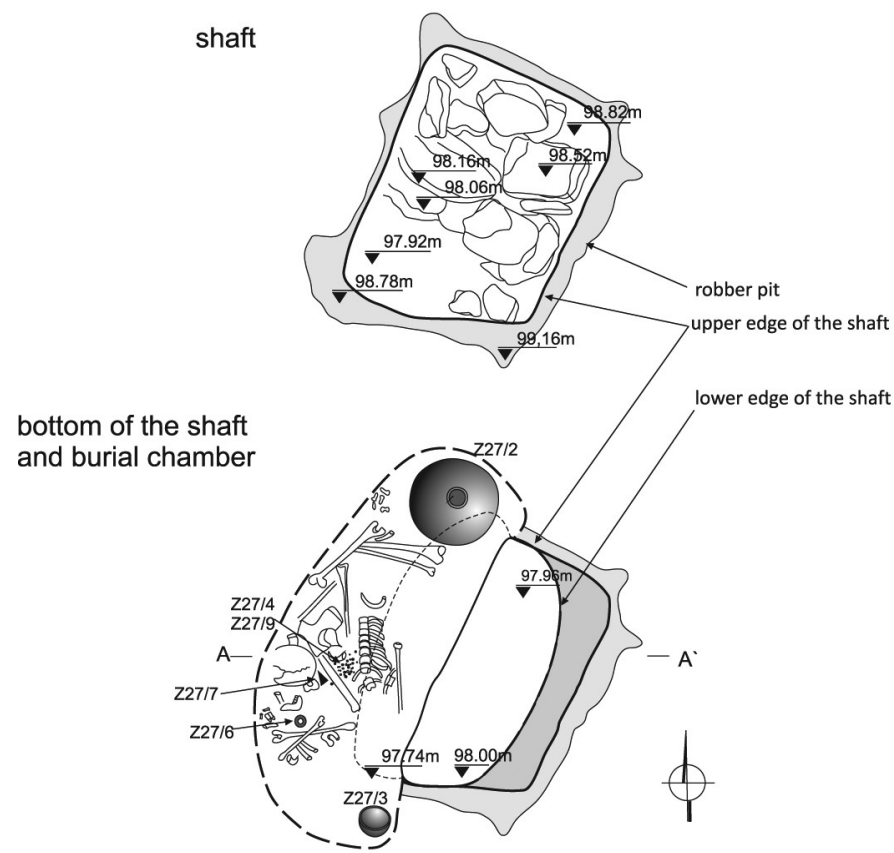

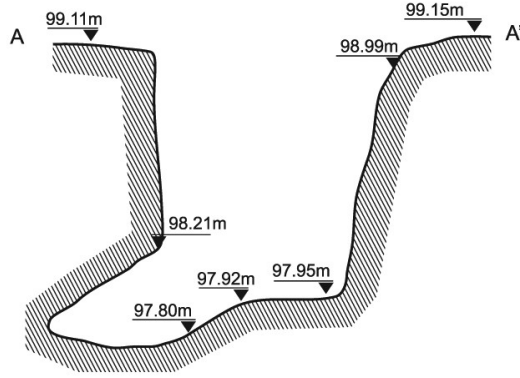

0
$2 \mathrm{~m}$

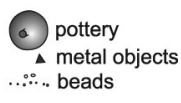

$\therefore$ metal objec (1)

FIGURE 3.133

Tumulus 27, ground plan and cross-section DRAWN BY K. JUSZCZYK-FUTKOWSKA, E. CZYŻEWSKAZALEWSKA, E. KLIMASZEWSKA-DRABOT, DIGITISED BY E. CZYŻEWSKA-ZALEWSKA

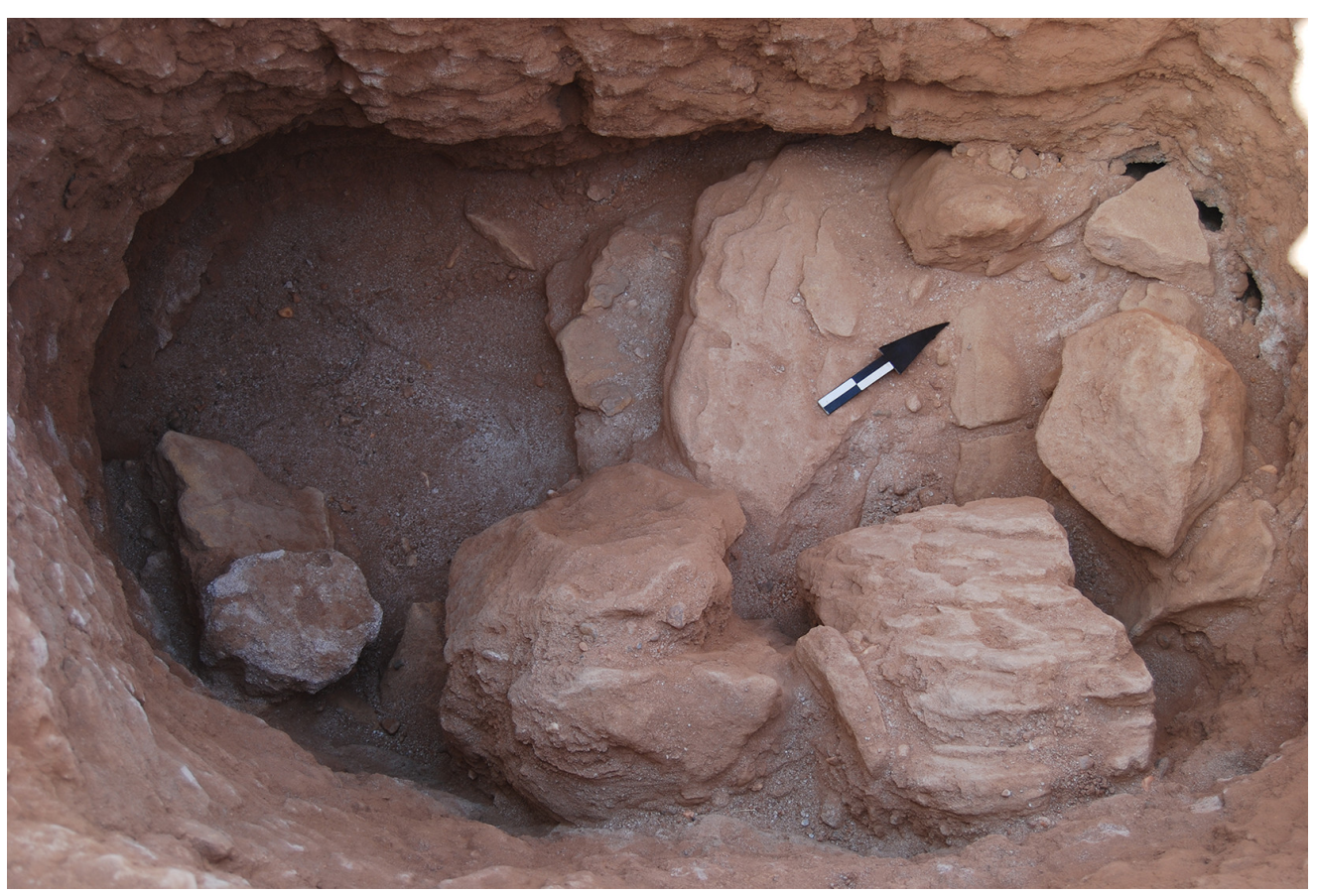

FIGURE 3.134 Tumulus 27, dismantled stone blocking wall in the burial shaft Рното ву о. BIAŁOSTOCKA 

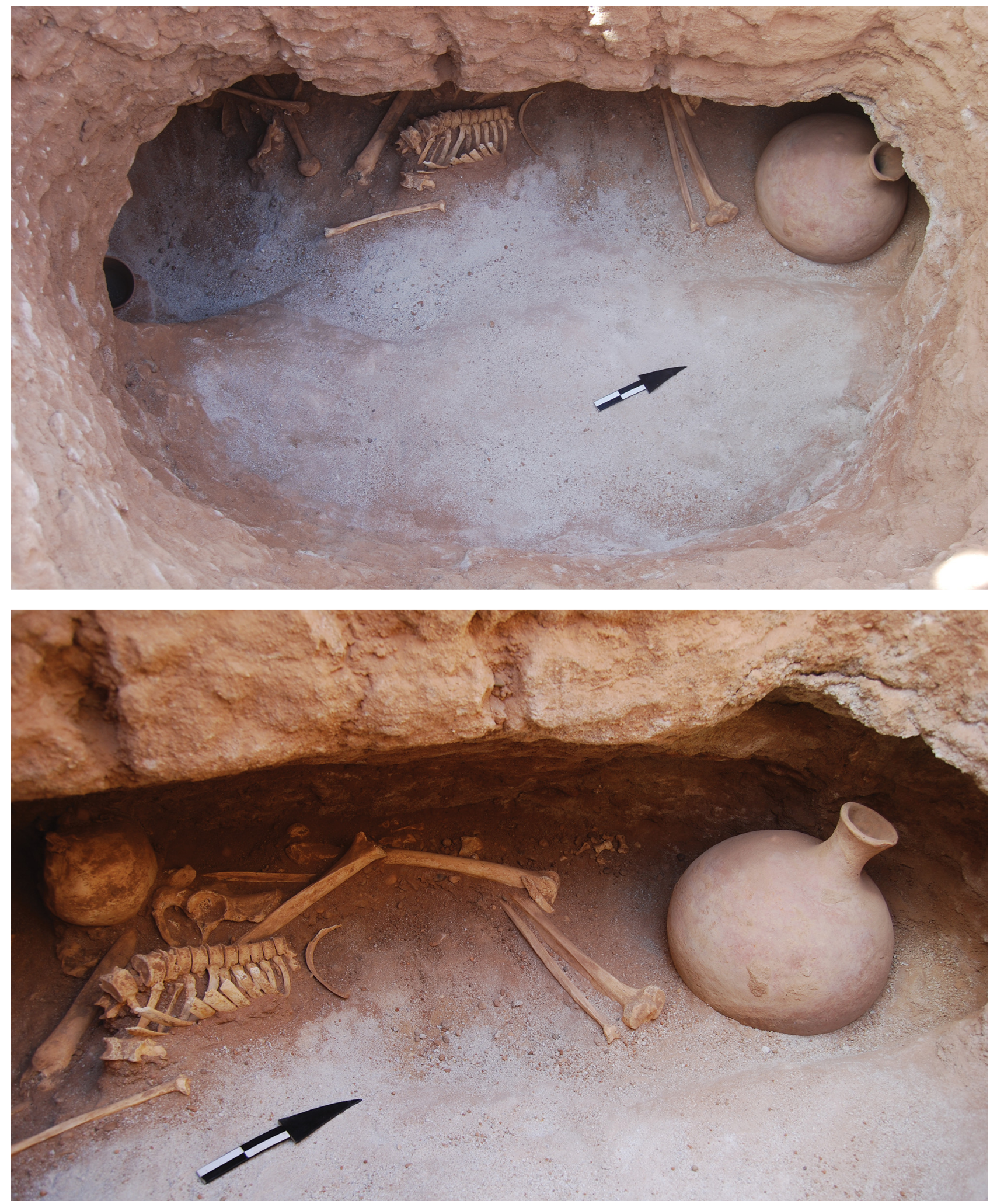

FIGURE 3.135 Tumulus 27, view of the disturbed human skeleton in the central part of the burial chamber, with head to the south РНОТО BY О. BIAєOSTOCKA 


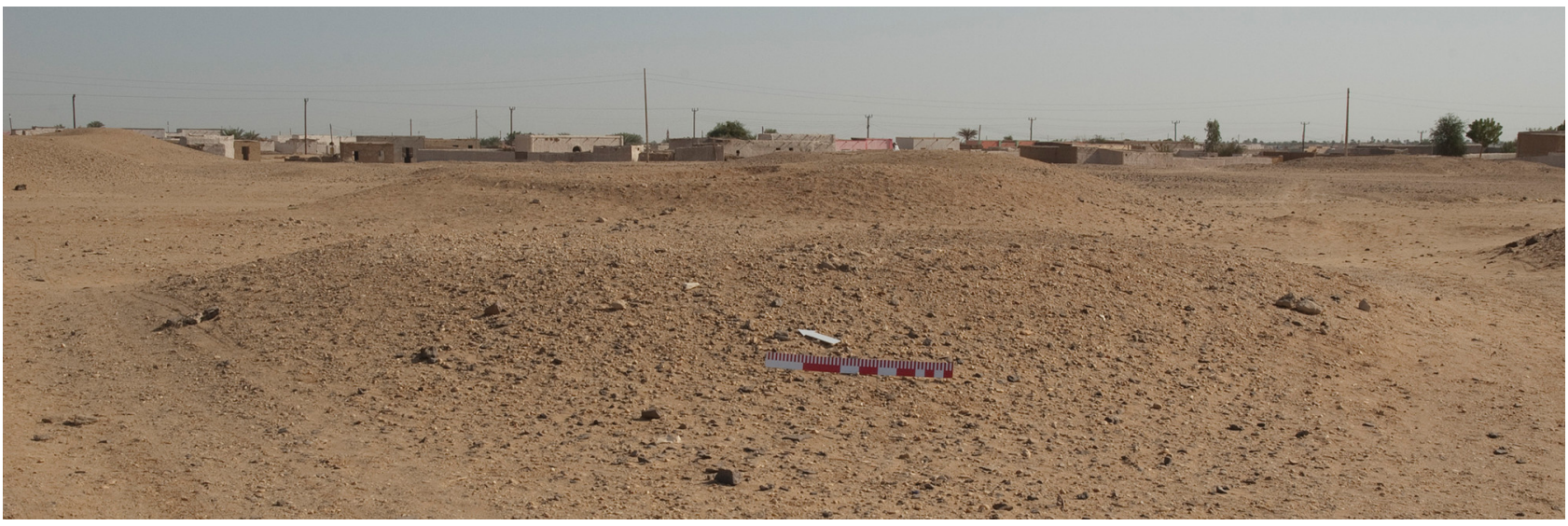

FIGURE 3.136 Tumulus 21, view of the superstructure, looking east PHOTO BY R. MAHLER

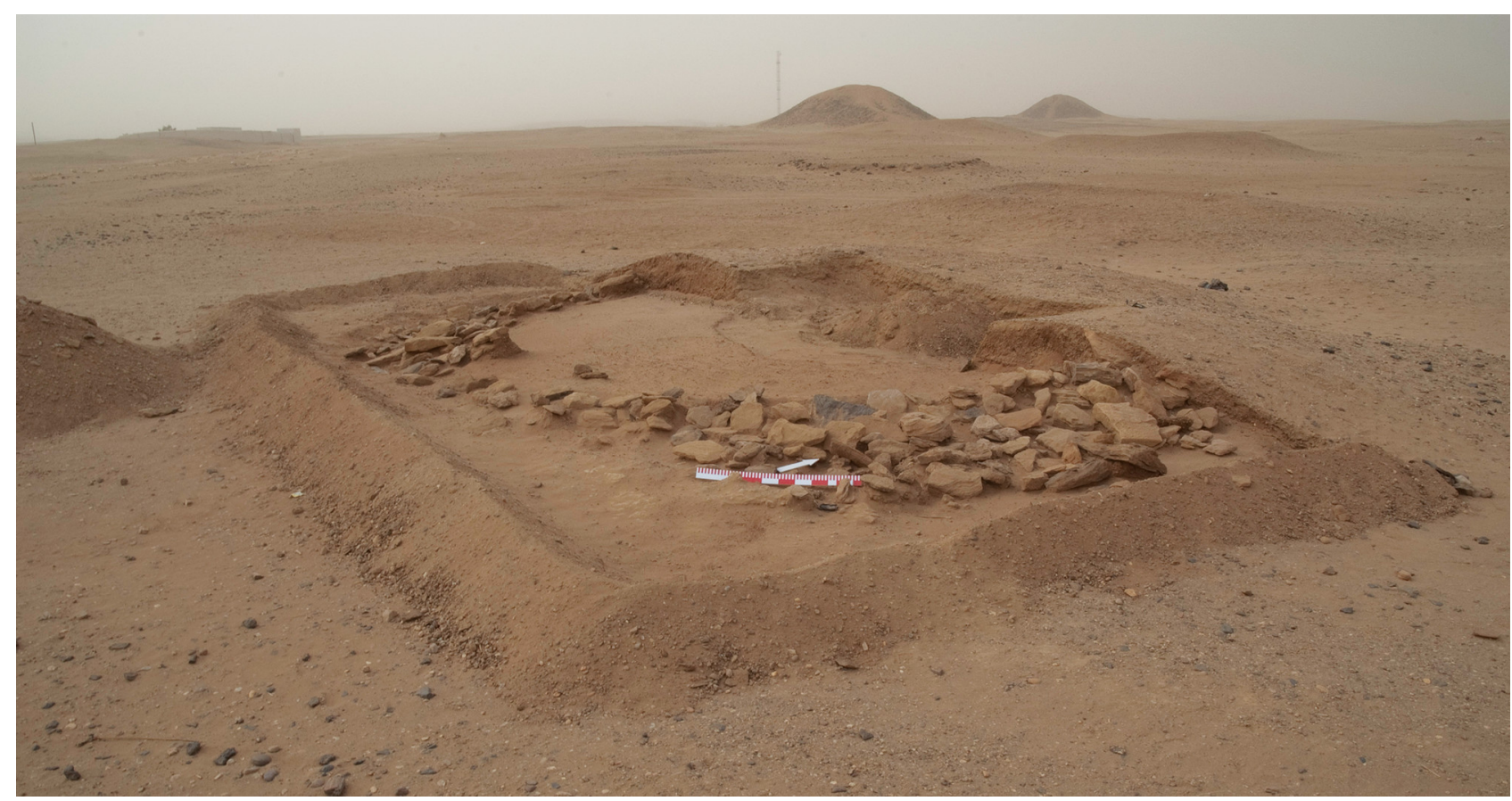

FIGURE 3.137 Tumulus 21, partially excavated superstructure, showing the southern side of the stone ring PHOTO BY R. MAHLER

chamber measures a maximum of $2.20 \mathrm{~m}$ long, $1.15 \mathrm{~m}$ wide and about $0.65 \mathrm{~m}$ in height. Sandstone blocks of different sizes were used to seal the burial chamber. However, the grave robbers dismantled the south-west side of the blocking wall, subsequently rifling through and destroying the burial. The devastation caused by robber activity, coupled with rising humidity levels, resulted in the southern and central parts of the roof collapsing onto the remains of the burial. Removal of the debris from the disturbed southern side of the chamber led to the discovery of two complete wheel-made, red-slipped, undecorated bowls, located near the entrance to the chamber.
This type of red bowl is quite common in the Dongola Reach and represents local production (more examples were found during earlier excavations at El-Ghaddar, Jebel Kulgeili and El-Kassinger Bahry: see Mahmoud El-Tayeb 1994; Ali Mohammed and Hussein 1999; Mahmoud elTayeb and Kołosowska 2007). One of the bowls contained some animal bone fragments. At the southern end of the chamber two medium-size beer jars (one a handmade dark ware and the other a wheel-made red-slipped ware, both undecorated) were discovered beneath the debris. All four vessels were found in situ [Fig. 3.14o top and middle]. Disarticulated and broken human bones mixed with earth 


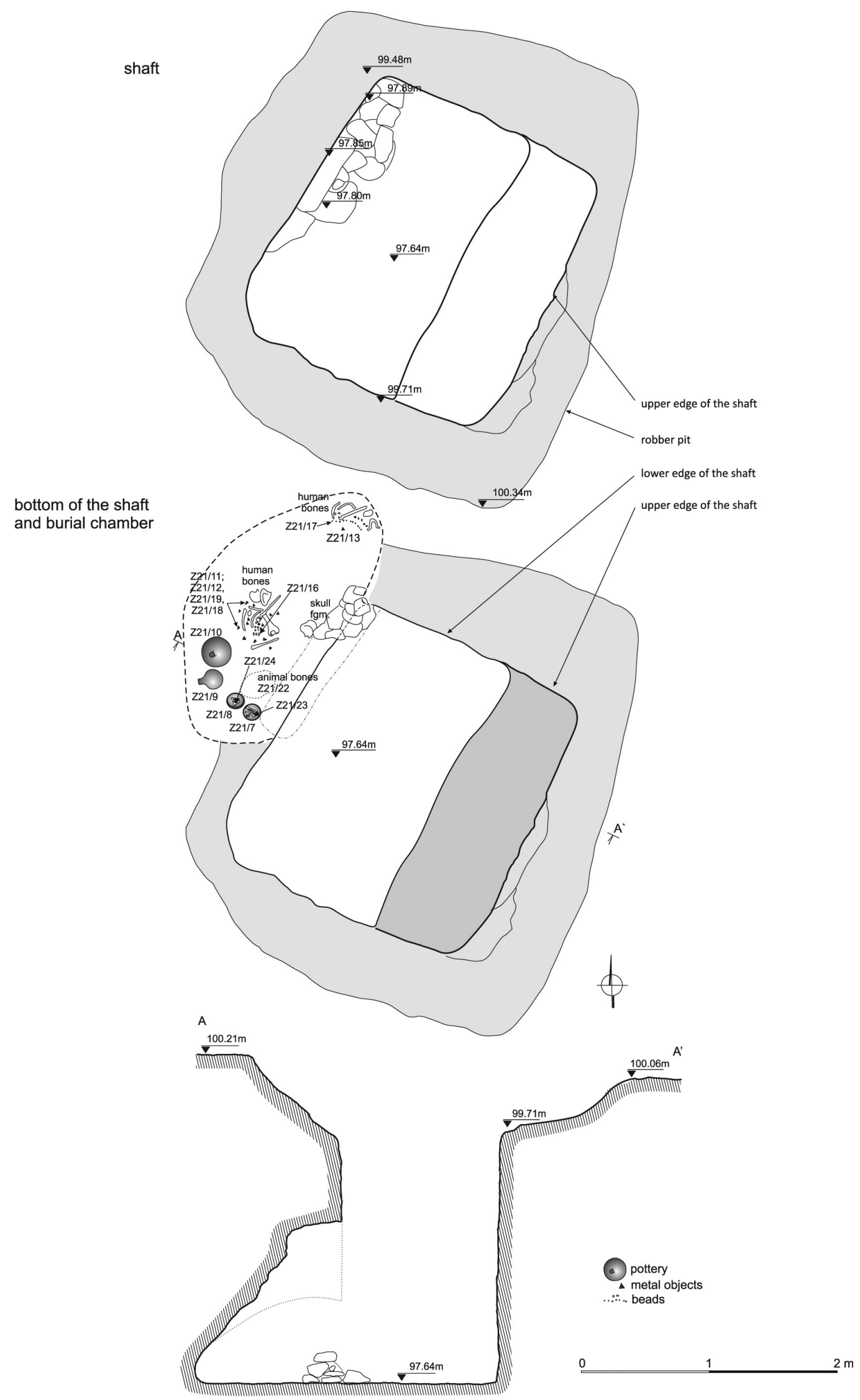

FIGURE 3.138 Tumulus 21, ground plan and cross-section

DRAWN BY A. GŁAૃB, E. SKOWROŃSKA, DIGITISED BY U. IWASZCZUK, E. CZYŻEWSKA-

ZALEWSKA 


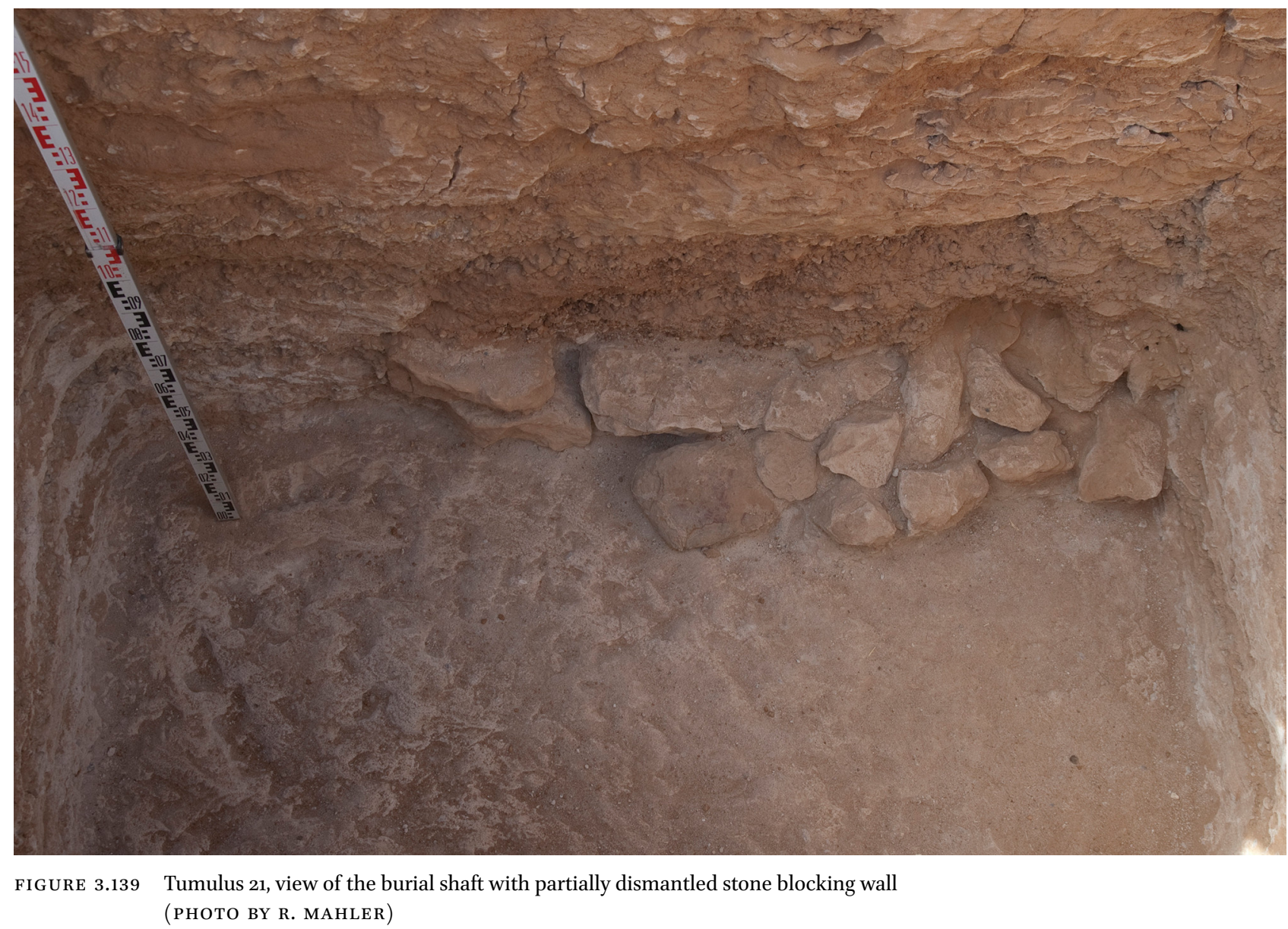

and debris were noted in two heaps located in the centre and at the northern end of the burial chamber. The bone fragments recovered from both parts of the chamber were intermingled with a number of small finds. These comprise objects made of iron: about ten arrowheads and fragments of two rings, all of them badly corroded. Two small rings made of copper alloy were also noted amongst the finds; one of them was found on a toe bone [Fig. 3.14o bottom]. Other finds included approximately 110 small beads made of different materials, such as faience, agate, and quartz. The poor condition of the human skeleton made it difficult to determine the original position of the body. Given the burial customs of the period, one would assume that the body would have been laid in a contracted position, on its left or right side, with the head to the south. In this case, however, the disarticulated head was found at the south-east side of the chamber. The aforementioned assumption stems from the fact that the smashed skull and some fragments of the upper limbs were noted in the centre, while bones of the lower limbs were found at the northern end of the chamber. The deposition of vessels containing offerings of food and drink at the south end of the chamber, usually above or around the head area, is a practice consistent with a well-known tradition of this period (Mahmoud El-Tayeb, Skowrońska, and Czyżewska 2016, 117-119).

\subsection{Tumulus 28}

This very low and badly plundered tumulus is located on the eastern fringe of the burial ground. The remains of the disturbed mound show that it was built from a mixture of earth and gravel [Fig. 3.141]. The rounded tumulus has a diameter of 13.00-13.20 $\mathrm{m}$ and features a slight depression at its top centre. Its maximum height is only about o.6o m.

In an effort to avoid wind erosion, the mound was excavated by dissecting it into north and south parts. Cleaning the southern part revealed traces of a robber pit in the centre of the tumulus, which had filled with windblown sand. It also came to light that the mound had originally been demarcated on the ground surface by large sandstone slabs. The construction of a stone ring around the perimeter of the mound is a practice repeatedly documented in the construction of type III burials at the ElZuma cemetery.

The substructure comprises a rectangular, vertical shaft [Fig. 3.142] with two side chambers at the bottom. The 

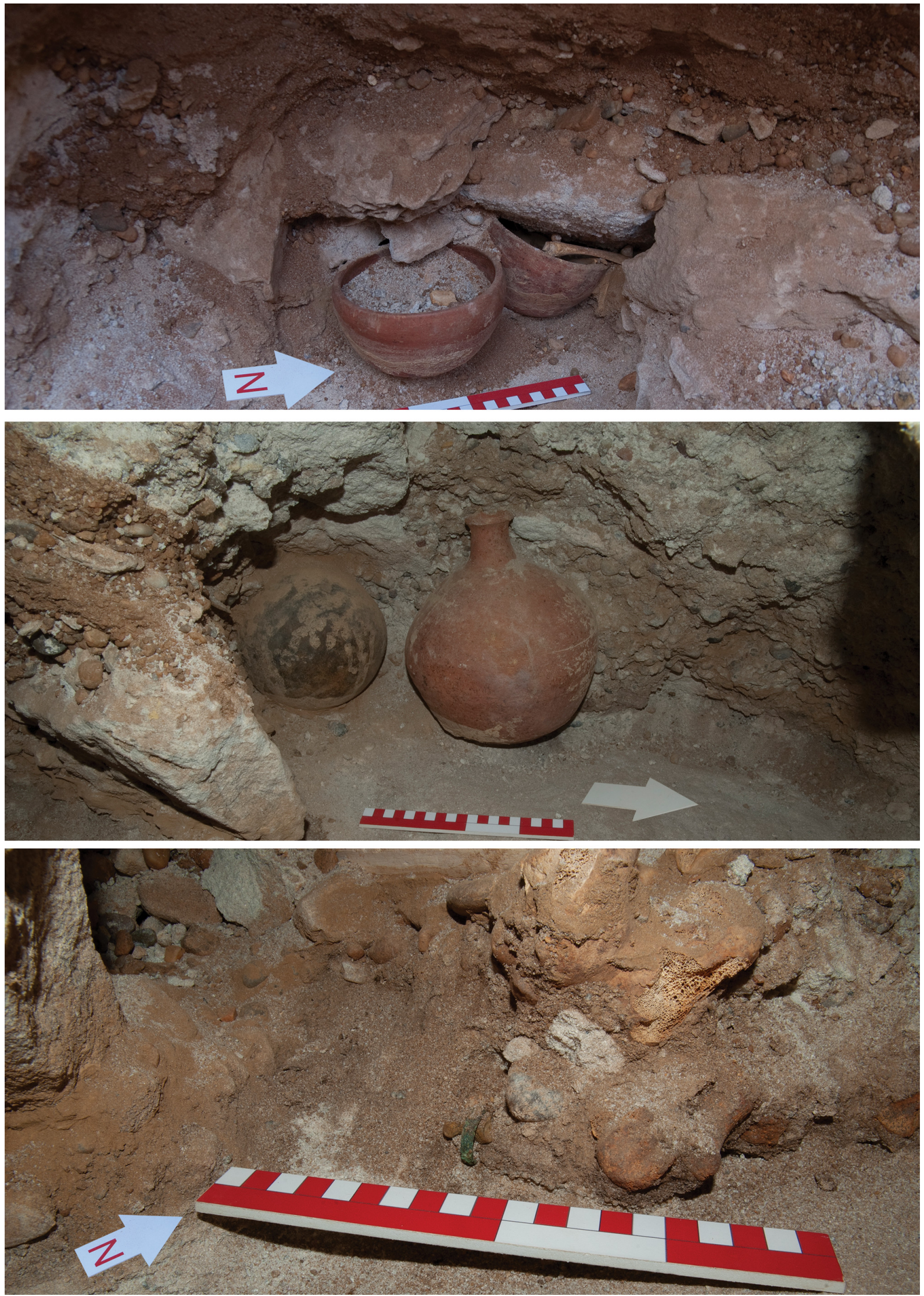

FIGURE 3.140 Tumulus 21, view of beer jars located at the southern end of the chamber (top and middle); view of the bronze ring on a human foot phalanx (bottom) PHOTOS BY R. MAHLER 


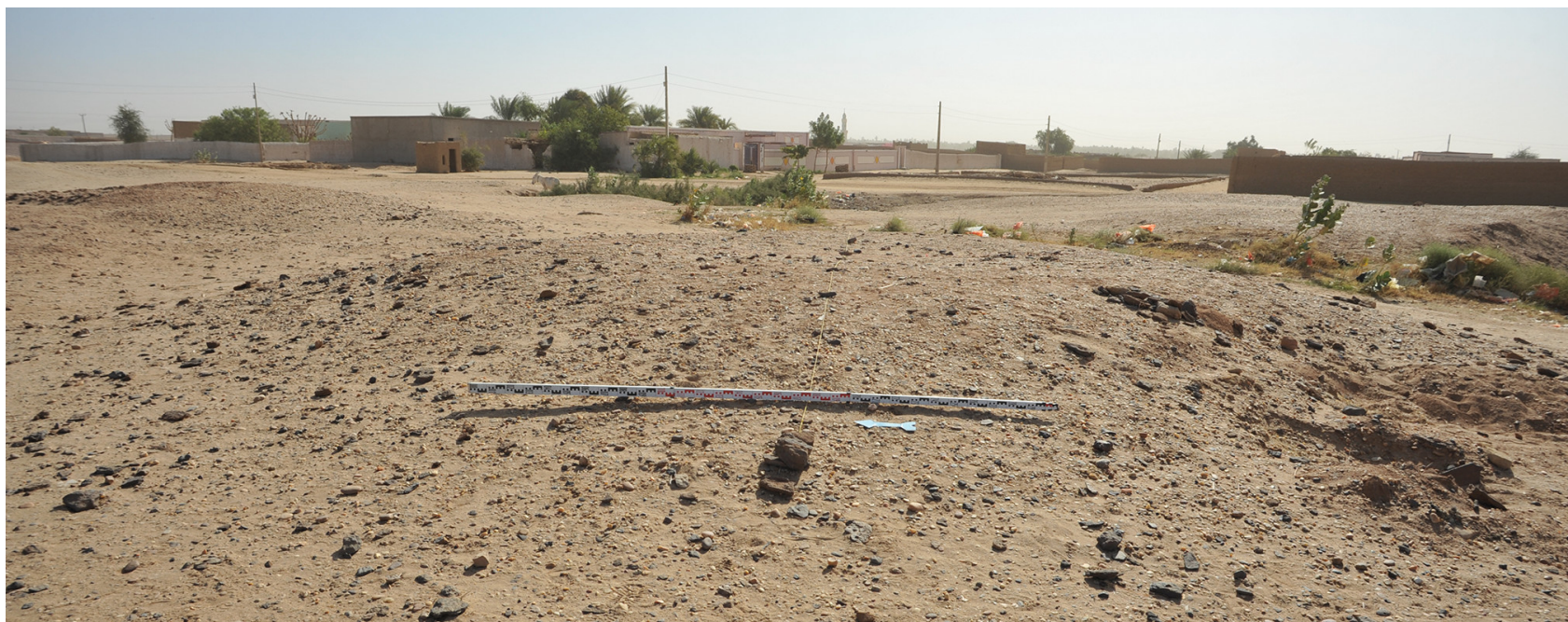

FIGURE 3.141 Tumulus 28, view of the superstructure, looking east PHOTO BY R. HAJDUGA

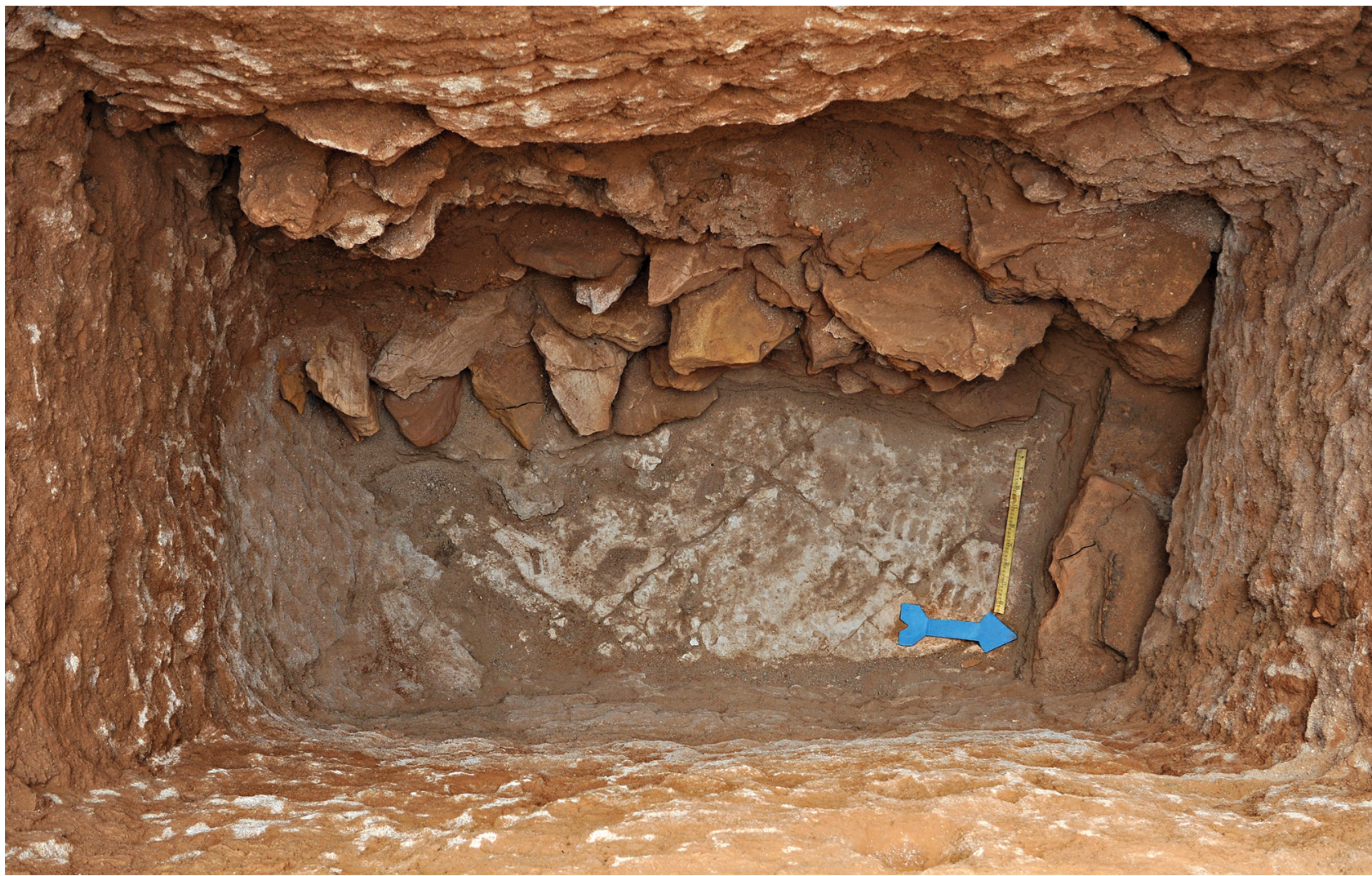

FIGURE 3.142 Tumulus 28, trapezoidal shaft with stone blocking wall of the burial chamber on the western side

PHOTO BY R. HAJDUGA 

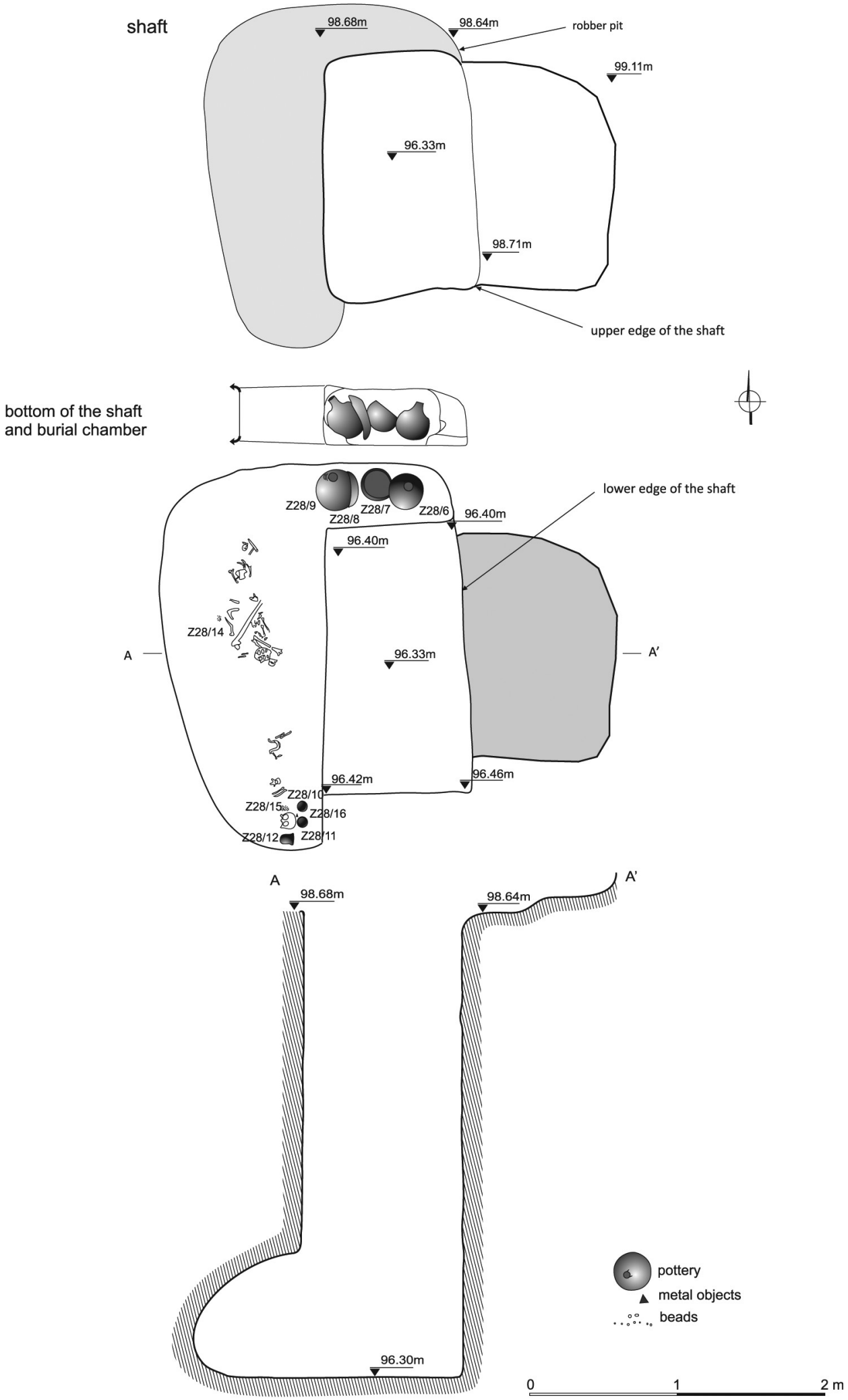

FIGURE 3.143 Tumulus 28, ground plan and cross-section

DRAWN BY R. HAJDUGA, DIGITISED BY J. BROCHOCKI, E. CZYŻEWSKA-ZALEWSKA 

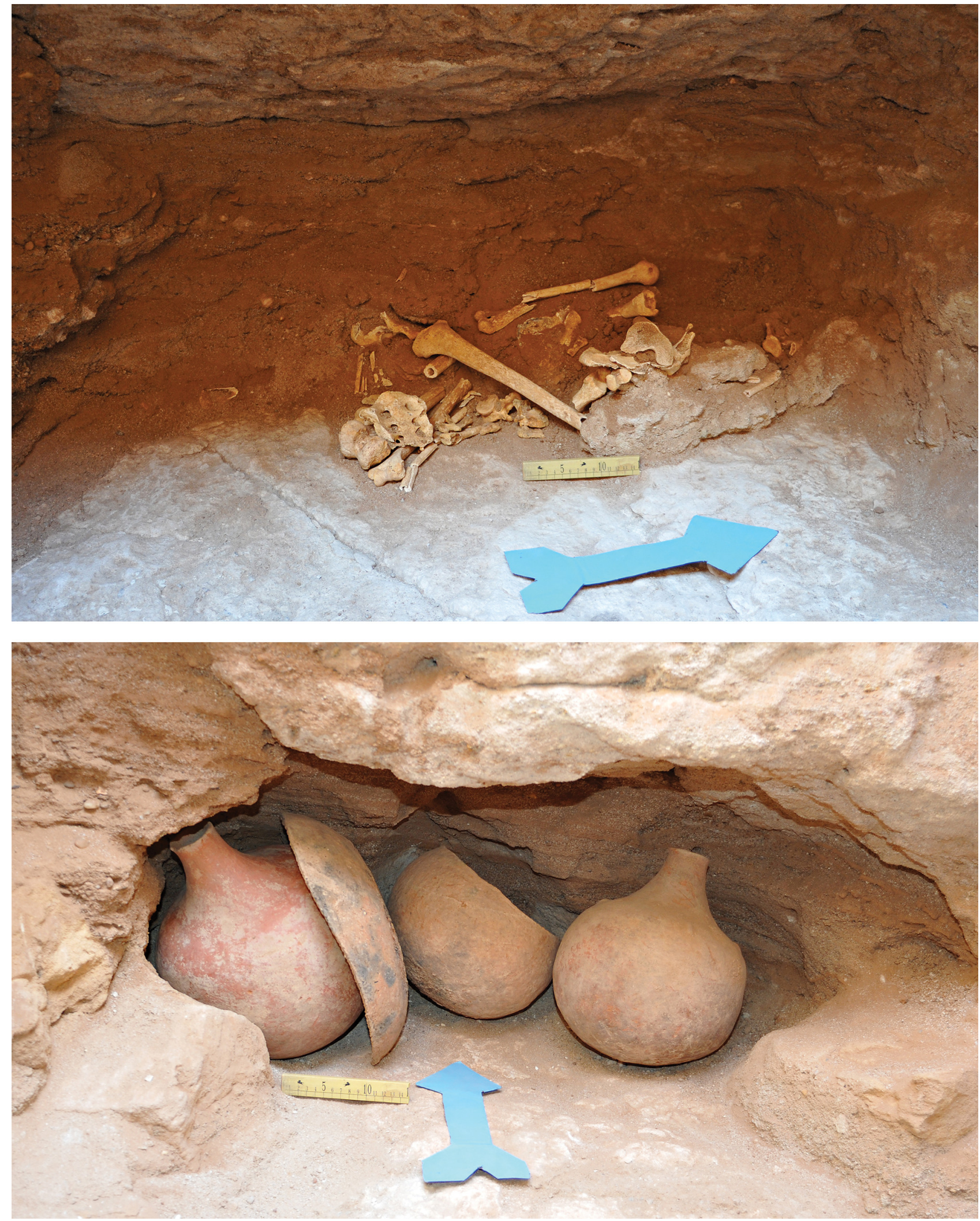

FIGURE 3.144 Tumulus 28, view of the disturbed skeleton in the main, western, burial chamber (top); view of offerings in the additional, northern, niche (bottom) PHOTOS BY R. HAJDUGA 
main one is hewn into the long west wall of the shaft, while a small secondary niche is cut into the short northern wall [Fig. 3.143].

The sides of the rectangular shaft measure $1.92 \mathrm{~m}(\mathrm{~W})$, $1.74 \mathrm{~m}(\mathrm{E}), 0.96 \mathrm{~m}(\mathrm{~N})$ and $1.40 \mathrm{~m}(\mathrm{~S})$, and it has a maximum depth of $3.10 \mathrm{~m}$ from the original ground surface. At the bottom of the shaft the two aforementioned chambers were found sealed with large, rough stone slabs. However, careful cleaning of the stone blocking wall revealed that the main (western) burial chamber had been accessed through a hole made in its south-west side, while the part of the blocking wall on the short northern side was found completely untouched by the robbers.

During excavation some broken fragments of human bones were noted in the south-west corner of the shaft. Furthermore, a small bottle, a cup and three bowl sherds were found scattered within the shaft fill, in addition to about 30 faience beads and one made of glass. These finds obviously attest to the fact that the chamber had been rifled.

The main chamber measures about $1.92 \mathrm{~m}$ in length, $1.15 \mathrm{~m}$ in width, and $0.80 \mathrm{~m}$ in height. As mentioned above, the chamber had been broken into through a robber hole on its south-west side. In consequence the interior was found in great disorder, with a single disarticulated human skeleton strewn across the floor. The skull and part of the upper limbs were found at the southern end of the chamber [Fig. 3.144 top]. Near them three wheel-made red cups, as well as some ostrich eggshell and faience, stone and glass beads were recorded. A pile of ribs, a mandible, and vertebra fragments, plus one highly corroded metal item (probably part of a knife) were located in the centre. Part of the lower limbs, pelvis, and foot bones were found in the north-west corner of the chamber. These discoveries suggest that the inhumation had followed the wellestablished canon of burial rites of the Terminal Meroitic period (also referred to as the post-Meroitic period), where the body was buried in a contracted position, head due south, facing east. This tradition was commonly noted in burials designated as type III at the El-Zuma cemetery.

The secondary chamber [Fig. 3.144 bottom], which is hewn into the short northern side of the shaft, measures about $0.95 \mathrm{~m}$ in length, $0.47 \mathrm{~m}$ in width, and $0.40 \mathrm{~m}$ in height. This small niche, which was found intact, was reserved for grave offerings. It contained four complete vessels: two handmade medium-size beer jars (bottles), one handmade cooking pot and one large, slightly concave dish (Arabic: gadah).

\section{$5 \quad$ List of Grave Goods}

\subsection{List of Grave Goods Excavated in Type I Tumuli}

Grave goods excavated in tumulus 2

Tunnel:

$$
\text { pottery-Z2/40 }
$$

Chamber 2: pottery-Z2/6, Z2/9-16, Z2/18-3o, Z2/32-35, Z2/37 (see Volume II, Chapter 7 and Fig. 7.135)

Chamber 3:

$$
\text { pottery-Z2/1-5, Z2/7-8, Z2/17, Z2/31, Z2/36, Z2/38-39 (see }
$$

Volume II, Chapter 7 and Fig. 7.135)

\section{Grave goods excavated in tumulus 3}

External shaft of tunnel: pottery $-\mathrm{Z}_{3} / 4, \mathrm{Z}_{3} / 6-7$ (see Volume II, Chapter 7 and

Fig. 7.136 )

Tunnel:

pottery $-\mathrm{Z}_{3} / 1-3, \mathrm{Z}_{3} / 5, \mathrm{Z}_{3} / 18$ (see Volume II, Chapter 7 and

Fig. 7.136)

ornaments- $\mathrm{Z}_{3} / 8-9$ (see Volume III, Chapters 4-5)

wood fragments - $\mathrm{Z}_{3} / 10, \mathrm{Z}_{3} / 14-15$ (see Volume III, Chap-

ter 18)

Chamber 1:

other metal items - $\mathrm{Z}_{3} / 17$ (see Volume III, Chapter 18)

wood fragments - $\mathrm{Z}_{3} / 12$ (see Volume III, Chapter 18)

Chamber 2: pottery - Z Z3/19 (see Volume II, Chapter 7 and Fig. 7.136) other metal items - $\mathrm{Z}_{3} / 11$ (see Volume III, Chapter 18) stone- $\mathrm{Z}_{3} / 13$ (see Volume III, Chapter 18)

\section{Grave goods excavated in tumulus 5}

Superstructure:

$$
\text { pottery- } \mathrm{Z}_{5} / 1-2, \mathrm{Z}_{5} / 3_{1}-37, \mathrm{Z}_{5} / 42 \text { (see Volume II, Chapter } 7
$$
and Fig. 7.137)

Sondage (S side of tumulus): pottery $-Z_{5} / 17, Z_{5} / 38$ (see Volume II, Chapter 7 and

Fig. 7.137)

Shaft:

ornaments- $\mathrm{Z}_{5} / 13$ (see Volume III, Chapters 4-5)

Tunnel:

pottery-Z5/18-22, Z5/39-41, Z5/43 (see Volume II, Chapter 7 and Fig. 7.137)

burial equipment - $\mathrm{Z}_{5} / 15^{-16}, \mathrm{Z}_{5} / 23^{-26}$ (see Volume III, Chapter 17)

ornaments - $\mathrm{Z}_{5} / 29$ (see Volume III, Chapters 4-5) other metal items $-\mathrm{Z}_{5} / 27-28$ (see Volume III, Chapter 18) miscellaneous - Z5/9 (see Volume III, Chapter 18)

Chamber 1:

pottery-Z5/3-4, Z5/14, Z5/3o (see Volume II, Chapter 7 and Fig. 7.137) 
ornaments - $\mathrm{Z}_{5} / 7-8, \mathrm{Z}_{5} / 10$ (see Volume III, Chapters 4-5) burial equipment-Z $\mathrm{Z}_{5} / 11-12$ (see Volume III, Chapter 17)

Chamber 2: pottery-Z5/5-6 (see Volume II, Chapter 7 and Fig. 7.137)

Grave goods excavated in tumulus 8

Tunnel:

pottery-Z8/1, Z8/3-4, Z8/6-7 (see Volume II, Chapter 7 and

Fig. 7.138)

burial equipment - Z8/8-9 (see Volume III, Chapter 17)

Chamber 1:

pottery-Z8/2, Z8/5 (see Volume II, Chapter 7 and Fig. 7.138) ornaments - Z8/10 (see Volume III, Chapters 4-5)

\section{Grave goods excavated in tumulus 1}

Superstructure:

pottery-Z1/12-13

Shaft:

pottery-Z1/1-11, Z1/16, Z1/21 (see Volume II, Chapter 7 and

Fig. 7.139)

organic material - Z1/14 (see Volume III, Chapter 18)

red brick- $\mathrm{Z} 1 / 15$

Tunnel:

pottery-Z1/17-20, Z1/22-26 (see Volume II, Chapter 7 and

Fig. 7.139)

ornaments-Z1/27 (see Volume III, Chapters 4-5)

Chamber 1:

pottery-Zil/28, $\mathrm{Z1} / 31$ (see Volume II, Chapter 7 and

Fig. 7.139)

ornaments- $\mathrm{Z}_{1} / 3 \mathrm{O}, \mathrm{Z1} / 3^{2-33}$ (see Volume III, Chapters 4-5)

burial equipment - Z11/29, Z1/34-38 (see Volume III, Chap-

ter 17 )

\section{Grave goods excavated in tumulus 4}

External shaft:

pottery - Z4/1 (see Volume II, Chapter 7 and Fig. 7.140)

Tunnel:

pottery-Z4/2, Z4/4, Z4/10, Z4/14, Z4/29-35, Z4/58-66,

$\mathrm{Z}_{4} / 77-8 \mathrm{o}, \mathrm{Z}_{4} / \mathrm{132}^{-135}, \mathrm{Z}_{4} / 181-182, \mathrm{Z}_{4} / 196-2 \mathrm{O} 2, \mathrm{Z}_{4} / 219-$

220, Z4/223-256 (see Volume II, Chapter 7 and Fig. 7.140)

ornaments - $\mathrm{Z}_{4} / 3, \mathrm{Z}_{4} / 11-13, \mathrm{Z}_{4} / 23, \mathrm{Z}_{4} / 45-54, \mathrm{Z}_{4} / 82, \mathrm{Z}_{4} / 84-$

85, Z4/89, Z4/95-98, Z4/105-106, Z4/108, Z4/113-131,

Z4/136-141, Z4/144-179, Z4/206-207, Z4/209-213, Z4/257

(see Volume III, Chapters 4-5)

burial equipment - $\mathrm{Z}_{4} / 7, \mathrm{Z}_{4} / 16-17, \mathrm{Z}_{4} / 19, \mathrm{Z}_{4} / 22, \mathrm{Z}_{4} / 26$,

$\mathrm{Z}_{4} / 7_{2}, \mathrm{Z}_{4} / 74-75, \mathrm{Z}_{4} / 8_{3}, \mathrm{Z}_{4} / 92, \mathrm{Z}_{4} / 143, \mathrm{Z} 4 / 189$ (see Vol-

ume III, Chapter 17)

weaponry-Z4/24, $\mathrm{Z}_{4} / 28, \mathrm{Z}_{4} / 56, \mathrm{Z}_{4} / 87-88, \mathrm{Z}_{4} / 107, \mathrm{Z}_{4} / 194$,

$\mathrm{Z}_{4} / 216$ (see Volume III, Chapter 14)

belt elements - $\mathrm{Z}_{4} / 20, \mathrm{Z}_{4} / 81$ (see Volume III, Chapter 15)

other metal items - $\mathrm{Z}_{4} / 18, \mathrm{Z}_{4} / 21, \mathrm{Z}_{4} / 25, \mathrm{Z}_{4} / 27, \mathrm{Z}_{4} / 68, \mathrm{Z}_{4} / 73$,
Z4/86, Z4/9o-91, Z4/93-94, Z4/142, Z4/215 (see Volume III, Chapter 18)

organic material-Z4/69-70, Z4/10o, Z4/184, Z4/192,

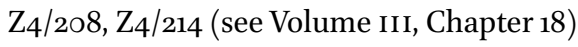

Grave goods excavated in tumulus 6

External shaft and tunnel:

pottery-Z6/7, Z6/11-15, Z6/17, Z6/19, Z6/24-26, Z6/38,

Z6/40 (see Volume II, Chapter 7 and Fig. 7.141)

Tunnel:

pottery-Z6/1-3, Z6/6, Z6/16, Z6/18, Z6/20-23, Z6/27-37,

Z6/39, Z6/41-58 (see Volume II, Chapter 7 and Fig. 7.141) miscellaneous - Z6/4-5 (see Volume III, Chapter 18)

\section{Grave goods excavated in tumulus 7}

Superstructure:

pottery- $\mathrm{Z}_{7} / 13, \mathrm{Z}_{7} / 2 \mathrm{O}-21, \mathrm{Z}_{7} / 23-24$ (see Volume II, Chapter 7 and Fig. 7.142)

External shaft: pottery- $\mathrm{Z}_{7} / 17, \mathrm{Z}_{7} / \mathbf{2 5}^{-40}, \mathrm{Z}_{7} / 41-44, \mathrm{Z}_{7} / 46-48, \mathrm{Z}_{7} / 54$,

$\mathrm{Z}_{7} / 85^{-93}$ (see Volume II, Chapter 7 and Fig. 7.142)

ornaments - $\mathrm{Z}_{7} / 79$ (see Volume III, Chapters 4-5)

Tunnel:

pottery- $\mathrm{Z}_{7} / 11-12, \mathrm{Z}_{7} / 14, \mathrm{Z}_{7} / 22, \mathrm{Z}_{7} / 49-53, \mathrm{Z}_{7} / 55^{-65}, \mathrm{Z}_{7} / 67-$

75 (see Volume II, Chapter 7 and Figs. 7.142-7.143)

wood fragments - $\mathrm{Z}_{7} / 45, \mathrm{Z}_{7} / 66, \mathrm{Z}_{7} / 76-78, \mathrm{Z}_{7} / 81-83$ (see

Volume III, Chapter 18)

ornaments- $\mathrm{Z}_{7} / 5, \mathrm{Z}_{7} / 7, \mathrm{Z}_{7} / 8-1 \mathrm{O}, \mathrm{Z}_{7} /$ 15-16, $_{7} / 66$ bis (see

Volume III, Chapters 4-5)

burial equipment - $\mathrm{Z}_{7} / 1, \mathrm{Z}_{7} / 19$ (see Volume III, Chapter 17)

weaponry- $\mathrm{Z}_{7} / 2-4$ (see Volume III, Chapter 14)

other metal items $-\mathrm{Z}_{7} / 5, \mathrm{Z}_{7} / 6, \mathrm{Z}_{7} / 18$ (see Volume III, Chapter 18 )

\subsection{List of Grave Goods Excavated in Type II Tumuli}

Grave goods excavated in tumulus 12

Superstructure:

pottery-Z12/1, Z12/3 (see Volume II, Chapter 7 and

Fig. 7.144)

ornaments - Z12/2 (see Volume III, Chapter 4)

Shaft:

pottery-Z12/5-27, Z12/30-53, Z12/59-66, Z12/68-70,

Z12/83-85, Z12/134-138 (see Volume II, Chapter 7 and

Figs. 7.144-7.146)

weaponry-Z12/54-55 (see Volume III, Chapter 14)

Chamber 1:

pottery-Z12/71-81 (see Volume II, Chapter 7 and Fig. 7.147)

ornaments-Z12/82 (see Volume III, Chapter 4)

Chamber 2:

pottery-Z12/129-133 (see Volume II, Chapter 7 and

Fig. 7.147) 
Chamber 3:

pottery-Z12/86-127 (see Volume II, Chapter 7 and

Fig. 7.148)

\section{Grave goods excavated in tumulus 13}

Superstructure:

pottery-Z13/39-40 (see Volume II, Chapter 7 and Fig. 7.149)

Shaft:

pottery-Z13/2-3, Z13/7-9, Z13/22, Z13/37-38, Z13/41 (see

Volume II, Chapter 7 and Fig. 7.149)

ornaments - Z $13 / 2-3$ (see Volume III, Chapter 4)

burial equipment - $\mathrm{Z}_{13} / 1, \mathrm{Z}_{13} / 4, \mathrm{Z}_{13} / 6$ (see Volume III, Chapter 17)

weaponry- $\mathrm{Z}_{13} / 5$ (see Volume III, Chapter 14)

Chamber 2:

pottery-Z13/16-21, Z13/23 (see Volume II, Chapter 7 and

Fig. 7.149)

Chamber 3:

pottery-Z13/24-28, Z13/35 (see Volume II, Chapter 7 and

Fig. 7.149)

Chamber 4:

pottery-Z13/12-14 (see Volume II, Chapter 7 and Fig. 7.149)

ornaments-Z13/29-34, Z13/36 (see Volume III, Chapters

4-5)

organic material/textile - $\mathrm{Z}_{13} / 15$ (see Volume III, Chapter 18)

Chamber 5:

pottery-Z13/10-11 (see Volume II, Chapter 7 and Fig. 7.149)

\section{Grave goods excavated in tumulus 14}

Superstructure:

pottery-Z14/1 (see Volume II, Chapter 7 and Fig. 7.150)

Shaft:

pottery-Z14/2-4, Z14/33-34 (see Volume II, Chapter 7 and

Fig. 7.150)

red brick- $\mathrm{Z} 14 / 35$

Chamber 1:

pottery-Z14/14-21 (see Volume II, Chapter 7 and Fig. 7.150)

burial equipment - Z14/31-32 (see Volume III, Chapter 17)

Chamber 2:

pottery-Z14/22-30 (see Volume II, Chapter 7 and Fig. 7.150)

Chamber 3:

pottery-Z14/5-13 (see Volume II, Chapter 7 and Fig. 7.150)

\section{Grave goods excavated in tumulus 15}

Superstructure:

pottery-Z15/1 (see Volume II, Chapter 7 and Fig. 7.151)

Shaft:

pottery-Z15/2-8, Z15/16-24 (see Volume II, Chapter 7 and

Fig. 7.151)

ornaments-Z15/9-10, Z15/13, Z15/33 (see Volume III,

Chapters 4-5) burial equipment - Z15/11-12, Z15/29 (see Volume III, Chapter 17)

Chamber 1:

pottery-Z15/43-53, Z15/56, Z15/59, Z15/61 (see Volume II,

Chapter 7 and Fig. 7.151)

burial equipment-Z15/55 (see Volume III, Chapter 17)

Chamber 2:

pottery-Z15/25-28, Z15/34-38 (see Volume II, Chapter 7 and Fig. $7.15^{2}$ )

\section{Grave goods excavated in tumulus 23}

Shaft:

pottery-Z23/1, Z23/32-34, Z23/41-43 (see Volume II, Chapter 7 and Fig. 7.153)

Chamber 1:

pottery-Z23/2-4, Z23/6-7, Z23/11-12, Z23/23-25, Z23/31,

Z23/35, Z23/37-38, Z23/40 (see Volume II, Chapter 7 and Fig. 7.153)

Chamber 2:

pottery-Z23/5, Z23/8-10, Z23/13-22, Z23/26-30, Z23/36,

Z23/39 (see Volume II, Chapter 7 and Fig. 7.153)

\section{Grave goods excavated in tumulus 24}

Superstructure:

pottery-Z24/1, Z24/2, Z24/51 (see Volume II, Chapter 7 and

Fig. 7.154)

stone $-\mathrm{Z} 24 / 47$

fossil-Z24/5o

Shaft:

pottery-Z24/3, Z24/5, Z24/7-8, Z24/11-15, Z24/24, Z24/26-

30, Z24/34, Z24/41, Z24/45 (see Volume II, Chapter 7 and

Fig. 7.154)

ornaments-Z24/4, Z24/48-49 (see Volume III, Chapters

4-5)

weaponry-Z24/6 (see Volume III, Chapter 14)

Chamber 1:

pottery-Z24/17-23, Z24/25, Z24/33, Z24/35-36, Z24/42-43,

Z24/53 (see Volume II, Chapter 7 and Fig. 7.154)

ornaments-Z24/46, Z24/55 (see Volume III, Chapters 4-5) other metal items - Z24/16, Z24/32, Z24/38, Z24/44 (see Vol-

ume III, Chapter 18)

burial equipment-Z24/31, Z24/52, Z24/54 (see Volume III,

Chapter 17)

Chamber 2:

pottery -Z24/10 (see Volume II, Chapter 7 and Fig. 7.154)

other metal items - Z24/9 (see Volume III, Chapter 18)

Chamber 3:

pottery-Z24/37, Z24/39 (see Volume II, Chapter 7 and

Fig. 7.155)

Chamber 4:

pottery -Z24/40 (see Volume II, Chapter 7 and Fig. 7.155) 


\section{Grave goods excavated in tumulus 25}

Shaft:

pottery-Z25/1-2, Z25/37-42 (see Volume II, Chapter 7 and

Fig. 7.156)

Chamber 1:

pottery-Z25/3-5, Z25/33-36 (see Volume II, Chapter 7 and

Fig. 7.156)

Chamber 2:

pottery-Z25/6-15, Z25/32 (see Volume II, Chapter 7 and

Fig. 7.156$)$

Chamber 3:

pottery-Z25/16-31 (see Volume II, Chapter 7 and Fig. 7.156)

\section{Grave goods excavated in tumulus 26}

Shaft:

pottery-Z26/36, Z26/39-41, Z26/53, Z26/6o-71 (see Vol-

ume II, Chapter 7 and Fig. 7.157)

ornaments - Z26/1 (see Volume III, Chapter 4)

burial equipment-Z26/2 (see Volume III, Chapter 17)

Chamber 1:

pottery-Z26/11-12, Z26/14-16, Z26/31-33, Z26/37-38,

Z26/44, Z26/47-48, Z26/51-52, Z26/58-59, Z26/84 (see

Volume II, Chapter 7 and Fig. 7.158)

ornaments - Z26/6 (see Volume III, Chapter 4)

burial equipment-Z26/3, Z26/7-8, Z26/10 (see Volume III, Chapter 17)

other metal items-Z26/9, Z26/89, Z26/91 (see Volume III, Chapter 18)

wood fragments-Z26/9o, Z26/92, Z26/93 (see Volume III, Chapter 18)

Chamber 2:

pottery-Z26/19, Z26/21-3o, Z26/42-43, Z26/45-46, Z26/50,

Z26/54-57, Z26/72, Z26/75-76, Z26/79, Z26/81, Z26/83,

Z26/87-88 (see Volume II, Chapter 7 and Fig. 7.158)

Chamber 3:

pottery-Z26/17, Z26/34-35, Z26/49 (see Volume II, Chapter 7 and Fig. $\left.7 \cdot 15^{8}\right)$

organic material/textile-Z26/4-5 (see Volume III, Chapter 18 )

Chamber 4:

pottery-Z26/13, Z26/18, Z26/20, Z26/73-74, Z26/77-78, Z26/8o, Z26/82, Z26/85-86 (see Volume II, Chapter 7 and Fig. 7.158$)$

\section{Grave goods excavated in tumulus 16}

Superstructure:

stone artefacts/objects-Z16/13 (see Volume III, Chapter 18)

Shaft:

pottery-Z16/1, Z16/38-43 (see Volume II, Chapter 7 and

Fig. 7.159)

ornaments-Z16/5 (see Volume III, Chapter 4)
weaponry-Z16/4, Z16/6-12, Z16/14-17 (see Volume III,

Chapter 14)

Chamber 1:

pottery-Zi6/2, Z16/3 (see Volume II, Chapter 7 and

Fig. 7.159)

ornaments - Z16/19-25 (see Volume III, Chapter 4)

organic material - Z16/18 unidentified small organic fragment

burial equipment-Z16/28-30, Z16/32-35 (see Volume III, Chapter 17)

weaponry-Z16/26-27, Z16/31, Z16/37 (see Volume III, Chapter 14)

belt elements - Z16/36 (see Volume III, Chapter 15)

\section{Grave goods excavated in tumulus 9}

Superstructure:

pottery-Z9/22-23, Z9/34 (see Volume II, Chapter 7 and Fig. 7.16o)

Shaft:

pottery-Z9/1, Z9/2, Z9/24-33, Z9/35 (see Volume II, Chap-

ter 7 and Fig. 7.16o)

ornaments - Z9/8-10 (see Volume III, Chapter 4)

burial equipment-Z9/11-12 (see Volume III, Chapter 17)

Chamber 1:

pottery-Z9/6-7, Z9/21 (see Volume II, Chapter 7 and

Fig. 7.16o)

ornaments-Z9/13-17 (see Volume III, Chapter 4)

burial equipment - Z9/18-20 (see Volume III, Chapter 17)

Chamber 2:

pottery-Z9/4-5 (see Volume II, Chapter 7 and Fig. 7.16o)

Chamber 3 :

pottery-Z9/3 (see Volume II, Chapter 7 and Fig. 7.16o)

\section{Grave goods excavated in tumulus 11}

Superstructure:

pottery-Z11/37-48, Z11/53-54 (see Volume II, Chapter 7 and Fig. 7.161)

Shaft:

pottery-Z11/1-5, Z11/50-51 (see Volume II, Chapter 7 and

Fig. 7.161)

red brick-Z11/49

Chamber 1:

pottery-Z11/6-15, Z11/52 (see Volume II, Chapter 7 and

Fig. 7.161)

ornaments - Z11/31 (see Volume III, Chapter 4)

burial equipment - Z11/33 (see Volume III, Chapter 17) weaponry - Z11/32 (see Volume III, Chapter 14) other metal items-Z11/36 (see Volume III, Chapter 18)

Chamber 2: pottery-Z11/16-30, Z11/34-35 (see Volume II, Chapter 7 and

Fig. 7.161) 


\subsection{List of Grave Goods Excavated in Type III Tumuli}

Grave goods excavated in tumulus 10

Shaft:

pottery-Z1o/54-57 (see Volume II, Chapter 7 and Fig. 7.162)

Burial chamber:

pottery-Z1o/1-29 (see Volume II, Chapter 7 and Fig. 7.162)

ornaments - $\mathrm{Z10} / 40, \mathrm{Z10} / 46, \mathrm{Z10} / 5^{\circ}-5^{2}$ (see Volume III,

Chapters 4-5)

weaponry-Z1o/3o, Z1o/32-39, Z1o/41-44, Z1o/47-49,

Z1o/53 (see Volume III, Chapter 14)

other metal items - Z1o/31 (see Volume III, Chapter 14)

scabbards and belt fittings - Z1o/45 (see Volume III, Chap-

ter 15)

\section{Grave goods excavated in tumulus 17}

Superstructure:

pottery-Z17/13 (see Volume II, Chapter 7 and Fig. 7.163)

Burial chamber:

pottery-Z17/1-3 (see Volume II, Chapter 7 and

Fig. 7.163)

ornaments-Z17/4, Z17/6-11 (see Volume III, Chapter 4)

weaponry-Z17/5, Z17/12 (see Volume III, Chapter 14)

\section{Grave goods excavated in tumulus 18}

Superstructure:

pottery-Z18/13 (see Volume II, Chapter 7 and Fig. 7.164)

Shaft:

pottery-Z18/1, Z18/14 (see Volume II, Chapter 7 and

Fig. 7.164)

ornaments-Z18/9, Z18/11-12 (see Volume III, Chapter 4)

Burial chamber:

pottery-Z18/2-8 (see Volume II, Chapter 7 and Fig.

$7.164)$

ornaments - Z18/10 (see Volume III, Chapter 4)

Grave goods excavated in tumulus 19

Superstructure:

pottery-Z19/1, Z19/9-12 (see Volume II, Chapter 7 and

Fig. 7.165)

stone-Z19/15

Shaft:

pottery-Z19/2-3, Z19/13-14 (see Volume II, Chapter 7 and

Fig. 7.165)

Burial chamber:

pottery-Z19/4-6, Z19/8 (see Volume II, Chapter 7 and

Fig. 7.165)

weaponry-Z19/7 (see Volume III, Chapter 14)

Grave goods excavated in tumulus 20

Superstructure:

ornaments-Z2O/12 (see Volume III, Chapter 4)
Shaft:

pottery-Z2O/1-2, Z2O/13-15 (see Volume II, Chapter 7 and

Fig. 7.166)

ornaments-Z2o/6-9 (see Volume III, Chapter 4)

Burial chamber:

pottery-Z2O/3-5 (see Volume II, Chapter 7 and Fig. 7.166)

ornaments-Z2O/10-11 (see Volume III, Chapter 4)

Grave goods excavated in tumulus 22

Superstructure:

stone $-\mathrm{Z}_{22} / 8$

Shaft:

pottery-Z22/3-4 (see Volume II, Chapter 7 and Fig. 7.167)

ornaments - Z22/9 (see Volume III, Chapter 4)

weaponry - Z22/7 (see Volume III, Chapter 14)

Burial chamber:

pottery-Z22/1-2, Z22/5-6 (see Volume II, Chapter 7 and

Fig. 7.167)

Grave goods excavated in tumulus 27

Superstructure:

pottery-Z27/12 (see Volume II, Chapter 7 and Fig. 7.168)

Shaft:

pottery-Z27/11 (see Volume II, Chapter 7 and Fig. 7.168)

weaponry -Z27/1 (see Volume III, Chapter 14)

Burial chamber:

pottery-Z27/2-3 (see Volume II, Chapter 7 and Fig. 7.168) ornaments-Z27/4-5, Z27/9 (see Volume III, Chapter 4) weaponry-Z27/6-7, Z27/10 (see Volume III, Chapter 14) organic materials - Z27/8 unidentified organic fragments

(see Volume III, Chapter 14)

\section{Grave goods excavated in tumulus 21}

Superstructure:

pottery-Z21/1-2, Z21/26-28 (see Volume II, Chapter 7 and

Fig. 7.169)

Shaft:

pottery-Z21/3-6 (see Volume II, Chapter 7 and Fig. 7.169) ornaments - Z21/14-15 (see Volume III, Chapter 4)

Burial chamber:

pottery-Z21/7-10 (see Volume II, Chapter 7 and Fig. 7.169)

ornaments - Z21/16-19 (see Volume III, Chapter 4)

weaponry-Z21/11-13 (see Volume III, Chapter 14)

Grave goods excavated in tumulus 28

Superstructure:

pottery-Z28/1, Z28/18 (see Volume II, Chapter 7 and

Fig. 7.170)

Shaft:

pottery-Z28/2-3, Z28/5 (see Volume II, Chapter 7 and

Fig. $7 \cdot 170)$ 
ornaments-Z28/4 (see Volume III, Chapter 4)

Burial chamber:

pottery-Z28/6-13 (see Volume II, Chapter 7 and Fig. 7.170)

ornaments - Z28/14-15, Z28/17 (see Volume III, Chapter 4)

other metal items - Z28/16 unidentified (see Volume III,

Chapter 18) 